\title{
Critical Physicochemical Properties for Nanoparticle Toxicity: Impact of Surface Coating and Size on Particle-Induced Cell Transformation and Inflammatory Response
}

\author{
Tiffany Kornberg \\ West Virginia University, tgkornberg@mix.wvu.edu
}

Follow this and additional works at: https://researchrepository.wvu.edu/etd

Part of the Cancer Biology Commons, Disease Modeling Commons, Other Pharmacy and Pharmaceutical Sciences Commons, Pharmacology Commons, Respiratory Tract Diseases Commons, and the Toxicology Commons

\section{Recommended Citation}

Kornberg, Tiffany, "Critical Physicochemical Properties for Nanoparticle Toxicity: Impact of Surface Coating and Size on Particle-Induced Cell Transformation and Inflammatory Response" (2019). Graduate Theses, Dissertations, and Problem Reports. 7430.

https://researchrepository.wvu.edu/etd/7430

This Dissertation is protected by copyright and/or related rights. It has been brought to you by the The Research Repository @ WVU with permission from the rights-holder(s). You are free to use this Dissertation in any way that is permitted by the copyright and related rights legislation that applies to your use. For other uses you must obtain permission from the rights-holder(s) directly, unless additional rights are indicated by a Creative Commons license in the record and/ or on the work itself. This Dissertation has been accepted for inclusion in WVU Graduate Theses, Dissertations, and Problem Reports collection by an authorized administrator of The Research Repository @ WVU.

For more information, please contact researchrepository@mail.wvu.edu. 
Critical Physicochemical Properties for Nanoparticle Toxicity: Impact of Surface Coating and Size on Particle-Induced Cell Transformation and Inflammatory Response

Tiffany Kornberg

Follow this and additional works at: https://researchrepository.wvu.edu/etd

Part of the Cancer Biology Commons, Disease Modeling Commons, Other Pharmacy and Pharmaceutical Sciences Commons, Pharmacology Commons, Respiratory Tract Diseases Commons, and the Toxicology Commons 


\section{Critical Physicochemical Properties for Nanoparticle Toxicity:}

Impact of Surface Coating and Size on ParticleInduced Cell Transformation and Inflammatory Response

\section{Tiffany G. Kornberg}

Dissertation submitted to the School of Pharmacy at West Virginia University

in partial fulfillment of the requirements for the degree of

Doctor of Philosophy in

Pharmaceutical Sciences

Liying Rojanasakul, $\mathrm{PhD}$

James M. Antonini, PhD

Vincent Castranova, $\mathrm{PhD}$

Todd Stueckle, PhD

Yon Rojanasakul, PhD

Department of Pharmaceutical Sciences

Morgantown, West Virginia 2019

Keywords: iron oxide, cerium oxide, nanoparticle, toxicity, in vitro, in vivo, physicochemical properties, carcinogenesis, inflammation, pulmonary fibrosis 


\title{
Abstract \\ Critical Physicochemical Properties for Nanoparticle Toxicity: Impact of Surface Coating and Size on Particle-Induced Cell Transformation and Inflammatory Response
}

\author{
Tiffany G. Kornberg
}

Nanoparticles, which measure $100 \mathrm{~nm}$ in at least one dimension, have surged in development, production, and use for a wide range of applications. However, the rapid pace of development for these emerging materials with unclear/unknown toxicity profiles makes it difficult to adequately assess health risk associated with exposure. One critical obstacle which limits scientific research to fill these critical knowledge gaps is the lack of accurate and predictive models for nanotoxicology studies, particularly those which involve occupationally relevant exposure scenarios (pulmonary exposure to low dose of particles in the circulating air). Typically, animal models are used to assess potential systemic toxicity. However, the time, cost, and resource heavy methods are insufficient due to the sheer number of new nanoparticles being produced and used each day. Cell culture-based systems have been suggested as a more rapid alternative which could be used to predict and rank potential toxicity of such emerging materials. However, the translation of an existing in vivo study to an in vitro model requires additional parameters to be considered for experimental design, and a lack to do so may contribute to the discrepancies and lack of clarity in the existing nanoparticle toxicity literature.

The key objective for my dissertation work was to illustrate how the better integration of in vitro and in vivo may be used to evaluate potential toxicity of two nano-metal oxides with unclear toxicity profiles: iron oxide nanoparticles (IONP) and cerium oxide nanoparticles (CONP), as well as how alterations in specific physicochemical properties may contribute to severity of the pulmonary adverse outcomes they may induce.

Some studies report IONP to be biologically benign, whereas others have linked IONP exposure to cancer-related adverse outcomes, including genotoxicity, neoplasticlike cell transformation, and tumor promotion in vivo. To assess this potential toxicity, a specific IONP $\left(\mathrm{nFe}_{2} \mathrm{O}_{3}\right)$ was evaluated in a physiologically relevant low dose/long term in vitro exposure model to identify its general toxicity and potential carcinogenic capacity, as well as how alterations in particle surface chemistry (with the addition of an amorphous silica coating) may impact overall toxicity. Results were compared to previously published in vivo data which showed $\mathrm{nFe}_{2} \mathrm{O}_{3}$ would promote tumor formation in mice.

CONP has a similarly unclear toxicity profile, with some studies suggesting CONP may reduce oxidative stress, whereas others show this particle to induce robust oxidative stress and inflammatory response. The chemical composition and valence state of CONP is known to be a critical component to its toxicity, and the inability to control for this in previous studies likely obscured any other physicochemical properties which may also play a role. Therefore, we evaluated size dependent toxicity of CONP using chemically identical particles, including their ability to induce inflammation, pro-fibrotic, and potential systemic toxicity within an occupationally relevant in vivo exposure model. Corresponding dose was used in an in vitro model system for a better understanding of potential mechanism underlying these outcomes, as well as to illustrate the potential use of an in vitro/in vivo integrated model system. 
Overall, my dissertation study results showed that an occupationally relevant low dose/long term exposure to IONP would induce neoplastic-like cell transformation in human bronchial epithelial cells, which was dramatically reduced with the alteration of its surface chemistry with an amorphous silica coating; Alteration of CONP size affected its inflammatory and pro-fibrotic response in male $\mathrm{C} 57 \mathrm{BL} / 6 \mathrm{~J}$ mice, with smaller sizes inducing a robust and sustained inflammatory response, while larger sizes induced a milder response but with increased fibrotic potential.

These results clearly show the impact of specific physicochemical properties on overall toxicity profile, as well as the importance of careful physiologically relevant model design for better in vitro to in vivo translation, with the ultimate goal of protecting those at risk of exposure to these new materials with unclear/unknown toxicity profiles. 


\section{Table of Contents:}

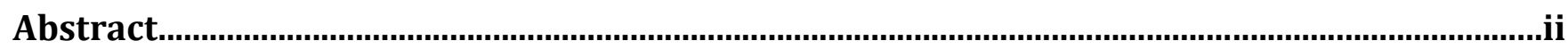

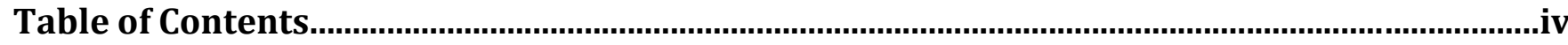

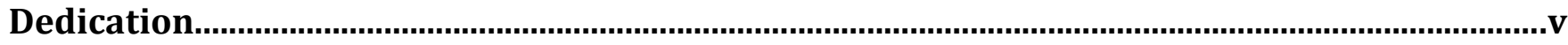

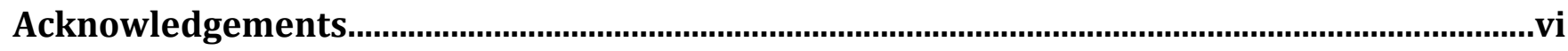

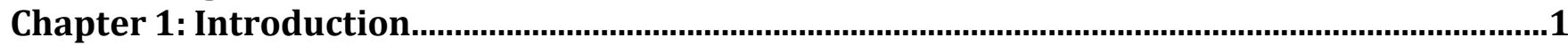

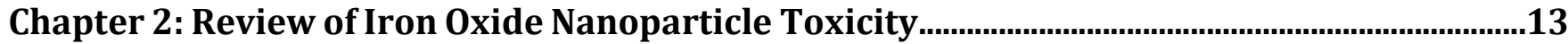

Chapter 3: Sub Chronic Iron Oxide Nanoparticle Exposure...............................................................56

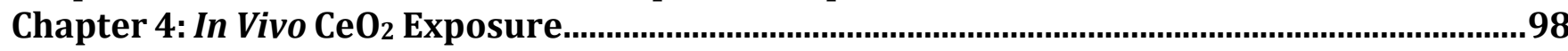

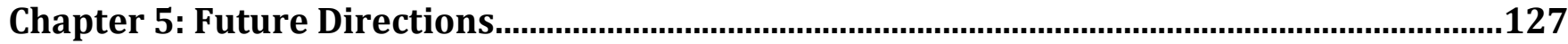

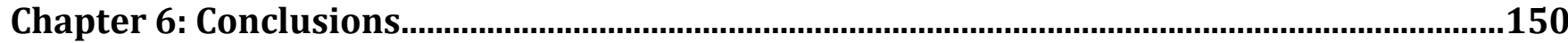

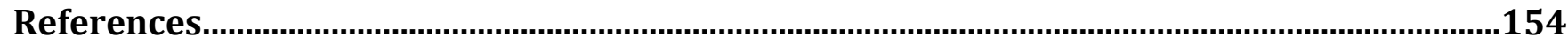




\section{Dedication:}

To my family, who made this all possible. Thank you for your continued and unwavering support. 


\section{Acknowledgements:}

I would like to acknowledge and thank the numerous people who have helped me throughout my graduate school career. First, my advisor - Dr. Liying Wang Rojanasakul - who has been an incredible mentor and source of support through this entire journey. None of this would have been possible without your help and expertise. Next, I would like to acknowledge and thank each of my committee members, who were invaluable resources during this process: Dr. Yon Rojanasakul, Dr. Todd Stueckle, Dr. Jim Antonini, and Dr. Vincent Castranova. Finally, I have been fortunate enough to work with very talented scientists, who have incredibly generous in their time to guide me through experimental failures and successes. Thank you to Dr. Donna Davidson who was my greatest inspiration to persevere. Thank you to Dr. Jayme Coyle for always supporting me, and helping me to become a better scientist. And thank you to Ray Derk and Jake Jensen, our other lab members who made this entire process bearable. 


\section{Chapter 1: Introduction}

\section{1-1. Nanoparticles: general}

Nano-sized particulates, which measure $100 \mathrm{~nm}$ or less in at least one dimension, are known to be incidentally released from industrial anthropogenic activities such as mining or welding. More recently, it has been discovered that when particles are specifically engineered to be on the nanoscale, they can take on unique properties which allow them to be utilized in a wide range of technological applications. For example, carbon based nanomaterials are lightweight but have enhanced tensile strength for use in building materials ${ }^{1,2}$. Cerium-oxide nanomaterials are being pursued as diesel additives to reduce emissions and improve fuel economy ${ }^{3}$. Nano-sized iron oxide has paramagnetic or super-paramagnetic properties, which allow for their utilization in MRI imaging techniques and targeted drug delivery systems ${ }^{4}$.

This knowledge has led to a surge in development of a rapidly expanding cohort of different types of nano-materials, with exciting potential for incorporation into consumer products, building materials, advanced biomedical treatment techniques, and more. In fact, even though nano-enabled products have only entered the marketplace within the last few decades, the nanotechnology market in the United States is expected to reach or exceed \$125 billion by the year 20245.

However, the unique properties of engineered nanomaterials, as well as the rapid surge in their production and use, has led to increased risk of exposure for certain populations. In particular, workers involved in the manufacture and incorporation of particles at the beginning of their life cycle, or the processing and recycling of these materials towards the end of their lifecycle, may be at greatest risk of pulmonary exposure to particles which have a poorly understood toxicity profile. The expansion and development of new types of particles is occurring so rapidly that traditional methods of toxicity assessment are unable to sufficiently assess potential risk, 
leading to critical knowledge gaps as to any potential hazards which may be associated with these new and emerging materials.

In general, it is believed that nanoparticles are able to induce more toxicity on a per mass basis than their fine (100-2500 $\mathrm{nm}^{6}$ ) sized counterparts, largely due to an increase in surface area ${ }^{7}$. This increased surface area is also known to affect bio-distribution ${ }^{8}$, particle translocation ${ }^{9}$, and particle uptake/elimination ${ }^{10}$, all which may also impact overall toxicity ${ }^{8}$. Other properties, such as surface charge/functionalization, particle shape, aspect ratio, and dissolution, may also affect toxicity ${ }^{11}$. How or which specific physicochemical properties may contribute to particle-induced adverse outcomes are somewhat unclear from the existing literature, and if better understood, could be used to inform particle design and overall reduce risk for those who may be exposed.

For a better understanding of the potential hazards associated with engineered nanomaterials, my dissertation focused on two key nano-metal oxides, which have potential applications in a wide variety of fields, as well as known risk of exposure for vulnerable workers.

\section{1-1a. Iron Oxide Nanoparticles}

Fine or micron size iron oxide has been used in a wide array of applications, including medicine, electronic tape, tattoo inks, and catalysts ${ }^{12,13}$. Specific types of iron oxide $\left(\mathrm{Fe}_{2} \mathrm{O}_{3}\right.$ and $\mathrm{Fe}_{3} \mathrm{O}_{4}$ ) can be purposefully engineered to be less than $100 \mathrm{~nm}$ in diameter, and possess unique paramagnetic or superparamagnetic properties at sizes of $10 \mathrm{~nm}$ or less. Because of this, iron oxide nanoparticles (IONP) are being incorporated into a wide range of consumer products and industrial applications including: biomedical (cell labeling, targeted drug delivery platforms, novel imaging techniques), electronics (circuitry, data storage), transportation (brake systems), and cosmetics (pigments) ${ }^{14,15}$. 
IONP are also being developed for use in targeted cancer treatments, MRI imaging techniques, and as environmental catalysts ${ }^{16}$, and can also be incorporated into thermoplastics or other types of materials ${ }^{17}$. However, despite these surges in production and use of IONP, their potential toxicity or its underlying mechanism remain unclear and poorly understood.

There have been a number of epidemiological studies which focused on adverse outcomes in workers who were exposed to fine sized iron oxide. Iron oxide particulates as a mixture of fine or unknown size are incidentally released from industrial applications such as iron ore mining and pyrite production, as well as industries which use iron oxide as a pigment or polishing agent, or involve the mechanical alteration of iron containing products ${ }^{18}$. These processes release iron oxide particulates into the circulating air, becoming an exposure risk for workers, including miners, foundry workers, smiths, and metal grinders ${ }^{7,13}$. Pulmonary exposure to high levels of iron is also known to occur via polluted air ${ }^{19}$, which has the potential to affect an even larger cohort of people. More recently, workers involved in the manufacture of $\mathrm{Fe}_{2} \mathrm{O}_{3}$-containing materials in China were shown to be exposed to low levels of $\mathrm{Fe}_{2} \mathrm{O}_{3}$ in the circulating air ${ }^{20}$. Workers in a similar type of manufacturing plant in Russia had elevated oxidative stress and inflammatory biomarkers following exposure to a similarly low level of a mostly nano-sized iron oxide aerosol 21 .

In general, studies have shown the potential for IONP to induce pulmonary adverse outcomes, including inflammation ${ }^{22-27}$, pulmonary fibrosis ${ }^{28,29}$, and genotoxicity in the lung 30,31 , as well as extra-pulmonary effects due to particle translocation $28,29,32$. Furthermore, both iron oxide and IONP have been tangentially linked to cancer development. Some studies have shown that iron ore miners, who are known to be exposed to iron oxide via the circulating air, have elevated risk of lung cancer as compared to a non-mining population ${ }^{33-36}$. However, confounding factors in these studies made it difficult to distinguish iron oxide specific effects. Some researchers have suggested that iron itself plays a critical role in the induction of cancer-related adverse outcomes, 
as well, especially for those who may be exposed to high levels of this metal particulate via polluted air ${ }^{37}$. However, due to the limited amount of information available on IONP-specific toxicity, no exposure limit recommendations specific to the nano/ultra-fine form of iron oxide can be made. Instead, IONP are currently regulated based on exposure limits and recommendations for fine sized iron oxide. The National Institute for Occupational Safety and Health (NIOSH) and the American Conference of Governmental Industrial Hygienists (ACGIH) have a recommended exposure limit of $5 \mathrm{mg} / \mathrm{m}^{3}$, while the Occupational Safety and Health Administration (OSHA) has a permissible exposure limit of $14 \mathrm{mg} / \mathrm{m}^{3} 38$. These relatively high exposure limits across agencies show iron oxide (and, by extension, IONP) is largely considered a "nuisance dust," meaning the iron oxide particulate itself is considered non-toxic for humans. This is despite some epidemiological evidence that associates the inhalation of iron oxide particulates with adverse respiratory outcomes in exposed workers ${ }^{18,33,39,40}$. However, the majority of these studies involved concurrent exposures to other carcinogens, which made it difficult to distinguish iron oxide specific effects and overall obscuring iron oxide specific toxicity.

\section{1-1b. Cerium Oxide Nanoparticles}

Nano-sized cerium oxide $\left(\mathrm{nCeO}_{2}\right)$ has also become a particle of interest across a wide spectrum of industries and applications. $\mathrm{nCeO}_{2}$ has been utilized as a glass polishing agent ${ }^{3}$, in development for biological and medical fields ${ }^{41}$, and as a diesel additive to reduce emissions ${ }^{42,43}$. Its role as a diesel fuel catalyst indicate an increased exposure risk to aerosolized exhaust particles for the general public. Several studies have been able to identify high levels of cerium exposure in populations in close proximity to motor vehicles or major roadways ${ }^{3,44}$.

However, despite the relatively widespread use of cerium oxide and $\mathrm{nCeO}_{2}$, there is still very limited toxicity information available. $\mathrm{nCeO}_{2}$ has a somewhat controversial toxicity profile, with 
some studies suggesting that it has the potential to induce systemic oxidative stress ${ }^{45}$, whereas others suggest this particle may actually protect against oxidative stress ${ }^{46,47}$. The transitional nature of $\mathrm{nCeO}_{2}$ valence state ${ }^{48}$ is a key factor in the discrepancies of observed adverse outcomes.

Some workers who are exposed to fine or nano-size cerium oxide via the circulating air were shown to develop a pulmonary disease known as "cerium pneumoconiosis," although concurrent exposures to other types of earth metals during these exposures prevented a cerium oxide-specific effect from being conclusively shown ${ }^{3}$. Other studies also indicate $\mathrm{nCeO}_{2}$ exposure may induce functional changes in alveolar macrophages ${ }^{49}$, resulting in pulmonary inflammation ${ }^{41,49}$, fibrosis ${ }^{50}$, and chronic lung injury ${ }^{51}$. However, this has also not been conclusively shown, and no underlying mechanisms outside of oxidative stress have been suggested or thoroughly explored in the existing literature.

Cerium and cerium oxide (>100 nm) are also perceived as "non-toxic" particles, as indicated by the lack of clear exposure limits or recommendations by either OSHA or ACGIH ${ }^{52}$, although rare earth oxides have an ACGIH established exposure limit of $15 \mathrm{mg} / \mathrm{m}^{3} 53$. Similar to IONP, there are also no nano-specific exposure limits for cerium oxide, most likely due to the lack of available literature on its potential toxicity.

Both CONP and IONP have unclear toxicity profiles with minimal exposure limits or recommendations, which ultimately fail to protect at risk workers. The discrepancies and lack of clarity as to actual particle-induced adverse outcomes in the existing literature is likely due to critical issues in how nanoparticle toxicity is currently evaluated, as well as the sheer number of different iterations for each of these particles (including changes in surface coating, functionalization, size, etc.), which prevent adequate assessments from being made for each one.

\section{1-2. Current Methods for Chronic Nanoparticle Toxicity Assessment}


A critical issue for IONP, CONP, and other types of emerging nano-materials is their unknown toxicity profile. Most nanoparticles are regulated based on exposure limits associated with their fine sized counterparts until more definitive conclusions about nano-specific toxicity can be made. The most common techniques to assess new/unknown materials involve whole animal models and short term/high dose toxicity ${ }^{54}$. However, these animal studies are both time and resource heavy, which makes it difficult to keep pace with the rapid development of new and unique types of nanomaterials using traditional methods ${ }^{55}$. Long term or chronic animal studies - which are necessary to better understand particle-induced chronic diseases- are cost prohibitive, preventing researchers from fully studying these potential adverse outcomes with relation to nanoparticles. Furthermore, the sheer number of new types of nanoparticles being produced and used each day make it impossible to adequately test each one using traditional in vivo methods within a reasonable amount of time.

To address this, some scientists have utilized cell culture methods to better assess potential nanoparticle toxicity in a more rapid and cost-effective way ${ }^{56}$. However, this approach can be just as flawed. For in vitro model systems, there are a number of additional parameters which must be taken into account in order to ensure results are going to be accurate and predictive of an in vivo or human response. For example, thorough particle characterization, calculated delivered dose, cell type used, potential assay interference, and human relevance must all be considered to ensure results from an in vitro assay can be translated or extrapolated to a human-relevant exposure scenario ${ }^{57}$.

One of the most common occupational exposure scenarios involves the inhalation of a low dose of particles in the circulating air over an extended period of time. This type of chronic exposure is more likely to result in chronic disease outcomes such as cancer development or pulmonary fibrosis ${ }^{58}$. Extended exposure to particle may result in chronic and continuous cell 
injury and induce damage without immediately pathological adverse effects ${ }^{59}$. Over time, chronic cell injuries and responding adaptations may accumulate to result in devastating consequences for workers exposed in these types of scenarios. However, the extended period of time involved in the development of these types of diseases makes them difficult to study at a pace on par with the development of new materials.

OECD guidelines for the assessment of chronic conditions require an extended period of time to conduct the study. For carcinogenesis, as an example, there is one recommended in vivo test from OECD, and requires two species (usually rodent) with data collected over the animal's lifespan (typically 2-3 years) ${ }^{60}$. These time and resource heavy methods are unable to totally address the need for carcinogenic assessment of emerging materials. In fact, due to the sheer number of new materials being produced and used each day, it is becoming increasingly urgent that more rapid and cost-effective methods are developed to assess the potential for new materials to induce these types of chronic conditions.

To at least partially accommodate this, OECD has also recommended in vitro cell transformation assays, which may be conducted on a shorter term basis, and can be used to predict particle-induced carcinogenicity in vivo ${ }^{61}$. However, with the development of cell culturebased systems, there are a number of additional parameters which must be accounted for to ensure accurate and predictive results. When these are not taken into consideration, the result is a lack of clarity as to actual particle toxicity. There are clear discrepancies in the existing IONP and CONP literature, and this lack of clarity is not unique to these two nano-metal oxides. Many other types of nanomaterials have similarly unknown or unclear aspects to their potential toxicity, particularly for particle-induced chronic disease states. Overall, this reveals the critical need for better methods of toxicity evaluation for new and emerging materials. More rapid assays need to be available, but must also be accurate and predictive of an in vivo or human response. 


\section{1-3. Emerging Techniques for Nanoparticle Toxicity Assessment}

There are several critical issues which need to be addressed with the design of in vitro screening techniques, so these assays can be better utilized to protect those at risk of exposure to new/emerging materials while keeping up with the rapid pace of nanoparticle discovery and development ${ }^{56}$. Tiered toxicity screening for nanoparticles is reliant on a true integration of in vitro and in vivo techniques. If better, more accurate, and more predictive in vitro models can be developed which will represent an in vivo or human response, these assays can be used to screen a large number of particles relatively quickly. This would allow scientists to select the most potentially hazardous ones for further, more in-depth study, and prioritize compounds for future animal studies ${ }^{57}$.

However, this type of approach only works if the in vitro models used are accurate and predictive of an in vivo or human response. Many traditional in vitro techniques give accurate toxicity results for fine/micron sized materials. However, the unique properties of nano-sized particles which allow them to be utilized in so many novel applications may also have a unique impact on obscuring results from these already established in vitro models. As such, there are a number of additional parameters which must be taken into consideration when designing and implementing an in vitro exposure for nanoparticle toxicity, specifically.

The first of these is thorough particle characterization. Although primary particle size as a dry powder should remain the same as long as particles are generated from the same source and in the same manner, the dispersion of particle in any kind of dosing medium will have a dramatic impact on particle agglomerate size and shape. Depending on particle zeta potential, and media protein content and viscosity, particle aggregation and agglomeration may change drastically. If particles agglomerate in an unexpected way, it may obscure actual particle-induced toxicity. For 
example, if a particle agglomerate was recognized by the cell as a larger structure than the primary particle size suggests, this would drastically impact observed results ${ }^{62}$. Therefore, thorough particle characterization, including hydrodynamic diameter, zeta potential, and surface area of agglomerates in the cell culture media are all necessary for an in vitro exposure.

Particle dissolution will also have a critical impact on overall toxicity. If a particle readily dissolves in water or the dosing medium, it is likely that the cells may never come in contact with the particle itself, making it difficult to determine a particle specific effect as compared to an ionic compound effect. Therefore, it is important to determine particle dissolution in its storage medium (e.g. water), delivery media (e.g. cell culture media), and once inside the cell, if possible (e.g. phagolysosome-like buffer). For IONP, in particular, the rate of dissolution is known to have an impact on IONP induced adverse effects, and varies quite a bit based on the type of particle generated and the specific medium used ${ }^{63}$.

Particle deposition rate will dictate the dose which is actually delivered to cells in an in vitro model system. If the calculated delivered dose varies significantly from the known administered dose, this could also obscure particle toxicity. In fact, many new types of nanomaterials, including clays, thermoplastics, and other platelet shaped particulates, are buoyant, and may never actually deposit onto cells. More recently, particle deposition rate has been modeled using the Distorted Grid (DG) dosimetry modeling system ${ }^{64-66}$, which takes into account specific factors such as particle effective density, media protein content, and media viscosity, to calculate delivered dose.

Another parameter which could also have an impact on results in an in vitro model system is cell type. For example, in the lung, response to foreign particle exposure relies on chemical interactions and communications between a vast array of cell types. Due to the complexity of this system, it can be difficult to replicate using cell culture models. There are several types of in vitro model systems which have been used in an attempt to replicate this, including mono-culture (one 
cell type), co-culture (two cell types), multicellular spheroid model systems, and even "organ-ona-chip" methods ${ }^{67}$. Although each of these model systems has clear advantages and disadvantages, one of the most necessary criteria that should be taken into consideration is the use of a relevant cell type, including disease state, species, and location in the body, in relation to the specific toxicity endpoints which are being studied. This is highly dependent on the overall goal of a study. For example, if the goal of a study is to assess IONP response in a healthy individual, only cell lines derived from a healthy individual should be used. If the goal of a study is to assess IONP impact on a particular endpoint, it is important to fully consider which cell types may be involved in that specific process, and which ones will allow for the most relevant assessment of a human response 68 .

Finally, potential assay interference is a critical factor which must be considered for nanoparticle toxicity studies. Assay interference is relatively common for these types of particles due to their small size and pigmented properties. For example, Kain, et al. ${ }^{69}$ noted that a specific IONP caused observable DNA damage when it was measured via the comet assay, but not when formamidopyrimidine DNA glycosylase (FPG) sites were used as an indicator instead. The authors attributed this to IONP interference with FPG, leading to inaccurate results. If particle interference is not known, measured, and accounted for, this could obscure actual particle-induced toxicity. In fact, several different types of IONPs have been shown to interact with the components of cytotoxicity assays ${ }^{70}$ and cytokine secretion assays ${ }^{71}$, as well as likely interfere with other types of assays which have not yet been reported. To counteract this, proper control experiments are necessary to account for potential particle interference ${ }^{72}$.

Overall, the goal for any in vitro model system, particularly within the context of a tiered toxicity screening approach, is to design the model in such a way that it will be representative of an actual in vivo or human exposure, so that results may be extrapolated to more complex model 
systems. If an in vitro experiment is unable to relate to a physiologically relevant in vivo or human exposure, it is unnecessary, and may critically contribute to the lack of cohesion in IONP and other nanoparticle toxicity literature.

\section{1-4. Dissertation}

The main objective of my dissertation was to assess toxicity of two types of metal oxide nanoparticles $\left(\mathrm{nFe}_{2} \mathrm{O}_{3}\right.$ and $\left.\mathrm{nCeO}_{2}\right)$ within the context of physiologically relevant in vitro and in vivo model systems, as well as how the alteration of specific physicochemical properties may impact their toxicity. For my dissertation, I hypothesized that changes in specific physicochemical properties of $\mathrm{nFe}_{2} \mathrm{O}_{3}$ (surface coating/chemistry) or $\mathrm{nCeO}_{2}$ (size) would impact their pulmonary toxicity.

Based on this, my dissertation is divided into key chapters centered around these topics. First, I delve into what is known about IONP toxicity based on the current literature, and how assay and model development may impact the uncertainty in its toxicity profile. Then, I utilize these concepts in a low dose/long term in vitro exposure model, to look at the impact of $\mathrm{nFe}_{2} \mathrm{O}_{3}$ on neoplastic-like cell transformation as a precursor to cancer-related adverse outcomes, as well as the use of an amorphous silica coating to alter particle surface chemistry, and how that may affect its toxicity. Next, I utilize $\mathrm{nCeO}_{2}$ within an occupationally relevant in vivo exposure model to evaluate size dependent effect on pulmonary inflammation, pro-fibrosis, and systemic toxicity, and compare results to corresponding in vitro studies. Finally, I focus on the potential mechanism underlying $\mathrm{nFe}_{2} \mathrm{O}_{3}$-induced cell transformation with preliminary data and supporting literature, to suggest potential future directions for this research.

The underlying concept of my dissertation research was to demonstrate examples of in vitro and in vivo model system integration, and to utilize these for a better understanding of particle- 
induced chronic diseases, such as pulmonary fibrosis or carcinogenesis. A more thorough integration of cell culture and whole animal model-based techniques would allow for better assessment of particle toxicity at a pace in concordance with the recent surge in production and use of nanoparticles in general. For my project, I showed this integration for $\mathrm{nFe}_{2} \mathrm{O}_{3}$ by comparing results to recently published in vivo work which utilized identical or very similar particles. I showed this integration for $\mathrm{nCeO}_{2}$ within my study, by directly comparing in vivo and in vitro response using corresponding doses.

To ensure the translational quality of my research, I carefully considered some critical parameters in model development, as have been previously alluded to. For my in vitro studies, particle agglomeration and deposition were carefully calculated, and delivered dose was based on translated occupationally and physiologically relevant doses. Cell type was selected to adequately represent the type of occupational exposure I was trying to model, and cells were exposed at a low dose continuously over an extended period of time to better represent chronic exposure conditions in humans. Potential particle interference was carefully accounted for, and measured end points were chosen based on relevant OECD guidelines. For my in vivo work, an occupationally relevant dose was carefully selected, and scaled to a comparable in vitro model system, again with cell type and experimental design selected to best represent a real-world exposure scenario.

Overall, the goal of this project was to assess the potential for two different nano-metal oxides ( $\mathrm{nCeO}_{2}$ and $\mathrm{nFe}_{2} \mathrm{O}_{3}$ ) within the context of physiologically relevant in vitro and in vivo models to induce chronic disease outcomes, as well as how alterations in specific physicochemical properties may impact this toxicity. The overall impact of this work was to better demonstrate how the integration of in vitro and in vivo models may be used to better guide tiered toxicity screening approaches for future materials with unclear or unknown toxicity profiles. 


\section{Chapter 2: Potential Toxicity and Underlying Mechanisms Associated with Pulmonary Exposure to Iron Oxide Nanoparticles: Conflicting Literature and Unclear Risk.}

\section{Chapter Introduction:}

IONP toxicity is a poorly understood topic. As design and production of these particles increases, so does risk of exposure for workers involved in their manufacture and processing. The controversial and unclear nature of IONP toxicity makes it difficult to set exposure limit recommendations. The goal of this review paper was to highlight what is already known about IONP toxicity, identify critical knowledge gaps in IONP literature, and address ways in which assay development can be used to generate more accurate and predictive toxicity information for IONP, all of which could be applied to other types of nano-metal oxides, as well.

Adapted from: T. Kornberg et al., "Potential Toxicity and Underlying Mechanisms Associated with Pulmonary Exposure to Iron Oxide Nanoparticles: Conflicting Literature and Unclear Risk," Nanomaterials, vol. 7, no. 10, p. 307, Oct. 2017. 


\title{
Potential Toxicity and Underlying Mechanisms Associated with Pulmonary Exposure to Iron Oxide Nanoparticles: Conflicting Literature and Unclear Risk
}

\author{
Tiffany G. Kornberg 1,2,*, Todd A. Stueckle ${ }^{2}$, James M. Antonini ${ }^{2}$, Yon Rojanasakul ${ }^{1}$, Vincent \\ Castranova ${ }^{1}$, Yong Yang ${ }^{3}$ and Liying W. Rojanasakul 1,2,* \\ 1 Pharmaceutical and Pharmacological Sciences, West Virginia University, Morgantown, WV, USA, 26505; \\ yrojan@hsc.wvu.edu (Y.R.); vcastran@hsc.wvu.edu (V.C.) \\ 2 Health Effects Laboratory Division National Institute for Occupational Safety and Health, Morgantown, WV, \\ USA, 26505; \\ jux5@cdc.gov (T.A.S.); jga6@cdc.gov (J.M.A.) \\ 3 Department of Biomedical Engineering, University of North Texas, Denton, TX, USA, 76207; \\ yong.yang@unt.edu \\ * Correspondence: yxb6@cdc.gov (T.G.K.); lmw6@cdc.gov (L.W.R.); Tel.: +1-304-285-5844 (T.G.K.); \\ +1-304-285-5954 (L.W.R.)
}

Received: 7 September 2017; Accepted: 28 September 2017; Published: 6 October 2017.

\begin{abstract}
:
Fine/micron-sized iron oxide particulates are incidentally released from a number of industrial processes, including iron ore mining, steel processing, welding, and pyrite production. Some research suggests that occupational exposure to these particulates is linked to an increased risk of adverse respiratory outcomes, whereas other studies suggest that iron oxide is biologically benign. Iron oxide nanoparticles (IONPs), which are less than $100 \mathrm{~nm}$ in diameter, have recently surged in use as components of novel drug delivery systems, unique imaging protocols, as environmental catalysts, and for incorporation into thermoplastics. However, the adverse outcomes associated with occupational exposure to IONPs remain relatively unknown. Relevant in vivo studies suggest that pulmonary exposure to IONPs may induce inflammation, pulmonary fibrosis, genotoxicity, and extra-pulmonary effects. This correlates well with in vitro studies that utilize relevant dose, cell type(s), and meaningful end points. A majority of these adverse outcomes are attributed to increased oxidative stress, most likely caused by particle internalization, dissolution, release of free iron ions, and disruption of iron homeostasis. However, because the overall toxicity profile of IONPs is not well understood, it is difficult to set safe exposure limit
\end{abstract}


recommendations that would be adequate for the protection of at-risk workers. This review article will focus on known risks following IONPs exposure supported by human, animal, and cell culturebased studies, the potential challenges intrinsic to IONPs toxicity assessment, and how these may contribute to the poorly characterized IONPs toxicity profile.

\section{2-1. Introduction}

The field of nanotechnology is expanding rapidly as scientists and engineers continue to develop innovative applications using nano-scaled materials. For example, iron oxide nanoparticles (IONPs) have been developed for use in targeted cancer treatment, new imaging techniques, and as environmental catalysts due to their unique paramagnetic properties ${ }^{16}$. They can be incorporated into thermoplastics and other materials due to their pigmented properties, as well ${ }^{17}$. Iron oxide particulates (both fine/micron- and ultra-fine/nano-sized) are known to become aerosolized during anthropogenic activities related to the iron and steel industries, as well as during the nanoparticle manufacturing process, where they may represent a significant portion of the circulating air for industrial workers [3, 4]. However, the actual adverse outcomes to human health induced by iron oxide particulate exposure remain highly controversial. The most common adverse health outcomes induced by iron oxide include permanent discoloration of the eyes, siderosis, and pneumoconiosis ${ }^{38}$. Some epidemiology studies also indicate adverse respiratory outcomes and increased risk of lung cancer following inhalation of iron oxide particulates in an occupational setting [3,5-7], whereas other researchers report iron oxide particulates to be biologically benign 34,39,40,74-76. The exact mechanisms underlying iron oxide particulate-induced adverse outcomes are poorly understood, but most research suggests they are related to the physicochemical properties of the iron or iron oxide metal compounds, and are largely due to iron oxide-induced or catalyzed oxidative stress. 
Iron is a transition metal, meaning it exists in several different valence states, and can form compounds with other elements such as oxygen. Iron oxides come in three main oxidative states: $\mathrm{FeO}, \mathrm{Fe}_{2} \mathrm{O}_{3}$, and $\mathrm{Fe}_{3} \mathrm{O}_{4}$. $\mathrm{FeO}$ (wustite) makes up a significant component of the earth's mantle and may have electrical conducting properties ${ }^{12}$. It is also used as a pigment for tattoo inks ${ }^{13}$, and is involved in the forge welding process. $\mathrm{Fe}_{2} \mathrm{O}_{3}$ (hematite) is ferromagnetic, and has two common structural forms. $\alpha-\mathrm{Fe}_{2} \mathrm{O}_{3}$ is rhombohedral and is the most common type of iron oxide mined during the iron ore mining process ${ }^{77}$. At high temperatures, $\alpha-\mathrm{Fe}_{2} \mathrm{O}_{3}$ is converted to the gamma form (maghemite), which has a cubic structure. $\gamma-\mathrm{Fe}_{2} \mathrm{O}_{3}$ becomes superparamagnetic at sizes of $10 \mathrm{~nm}$ or less, making it relatively popular for biomedical applications. $\mathrm{Fe}_{3} \mathrm{O}_{4}$ (magnetite) is ferrimagnetic and was a primary component in rudimentary forms of the compass ${ }^{78}$. On the nano-scale, $\mathrm{Fe}_{3} \mathrm{O}_{4}$ will take on paramagnetic or superparamagnetic properties, which also allow it to be utilized in a broad range of applications.

Examples of applications that rely on micron/fine-sized iron oxide include: medicine, electronic tape, pigments, and catalysts. Both $\gamma-\mathrm{Fe}_{2} \mathrm{O}_{3}$ and $\mathrm{Fe}_{3} \mathrm{O}_{4}$ can be purposefully engineered to be less than $100 \mathrm{~nm}$ in diameter, and possess unique paramagnetic or superparamagnetic properties at sizes of $10 \mathrm{~nm}$ or less. Because of this, IONPs are being incorporated into a wide range of consumer products and industrial applications ${ }^{14}$, including biomedical (cell labeling, targeted drug delivery platform, and novel imaging techniques), electronics (circuitry, data storage), transportation (brake systems), and cosmetics (Figure 2-1).

Although IONPs are involved in a broad range of applications, their toxicological profile remains unclear. This review will first focus on what is known of IONPs toxicity based on representative human, in vivo, and in vitro-based studies. Representative epidemiology studies will be used to highlight potential adverse outcomes induced by IONPs exposure based on fine/micron-sized iron oxide reports (summarized in Table 2-1), followed by in vivo and in vitro studies to better ascertain 
IONPs-induced adverse outcomes, as well as the potential underlying mechanism. Then, intrinsic issues with IONPs toxicity assessment will be addressed, and further clarified how these issues may contribute to the lack of certainty regarding IONPs-induced adverse outcomes. This review is not meant to be a comprehensive review of IONPs toxicity literature, but rather a critical evaluation of the literature that does exist, and why so much of it appears to be conflicting. 


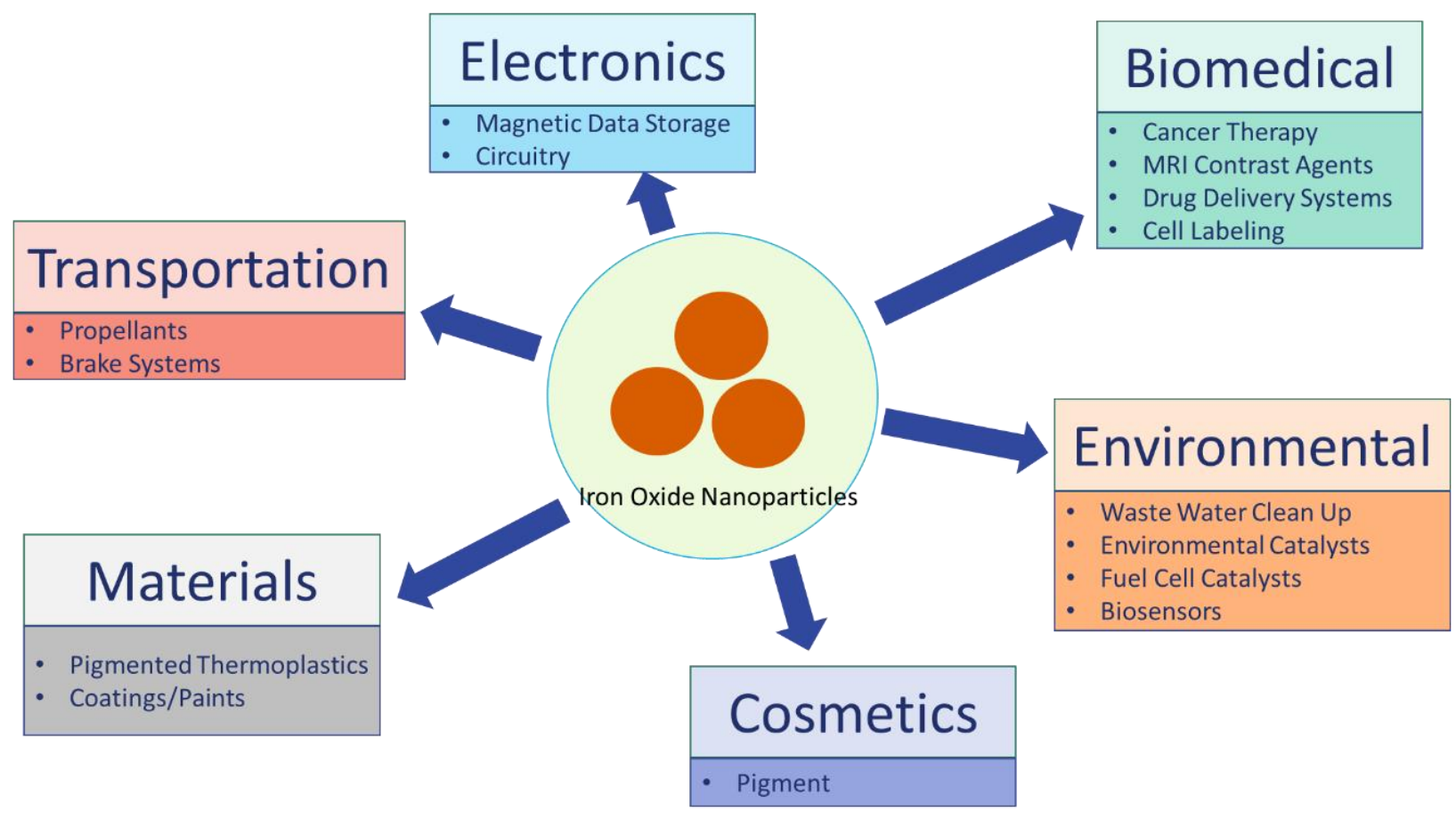

Figure 2-1. IONPs Uses by Humans and Potential Exposure Sources. IONPs are currently being used in a wide range of fields, including biomedical, electronic, transportation, environmental, materials, cosmetics, and more. Currently, biomedical uses for IONPs, including cancer therapy, MRI contrast agents, and targeted drug delivery systems may involve injection into humans. Cosmetics products may involve dermal application. IONPs use in propellants, or as pigmented components of coatings/paints may result in pulmonary exposure. However, adverse outcomes resulting from these exposures remain largely unknown. 


\section{2-2. Potential Toxicity of IONPs Based on Human Studies}

\section{2-2a. Mining/Industrial Applications_Fine/Unknown-Sized Iron Oxide}

Human exposure to iron oxide particulates, especially for miners and industrial workers, has been relatively well studied. There are a wide range of industries that involve worker exposure to fine/micron-sized iron or iron oxide particulates. These include iron ore mining and pyrite production, as well as industries which use iron oxide as a pigment or polishing agent, or which involve the mechanical alteration of iron containing products ${ }^{18}$. These processes release iron oxide particulates into the circulating air, becoming an exposure risk for workers, including miners, foundry workers, smiths, and metal grinders [7, 12]. An occupational exposure is more likely to be continuous or extended ${ }^{73}$, thus potentially leading to exacerbated risk of chronic health conditions. However, iron or iron oxide dusts often contain quartz or silica ${ }^{34}$, as well as mixtures of other workplace particulates (e.g., welding), which make it difficult to distinguish iron oxide-specific effects. Furthermore, the size of the iron oxide released during these processes often varies greatly. Therefore, the actual adverse outcomes induced by iron oxide particulates in these settings remain controversial and unclear.

Iron ore mining is known to release iron oxide dust, and many researchers have focused on this occupation to elucidate the potential adverse outcomes associated with iron oxide particulate exposure. Boyd et al. ${ }^{33}$ found that underground iron ore miners had an almost $75 \%$ increased risk of lung cancer related death as compared to local, non-mining subjects. The authors attributed these deaths to the potentially carcinogenic effect of iron oxide. Studies which followed iron ore miners in both Finland ${ }^{79}$ and China ${ }^{36}$ reported similar outcomes. A lack of ventilation during the mining process, which leads to increased particulate exposure ${ }^{36}$, was used as additional evidence that the iron oxide particulates released during the mining process were most likely responsible for subsequent lung cancer-related deaths. However, these three studies also note that an excessive 
amount of radon daughters, as well as the inability to fully characterize particulate size and composition in the circulating air, made it difficult to conclusively attribute the observed increased risk of lung cancer to iron oxide exposure, specifically.

Currently, the Occupational Safety and Health Administration (OSHA) has a permissible exposure limit of $14 \mathrm{mg} / \mathrm{m}^{3}$ for fine iron oxide over the course of an 8 hour workday. The National Institute for Occupational Safety and Health (NIOSH) set a recommended exposure limit (REL) of 5 $\mathrm{mg} / \mathrm{m}^{3}$ for iron (in iron oxide) over a 10 hour work day, while the American Conference of Governmental Industrial Hygienists (ACGIH) recommended $5 \mathrm{mg} / \mathrm{m}^{3}$ limit for the respirable fraction of iron oxide over an 8 hour workday ${ }^{38}$. However, there is currently no separate REL for IONPs due to lack of toxicity and hazard assessment, which may put vulnerable workers at risk of IONPs-induced adverse outcomes. This has become a more critical problem recently, due to the rapid development and projected influx of IONPs-based applications.

\section{2-2b. Ultrafine and Nano-Sized Iron Oxide}

IONPs are currently being incorporated into a wide range of consumer products. As applications for IONPs expand, there is an increasing concern for potential toxicity induced by these materials, especially for those who would be exposed in an occupational setting. It is generally believed that decreasing particle size leads to increasing toxicity on a per mass basis due to increased particle surface area and number [22,23]. Therefore, IONPs may have increased potential to induce adverse health effects as compared to their fine/micron-sized counterparts. However, there is currently very little known about these potential risks. The limited human data on IONPs toxicity largely focuses on either occupational exposures to particulate mixtures, which are known to include iron or iron oxide (such as welding, iron smelting, or steel processing), or workers in IONPs 
manufacturing facilities. Representative studies are presented below, and are summarized in Table $2-2$.

There are a large number of mixed particulate exposures that contain iron or iron oxide particulates, including certain types of welding fumes. Andujar et al. ${ }^{81}$ used a cohort of 21 welders to assess welding fume exposure as a potential cause for observed lung changes in patients. The authors collected lung samples from 21 welders who had worked for an average of 27 years each, and compared the tissue to similarly obtained lung samples from 21 matched controls. The welders were shown to have increased fibrotic lesions and elevated lung iron levels as compared to nonwelders. This was shown in conjunction with iron oxide, manganese oxide, and chromium oxide particulates internalized within alveolar macrophages. When the authors synthesized representative nanoparticles (including $\mathrm{Fe}_{2} \mathrm{O}_{3}$ and $\mathrm{Fe}_{3} \mathrm{O}_{4}$ ) and used them to treat human macrophages in vitro, the IONPs were found to induce pro-inflammatory cytokine secretion ${ }^{81}$. This directly implicates iron oxide as being a driver for an inflammatory response, which when dysregulated or dysfunctional, can be known to contribute to pulmonary fibrosis as was observed in these welders.

IONPs are also specifically engineered for a wide range of consumer products and applications, leading to the recent increase of IONPs manufacturing facilities. Unfortunately, due to the relatively high exposure limit recommendation for fine iron oxide, along with the greater toxic potential of nano-sized particulates in general, these types of facilities have the potential to provide much better evidence for IONPs-specific-induced adverse effects. Xing et al. ${ }^{20}$ assessed the concentration of airborne nanoparticles in a factory which manufactured $\mathrm{Fe}_{2} \mathrm{O}_{3}$-based materials via chemical synthesis. Air sampling locations were chosen based on proximity to one of four major steps involved in this synthesis process, and included two packaging locations, a powder screening location, and a material feeding area. The authors found a significantly higher amount of $\mathrm{Fe}_{2} \mathrm{O}_{3}$ 
between 10 and $1000 \mathrm{~nm}$ in diameter in these four locations as compared to both indoor and outdoor background particulate levels. They reported an average (across all four sites) of three fold increased number of particles, two fold increase in $\mathrm{mg} / \mathrm{m}^{3}$ particle concentration, and almost two fold increase in total particle surface area as compared to background particulate levels. Total exposure ranged from 0.04 to $0.28 \mathrm{mg} / \mathrm{m}^{3}$ depending on site, which is much lower than the previously described OSHA permissible exposure limit $\left(14 \mathrm{mg} / \mathrm{m}^{3}\right.$ for fine iron oxide over an $8-\mathrm{h}$ work day). However, the authors did not assess if any adverse health outcomes were reported in these exposed workers.

Pelclova et al. ${ }^{21}$ assessed workers known to be exposed to an iron oxide aerosol ( $80 \%$ of which was less than $100 \mathrm{~nm}$ in diameter) in a nanoparticle manufacturing facility. Median mass exposure concentrations were $0.083 \mathrm{mg} / \mathrm{m}^{3}$, or 66,800 particles $/ \mathrm{cm}^{3}$ (lower than the OSHA permissible exposure limit, but roughly similar to the Xing et al. ${ }^{20}$ reported exposure) with an average of 10 years exposure per worker. Workers were evaluated at the end of a work shift, and were found to have elevated oxidative stress and inflammatory biomarkers in exhaled breath condensate and urine, indicating the potential for IONPs to induce adverse outcomes with a long-term occupational exposure. A caveat to this study, however, is the transient nature of oxidative stress biomarkers in the urine. A more thorough evaluation of these workers, as well as a larger sample size, would be necessary to definitively illustrate the potential systemic oxidative stress response induced by IONPs occupational exposure, and to better link this response to subsequent adverse health outcomes.

Overall, these studies provide direct evidence that workers involved in the IONPs synthesis or manufacturing process are exposed to IONPs in an occupational setting, and that this exposure can lead to oxidative stress and inflammation over an extended period of time. Due to the limited amount of information available, however, no exposure limit recommendations for IONPs have 
been made, and both its full toxicity profile and the underlying mechanisms of action are still poorly understood.

\section{2-3. Toxicity of IONPs-In Vivo Studies}

In vivo toxicity testing is currently the primary source of information to establish potential risk following particle exposure. The observed animal response can be extrapolated to risk of adverse outcomes in humans, and is used to help establish or support safe exposure limit recommendations. The most common route of IONPs exposure in an occupational setting is via inhalation. However, very few in vivo studies have been done which assess this route for IONPs-induced toxic effects. Furthermore, the resulting data often show conflicting results, or are otherwise inconclusive. The studies which do report adverse outcomes following IONPs pulmonary exposure reveal subsequent inflammation $22-27$, pulmonary fibrosis [31, 32], genotoxicity [33, 34], and extra-pulmonary effects 28,29,32, almost all of which are attributed to IONPs-induced excessive oxidative stress. Representative studies are presented below, and are summarized in Table 2-3.

\section{2-3a. Inflammation}

The inhalation of a foreign particle will likely induce an inflammatory response immediately following exposure. This allows lung immune cells to identify and remove foreign material from the lung, in an attempt to minimize tissue injury and damage. If the particle persists and inflammation becomes prolonged, it may become dysfunctional and can ultimately lead to development of fibrosis, cancer, or other adverse outcomes [38, 39]. IONPs have been shown to induce an acute inflammatory response in both rats and mice, which in some cases may become prolonged or chronic ${ }^{23}$. IONPs may also modulate a pulmonary allergic reaction $[29,30]$.

Park et al. ${ }^{22}$ exposed ICR mice via a single intratracheal instillation to $\mathrm{Fe}_{3} \mathrm{O}_{4}$ (5.3 nm primary particle size) at the dose of 250, $500 \mu \mathrm{g} / \mathrm{kg}$, or $1 \mathrm{mg} / \mathrm{kg}$ (about 0.005 to $0.02 \mathrm{mg} / \mathrm{mouse}$ ), and 
assessed the inflammatory response up to 28 days post exposure. The authors reported an initial, acute inflammatory response one day post exposure, and lower but still significantly elevated inflammatory cytokine levels up to 28 days post exposure, indicating both acute and prolonged IONPs-induced inflammatory responses. The authors also reported an increase in the expression of genes related to inflammation and tissue damage (including heat shock proteins and matrix metalloproteinases) throughout the study's time course, as well as significant formation of micro granulomas-a potential precursor to fibrosis. These adverse effects were primarily attributed to excessive oxidative stress, as indicated by a significant reduction in glutathione (GSH) in the lavage fluid.

This same group also evaluated $\mathrm{Fe}_{2} \mathrm{O}_{3}$ particles (209.4 nm agglomerates) with a needle-like shape in ICR mice. Mice were administered the particles via a single intratracheal instillation $(0.5$, 1 , or $2 \mathrm{mg} / \mathrm{kg}$, or about 0.01 to $0.04 \mathrm{mg} /$ mouse). The authors were able to show that the particles remained in the lung even 90 days post exposure, with many particles having been engulfed by alveolar macrophages. A failure to completely remove foreign particles from the lung has the potential to contribute to a chronic or dysregulated inflammatory response. The highest dose used in this study led to significant infiltration of inflammatory cells into the lung (neutrophils and lymphocytes), as well as a dose dependent increase in lactate dehydrogenase activity (LDH), increase in chemokine secretion, and increase in antigen presentation related protein expression. Overall, the authors concluded that IONP exposure induced a Th1 polarized immune response in the lungs ${ }^{23}$.

Sadeghi et al. ${ }^{24}$ dosed Wistar rats with 20 or $40 \mathrm{mg} / \mathrm{kg} \mathrm{Fe} 2 \mathrm{O}_{3}(20 \mathrm{~nm})$ via repeated intratracheal instillations (either 7 or 14 times, once every other day). The authors found signs of pulmonary inflammation and injury, including pulmonary emphysema, and an increased presence of neutrophils, eosinophils, and lymphocytes. The authors also noted elevated hepatic enzymes in the 
blood serum, which is indicative of hepatic cell injury and liver damage. They attributed this to excessive oxidative stress, as indicated by an increase in free radicals and a reduction in GSH in the lung tissue.

Srinivas et al. ${ }^{25}$ exposed Wistar rats via head and nose only inhalation (4 hour continuous exposure) to $\mathrm{Fe}_{3} \mathrm{O}_{4}(15-20 \mathrm{~nm})$ at a reported actual aerosol concentration of $640 \mathrm{mg} / \mathrm{m}^{3}$ based on mass median aerodynamic diameter and geometric standard deviation within respirable rangemuch higher than the OSHA permissible occupational exposure limit. Lung burden following exposure was not measured. The authors assessed lung injury and inflammation up to 14 days postexposure, and showed that IONPs were able to induce acute cytotoxicity and inflammatory responses, as indicated by increased $\mathrm{LDH}$, neutrophil infiltration, and pro-inflammatory cytokines in both lavage fluid and blood. The inflammatory response was sustained out to 14 days post exposure, although it decreased in severity in a time dependent manner. Once again, the authors attributed these adverse outcomes to excessive oxidative stress, as indicated by a significant reduction in GSH and antioxidant enzyme activities within this same time frame ${ }^{25}$. However, due to the excessive concentration used in this study, the observed response may have been due to overloading the lungs with particle, which would compromise normal pulmonary clearance mechanisms.

IONPs may also have the capacity to alter a typical immune response. Ban et al. ${ }^{26}$ compared nano $(35 \mathrm{~nm})$ and sub-micron $(147 \mathrm{~nm})$-sized $\mathrm{Fe}_{2} \mathrm{O}_{3}$ particles at 100, 250, or $500 \mu \mathrm{g} / \mathrm{mouse}$. The animals were exposed via intratracheal instillation both before and after sensitization with ovalbumin (OVA), and the Th2 immune response was assessed. The authors found that the allergic response induced by OVA was inhibited with the middle or high doses of IONPs, but was actually enhanced at the lowest dose used for treatment, whereas the submicron-sized particles at the 
lowest dose had no effect at all. The authors were only able to conclude that the pulmonary immune response is sensitive to IONP exposure.

Gustafsson et al. ${ }^{27}$ used a similar $\mathrm{Fe}_{2} \mathrm{O}_{3}$ particle $(30 \mathrm{~nm})$ in conjunction with the OVA sensitization model to further elucidate how IONPs may alter the immune response. In this case, the authors showed that intratracheal instillation of $\mathrm{Fe}_{2} \mathrm{O}_{3}$ alone $(2.5 \mathrm{mg} / \mathrm{kg}$ body weight $)$ induced a pulmonary inflammatory response in non-sensitized or OVA challenged Balb/c mice, as indicated by an increase in neutrophils, eosinophils, and lymphocytes in the airways. However, OVAsensitized and challenged mice exposed to IONPs had a decreased inflammatory response. The authors attributed this to excessive cell death in already inflamed airways and in the lung draining lymph nodes (LDLN), most likely caused by excessive reactive oxygen species (ROS) generation in the resulting pro-oxidative environment.

Overall, these studies clearly indicate that IONPs have the capacity to induce lung inflammation and injury in both mice and rats, and that this is most commonly attributed to IONPs-induced oxidative stress.

\section{2-3b. Pulmonary Fibrosis}

Chronic inflammation has the potential to lead to pulmonary fibrosis, which is characterized by an increase in proliferation and collagen production by alveolar fibroblasts. This can be triggered by inflammatory cytokines such as TGF- $\beta$, and will normally occur following a foreign particle exposure or other type of lung injury to help initiate lung healing ${ }^{86}$. However, excessive or dysregulated fibrosis may lead to irreversible lung scarring, and have an impact on overall breathing capacity and oxygen intake. Based on the known capacity for IONPs to induce a pulmonary inflammatory response that has the potential to become chronic, it would seem logical that these particles may also have some sort of fibrotic capacity. Although very few studies exist, 
those summarized below show a clear potential fibrotic capacity of IONPs. Furthermore, these studies largely agree on oxidative stress and particle overload as being primary instigators of this potential adverse outcome.

Zhu et al. ${ }^{82}$ used a single intratracheal instillation of $\mathrm{Fe}_{2} \mathrm{O}_{3}$ particles ( $22 \mathrm{or} 280 \mathrm{~nm}$ ) to expose Sprague Dawley rats to 0.8 and $20 \mathrm{mg} / \mathrm{kg}$ body weight and assessed subsequent adverse outcomes. One day post-exposure, the animals showed a peak in inflammation, as indicated by an increase in immune cell infiltration. By day 30, the animals exhibited markers of pro-fibrosis and lung emphysema, an increase in microvascular permeability, cell lysis, and other indicators of lung injury. The authors noted particle overloaded alveolar macrophages, and, again, attributed the observed adverse outcomes to an IONPs-induced oxidative stress response.

Szalay et al. ${ }^{83}$ used a single intratracheal instillation in Wistar rats ( 1 or $5 \mathrm{mg} / \mathrm{kg}$ body weight) of $\mathrm{Fe}_{3} \mathrm{O}_{4}$ ( $<50 \mathrm{~nm}$ diameter) and assessed potential fibrotic capacity of these particles. The authors reported a weak pulmonary fibrosis 30 days post exposure, but found no changes in extrapulmonary organs.

A caveat to both of these studies, however, is that IONPs fibrotic capacity was only assessed up to 30 days post exposure, while most in vivo studies assess fibrotic outcomes after a longer time period. Therefore, while the above studies clearly demonstrate the pro-fibrotic capacity of IONPs, later time points are necessary to determine this more conclusively. Not only are there very few chronic in vivo IONPs studies, but the ones available do not include pulmonary fibrosis as a measured endpoint. This represents a clear and significant knowledge gap in the IONPs toxicity profile.

\section{2-3c. Genotoxicity and Carcinogenic Potential}


The potential genotoxicity of IONPs is also inconclusive. Some studies report no genotoxic effect of IONPs ${ }^{87}$, although study design issues make it difficult to conclusively determine this 88 . Furthermore, there are very few papers that assess this end point at all. This is likely due to a combination of factors, including the extended period of time it may take for tumors to develop in an in vivo model system, as well as the perceived benign quality of iron oxide dust ${ }^{89}$. However, pulmonary response after an extended period of time is a major concern for workers in an occupational setting who may be exposed to a particle over months or years, but may not experience cancer-related symptoms until much later. As mentioned previously, some studies involving fine or unknown-sized iron oxide particulates show an association between iron oxide exposure and lung cancer development in miners and other industrial workers. An overload of free iron in the lungs (siderosis) is also known to be associated with increased risk of cancer development ${ }^{90}$. Genotoxicity is often a crucial first initiating step in cancer development, and is an important endpoint that can be used to evaluate carcinogenic potential in vivo.

Totsuka et al. ${ }^{30}$ used an intratracheal instillation of $\mathrm{Fe}_{3} \mathrm{O}_{4}(10 \mathrm{~nm}$ primary particle size) to expose both ICR and gpt delta mice at 0.05 or $0.2 \mathrm{mg}$ per animal. Three hours post-exposure, the ICR mice showed signs of significant lung damage ${ }^{30}$, and 24 hours post exposure they had significantly increased formation of DNA adducts (DNA covalently bound to carcinogenic compound) with elevated etheno-deoxycytidine $(\epsilon \mathrm{dC})$ levels. $\epsilon \mathrm{dC}$ is an indicator of inflammation and oxidative stress ${ }^{31}$. Eight weeks post-exposure, the gpt delta mice had increased gpt mutations (another indication of DNA damage), lipid peroxidation-related DNA adducts, inflammatory cell infiltration, and the formation of focal granulomas ${ }^{30}$. These results clearly indicate the potential for IONPs to induce genotoxicity, even within a very short time frame, and at a relatively low dose.

Genotoxicity is generally believed to be a significant driver of tumor development. However, there have been no in vivo studies that assess the actual carcinogenic potential of these particles. 
Even older in vivo cancer studies, which utilized an unknown or unreported-sized iron oxide, are scarce. Campbell et al. ${ }^{91}$ exposed groups of 8-10 mice to $0.5 \mathrm{~g} \mathrm{Fe}_{2} \mathrm{O}_{3} \cdot \mathrm{H}_{2} \mathrm{O}$ for six hours a day, five days a week, over an entire year to mimic an occupational exposure scenario. At 800 days post exposure, the iron oxide-exposed mice had significantly increased formation of primary lung tumors as compared to control animals. However, the iron oxide particles were not characterized, and their actual size is unknown. Particularly with regards to IONPs, the potential carcinogenicity has not been well explored, and indicates a very clear knowledge gap in IONPs-induced adverse effects.

\section{2-3d. Extra-Pulmonary Effects}

IONPs, due to their small size, may be able to translocate to other organ systems following pulmonary exposure either as intact particles or as its solubilized constituents. Radioactively labeled IONPs have been shown to enter the circulating blood stream less than 10 minutes following a pulmonary exposure ${ }^{28}$ and ultimately end up in organs which play a role in the mononuclear phagocyte system, including the liver, spleen, and kidney. This may lead to extra-pulmonary effects via the same or different mechanisms as IONPs pulmonary adverse effects. Once at these secondary sites, IONPs may dissolve, or may accumulate as whole particles and induce tissue damage. Furthermore, IONPs have been shown to activate or alter components of the blood such as platelets 92, and as was previously alluded to, may activate the immune system as well $[29,30]$.

Al Faraj et al. ${ }^{29}$ used magnetic resonance imaging to document superparamagnetic $\mathrm{Fe}_{2} \mathrm{O}_{3}$ translocation after an intrapulmonary administration. The particles $(129.3 \mathrm{~nm})$ were coated with polyethylene glycol and had either positively- or negatively- charged functionalization groups to enhance biocompatibility. After intrapulmonary administration into Balb/c mice at a calculated dose of $0.8 \mathrm{mmol}$ iron/kg body weight, the authors looked for nanoparticles in several major organ 
systems at two hours, one day, two days, one week, two weeks, and one month post-exposure. They showed rapid movement of the particles to the liver at one day post-exposure, but this hepatic iron was almost completely cleared by later time points. The authors also showed that inflammatory biomarkers, lipid peroxidation, and DNA damage all increased with IONPs exposure as compared to non-treated control animals. Although previous studies showed that IONPs may persist in the lungs, this study indicates that if the particle translocates to a secondary site, it may be more rapidly cleared from there.

Wang et al. ${ }^{32}$ used intratracheal instillation of $30 \mathrm{~nm} \mathrm{Fe} 2 \mathrm{O}_{3}$ into Wistar rats (twice per day for 3 consecutive days at $8.5 \mathrm{mg} / \mathrm{kg}$ body weight) and evaluated particle persistence in the lung, as well as translocation to, and persistence in, the liver. They showed significant increase in overall iron content in both the lung and the liver, as well as clear indications of IONPs-induced lung and liver tissue damage, as determined via histopathology. The authors do not, however, assess the source of the elevated iron in the lung and liver. It could be from IONPs translocation, dissolution, and release of free iron ions, or may be due to IONPs sequestration of iron from the mitochondria or other organelles, leading to a cellular compensatory response.

Overall, the existing in vivo literature shows that pulmonary exposure to IONPs may lead to lung inflammation, injury, and immune modulation, with some studies also suggesting pro-fibrotic or fibrotic potential. There are conflicting studies as to the mutagenic potential of IONPs, with only one study showing actual tumor development (using an unreported size iron oxide). IONPs have also been shown to rapidly enter the circulatory system, potentially inhibiting platelet activation ${ }^{92}$, as well as traveling to other major organ systems and causing tissue damage at these secondary sites. Although in vivo studies provide information on potential IONPs-induced adverse outcomes, there are also several significant knowledge gaps, including fibrotic potential and carcinogenic 
capacity. This lack of information makes it difficult to evaluate risk to a human population, and prevents a clear understanding of the IONPs toxicological profile. 
Table 2-1. Referenced iron oxide (unknown or unreported size) human studies.

\begin{tabular}{|c|c|c|c|c|}
\hline Reference & Cohort & $\begin{array}{c}\text { Exposure } \\
\text { Particulates } \\
\end{array}$ & Size & Adverse Outcomes \\
\hline 33 Boyd & $\begin{array}{l}6000 \text { underground and surface } \\
\text { hematite iron ore miners (UK) }\end{array}$ & $\begin{array}{l}\text { Iron oxide dust with } \\
10-12 \% \text { silica content, } \\
\text { radon }\end{array}$ & Unknown & $\begin{array}{l}\text { 70\% increased lung cancer } \\
\text { mortality rate }\end{array}$ \\
\hline${ }^{79}$ Siew & $\begin{array}{l}\text { Employed males 1906-1945 } \\
\text { (Finland) }\end{array}$ & $\begin{array}{l}\text { Iron fumes/dust, } \\
\text { welding fumes }\end{array}$ & Unknown & $\begin{array}{c}\text { Increased risk of lung cancer } \\
\text { following exposure to one or both } \\
\text { types of particulates }\end{array}$ \\
\hline${ }^{36}$ Chen & $\begin{array}{c}\text { Underground iron ore miners and } \\
\text { surface workers (Longyan and } \\
\text { Taochong, China) }\end{array}$ & $\begin{array}{c}3.8 \mathrm{mg} / \mathrm{m}^{3} \text { total } \\
\text { airborne dust, } 28 \% \\
\text { iron content }\end{array}$ & Unknown & $\begin{array}{l}\text { Increased incidences of non- } \\
\text { malignant respiratory disease and } \\
\text { lung cancer }\end{array}$ \\
\hline $\begin{array}{l}34 \text { Faulds \& } \\
\text { Stewart }\end{array}$ & $\begin{array}{c}\text { Hematite miners decreased } \\
\text { 1932-1953 (West Cumberland, } \\
\text { UK) }\end{array}$ & $\begin{array}{l}\text { Ferric oxide with } 10- \\
12 \% \text { silica content }\end{array}$ & Unknown & $\begin{array}{c}\text { Almost } 5 \text { fold increased incidences } \\
\text { of lung carcinomas at time of death } \\
\text { (attributed to silica content) }\end{array}$ \\
\hline
\end{tabular}


Table 2-2. Referenced iron oxide nanoparticle human studies.

\begin{tabular}{|c|c|c|c|c|}
\hline Reference & Cohort & $\begin{array}{c}\text { Exposure } \\
\text { Particulates } \\
\end{array}$ & Size & Adverse Outcomes \\
\hline${ }^{81}$ Andujar & $\begin{array}{l}21 \text { welders, average } \\
27 \text { years exposure }\end{array}$ & $\begin{array}{l}\text { Iron oxide, } \\
\text { manganese } \\
\text { oxide, } \\
\text { chromium } \\
\text { oxide }\end{array}$ & $\begin{array}{l}\text { Unknown/not- } \\
\text { reported }\end{array}$ & $\begin{array}{l}\text { Fibrotic lesions, elevated iron load. In vitro } \\
\text { treatment with representative nanoparticles caused } \\
\text { increased secretion of pro-inflammatory cytokines. }\end{array}$ \\
\hline${ }^{21}$ Pelclova & $\begin{array}{c}14 \text { workers in iron } \\
\text { oxide pigment } \\
\text { production facility, } \\
\text { average } 10 \text { years } \\
\text { exposure }\end{array}$ & $\begin{array}{l}\text { Iron oxide } \\
\text { (primarily } \alpha- \\
\left.\mathrm{Fe}_{2} \mathrm{O}_{3}\right)\end{array}$ & $\begin{array}{l}80 \% \text { measured } \\
\text { particles less than } 100 \\
\text { nm in diameter }\end{array}$ & $\begin{array}{l}\text { Elevated oxidative stress and inflammatory } \\
\text { biomarkers in exhaled breath condensate and urine. }\end{array}$ \\
\hline
\end{tabular}




\section{2-4. Toxicity of IONPs-In Vitro Studies}

Clearly, there is a critical need for a more complete toxicological profile of IONPs. In tandem, there is a dramatic increase in sheer number of new types of other nanomaterials, with similar knowledge gaps as to their unique potential to induce adverse outcomes. Overall, it is becoming increasingly urgent that more rapid methods are developed to better assess potential toxicity of these emerging materials, while concurrently maintaining robust and rigorous scientific methods to ensure these models are relevant and predictive of an in vivo and human response. In order to do this, many researchers are pushing for better in vitro model development, which would allow for a useful tiered hazard assessment of nanomaterials, in general.

There are many advantages to using in vitro model systems for toxicity assessment. In addition to the potential for more rapid toxicological evaluation, these models can also provide more information on the potential mechanism or mode of action of particle-induced toxicity. However, this can only be done if these in vitro model systems are predictive and representative of a human exposure and response. The overall goal with these systems, in the context of a tiered toxicity testing approach, is to utilize in vitro methods to rapidly screen a large number of nanomaterials for specific end points or adverse outcomes, also known as a high-throughput screening approach. These results can then be used to prioritize the most potentially hazardous materials for further in vivo studies.

However ideal this situation may seem, there are several issues with nanoparticle in vitro toxicity testing, which prevent this from being fully realized, and the study of IONPs in vitro toxicity is representative of these issues. Some studies report essentially no cytotoxic effect with exposure 93-95, whereas others report major dysfunction in macrophages 96 and mitochondria 97 , and even DNA damage $69,98,99$ induced by these particles. This lack of agreement is likely due to overall issues 
with in vitro model system experimental design and exposure conditions, and ultimately prevents them from being useful for hazard assessment purposes. In order to better utilize cell culture systems as even an initial screening tool, these major issues must be recognized and systematically addressed.

In the following section, this review will first discuss important considerations when developing an in vitro model system, including dose, particle agglomeration, particle uptake, cell type, and relevant end points, which may all have an impact on observed adverse outcomes. Next, this review will use these established criteria to critically examine the existing IONPs in vitro literature, and will highlight occupationally relevant IONPs in vitro studies which appear to correlate well to previously discussed in vivo results. All referenced in vitro studies are summarized in Table 2-4.

\section{2-4a. Issues with In Vitro Model Systems}

\section{2-4a.i. Particle Dose}

An issue common to both in vitro and in vivo experimental design is the use of a relevant dose. With in vivo studies, based on mode of exposure and observed particle deposition, the delivered dose can be determined and compared to actual human burden to ensure dose relevancy. With in vitro studies, however, there are several other factors which will influence how much of the administered dose is actually delivered to the cells, and in what time frame that exposure may occur. Furthermore, a confounding factor specific to IONPs and other emerging nanomaterials is the lack of knowledge of what constitutes an occupationally relevant dose. There are, currently, only two studies which show actual human exposure to IONPs in an occupational setting $\left(0.04-0.28 \mathrm{mg} / \mathrm{m}^{3}\right.$ ${ }^{20}$ or $0.083 \mathrm{mg} / \mathrm{m}^{321}$ ) and a much higher OSHA permissible exposure limit (14 mg/m² over $\left.8 \mathrm{~h}^{38}\right)$. 
Because the OSHA permissible exposure limit is likely to be the worst case exposure scenario, some researchers have focused on this dose specifically, and used it to better assess the translation from occupationally relevant animal exposure to in vitro model system. For example, Teeguarden et al. ${ }^{100}$ exposed Balb/c mice to a $12.8 \mathrm{~nm} \mathrm{Fe} \mathrm{NO}_{4}$ particle via inhalation. Mice were exposed to 19.9 $\mathrm{mg} / \mathrm{m}^{3}$ particle over $4 \mathrm{~h}$, which is less $\left(80 \mathrm{mg} \cdot \mathrm{h} / \mathrm{m}^{3}\right)$ than the OSHA permissible exposure limit for fine-sized $\mathrm{Fe}_{2} \mathrm{O}_{3}$ particles $\left(14 \mathrm{mg} / \mathrm{m}^{3}\right.$ over $8 \mathrm{~h}$ or $\left.112 \mathrm{mg} \cdot \mathrm{h} / \mathrm{m}^{3}\right)$. After this inhalation exposure, the authors assessed target tissue dose in the bronchial region (about $1 \mu \mathrm{g} / \mathrm{cm}^{2}$ ), and the alveolar region $\left(0.003-0.13 \mu \mathrm{g} / \mathrm{cm}^{2}\right)$ of the lung. Based on these results, it would seem reasonable that an in vitro model system using cells derived from the bronchial region of the lung would require a higher dose of particle than cells derived from the alveolar region of the lung in order to obtain results that would be most representative for the deposited dose used in an in vivo exposure.

Although their findings have not necessarily been taken into account with other in vitro studies, this paper is an important guideline to use when evaluating in vitro studies and determining their potential relevance to an occupational exposure scenario.

\section{2-4a.ii. Particle Aggregation, Agglomeration, and Assay Interference}

Even if particle deposition is taken into account, the administered in vitro dose may still not be representative of the delivered dose that reaches the cells. Agglomerate size, liquid media density, media protein content, and other factors will affect particle settling rate and dosimetry. This, in turn, may affect the administered to delivered dose ratios, and may have a major impact on subsequent adverse outcomes ${ }^{66}$.

In fact, particle aggregation and agglomeration have already been shown to play a major role in the severity of IONP-induced adverse outcomes. As previously mentioned, it is generally accepted that smaller particles are able to induce more toxicity on a per mass basis due to increased surface 
area and particle number $[22,23]$. However, if these particles agglomerate in an unanticipated way, the observed adverse outcomes may be different than predicted. This would especially be the case if the agglomerate was recognized by the cell as a larger structure than the primary particle size suggests. This may not only lead to inaccurate toxicity assessment, but may also obscure potential size dependent particle toxicity.

For example, Karlsson et al. ${ }^{94}$ showed no size-dependent toxicity when comparing "nano" and "sub-micron"-sized $\mathrm{Fe}_{2} \mathrm{O}_{3}$ and $\mathrm{Fe}_{3} \mathrm{O}_{4}$ particles-even with a relatively high dose $\left(40 \mu \mathrm{g} / \mathrm{cm}^{2}\right)$ administered to A549 cells. This is most likely due to particle agglomerate size. The primary particle size of the "nano" $\mathrm{Fe}_{2} \mathrm{O}_{3}$ was $30-60 \mathrm{~nm}$, but once in suspension become about $1600 \mathrm{~nm}$, making it very similar in size to the $150-1000 \mathrm{~nm}$ "sub-micron" $\mathrm{Fe}_{2} \mathrm{O}_{3}$. Similarly, the "nano" $\mathrm{Fe}_{3} \mathrm{O}_{4}$ had a primary particle size of $20-40 \mathrm{~nm}$, but became greater than $200 \mathrm{~nm}$ as an agglomerate in suspension, again making it almost the same size as the 100-500 nm "sub-micron" $\mathrm{Fe}_{3} \mathrm{O}_{4}$ used. In fact, other researchers have shown that the agglomerate size of $\mathrm{Fe}_{3} \mathrm{O}_{4}(12.1 \mathrm{~nm}$ primary particle size) will vary significantly (199-453 nm) based on FBS content and overall density of the dosing media ${ }^{101}$.

Additionally, the $\mathrm{pH}$ of the dosing media may have an impact on IONPs capacity to generate ROS 102. The pH dependent dual enzymatic activity of IONPs may also obscure results if the dosing media used is not physiologically relevant. It is, therefore, critical that IONPs-and other nanomaterials, as well-are fully characterized in the media or vehicle that will be used for treatment.

Another factor that may interfere with perceived IONPs-induced adverse outcomes is assay interference. This is relatively common due to the small size and pigmented properties of IONPs. For example, Kain et al. ${ }^{69}$ noted that $\mathrm{Fe}_{3} \mathrm{O}_{4}$ particles $(20-40 \mathrm{~nm}$ primary particle size, agglomerates $>200 \mathrm{~nm}$ ) caused DNA damage in Beas-2B cells after 4 hours of exposure to $20 \mu \mathrm{g} / \mathrm{cm}^{2}$ when this damage was measured via the comet assay, but that no oxidative DNA damage could be detected 
when formamidopyrimidine DNA glycosylase (FPG) sites were used as an indicator instead. The authors attributed this to IONP interference with FPG, leading to inaccurate results. Overall, the authors concluded that multiple methods should be used to verify results if particle interference is unknown with a particular assay. In fact, many different types of IONPs have been shown to interact with the components of cytotoxicity assays ${ }^{70}$ and cytokine secretion assays ${ }^{71}$, and likely interfere with others which have not yet been reported.

\section{2-4a.iii. Relevant Cell Type}

In the lung, response to foreign particle exposure relies on chemical interactions and communications between a vast array of cell types. Due to the complexity of this system, it can be difficult to replicate this using cell culture models. There are several types of in vitro model systems that have been used, including mono-culture (one cell type), co-culture (two cell types), multicellular spheroid model systems, and even "organ-on-a-chip" methods. Although each of these model systems has clear advantages and disadvantages, one of the most necessary criteria that should be taken into consideration, is the use of a relevant cell type, including relevant disease state, species, and location in the body. This is also highly dependent on the overall goal of a study. For example, if the goal of a study is to assess IONPs response in a healthy individual, only cell lines derived from a healthy individual should be used. If the goal of a study is to assess IONPs impact on a particular endpoint, it is important to fully consider which cell types may be involved in this process, and which will allow for the most relevant assessment of a human response.

It is also important to consider the species of origin to determine if a cell line is going to be useful for a particular study. Although in vivo studies are typically used to establish potential risk following exposure to humans, and a good indicator of the success of an in vitro study is its correlation to in vivo results, it is also crucial to consider the differences between human and animal 
response with IONPs exposure. A mouse cell line is likely to be the best predictor of an in vivo mouse response, but a human cell line may be more predictive of a human response. Therefore, it is exceedingly important to consider mouse compared to human response both when designing cell culture-based systems, and for in vivo and in vitro experimental design.

It is also important to match organ location of a cell line used in vitro to the exposure scenario and end point being studied, so as to ensure the most predictive and relevant results. The same cell type from the same species but originating from two different organ systems may have an extreme impact on response following IONPs exposure. For example, mouse alveolar macrophages are known to have relatively low lysosomal activity as compared to mouse peritoneal macrophages. Park et al. ${ }^{103}$ showed that this difference has a subsequent impact on IONPs-induced adverse outcomes. The authors exposed murine alveolar macrophages at a range of doses from about 1.89 to $15 \mu \mathrm{g} / \mathrm{cm}^{2}$ of $\mathrm{Fe}_{2} \mathrm{O}_{3}$ (102 nm in cell culture media). After 24 hours and at the highest dose used, they found a $40 \%$ decrease in cell viability, a $25 \%$ decrease in ATP production, and a 2 fold increase in both ROS and nitric oxide production as compared to non-treated controls. However, during a previous study which used the same nanoparticle but different cell line (mouse peritoneal macrophages) the authors saw a $20 \%$ decrease in cell viability, $40 \%$ decrease in ATP production, a 5 fold increase in ROS, and a 2.5 fold increase in nitric oxide as compared to non-treated controls 104. They concluded that this difference between studies was most likely due to the differences in lysosomal activity and other characteristics which differentiate mouse alveolar macrophages from mouse peritoneal ones.

Clearly, the use of a relevant cell type is crucial for relevant and predictive results. However, very few IONPs studies utilize an in vitro model that is well matched to a specific end point and exposure scenario. This is likely a major contributor to the lack of cohesion or agreement on IONPsinduced adverse outcomes based on in vitro studies. 


\section{2-4b. Underlying Mechanisms of IONPs-Induced Adverse Effects}

By limiting IONPs literature to those studies which utilize relevant parameters based on the discussion above, in vitro IONPs studies appear to correlate well to observed in vivo outcomes. In vitro, IONPs have been shown to induce oxidative stress and a decrease in cell viability, as well as genotoxicity and neoplastic-like cellular transformation. These may all be components of, or precursors to, inflammation, pulmonary fibrosis, and potential carcinogenic capacity.

Oxidative stress and cell viability are basic assessments of potential particle toxicity, and also provide information as to the potential inflammatory capacity of a particle. Bhattacharya et al. 98 showed that a dose of $2 \mu \mathrm{g} / \mathrm{cm}^{2}$ (roughly comparable to Teeguarden et al. 100 established IONPs deposition in the bronchial region) of $\mathrm{Fe}_{2} \mathrm{O}_{3}(50 \mathrm{~nm})$ induced a $15 \%$ decrease in cell viability, as well as elevated ROS generation in human bronchial fibroblasts (IMR-90). A study done with a less relevant, but still of human lung origin, cell line showed similar results with $\mathrm{Fe}_{3} \mathrm{O}_{4}(174 \mathrm{~nm}$ agglomerate). At about $3.03 \mu \mathrm{g} / \mathrm{cm}^{2}$, Dwivedi et al. ${ }^{97}$ showed that IONPs induced a decrease in cell viability and indications of oxidative stress, including an increase in lipid peroxidation and a decrease in GSH in A549 cells.

As with in vivo work, one area in which in vitro nanotoxicology is generally lacking is in the assessment of carcinogenic potential of emerging nanomaterials. The major difficulty with this particular endpoint is that cancer is a multi-step, multi-cellular process that usually occurs over extended time periods. Therefore, acute in vitro exposures are unable to provide sufficient information about this particular area. However, there is some in vitro support for IONPs-induced genotoxicity, and the potential development of a cancer-like phenotype.

IONPs have been shown to cause DNA damage using relevant experimental parameters as described above. Bhattacharya et al. ${ }^{98}$ showed 10 and $50 \mu \mathrm{g} / \mathrm{cm}^{2}$ doses of $\mathrm{Fe}_{2} \mathrm{O}_{3}(50 \mathrm{~nm})$ can cause double stranded DNA breaks (as measured via the comet assay) in both IMR-90 and Beas-2B cell 
lines. Watson et al. ${ }^{105}$ also showed the potential genotoxicity of IONPs using a novel CometChip assay, which functions similarly to the comet assay, but also takes into consideration potential particle interference as described above. Using this innovative platform, the authors showed that $\mathrm{Fe}_{2} \mathrm{O}_{3}$ (19.7 nm primary particle size, 934-1444 nm agglomerates) induced significant double stranded DNA breaks as compared to non-treated control cells, at doses of about $3.03 \mu \mathrm{g} / \mathrm{cm}^{2}$. IONPs-induced genotoxicity, as shown in both of these studies, may lead to neoplastic-like cellular transformation, which has been separately shown to be induced by IONPs exposure.

Sighinolfi et al. ${ }^{99}$ used $\mathrm{Fe}_{3} \mathrm{O}_{4}$ particles $(161 \mathrm{~nm})$ in the Balb/3T3 cell transformation assay at a dose of about $2.76 \mu \mathrm{g} / \mathrm{cm}^{2}$. This assay measures cellular transformation in mouse fibroblast cells and compares transformation rate induced by the particles to that of known tumor promoters. The authors found that IONPs exposure induced toxicity after 72 hours, and was also able to promote tumoral foci, although they could not initiate them. These tumoral foci appeared to develop in conjunction with large IONPs agglomerates, and the authors noted that these agglomerates could potentially serve as a scaffold for foci engraftment ${ }^{99}$. It should be noted, however, that since most tumors are of epithelial origin, the use of fibroblasts in this example to assess the tumorigenic potential of a particle should be taken with caution.

Our research group developed an epithelial cell-based assay by using primary small airway epithelial cells to assess the capacity of $\mathrm{Fe}_{2} \mathrm{O}_{3}(12 \mathrm{~nm}$ primary particle size) to induce a neoplasticlike cellular transformation ${ }^{106}$. In this study, a low-dose sub-chronic exposure model $\left(0.6 \mu \mathrm{g} / \mathrm{cm}^{2}\right.$ continuously for 10 weeks) was used to mimic an occupationally relevant exposure scenario. After 10 weeks, the IONPs treated cells underwent a significant and dramatic neoplastic-like cellular transformation, as indicated by an increase in cell proliferation, formation of attachmentindependent colonies, and immortalization. Overall, there is early evidence to suggest that IONPs 
can induce genotoxicity, and may cause a neoplastic-like cellular transformation under occupationally relevant exposure conditions.

A critical question underlying the IONPs toxicity profile is the mechanism behind IONPsinduced adverse effects. By again limiting literature to studies that utilize relevant parameters, as discussed above, IONPs-induced oxidative stress appears to be a critical component of observed adverse outcomes both in vitro and in vivo. A proposed mechanism to this is heavily reliant on particle uptake, dissolution, and release of free iron ions into the cell's catalytically active labile iron pool (Figure 2-2a). If IONPs are engulfed via phagocytosis, they will end up inside a phagosome. These phagosomes can then fuse with a lysosome, so the resulting acidic environment will degrade its contents. IONPs, however, may instead dissolve, releasing free iron ions $\left(\mathrm{Fe}^{2+}\right)$ into the cell's cytoplasm ${ }^{107}$. This catalytically available iron ${ }^{108}$ can then participate in the Fenton reaction and generate ROS 109 , an excess of which can ultimately induce DNA damage, lead to an inflammatory response, and/or carcinogenic related outcomes. In fact, Malvindi et al. ${ }^{110}$ were able to show that $\mathrm{Fe}_{3} \mathrm{O}_{4}(32 \mathrm{~nm})$ induced adverse effects on A549 cells $\left(3 \mu \mathrm{g} / \mathrm{cm}^{2}\right)$, which included decreased cell viability and increased LDH, ROS, and DNA damage. However, these outcomes were largely ablated with the use of an iron chelator. This clearly indicates that a primary source for IONPs-induced damaging effects may be due to excessive free iron ions causing an oxidative stress response.

Furthermore, Park et al. ${ }^{103}$ were able to show that the difference in solubility between $\mathrm{Fe}_{3} \mathrm{O}_{4}$ and $\mathrm{Fe}_{2} \mathrm{O}_{3}$ nanoparticles could be linked to the severity of subsequent adverse outcomes-less soluble $\mathrm{Fe}_{2} \mathrm{O}_{3}$ also had a less severe impact on murine alveolar macrophages as compared to the more highly soluble $\mathrm{Fe}_{3} \mathrm{O}_{4}$. Additionally, Freyria et al. ${ }^{95}$ clearly connected the mild solubility and poor reactivity of $\alpha-\mathrm{Fe}_{2} \mathrm{O}_{3}$ to the almost negligible adverse outcomes observed following exposure, which included no cytotoxicity, necrosis, DNA damage, nor nitrate release in several cell types, regardless of particle size $(87,238$, or $1100 \mathrm{~nm})$ or high dose used $\left(20-100 \mu \mathrm{g} / \mathrm{cm}^{2}\right)$. Overall, these 
studies clearly show the demonstrable link between IONPs dissolution and subsequently observed adverse outcomes.

Other studies also suggest that IONPs may be involved in the sequestration of iron from mitochondria or other organelles, causing cellular compensation and prompting an influx of free iron ions into the cell's labile iron pool 111. Again, this would result in an overall excess of catalytically available iron, which can then participate in the Fenton reaction, and lead to increased ROS production within the cell as previously discussed. Overall, both proposed mechanisms remain largely unstudied, likely due to difficulty in differentiating the source of this catalytically available iron, as well as the complex network of proteins that are involved in maintaining the cellular iron homeostatic balance (Figure 2-2b).

Iron homeostasis is carefully regulated within a cell, particularly because iron is the major oxygen carrier in humans and is crucial for electron transfer and normal cellular functions. Catalytically active iron, which is diffusible and able to participate in redox reactions, is localized within a cytosolic labile iron pool ${ }^{90}$. Due to the sheer amount of available and inhalable iron in the atmosphere, the lung relies on the protein Divalent Metal Transporter 1 (DMT1), which is involved in the import of free iron into the cell. There, it can then be sequestered in the iron storage protein Ferritin (FTH) to limit its capacity to generate free radicals. Free iron may also be bound to the transferrin protein, which can then be imported into the cell via the transport protein CD71. Ultimately, iron may be exported out of the cell via Ferroportin (FPN) or a ZRT-IRE like protein (ZIP14) 112. Expression levels of DMT1, FPN, and ZIP14 have all been shown to increase with an influx of iron content ${ }^{113-115}$ to help combat potential toxicity associated with excessive free iron.

Generally, the lung and other organs are well equipped to deal with potential iron overload, which is suggested by the complex network of proteins involved in maintaining iron homeostasis. However, if IONPs are able to disrupt this careful balance-either through directly dissolving and 
releasing iron into the catalytically active labile iron pool, or by affecting iron stores within the mitochondria or other organelles-IONPs have the potential to overload this protective pathway, leading to an overall excess of iron in the catalytically active labile iron pool. This iron overload has been linked to increased pathogenesis of atherosclerosis ${ }^{115}$, and increased iron levels in the lung are also associated with increased rates of lung pneumonia and lung infection ${ }^{116}$. Furthermore, the excessive oxidative stress may induce mitochondrial damage, which could then have deleterious effects on the cell, including increased induction of autophagy $[75,76]$, as well as overall respiratory disease and pulmonary dysfunction $[77,78]$.

Based on this proposed mechanism of action and published literature, the key to IONPs-induced adverse outcomes appears to be largely reliant on particle dissolution and release of free iron ions. If this aspect can be affected by altering IONPs design, it may be possible to design a less hazardous IONPs which retains the properties necessary for its inclusion in biomedical or other applications. This would be a core component of a "safe by design" hazard reduction or prevention strategy. 
Table 2-3. Referenced iron oxide nanoparticle in vivo studies.

\begin{tabular}{|c|c|c|c|c|c|c|c|}
\hline Study & Animal & Particle & $\begin{array}{c}\text { Primary } \\
\text { Particle Size }\end{array}$ & Dose & $\begin{array}{c}\text { Mode/Duration } \\
\text { of Exposure }\end{array}$ & $\begin{array}{r}\text { Time } \\
\text { Points }\end{array}$ & $\begin{array}{c}\text { Adverse } \\
\text { Outcomes }\end{array}$ \\
\hline 22 Park & ICR mice & $\mathrm{Fe}_{3} \mathrm{O}_{4}$ & $5.3 \mathrm{~nm}$ & $\begin{array}{c}0.25,0.5,1 \\
\mathrm{mg} / \mathrm{kg} \\
\text { body } \\
\text { weight }\end{array}$ & $\begin{array}{l}\text { Intratracheal } \\
\text { instillation }\end{array}$ & $\begin{array}{c}1,7,14,28 \\
\text { days }\end{array}$ & Inflammation \\
\hline 23 Park & ICR mice & $\mathrm{Fe}_{2} \mathrm{O}_{3}$ & $\begin{array}{c}10 \mathrm{~nm} \\
(209.4 \mathrm{~nm} \\
\text { agglomerate) }\end{array}$ & $\begin{array}{l}0.5,1,2 \\
\mathrm{mg} / \mathrm{kg} \\
\text { body } \\
\text { weight } \\
\end{array}$ & $\begin{array}{l}\text { Intratracheal } \\
\text { instillation }\end{array}$ & 90 days & $\begin{array}{l}\text { Inflammation, Th1 } \\
\text { polarized immune } \\
\text { response }\end{array}$ \\
\hline${ }^{24}$ Sadeghi & $\begin{array}{l}\text { Wistar } \\
\text { rats }\end{array}$ & $\mathrm{Fe}_{2} \mathrm{O}_{3}$ & $20 \mathrm{~nm}$ & $\begin{array}{l}20 \text { or } 40 \\
\mathrm{mg} / \mathrm{kg} \\
\text { body } \\
\text { weight }\end{array}$ & $\begin{array}{c}\text { Intratracheal } \\
\text { instillation ( } 7 \text { or } 14 \\
\text { times, once every } \\
\text { other day) }\end{array}$ & $\begin{array}{c}1 \text { day post } \\
\text { exposure } \\
\text { set } \\
\text { completion }\end{array}$ & $\begin{array}{c}\text { Inflammation, liver } \\
\text { damage }\end{array}$ \\
\hline 25 Srinivas & $\begin{array}{l}\text { Wistar } \\
\text { rats }\end{array}$ & $\mathrm{Fe}_{3} \mathrm{O}_{4}$ & $15-20 \mathrm{~nm}$ & $\begin{array}{c}640 \\
\mathrm{mg} / \mathrm{m}^{3}\end{array}$ & $\begin{array}{c}\text { Inhalation, } 4 \mathrm{~h} \\
\text { continuous }\end{array}$ & $\begin{array}{c}1,2,14 \\
\text { days }\end{array}$ & Inflammation \\
\hline $82 \mathrm{Zhu}$ & $\begin{array}{l}\text { Sprague } \\
\text { Dawley } \\
\text { rats }\end{array}$ & $\mathrm{Fe}_{2} \mathrm{O}_{3}$ & $\begin{array}{c}22 \text { or } 280 \\
\mathrm{~nm}\end{array}$ & $\begin{array}{l}0.8 \text { or } 20 \\
\mathrm{mg} / \mathrm{kg} \\
\text { body } \\
\text { weight }\end{array}$ & $\begin{array}{l}\text { Intratracheal } \\
\text { instillation }\end{array}$ & 1,30 days & $\begin{array}{l}\text { Inflammation, pro- } \\
\text { fibrosis, longer } \\
\text { prothrombin and } \\
\text { activated partial } \\
\text { thromboplastin } \\
\text { times }\end{array}$ \\
\hline${ }^{83}$ Szalay & $\begin{array}{l}\text { Wistar } \\
\text { rats }\end{array}$ & $\mathrm{Fe}_{3} \mathrm{O}_{4}$ & $<50 \mathrm{~nm}$ & $\begin{array}{c}1 \text { or } 5 \\
\mathrm{mg} / \mathrm{kg} \\
\text { body } \\
\text { weight }\end{array}$ & $\begin{array}{l}\text { Intratracheal } \\
\text { instillation }\end{array}$ & $\begin{array}{l}1,3,7,14 \\
30 \text { days }\end{array}$ & Weak fibrosis \\
\hline
\end{tabular}




\begin{tabular}{|c|c|c|c|c|c|c|c|}
\hline 30 Totsuka & $\begin{array}{l}\text { ICR or gpt } \\
\text { delta mice }\end{array}$ & $\mathrm{Fe}_{3} \mathrm{O}_{4}$ & $10-100 \mathrm{~nm}$ & $\begin{array}{r}0.05 \text { or } 0.2 \\
\mathrm{mg} / \text { animal }\end{array}$ & $\begin{array}{l}\text { Intratracheal } \\
\text { instillation }\end{array}$ & 3 h, 8 wks & $\begin{array}{c}\text { DNA damage in } \\
\text { lungs, DNA adduct } \\
\text { formation, } \\
\text { inflammation, focal } \\
\text { granuloma } \\
\text { formation }\end{array}$ \\
\hline 31 Ishino & ICR mice & $\mathrm{Fe}_{3} \mathrm{O}_{4}$ & $10-100 \mathrm{~nm}$ & $\begin{array}{c}0.2 \\
\mathrm{mg} / \text { animal }\end{array}$ & $\begin{array}{l}\text { Intratracheal } \\
\text { instillation }\end{array}$ & 1 day & $\begin{array}{r}\text { DNA adducts } \\
(\text { elevated } \epsilon \mathrm{dC})\end{array}$ \\
\hline $\begin{array}{c}91 \\
\text { Campbell }\end{array}$ & $\begin{array}{c}\text { Mice } \\
\text { (strain } \\
\text { unknown) }\end{array}$ & $\mathrm{Fe}_{2} \mathrm{O}_{3} \cdot \mathrm{H}_{2} \mathrm{O}$ & Unknown & $\begin{array}{l}0.5 \mathrm{~g} \text { for } \\
8-12 \\
\text { animals }\end{array}$ & $\begin{array}{l}\text { Inhalation, } 6 \mathrm{~h} / \text { day } \\
\text { continuous, } 5 \\
\text { days/week, } 1 \text { year }\end{array}$ & $\begin{array}{l}\text { Up to } 800 \\
\text { days (or } \\
\text { death of } \\
\text { animal) }\end{array}$ & $\begin{array}{l}\text { Primary lung } \\
\text { tumors }\end{array}$ \\
\hline $28 \mathrm{Zhu}$ & $\begin{array}{l}\text { Sprague } \\
\text { Dawley } \\
\text { rats }\end{array}$ & ${ }^{59} \mathrm{Fe}_{2} \mathrm{O}_{3}$ & $22 \mathrm{~nm}$ & $\begin{array}{c}4 \\
\mathrm{mg} / \text { animal }\end{array}$ & $\begin{array}{l}\text { Intratracheal } \\
\text { instillation }\end{array}$ & $\begin{array}{l}\text { Daily, up to } \\
50 \text { days }\end{array}$ & $\begin{array}{l}\text { IONPs can pass } \\
\text { into systemic } \\
\text { circulation, and is } \\
\text { distributed to } \\
\text { mononuclear } \\
\text { phagocyte rich } \\
\text { organs }\end{array}$ \\
\hline${ }^{29}$ Al Faraj & $\begin{array}{l}\text { Balb/c } \\
\text { mice }\end{array}$ & $\mathrm{Fe}_{2} \mathrm{O}_{3}$ & $129.3 \mathrm{~nm}$ & $\begin{array}{l}0.8 \mathrm{mmol} \\
\text { iron } / \mathrm{kg} \\
\text { body } \\
\text { weight }\end{array}$ & $\begin{array}{l}\text { Intrapulmonary } \\
\text { administration } \\
\text { (once or three } \\
\text { times on } \\
\text { consecutive days) }\end{array}$ & $\begin{array}{c}2 \text { h, } 1 \text { or } 2 \\
\text { days, } 1 \text { or } 2 \\
\text { weeks, } 1 \\
\text { month }\end{array}$ & $\begin{array}{c}\text { Particle } \\
\text { translocation to } \\
\text { liver, lipid } \\
\text { peroxidation, DNA } \\
\text { damage, } \\
\text { inflammation } \\
\text { biomarkers }\end{array}$ \\
\hline 32 Wang & $\begin{array}{l}\text { Wistar } \\
\text { rats }\end{array}$ & $\mathrm{Fe}_{2} \mathrm{O}_{3}$ & $30 \mathrm{~nm}$ & $\begin{array}{l}8.5 \mathrm{mg} / \mathrm{kg} \\
\text { body } \\
\text { weight }\end{array}$ & $\begin{array}{l}\text { Dry powder nasal } \\
\text { spray, twice daily } \\
\text { for three days }\end{array}$ & Up to $36 \mathrm{~h}$ & $\begin{array}{c}\text { Severe lung and } \\
\text { liver tissue damage }\end{array}$ \\
\hline
\end{tabular}




\begin{tabular}{|c|c|c|c|c|c|c|c|}
\hline${ }^{26} \mathrm{Ban}$ & $\begin{array}{l}\mathrm{Balb} / \mathrm{c} \\
\text { mice }\end{array}$ & $\mathrm{Fe}_{2} \mathrm{O}_{3}$ & $\begin{array}{c}35 \text { or } 147 \\
\mathrm{~nm}\end{array}$ & $\begin{array}{c}100,250, \\
\text { or } 500 \\
\mu \mathrm{g} / \text { mouse }\end{array}$ & $\begin{array}{c}\text { Intratracheal } \\
\text { administration } \\
\text { (four times) with or } \\
\text { without OVA } \\
\text { sensitization } \\
\end{array}$ & $\begin{array}{c}24,48 \mathrm{~h} \\
\text { after } \\
\text { completion } \\
\text { of exposure } \\
\text { set } \\
\end{array}$ & $\begin{array}{l}\text { Inhibition of OVA- } \\
\text { induced allergic } \\
\text { response at high } \\
\text { dose, enhancement } \\
\text { with low dose }\end{array}$ \\
\hline $\begin{array}{c}27 \\
\text { Gustafsson }\end{array}$ & $\begin{array}{l}\text { Balb/c } \\
\text { mice }\end{array}$ & $\mathrm{Fe}_{2} \mathrm{O}_{3}$ & $30 \mathrm{~nm}$ & $\begin{array}{c}2.5 \mathrm{mg} / \mathrm{kg} \\
\text { body } \\
\text { weight }\end{array}$ & $\begin{array}{l}\text { Intratracheal } \\
\text { instillation with or } \\
\text { without OVA } \\
\text { sensitization }\end{array}$ & $\begin{array}{c}1,2,7 \text { days } \\
\text { post } \\
\text { exposure }\end{array}$ & $\begin{array}{c}\text { Decreased } \\
\text { inflammation with } \\
\text { IONP and OVA } \\
\text { attributed to } \\
\text { excessive cell death } \\
\text { in inflamed airways } \\
\text { and lung draining } \\
\text { lymph nodes }\end{array}$ \\
\hline $\begin{array}{c}100 \\
\text { Teeguarden }\end{array}$ & $\begin{array}{l}\text { Balb/c } \\
\text { mice }\end{array}$ & $\begin{array}{c}\text { Super- } \\
\text { paramagnetic } \\
\text { IONPs }\end{array}$ & $12.8 \mathrm{~nm}$ & $\begin{array}{c}19.9 \\
\mathrm{mg} / \mathrm{m}^{3}\end{array}$ & $\begin{array}{l}\text { Inhalation, four } \\
\text { hour continuous }\end{array}$ & $\begin{array}{l}\text { Up to } 7 \\
\text { days }\end{array}$ & $\begin{array}{c}\text { Particle deposition, } \\
\text { interstitial } \\
\text { inflammation, } \\
\text { macrophage } \\
\text { infiltration } \\
\end{array}$ \\
\hline
\end{tabular}


Table 2-4. Referenced iron oxide nanoparticle in vitro studies.

\begin{tabular}{|c|c|c|c|c|c|c|}
\hline Study & Cell Type & Particle Type & $\begin{array}{l}\text { Primary } \\
\text { Particle } \\
\text { Size } \\
\end{array}$ & $\begin{array}{l}\text { Agglomerate } \\
\text { Size in Dosing } \\
\text { Media }\end{array}$ & $\begin{array}{c}\text { Particle } \\
\text { Dose } \\
\left(\mu \mathrm{g} / \mathrm{cm}^{2}\right)\end{array}$ & Adverse Outcomes \\
\hline $\begin{array}{c}101 \\
\text { Watanabe }\end{array}$ & A549 & $\begin{array}{l}\text { Magnetic } \\
\mathrm{Fe}_{3} \mathrm{O}_{4}\end{array}$ & $10 \mathrm{~nm}$ & $197 \mathrm{~nm}$ & $\begin{array}{c}0.303-30.3 \\
\mu \mathrm{g} / \mathrm{cm}^{2}\end{array}$ & $\begin{array}{c}\text { Cell membrane damage, } \\
\text { increased ROS and oxidative DNA } \\
\text { damage, decreased GSH, } \\
\text { increased CD44+ fraction and } \\
\text { HO- } 1 \text { expression }\end{array}$ \\
\hline${ }^{94}$ Karlsson & A549 & $\mathrm{Fe}_{2} \mathrm{O}_{3}, \mathrm{Fe}_{3} \mathrm{O}_{4}$ & $\begin{array}{c}\mathrm{Fe}_{2} \mathrm{O}_{3}: \\
29 \mathrm{~nm}, \\
<1 \mu \mathrm{m} \\
\mathrm{Fe} 304: \\
20-30 \\
\mathrm{~nm}, 0.5 \\
\mu \mathrm{m}\end{array}$ & $\begin{array}{c}\mathrm{Fe}_{2} \mathrm{O}_{3}: 1600 \mathrm{~nm} \text {, } \\
\text { 150-1000 nm } \\
\mathrm{Fe}_{3} \mathrm{O}_{4}:>200 \mathrm{~nm} \text {, } \\
\text { 100-500 nm } \\
\mathrm{Fe} 203: 102 \mathrm{~nm} \\
\mathrm{Fe} 304: 26 \mathrm{~nm}\end{array}$ & $40 \mu \mathrm{g} / \mathrm{cm}^{2}$ & $\begin{array}{l}\text { Cytotoxicity, mitochondrial } \\
\text { damage, DNA damage }\end{array}$ \\
\hline 104 Park & $\begin{array}{c}\text { Murine } \\
\text { peritoneal } \\
\text { macrophages }\end{array}$ & $\mathrm{Fe}_{2} \mathrm{O}_{3}$ & NR & $102 \mathrm{~nm}$ & $\begin{array}{l}1.95-15 \\
\mu \mathrm{g} / \mathrm{cm}^{2}\end{array}$ & $\begin{array}{c}\text { Cytotoxicity, decreased ATP } \\
\text { production, increased ROS, nitric } \\
\text { oxide, TNF- } \alpha \text { secretion }\end{array}$ \\
\hline${ }^{69}$ Kain & Beas2B & $\mathrm{Fe}_{3} \mathrm{O}_{4}$ & $\begin{array}{c}20-40 \\
\mathrm{~nm}\end{array}$ & $<200 \mathrm{~nm}$ & $20 \mu \mathrm{g} / \mathrm{cm}^{2}$ & DNA damage \\
\hline $\begin{array}{c}98 \\
\text { Bhattacharya }\end{array}$ & $\begin{array}{l}\text { IMR-90, } \\
\text { Beas2B }\end{array}$ & $\mathrm{Fe}_{2} \mathrm{O}_{3}$ & NR & $50 \mathrm{~nm}$ & $\begin{array}{c}2-50 \\
\mu \mathrm{g} / \mathrm{cm}^{2}\end{array}$ & $\begin{array}{c}\text { Cytotoxicity, DNA damage, } \\
\text { increased ROS }\end{array}$ \\
\hline${ }^{97}$ Dwivedi & A549 & $\mathrm{Fe}_{3} \mathrm{O}_{4}$ & $36 \mathrm{~nm}$ & $174 \mathrm{~nm}$ & $\begin{array}{l}3.03-15 \\
\mu \mathrm{g} / \mathrm{cm}^{2}\end{array}$ & $\begin{array}{l}\text { Cytotoxicity, increased ROS, } \\
\text { decreased GSH and } \\
\text { mitochondrial membrane } \\
\text { potential }\end{array}$ \\
\hline${ }^{99}$ Sighinolfi & $\begin{array}{c}\text { Mouse } \\
\text { fibroblasts }\end{array}$ & $\mathrm{Fe}_{3} \mathrm{O}_{4}$ & $\begin{array}{c}20-50 \\
\mathrm{~nm}\end{array}$ & $161 \mathrm{~nm}$ & $2.76 \mu \mathrm{g} / \mathrm{cm}^{2}$ & $\begin{array}{l}\text { Promote tumoral foci, scaffold } \\
\text { for foci engraftment }\end{array}$ \\
\hline
\end{tabular}




\begin{tabular}{|c|c|c|c|c|c|c|}
\hline 106 Stueckle & pSAEC & $\mathrm{Fe}_{2} \mathrm{O}_{3}$ & $19 \mathrm{~nm}$ & $341.56 \mathrm{~nm}$ & $0.6 \mu \mathrm{g} / \mathrm{cm}^{2}$ & $\begin{array}{l}\text { Increased formation of } \\
\text { attachment independent colonies }\end{array}$ \\
\hline 110 Malvindi & A549 & $\mathrm{Fe}_{3} \mathrm{O}_{4}$ & $32 \mathrm{~nm}$ & $107 \mathrm{~nm}$ & $3 \mu \mathrm{g} / \mathrm{cm}^{2}$ & $\begin{array}{c}\text { Cytotoxicity, increased LDH, } \\
\text { ROS, DNA damage }\end{array}$ \\
\hline 95 Freyria & $\begin{array}{c}\text { A549, } \\
\text { murine } \\
\text { alveolar } \\
\text { macrophages }\end{array}$ & $\mathrm{Fe}_{2} \mathrm{O}_{3}$ & $\begin{array}{l}87 \mathrm{~nm}, \\
238 \mathrm{~nm}, \\
1100 \mathrm{~nm}\end{array}$ & $\begin{array}{l}69 \mathrm{~nm}, 357 \mathrm{~nm}, \\
888 \mathrm{~nm}\end{array}$ & $\begin{array}{r}1-100 \\
\mu \mathrm{g} / \mathrm{cm}^{2}\end{array}$ & $\begin{array}{c}\text { No effect on LDH, DNA damage, } \\
\text { apoptosis/necrosis, extracellular } \\
\text { nitrite }\end{array}$ \\
\hline [89] Shukla & A549 & $\begin{array}{c}\mathrm{Fe}_{3} \mathrm{O}_{4}, \\
\text { chitosan } \\
\text { oligosaccharide } \\
\text { coating }\end{array}$ & $6 \mathrm{~nm}$ & NR & $\begin{array}{l}156-1250 \\
\mu \mathrm{g} / \mathrm{cm}^{2}\end{array}$ & $\begin{array}{c}\text { With coating: reduced } \\
\text { cytotoxicity, decreased } \\
\text { deformation of mitochondrial } \\
\text { membranes, ROS production, } \\
\text { decreased particle degradation } \\
\text { and more controlled release of } \\
\text { iron ions }\end{array}$ \\
\hline [85] Tian & $\begin{array}{l}\text { Human } \\
\text { mesenchymal } \\
\text { stem cells }\end{array}$ & $\begin{array}{l}\mathrm{Fe}_{3} \mathrm{O}_{4} \text {, silica } \\
\text { coating }\end{array}$ & $8 \mathrm{~nm}$ & NR & $\begin{array}{l}100 \mu \mathrm{g} \\
\mathrm{Fe} / \mathrm{mL} \\
\text { (unable to } \\
\text { determine } \\
\text { equivalent } \\
\mu \mathrm{g} / \mathrm{cm}^{2} \\
\text { dose) }\end{array}$ & $\begin{array}{c}\text { With coating: slower } \\
\text { metabolism/particle excretion, } \\
\text { less iron ion release in acidic } \\
\text { environment }\end{array}$ \\
\hline [88] Guldris & $\begin{array}{l}\text { Rat } \\
\text { mesenchymal } \\
\text { stem cells }\end{array}$ & $\begin{array}{l}\text { Super- } \\
\text { paramagnetic } \\
\text { IONPs, PAA } \\
\text { coating }\end{array}$ & $7 \mathrm{~nm}$ & $18,35 \mathrm{~nm}$ & $\begin{array}{l}\text { Up to } 62.5 \\
\mu \mathrm{g} / \mathrm{cm}^{2}\end{array}$ & $\begin{array}{l}\text { No effect on cell viability, cell } \\
\text { injury/damage }\end{array}$ \\
\hline
\end{tabular}




\section{2-5. "Safe by Design" IONPs Hazard Reduction Strategies}

"Safe by design" hazard reduction strategy is the idea that if a nanoparticle can be designed in a way which both enhances its properties utilized for specific applications while simultaneously reducing its toxicity, this may have overall positive outcomes on worker-related safety concerns. It most often involves the alteration of one or more physicochemical properties of the particle to help alleviate its toxicity without compromising its intended purpose. Dissolution rate, surface coating, and functionalization can all be altered, and have all been shown to have an effect on overall IONPsinduced adverse outcomes. IONPs dissolution, which appears to be a key component of subsequent adverse outcomes, can be alleviated primarily by altering particle surface coating and functionalization, as will be discussed below.

\section{2-5.a. Alterations in IONPs Physicochemical Properties May Reduce Hazard}

\section{2-5a.i. Particle Surface Coating and Functionalization}

Nanoparticle surface coating and functionalization are major components of nanoparticles which allow them to be used for specific applications. The surface coating can be altered to increase biocompatibility ${ }^{121}$, to enhance paramagnetic or superparamagnetic properties for clinical and therapeutic applications $[80,81]$, or to enhance catalytic properties [82, 83]. An increase in coating thickness (and subsequent overall nanoparticle size) will increase relaxation times, allowing for better imaging results ${ }^{126}$. Surface modifications, such as lipids or polymers, have also been shown to stabilize nanoparticles in suspension, and could potentially control in vivo translocation $[79,80]$. In tandem, a change in surface coating or functionalization has also been shown to reduce particle dissolution rate, and may reduce or prevent IONPs-induced adverse outcomes by acting as a "shield" to prevent or delay particle dissolution in the lysosome $[85,86]$. 
Particle surface coating and availability of surface binding sites have been shown to affect $\mathrm{Fe}_{2} \mathrm{O}_{3}$ particle $(31 \mathrm{~nm})$-induced cytotoxicity in both Beas-2B and A549 cells ${ }^{129}$. Furthermore, other researchers have shown that different IONPs coating types (dextran, amino-alcohol glucose derivative, or citrate) will affect $\mathrm{Fe}_{2} \mathrm{O}_{3}$ ( $7 \mathrm{~nm}$ primary particle size) dissolution rate in a coating dependent manner once in an acidic, lysosome-like environment ${ }^{127}$. The addition of a polyacrylic acid (PAA) coating onto superparamagnetic IONPs $(7 \mathrm{~nm})$ also reduced the leaching of iron in a neutral $\mathrm{pH}$ cell culture media ${ }^{130}$. In this case, PAA-coated IONPs were also less likely to aggregate, and did not induce any significant cytotoxicity when used to treat rat mesenchymal stem cells.

Shukla et al. ${ }^{131}$ evaluated chitosan oligosaccharide coated $\mathrm{Fe}_{3} \mathrm{O}_{4}$ particles $(6 \mathrm{~nm})$. This coating is known to increase hydrophilicity and biocompatibility for use in a wide variety of biomedical applications. Even at very high doses (about 156-1250 $\mu \mathrm{g} / \mathrm{cm}^{2}$ ), the authors found reduced cytotoxicity (as measured via MTT assay and cell staining), decreased deformation of mitochondrial membranes, and decreased ROS production in A549 cells with the coated nanoparticles as compared to uncoated. Furthermore, TEM-EDX elemental analysis revealed that the coated nanoparticles underwent less degradation in the cells and had a slower release of iron ions.

Tian et al. ${ }^{128}$ examined silica-coated and uncoated $\mathrm{Fe}_{3} \mathrm{O}_{4}$ particles $(8 \mathrm{~nm})$ in a lysosomal model system, and found that fewer $\mathrm{Fe}^{3+}$ ions were released with the coated nanoparticles as compared to uncoated ones. Furthermore, these coated particles were taken up by human mesenchymal stem cells at a similar rate to uncoated particles but were metabolized and excreted more slowly. This could potentially be of positive benefit for the particles to be better utilized in a biomedical setting.

Polymer functionalization may also have a direct impact on IONPs-induced toxicity. For example, Cochran et al. ${ }^{132}$ utilized a poly (trolox ester) coated iron oxide nanoparticle. The poly (trolox ester) was specifically designed to release trolox locally to help combat IONPs-induced prooxidant effects. Their results showed that human endothelial cells (HUVECs) treated with about 
$9.375 \mu \mathrm{g} / \mathrm{cm}^{2}$ IONPs had significantly decreased cell viability and increased ROS generation than non-treated control cells. However, cells treated with a poly (trolox ester) coated iteration of the same nanoparticle showed similar viability and ROS generation as the non-treated control cells. The authors conclude that the addition of a polymer coating may be able to directly counteract IONPsinduced oxidative stress related adverse outcomes. A major caveat with particle coating and functionalization toxicity assessment, however, is that there are an infinite number of coatings and functionalization combinations which could be used with IONPs, not all of which may be relevant for human health. Furthermore, there are many coatings that may impart novel function while reducing toxicity, but haven't been developed or investigated yet.

Overall, these studies highlight that particle dissolution as related to surface coating and functionalization may play a major role in determining in vitro adverse outcomes following IONPs exposure. An alteration in these physicochemical properties could be used to help alleviate this toxicity, as well as to potentially enhance other properties that allow for IONPs use in a broad range of applications. 
(a)
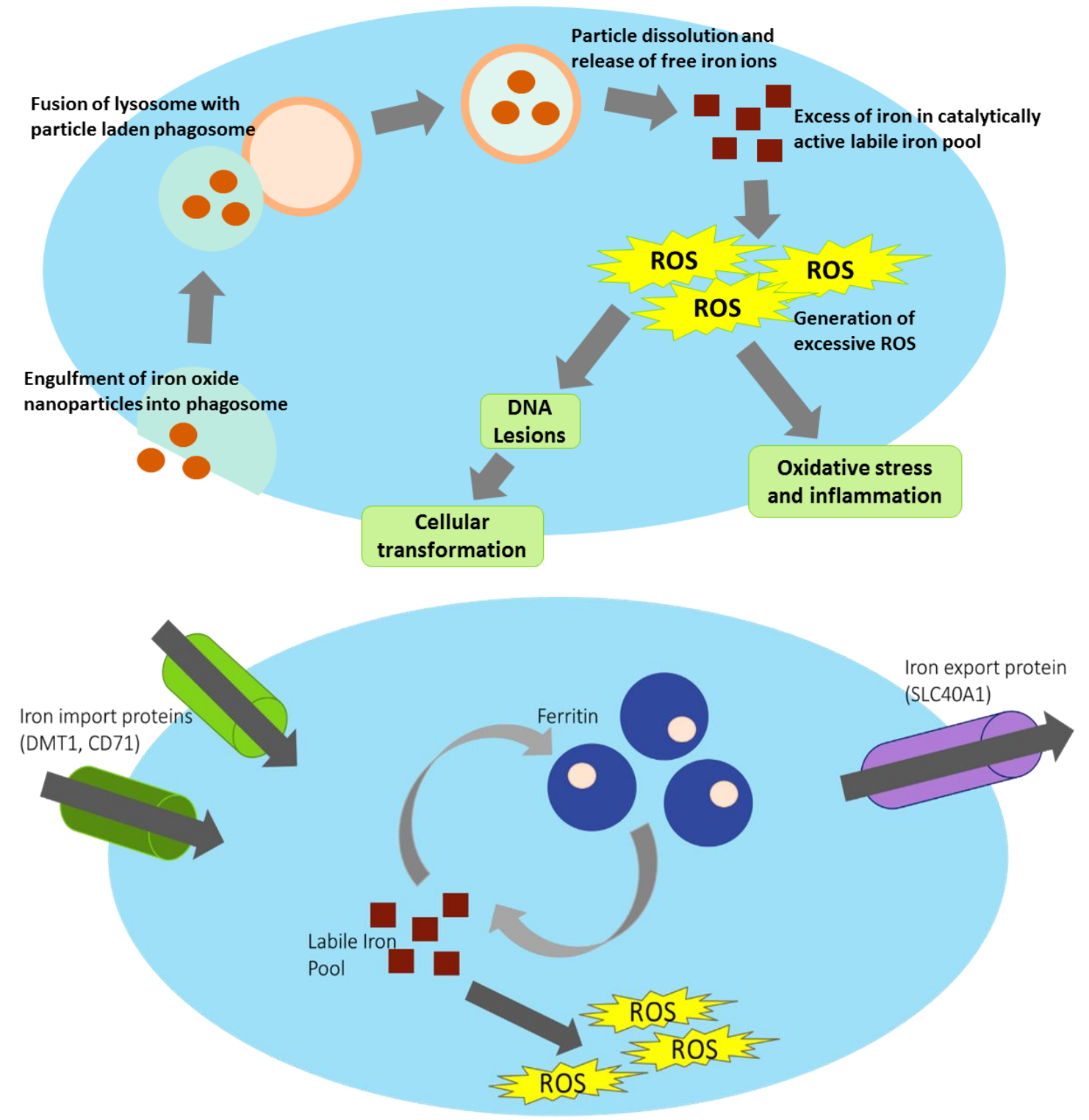

(b)

Figure 2-2. (a) Proposed mechanism behind IONPs-induced iron homeostasis disruption and subsequent adverse outcomes. If IONPs are engulfed by the cell via phagocytosis and end up in a phagosome, this membrane bound vesicle will then fuse with the lysosome, creating an acidic environment for degradation. However, once in this acidic environment, IONPs will instead dissolve, releasing free iron ions into the cell's catalytically active labile 
iron pool. This may ultimately result in increased and excessive ROS generation, and subsequent adverse outcomes. Dissolved particle may also affect iron stores in mitochondria and other organelles (not shown). (b) Maintenance of iron homeostasis via iron import proteins, iron storage proteins, and iron export proteins. In order to maintain appropriate iron levels within a cell, a complex network of iron-related proteins are involved in iron import, storage, and export. Example proteins for these processes (DMT1, CD71; ferritin; SLC40A1, respectively) are shown). Free $\mathrm{Fe}^{2+}$ in the labile iron pool is necessary for cellular function, but too much can cause an excess of reactive oxygen species generation via participation in the Fenton reaction. The labile iron pool is carefully maintained using iron storage mechanisms via ferritin. In pathologic conditions, increased iron in LIP will generate an excess of free hydroxyl radicals and induce adverse outcomes within the cell. 


\section{2-6. Summary}

Currently, prevailing information on the toxicity of IONPs suggests potential risk associated with exposure, including inflammation, fibrosis, genotoxicity, and extra-pulmonary effects, all of which have been attributed to increased oxidative stress following exposure. The majority of this literature correlates particle internalization, dissolution, and subsequent release of free iron ions to be the primary source for these adverse outcomes. Some emerging studies show promise in the alteration of physicochemical properties of these nanoparticles (particularly surface coating and functionalization) to help prevent or reduce this toxicity. However, there is still little concurrence on its actual effectiveness, or the resulting impact on nanoparticle function. Therefore, more research involving long term in vivo exposure to assess particle distribution, and in vitro work that utilizes relevant parameters (such as dose, cell type, and relevant end points), must be conducted to better ascertain the risk associated with IONPs exposure. Furthermore, there is a major knowledge gap as to which physicochemical alterations could affect bioactivity and toxicity following exposure, and which ones could be altered to reduce this toxicity. Without this information, it is exceedingly difficult to make accurate recommendations for safe exposure limits. Despite this, IONPs continue to be incorporated into consumer products and can be released during the manufacturing process, or throughout its lifecycle, becoming a source of potential hazard for atrisk workers. Therefore, there is a critical need to better characterize the IONPs toxicity profile, and to establish more robust in vitro and in vivo toxicity assessment, so as to better assess risk for a wide range of nanomaterials and to protect at-risk workers. 


\section{Chapter 3: Iron oxide nanoparticle-induced neoplastic-like cell transformation in vitro is reduced with protective amorphous silica coating.}

Chapter Introduction:

The overall goal for this research project was to assess the potential for a specific IONP $\left(\mathrm{nFe}_{2} \mathrm{O}_{3}\right)$ to induce neoplastic-like adverse outcomes within the context of a physiologically relevant low dose/long term exposure. This research also showed how the alteration of particle surface coating, via the addition of an amorphous silica coating, may impact observed adverse outcomes.

Adapted from: T. Kornberg et al., "Iron oxide nanoparticle-induced neoplastic-like cell transformation in vitro is reduced with protective amorphous silica coating," Chemical Research in Toxicology. Accepted 23 October, 2019. 


\section{Iron oxide nanoparticle-induced neoplastic-like cell}

\section{transformation in vitro is reduced with protective}

\section{amorphous silica coating.}

Tiffany G. Kornberg ${ }^{\dagger} \S$ *, Todd A. Stueckle ${ }^{\S}$, Jayme Coyle ${ }^{\S}$, Raymond Derk ${ }^{\S}$, Philip Demokritoull, Yon Rojanasakul , Liying W. Rojanasakul,,$*$

'Department of Pharmaceutical and Pharmacological Sciences, School of Pharmacy, West Virginia University, Morgantown, WV 26506.

${ }^{\S}$ Allergy and Clinical Immunology Branch, Health Effects Laboratory Division, National Institute for Occupational Safety and Health, Morgantown, WV 26505.

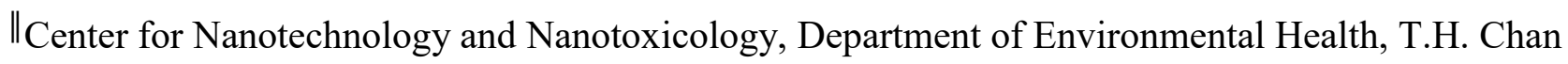
School of Public Health, Harvard University, Boston, MA 02115 


\section{ABSTRACT}

Iron oxide nanoparticles (IONP) have recently surged in production and use in a wide variety of biomedical and environmental applications. However, their potential long-term health effects, including carcinogenesis, are unknown. Limited research suggests IONP can induce genotoxicity and neoplastic transformation associated with particle dissolution and release of free iron ions. "Safe by design" strategies involve the modification of particle physicochemical properties to affect subsequent adverse outcomes, such as an amorphous silica coating to reduce IONP dissolution and direct interaction with cells. We hypothesized that long-term exposure to a specific IONP $\left(\mathrm{nFe}_{2} \mathrm{O}_{3}\right)$ would induce neoplastic-like cell transformation, which could be prevented with an amorphous silica coating $\left(\mathrm{SiO}_{2}-\mathrm{nFe}_{2} \mathrm{O}_{3}\right)$. To test this hypothesis, human bronchial epithelial cells (Beas-2B) were continuously exposed to $0.6 \mu \mathrm{g} / \mathrm{cm}^{2}$ administered dose of $\mathrm{nFe}_{2} \mathrm{O}_{3}\left(\sim 0.58 \mu \mathrm{g} / \mathrm{cm}^{2}\right.$ delivered dose $), \mathrm{SiO}_{2}-\mathrm{nFe}_{2} \mathrm{O}_{3}\left(\sim 0.55 \mu \mathrm{g} / \mathrm{cm}^{2}\right.$ delivered dose $)$, or gas metal arc mild steel welding fumes (GMA-MS, $\sim 0.58 \mu \mathrm{g} / \mathrm{cm}^{2}$ delivered dose) for 6.5 months. GMAMS are composed of roughly $80 \%$ iron/iron oxide and were recently classified as a total human carcinogen. Our results showed that low-dose/long-term in vitro exposure to $\mathrm{nFe}_{2} \mathrm{O}_{3}$ induced a time dependent neoplastic-like cell transformation, as indicated by increased cell proliferation and attachment independent colony formation, and which closely matched that induced by GMA-MS. This transformation was associated with decreases in intracellular iron, minimal changes in reactive oxygen species (ROS) production, and the induction of double stranded DNA damage. An amorphous silica-coated but otherwise identical particle $\left(\mathrm{SiO}_{2}-\mathrm{nFe}_{2} \mathrm{O}_{3}\right)$ did not induce this neoplastic-like phenotype or changes in the parameters mentioned above. Overall, the presented data suggests the carcinogenic potential of long term $\mathrm{nFe}_{2} \mathrm{O}_{3}$ exposure and the utility of an amorphous silica coating in "safe by design" hazard reduction strategy, within the context of a physiologically relevant exposure scenario (low-dose/long-term), with model validation using GMA-MS. 


\section{3-1. INTRODUCTION}

Nano-sized materials, which are specifically engineered to be $100 \mathrm{~nm}$ or smaller in at least one dimension, have emerged as novel solutions to critical issues in areas such as medicine, biotechnology, and transportation. Of these, iron oxide nanoparticles (IONP) have been investigated as unique components of MRI imaging techniques ${ }^{133}$, targeted drug delivery systems ${ }^{134}$, environmental catalysts ${ }^{135}$, and incorporation into thermoplastics ${ }^{17,136}$, food products ${ }^{137}$, and toners for printing equipment ${ }^{138}$. IONP, as well as many other types of nano-metal oxides, have also grown in interest, production, and utilization for consumer products including agriculture and food applications ${ }^{139-141}$. This surge may translate to increased risk of exposure for those involved in particle manufacture and use across its life cycle. However, potential adverse health outcomes following extended periods of exposure to IONP remain unclear.

One of the most common routes for human exposure is the inhalation of particulates in the circulating air, which usually occurs at low doses over long periods of time. This type of exposure can have distinct adverse outcomes for vulnerable populations. Chronic pulmonary exposure to metal-oxide particulates has been associated with cancer development in miners, welders, and other types of industrial workers ${ }^{142}$. However, potential cancer-related outcomes induced by IONP, as well as other types of nanometal oxides, remain poorly understood. For IONP, the current standard is to regulate exposure based on fine sized $\left(100-2500 \mathrm{~nm}^{6}\right)$ iron oxide exposure limits, even though evidence suggests that nano-sized particulates may pose a greater risk with exposure on a per mass basis than their fine-sized counterparts $7,80$.

As a further complication, fine sized iron oxide has an unclear and controversial toxicity profile. Some researchers suggest this particulate to be essentially benign ${ }^{34,39,40,74-76}$, whereas others associate exposure with adverse pulmonary outcomes, including increased risk of lung cancer in iron ore miners ${ }^{33,36,79}$. Similarly, IONP-induced adverse health outcomes are also largely unclear. It is known there is some risk of occupational exposure to IONP ${ }^{20,21}$, with unknown or unreported adverse outcomes. In 
laboratory settings, some researchers report no effect following IONP exposure ${ }^{93-95}$, whereas others indicate that IONP or IONP-containing materials may induce genotoxicity ${ }^{30,31,98,143}$, neoplastic-like cell transformation ${ }^{99,144}$, in vivo tumor formation ${ }^{145,146}$, and neurotoxicity ${ }^{147}$.

Gas metal arc welding fumes (GMA) have recently been re-classified as a Group 1 total human carcinogen ${ }^{148}$. GMA generated from mild steel welding (GMA-MS) contain roughly 80\% iron/iron oxide particulates which fall within the nano-size range. GMA-MS exposure is associated with fibrotic lesions and elevated lung iron levels in humans ${ }^{81}$, as well as lung tumor development ${ }^{145,146}$ and lung cancer progression ${ }^{149}$. Although GMA-MS contains largely insoluble iron, it still provides a useful reference for potential IONP-induced adverse outcomes, particularly those related to the induction or promotion of lung cancer.

The aims of this study were to assess the potential for IONP to induce neoplastic-like cell transformation within the context of an occupationally relevant sub-chronic in vitro exposure model (low dose/long term), and to examine the potential protective qualities of an amorphous silica coating under these conditions. GMA-MS particles were used as a positive control, as they have been previously shown to promote carcinogenic outcomes in vivo ${ }^{145,146}$. Particle induced changes in intracellular iron, ROS production, and DNA damage associated with the cell transformation were also evaluated throughout the long term exposure.

\section{3-2. EXPERIMENTAL METHODS}

\section{3-2a. Particle Generation, Preparation, Characterization, and Dosimetry}

$\mathrm{nFe}_{2} \mathrm{O}_{3}, \mathrm{SiO}_{2}-\mathrm{nFe}_{2} \mathrm{O}_{3}$, and $\mathrm{SiO}_{2}$ were generated at Harvard University Center for Nanotechnology and Nanotoxicology (Boston, MA) using the VEGNES-FSP system ${ }^{150}$. Briefly, this flame spray pyrolysis synthesis platform involves the dispersion of organometallic precursors (iron) and their combustion to form $\mathrm{nFe}_{2} \mathrm{O}_{3}$. Immediately following combustion, particles were sprayed with $\mathrm{SiO}_{2}$ vapor to form a nanothin amorphous silica coating ${ }^{150,151}$, before collection on Teflon filters. Particles were then extracted as 
powders for subsequent experiments. Gas metal arc mild steel welding fumes (GMA-MS) were generated at the Lincoln Electric Co. (St. Louis, MO), and provided by Dr. James M. Antonini from CDC/NIOSH (Morgantown, WV). These fumes were generated in a fume chamber by a skilled welder, and particulates were collected on filters for use in this study ${ }^{152}$. Aeroxide $\mathrm{TiO}_{2}$ (80:20 anatase/rutile structure, Evonik) was supplied from the Degussa Corporation (Parsippany, NJ) and provided by Dr. Tina Sager from CDC/NIOSH (Morgantown, WV) ${ }^{153}$. $\mathrm{TiO}_{2}$ particulates were sieved at a vibration amplitude of 50, and then filtered three times using Teflon filters $(1.18 \mathrm{~mm}, 250 \mathrm{~nm}$, and $45 \mathrm{~nm})$. Only particles which were able to pass through all three filters were used for treatments. $\mathrm{TiO}_{2}$ was used as a reference particle control, as the same particle is the source material for NIST Standard Reference Material for $\mathrm{TiO}_{2}{ }^{154}$.

Partial particle characterization in pristine powder phase was previously determined as described for $\mathrm{nFe}_{2} \mathrm{O}_{3}, \mathrm{SiO}_{2}-\mathrm{nFe}_{2} \mathrm{O}_{3}$, and $\mathrm{SiO}_{2}\left(\mathrm{~d}_{\mathrm{XRD}}, \mathrm{SSA}\right.$, and iron/iron oxide content $){ }^{150}, \mathrm{TiO}_{2}\left(\mathrm{~d}_{\mathrm{XRD}}\right)^{153}$, and GMAMS (iron/iron oxide content) ${ }^{152}$. dXRD of GMA-MS was calculated based on representative SEM images. Particles were suspended in sterilized MilliQ water at a concentration of $1 \mathrm{mg} / \mathrm{mL}$ in sterilized glass test tubes. Particle suspensions were sonicated with a cup horn sonicator (Sonics Vibra Cell, Newton, CT) based on sonicator efficiency and calculated critical energy needed to generate stable particle agglomerates $\left(\mathrm{nFe}_{2} \mathrm{O}_{3} / \mathrm{SiO}_{2}-\mathrm{nFe}_{2} \mathrm{O}_{3}: 242 \mathrm{~J} / \mathrm{mL}, \mathrm{SiO}_{2}: 161 \mathrm{~J} / \mathrm{mL}, \mathrm{TiO}_{2}: 161 \mathrm{~J} / \mathrm{mL}\right.$, GMA-MS: $\left.242 \mathrm{~J} / \mathrm{mL}\right)$ 65,155,156, and were then serially diluted in BEGM for subsequent treatment. Fresh particle stock suspensions in water were prepared every four weeks and sonicated a maximum of eight consecutive times in water, with hydrodynamic diameter $\left(\mathrm{d}_{\mathrm{H}}\right)$ in medium determined separately for each sonication.

Hydrodynamic diameter $\left(\mathrm{d}_{\mathrm{H}}\right)$ and zeta potential $(\zeta)$ for all particles following suspension in MilliQ water, sonication, and serial dilution in complete cell culture medium was determined by dynamic light scattering (DLS, ZetaSizer Nano ZS, Model Zen3600, Malvern, Surrey, United Kingdom) using previously described methods ${ }^{65,156}$. Zeta potential was determined using the ZetaSizer Nano Series Dip Cell (Model Zen1002, Malvern, Surrkey, United Kingdom). For scanning electron microscopy (SEM) with energy dispersive x-ray (EDX), particles in cell culture medium were further diluted in filtered 
distilled water (1:10) and agitated manually to maintain dispersion. Following this, particles were vacuum filtered onto a polycarbonate filter, which was then mounted on an aluminum stub and sputter coated with gold palladium. SEM images were taken on a Hitachi S4800 field emission scanning electron microscope (Hitachi, Tokyo, Japan) at magnifications of $15,000,25,000$, or 50,000X. For transmission electron microscopy (TEM), one drop of diluted particle sample was placed on a formvar-coated 200 mesh copper grid and evaporated overnight before imaging on a JEOL 1400 transmission electron microscope (JEOL, Tokyo, Japan).

Particle release of free iron in $\mathrm{H}_{2} \mathrm{O}$, culture medium (BEGM), and phagolysosome-like buffer was assessed using Inductively Coupled Plasma-Optical Emission Spectroscopy (ICP-OES) at CDC/NIOSH (Cincinnati, $\mathrm{OH}$; calculated limit of quantification: $0.0566 \mathrm{ug} / \mathrm{mL}$ ). Particles were serially diluted in $1 \mathrm{~mL}$ water, BEGM, or phagolysosome-like buffer (prepared as previously described ${ }^{157}$ ) at the concentration of $20 \mu \mathrm{g} / \mathrm{mL}$, then stored in $37^{\circ} \mathrm{C}$ incubator to replicate cell culture conditions. Particle-free vehicle controls were also prepared and stored. 72 hours later, particle suspensions were centrifuged $(13,000 \mathrm{rpm}$ for 10 minutes) and filtered (0.2 $\mu \mathrm{m}$ PTFE, ThermoFisher), and the resulting supernatant was assessed for soluble iron content via ICP-OES. Percent dissolved particle was calculated based on beginning mass of particle and mass of detectable soluble iron.

Volume weighted size distribution and effective density of particle suspensions in medium (calculated as previously described ${ }^{158}$ ) were incorporated into distorted grid (DG) fate and transport modeling algorithm in MatLab v.2006b developed at Harvard University ${ }^{65,66,159}$ to assess cell deposited dose metrics as a function of exposure time.

\section{2b. Cell Culture and Exposure}

Naïve Beas-2B cells (ATCC) were cultured in serum-free BEGM (basal medium with 1\% penicillin/streptomycin, $0.4 \%$ bovine pituitary extract, $0.1 \%$ hydrocortisone, human epithelial growth factor, epinephrine, transferrin, insulin, retinoic acid, and triiodothyronine) from Lonza (Walkersville, 
MD) for a minimum of two passages before beginning exposures. Cells were passaged according to the ATCC guidelines. For acute exposures, Beas-2B were seeded at 10,000 cells per well in a 96-well plate (Corning). 24 hours post-plating, medium was aspirated out and replaced with specific particle treatments, or particle-free vehicle control, which were prepared as described above, and serially diluted in BEGM to appropriate doses. Administered doses ranged from $0.2 \mu \mathrm{g} / \mathrm{cm}^{2}(0.66 \mu \mathrm{g} / \mathrm{mL})$ to $2.0 \mu \mathrm{g} / \mathrm{cm}^{2}(6.6 \mu \mathrm{g} / \mathrm{mL})$ for acute studies, and a sub-toxic dose was selected for sub-chronic treatment based on these results and previous literature ${ }^{100}$.

For sub-chronic exposures, Beas-2B (passage 3) were seeded at 50,000 cells/well in six-well plates (Corning), with four biological replicates per treatment group, from which at least three biological replicates were used for any subsequent assay. At 24 hours post-seeding, the medium was aspirated out and replaced with specific particle treatments, prepared as described above. All particle treatments were administered at $0.6 \mu \mathrm{g} / \mathrm{cm}^{2}(2.88 \mu \mathrm{g} / \mathrm{mL})$. Particle-free vehicle exposed cells served as passage controls. Medium with particle treatments was replaced every three to four days. When cells were approximately 80-90\% confluent (roughly once a week), cells were washed, trypsin/EDTA released from plate, and random selection of cells were re-plated at seeding density of 50,000 cells/well in $75 \%$ of total volume. Particle treatments were added directly to these wells approximately 3 hours later in the remaining $25 \%$ volume. Remainder of cells from each passage/re-plating were used for cell transformation and ROSrelated assays, or frozen back for future studies.

\section{3-2c. Particle Uptake}

Beas-2B (passage 3) were seeded at 50,000 cells/well in six-well plates (Corning) and exposed to specific particle treatment 24 hours later as described above. Medium with particle treatment was replaced three days later. When cells were $80-90 \%$ confluent (one week later), cells were washed, passaged, and prepared for transmission electron microscopy (TEM) as previously described ${ }^{160}$. Briefly, cells were suspended in Karnovsky's fixative and pelleted, then fixative was removed and replaced with 4\% agarose. 
After congealment, excess agar was trimmed away and fresh Karnovsky’s fixative was added overnight. The pellet was rinsed ( $8 \%$ sucrose- $0.9 \%$ sodium chloride buffer), then osmium teroxide was added. En bloc staining was done using $1 \%$ tannic acid and $0.5 \%$ uranyl acetate. The pellet was dehydrated using a graded series of ethanol, then cells were embedded in epoxy resin and polymerized. Blocks were sectioned at $70 \mathrm{~nm}$ onto 200 mesh copper grids and stained (4\% Uranyl Acetate and Reynold's Lead Citrate). Imaging was done at 1,500 to $3,000 \mathrm{X}$ or 10,000 to $50,000 \mathrm{X}$ magnification on a JEOL 1400 transmission electron microscope (JEOL, Tokyo, Japan).

\section{3-2d. Reactive Oxygen Species Production}

For acute (18, 24 hours) and sub-chronic exposures (48, 62, 69, 76, 97, 104, 118, 125, 132, 145, 195 days continuous exposure), treated Beas-2B cells were seeded at 10,000 cells/well in a clear bottom black 96-well plate (Corning), stained with $10 \mu \mathrm{M}$ DCF-H and $1 \mu \mathrm{M}$ Hoescht-33342 (Sigma-Aldrich, St. Louis, MO), and incubated at $37^{\circ} \mathrm{C}$ for 30 minutes. Cells were washed once with BEGM, and imaged in warm PBS at 20X magnification, with 9 image sites per well. Imaging using DAPI and FITC filters were analyzed using high content screening on an ImageXpress Micro XLS apparatus with MetaXpress v5.3 software (Molecular Devices, San Jose, California). Using the MultiWavelength Application Module in MetaXpress, minimum/maximum cell diameters and minimum intensity thresholds were used to identify each nucleus (DAPI) and intracellular ROS (FITC). Masks were applied to positively identify cells for each imaged site. Only FITC masks containing a nucleus were included in the analysis. Integrated intensity of fluorescent signal from each cell (evaluated using cell mask) was calculated and averaged for quantification. $10 \mu \mathrm{M} \mathrm{H}_{2} \mathrm{O}_{2}$ treatment was used as a positive control for ROS detection, and particle only controls were used to verify there was minimal particle interference (data not shown).

\section{3-2e. Cell Proliferation}

Acute and sub-chronic exposures were done at previously indicated time points. Treated Beas-2B cells were plated at 10,000 cells/well in a 96-well plate with at least four technical replicates per biological 
replicate and treatment group. At appropriate time points, cells were incubated with WST-1 reagent (Sigma Aldrich, St. Louis, MO) at a 1:10 dilution for two hours, then absorbance at $450 \mathrm{~nm}$ was measured using a spectrophotometer (SpectraMax, Molecular Devices, San Jose, California), according to manufacturer's instructions.

\section{3-2f. Attachment Independent Colony Formation}

Soft agar colony assay was conducted as previously described ${ }^{144}$ at 55, 83, 111, 138, 174, and 202 days of continuous exposure. Briefly, $0.5 \% \mathrm{w} / \mathrm{v}$ agar medium was prepared and plated in six-well plates (1.25\% Difco agar, $15 \% \mathrm{v} / \mathrm{v}$ fetal bovine serum, and growth supplements at concentrations consistent with complete cell culture medium in 2X MEM). After the base layer was solidified, cells were suspended in $33 \%$ agar at $1 \times 10^{4}$ cells/well and slowly layered onto precast agar in triplicate six-well plates. Plates were stored in $37^{\circ} \mathrm{C}$ incubator for 14 days, and colonies were digitally photographed under light microscopy (1.25X). Five representative pictures from each well were taken, totaling 15 pictures per biological replicate. Only colonies $>50 \mu \mathrm{m}$ in diameter were included in counts, which were done manually using ImageJ Grid and CellCounter plugins.

\section{3-2g. Intracellular Iron and Lysosome Counts}

At select time points during sub-chronic exposure (91, 132, and 202 days), treated cells were seeded at 10,000 cells per well in a 96-well clear bottomed black plate (Corning). When cells were at least 70\% confluent, Beas-2B were fluorescently stained with $1 \mu \mathrm{M}$ PhenGreen SK, $1 \mu \mathrm{M}$ Deep Red LysoTracker, and $1 \mu \mathrm{M}$ Hoechst 33342 . Plates were incubated at $37^{\circ} \mathrm{C}$ for 30 minutes. Cells were washed once and imaged in warm Fluorobrite clear DMEM (ThermoFisher) at 20X magnification for intracellular iron, then 40X magnification for lysosome counts, with 9 imaging sites per well for each. Imaging (DAPI, FITC, and Cy5 filters) and analysis were done using ImageXpress apparatus and MetaXpress software as described above. Using this program, individual intracellular lysosomes were identified using 
minimum/maximum diameter masks, counted using the TransFlour HT module, and averaged per cell for each image site and treatment group. Integrated intensity of PhenGreen fluorescent signal from each cell was calculated using cell mask and averaged for quantification of intracellular iron. PhenGreen fluorescent signal from acute intracellular iron studies was measured using Varioskan Lux fluorescent plate reader (excitation: $492 \mathrm{~nm}$, emission: $517 \mathrm{~nm}$ ). PhenGreen fluorescent signal is quenched upon binding to free iron ions. Therefore, inverse of integrated intensity of fluorescent signal was calculated using non-treated control cell fluorescence as threshold (F0/F), as has been previously described ${ }^{161}$. Iron specificity of PhenGreen was assessed using $\mathrm{FeSO}_{4}$ as a positive control, and pyridoxal isonicotinoyl hydrazine (PIH, Sigma-Aldrich) as an intracellular iron chelation control).

\section{3-2h. $\gamma H 2 A X$ Assay for DNA damage}

Treated Beas-2B cells from sub-chronic exposure (91, 132, and 202 days) were seeded at 10,000 cells per well in a 96-well clear bottomed black plate (Corning). When cells were at least 70\% confluent, the Beas-2B were fixed in 4\% paraformaldehyde, permeabilized with $0.25 \%$ Triton-X, and then washed with PBS, all at ambient room temperature. 48 hours later, cells were incubated with $0.5 \%$ phosphorylated$\gamma \mathrm{H} 2 \mathrm{AX}$ primary antibody (1:250, Cell Signaling, Danvers, MA) for one hour, washed in PBS, and fluorescently tagged using AlexaFlour-555 secondary antibody (1:500) and $1 \mu \mathrm{M}$ Hoechst 33342 . Imaging (at 20X magnification) and analysis were performed using the ImageXpress apparatus and MetaXpress software as described above. Minimum/maximum cell diameters and minimum intensity thresholds were used to identify each nucleus (DAPI) as described above. Average nuclear intensity of top 3\% of nontreated cells was used as threshold for positive or negative scoring of all cell treatments, to determine percentage of cells with positive $\gamma \mathrm{H} 2 \mathrm{AX}$ damage. $10 \mu \mathrm{M} \mathrm{H}_{2} \mathrm{O}_{2}$ treatment was used as a positive control (data not shown).

\section{3-2i. Statistical Analyses}


Data represents mean \pm standard error of the mean $(\mathrm{SE})$ from three or more biological replicates and four or more technical replicates per biological replicate. Samples were normalized to non-treated control for each biological replicate, then combined for all figures. Following normalization, samples were analyzed using a two-way ANOVA with Tukey's post-hoc test for multiple comparisons to determine significance. Statistical significance is indicated in each figure as $* \mathrm{p}<0.05, * * \mathrm{p}<0.01, * * * \mathrm{p}<0.001$, and $* * * * \mathrm{p}<0.0001$. All statistical analyses were performed using GraphPad Prism Software (La Jolla, CA).

\section{3-3. RESULTS.}

\section{3-3a. Particle Characterization}

First, particles were evaluated for agglomerate hydrodynamic diameter and zeta potential following preparation and sonication in sterilized water, then serial dilution in complete cell culture media (BEGM), using DLS (Table 3-1). All test particles had roughly similar primary particle diameters (dxRD ranging from $15-45 \mathrm{~nm}$ ), and zeta potentials (ranging from -15.63 to -8.84 $\mathrm{mV}$ ) in BEGM, but with diverse agglomerate hydrodynamic diameters, ranging from $1114 \mathrm{~nm}(\mathrm{GMA}-\mathrm{MS})$ to $2570 \mathrm{~nm}\left(\mathrm{nFe}_{2} \mathrm{O}_{3}\right)$.

Dispersed particle agglomerates were visualized using TEM (Figure 3-1A) and SEM (Figure 31B). SEM-EDX (Figure 3-1C) indicated an amorphous silica coating on $\mathrm{SiO}_{2}-\mathrm{nFe}_{2} \mathrm{O}_{3}$, and also showed that GMA-MS particulates were primarily comprised of insoluble iron and small amounts of other metals.

\section{3-3b. Acute Cytotoxicity Assessment}

Next, the acute bio-effect of particle treatments $\left(\mathrm{nFe}_{2} \mathrm{O}_{3}, \mathrm{SiO}_{2}-\mathrm{nFe}_{2} \mathrm{O}_{3}, \mathrm{GMA} \mathrm{MS}, \mathrm{SiO}_{2}\right.$, and $\left.\mathrm{TiO}_{2}\right)$ was evaluated. Reactive oxygen species (ROS) production and proliferative capacity were used as basic indicators of particle-induced changes in cell activity (Figure 3-2). Beas-2B cells were exposed to a range of administered doses $\left(0.2-2.0 \mu \mathrm{g} / \mathrm{cm}^{2}\right)$ of particle treatments for up to 24 hours, and ROS production and cell proliferation were assessed. For ROS production, treated Beas-2Bs showed a dose response for all particle treatments, with the greatest ROS response overall at 18 hours post-exposure (Figure 3-2A). 
$2.0 \mu \mathrm{g} / \mathrm{cm}^{2}$ administered dose of $\mathrm{nFe}_{2} \mathrm{O}_{3}$, GMA-MS, and $\mathrm{TiO}_{2}$ all induced significantly elevated $\mathrm{ROS}$ production compared to non-treated controls at 18 hours post-exposure, with GMA-MS and $\mathrm{TiO}_{2}$ exposed cells retaining this elevated ROS at 24 hours. There was no significant cell death induced by any particle treatments, and higher doses of $\mathrm{SiO}_{2}$ and the lowest dose of $\mathrm{TiO}_{2}$ induced significantly elevated proliferation at 24 hours post-exposure (Figure 3-2D). Intracellular iron was evaluated using the fluorophore PhenGreen SK and iron chelator PIH). In Beas-2B cells, the majority of iron is sequestered, and not catalytically active. PIH as a chelator, and PhenGreen as a fluorescent marker, actively target chelatable iron within the cell's catalytically active labile iron pool ${ }^{162}$, as is indicated with $\mathrm{FeSO}_{4}$ treatment, which was used as a control. There were no significant changes in intracellular iron across particle treatments at 18- or 24-hours post-exposure (Figure 3-3). Cells exposed to higher doses of GMAMS ( 0.6 or $2.0 \mu \mathrm{g} / \mathrm{cm}^{2}$ administered dose) showed a trend of elevated intracellular iron at 24 hours postexposure. Overall, the acute treatment data supported $0.6 \mu \mathrm{g} / \mathrm{cm}^{2}$ as a sub-toxic dose for sub-chronic treatment. 
Table 3-1. Colloidal/physicochemical characterization of dispersed nanoparticles after one sonication. ${ }^{\text {a }}$

\begin{tabular}{|c|c|c|c|c|c|c|c|c|}
\hline ENM & $\begin{array}{l}\text { dXRD } \\
(\mathrm{nm})\end{array}$ & $\begin{array}{l}\text { SSA } \\
\left(\mathrm{m}^{2} / \mathrm{g}\right)\end{array}$ & $\begin{array}{l}\zeta \quad(\mathrm{mV}), \\
{[\text { measured }} \\
\mathrm{pH}]\end{array}$ & $\begin{array}{l}\text { Iron/Iron } \\
\text { Oxide } \\
\text { Content } \\
(\%)\end{array}$ & $\mathrm{d}_{\mathrm{H}}(\mathrm{Z}$ avg., $\mathrm{nm})$ & PDI & $\begin{array}{l}\rho \text { ENM } \\
\left(\mathrm{g} / \mathrm{cm}^{3}\right)\end{array}$ & $\rho_{\mathrm{EV}}\left(\mathrm{g} / \mathrm{cm}^{3}\right)$ \\
\hline $\mathrm{nFe}_{2} \mathrm{O}_{3}$ & 19.6 & 42 & $-8.63[7.55]$ & 100 & 2570 & 0.43 & 5.242 & 1.534 \\
\hline $\mathrm{SiO}_{2}-\mathrm{nFe}_{2} \mathrm{O}_{3}$ & 21.3 & 49 & -13 [7.54] & 66 & 1895 & 0.28 & 5.242 & 1.273 \\
\hline $\mathrm{SiO}_{2}$ & 19 & 147 & $-15.63[7.58]$ & 0 & 1774 & 0.16 & 2.648 & 1.08 \\
\hline $\begin{array}{l}\text { Gas Metal Arc Mild } \\
\text { Steel Welding } \\
\text { Fumes }\end{array}$ & $\begin{array}{l}15- \\
45\end{array}$ & nd & -10.49 [7.53] & 80 & 1114 & 0.28 & 5.7 & 2.362 \\
\hline $\mathrm{TiO}_{2}$ & 23 & nd & $-8.56[7.59]$ & 0 & 2085 & 0.17 & 4.26 & 1.391 \\
\hline
\end{tabular}

\footnotetext{
${ }^{\text {a }}$ Primary particle size as determined by X Ray diffraction $\left(\mathrm{d}_{\mathrm{XRD}}\right)$, surface area (SSA), hydrodynamic diameter $\left(\mathrm{d}_{\mathrm{H}}\right)$, zeta potentials $(\zeta)$, iron/iron oxide content, polydispersity index (PDI), raw material density $\left(\rho_{\mathrm{ENM}}\right)$, and agglomerate effective density $\left(\rho_{\mathrm{EV}}\right)$ of all particle treatments in complete cell culture media (BEGM). nd: no data.
} 


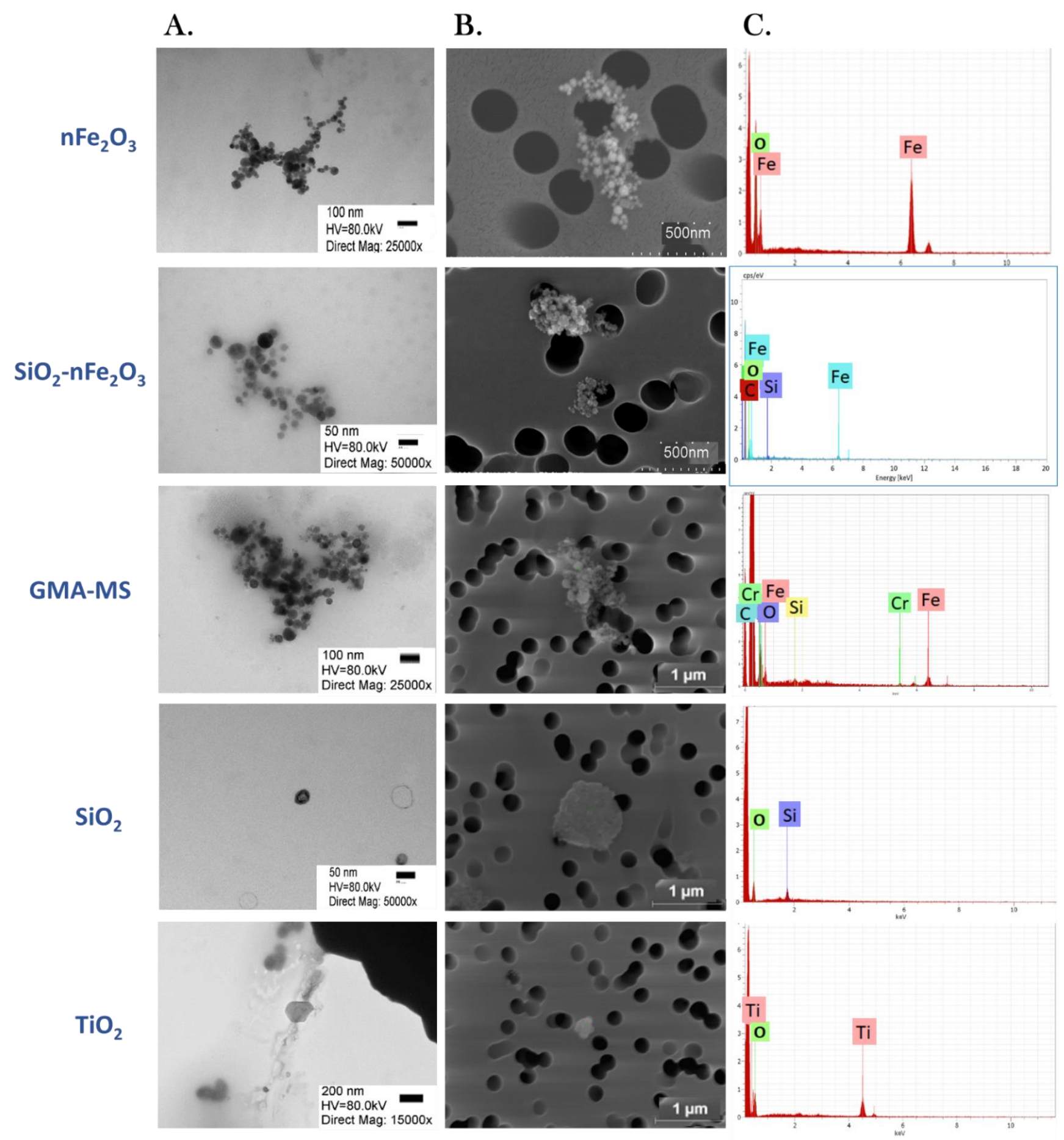

Figure 3-1. Representative SEM and TEM images of particle treatments. Particle agglomeration in complete cell culture medium was visualized using $A$ ) transmission electron microscopy (TEM), B) scanning electron microscopy (SEM), and C) SEM-Energy Dispersive X-Ray Spectroscopy (SEMEDX). For TEM, magnification ranged from 15,000 to 50,000X. 

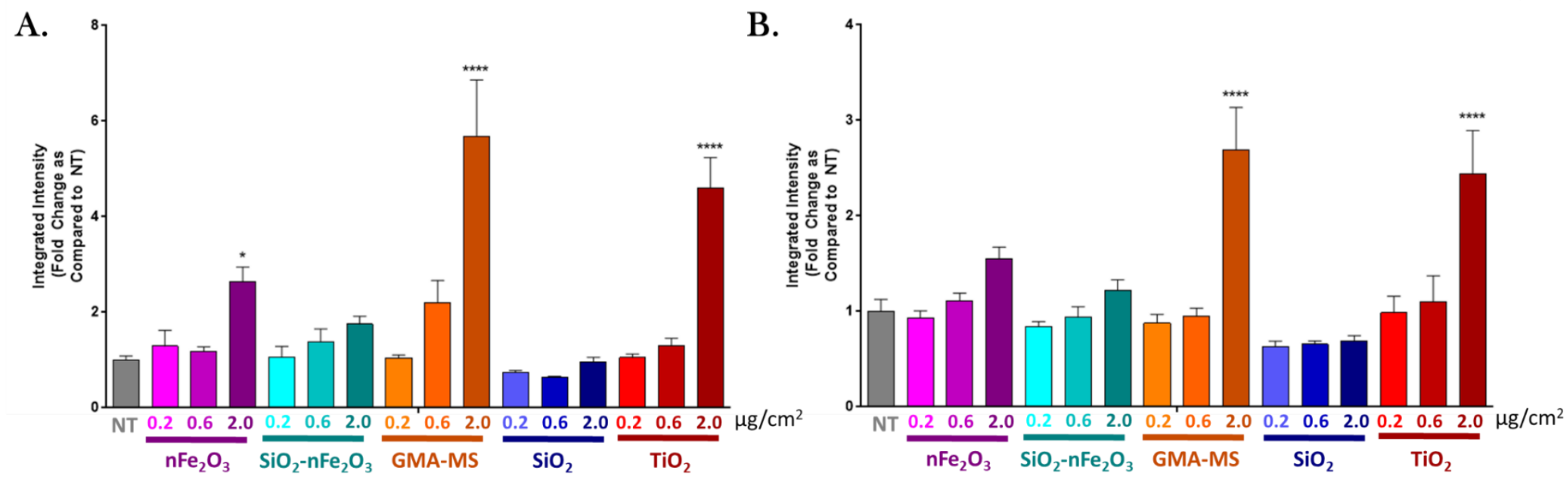

C.

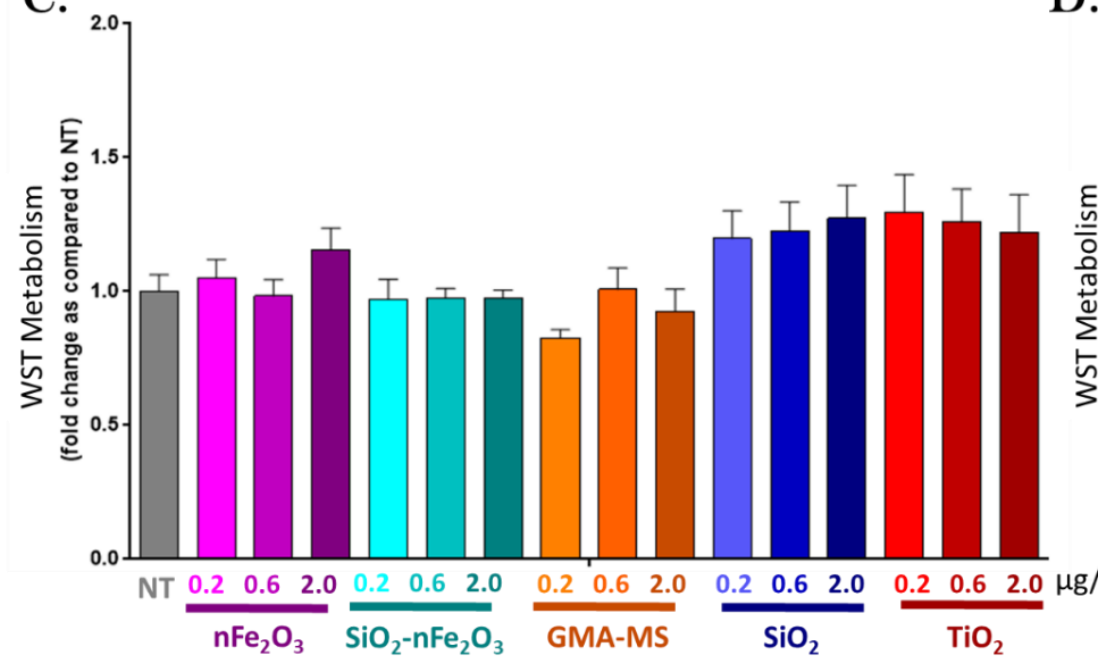

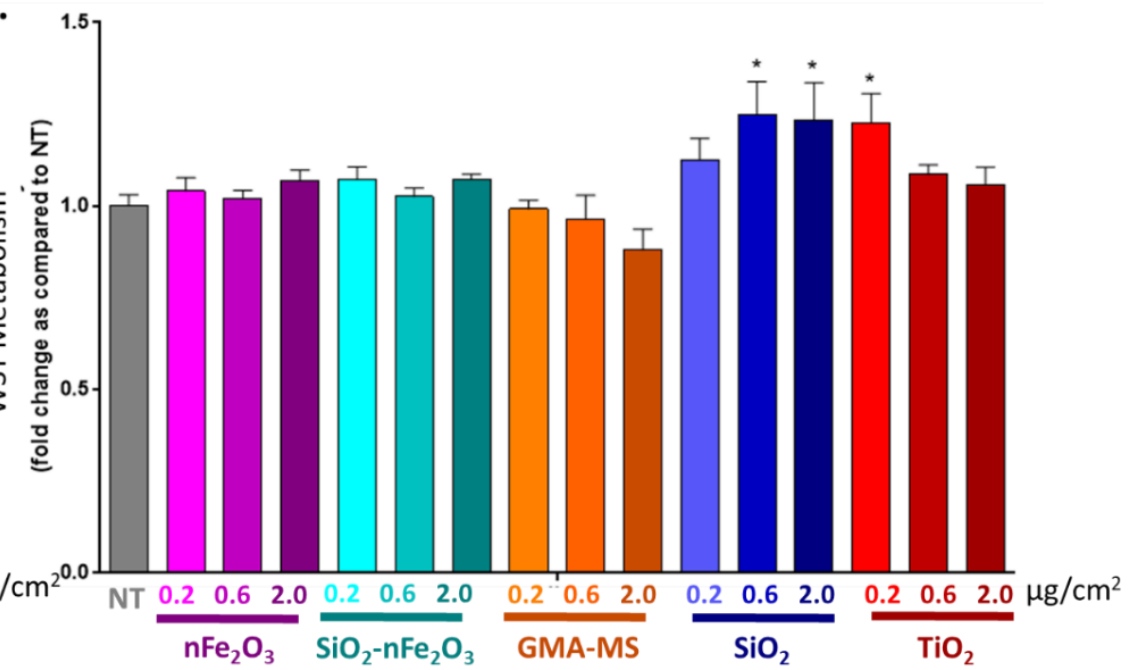

Figure 3-2. Acute particle-induced changes in ROS production (DCF assay) at $A$ ) 18 and $B$ ) 24 hours, and WST metabolism at $C$ ) 18 and $D$ ) 24 hours post-exposure. Doses refer to administered dose. Error bars indicate mean $\pm \mathrm{SE}(\mathrm{n}=3) .{ }^{*} \mathrm{p}<0.05,{ }^{* * * *} \mathrm{p}<0.0001$ from non-treated control (NT). 

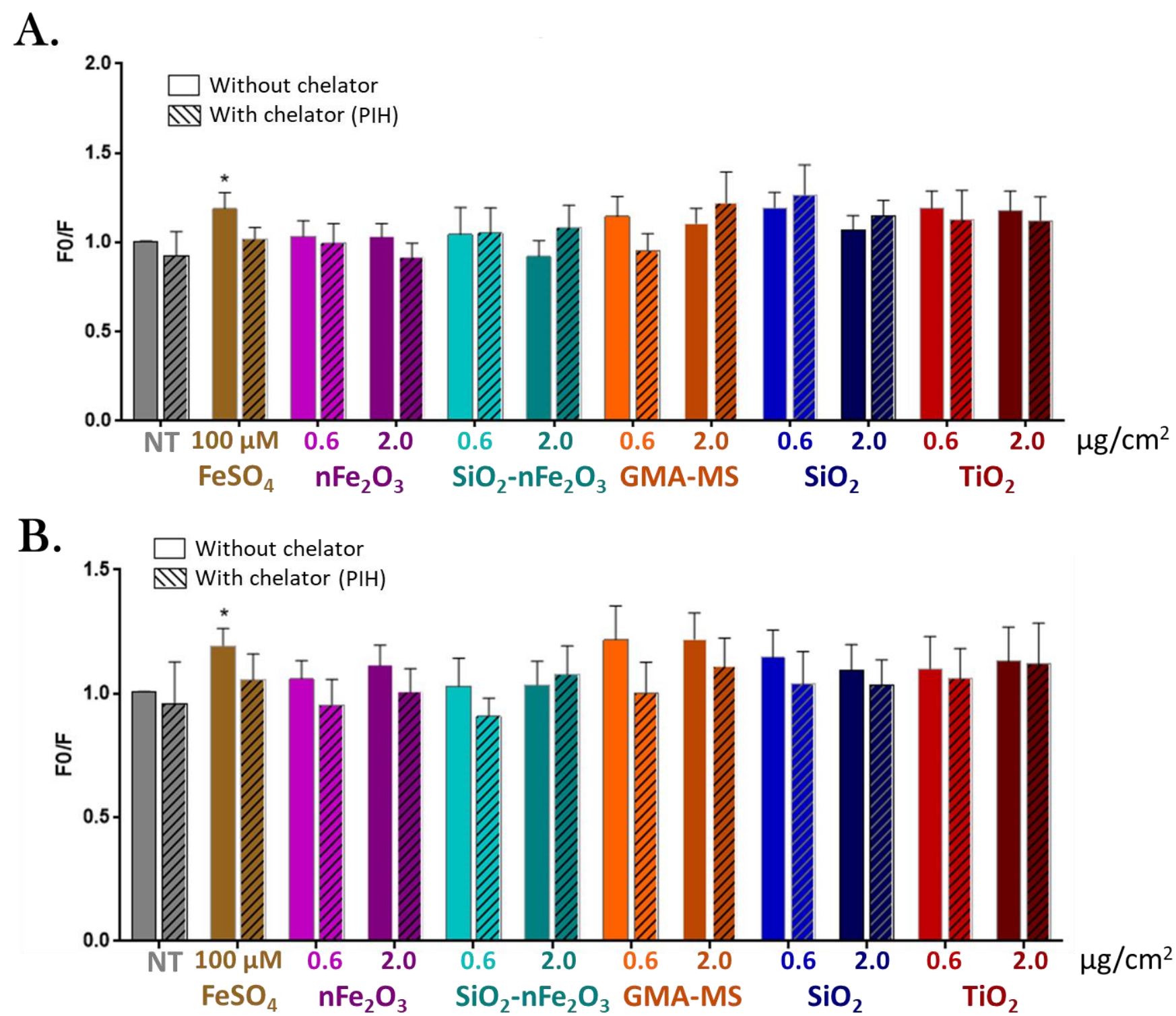

Figure 3-3. Acute particle-induced changes in intracellular iron (PhenGreen fluorescence) at $A$ ) 18 and B) 24 hours. Doses refer to administered dose. Error bars indicate mean $\pm \mathrm{SE}(\mathrm{n}=4)$. Cross hatches indicate addition of $100 \mu \mathrm{M}$ pyridoxal isonicotinoyl hydrazine (PIH, iron chelator). In Beas-2B cells, the majority of iron is sequestered, and not catalytically active. PIH as a chelator, and PhenGreen as a fluorescent marker, actively target chelatable iron within the cell's catalytically active labile iron pool ${ }^{162}$, which is why it had minimal effect on acutely treated Beas-2B, with the exception of FeSO4 treatment. F0/F: inverse integrated intensity of fluorescent signal. ${ }^{*} \mathrm{p}<0.05$ from same particle treatment without PIH chelation. 


\section{3-3c. Sub-Chronic Cell Transformation}

Based on previous in vitro and in vivo research, and results from the above acute experiments, an administered dose of $0.6 \mu \mathrm{g} / \mathrm{cm}^{2}(2.88 \mu \mathrm{g} / \mathrm{mL})$ was selected for the sub-chronic exposure. A recent study by Teeguarden et al. ${ }^{100}$ exposed Balb/c mice to a similarly sized iron oxide $\left(\mathrm{Fe}_{3} \mathrm{O}_{4}\right)$ particle via inhalation at $19.9 \mathrm{mg} / \mathrm{m}^{3}$ over 4 hours $\left(80 \mathrm{mg}^{*} \mathrm{~h} / \mathrm{m}^{3}\right)$, which is slightly lower than the OSHA permissible exposure limit (PEL) for fine sized $\mathrm{Fe}_{2} \mathrm{O}_{3}$ particles $\left(14 \mathrm{mg} / \mathrm{m}^{3}\right.$ over 8 hours or $\left.112 \mathrm{mg} * \mathrm{~h} / \mathrm{m}^{3}\right)$. Following the exposure, target tissue dose in the bronchial region was calculated to be about $1 \mu \mathrm{g} / \mathrm{cm}^{2}$. Previous research by our group ${ }^{144}$ also indicated that at $0.6 \mu \mathrm{g} / \mathrm{cm}^{2}$ administered dose, $\mathrm{nFe}_{2} \mathrm{O}_{3}$ induced a neoplastic-like cell transformation in primary human small airway epithelial cells. Therefore, in the present study, Beas-2B cells were exposed to this low dose $\left(0.6 \mu \mathrm{g} / \mathrm{cm}^{2}\right)$ of $\mathrm{nFe}_{2} \mathrm{O}_{3}, \mathrm{SiO}_{2}-\mathrm{nFe}_{2} \mathrm{O}_{3}, \mathrm{GMA}-\mathrm{MS}$, or particle controls $\left(\mathrm{TiO}_{2}, \mathrm{SiO}_{2}\right)$ continuously for 6.5 months, and assessed throughout for indications of neoplastic-like cell transformation, particularly at time points surrounding two, four, and six months. Uncontrolled or dysregulated cell proliferation is a classic hallmark of cancer ${ }^{163}$. Therefore, this was used as an initial indicator of potential cell transformation throughout the exposure period (Figure 3-4). Beginning at 97 days ( $\sim 3.25$ months) of continuous exposure, $\mathrm{nFe}_{2} \mathrm{O}_{3}$ exposed cells had a trend of decreased proliferation, which began to increase at 118 days, as compared to non-treated controls. By 125 days ( 4.5 months), the $\mathrm{nFe}_{2} \mathrm{O}_{3}$ exposed cells had almost a two-fold significant increase in proliferation as compared to nontreated control cells. Elevated proliferation was maintained through the rest of the exposure period (6.5 months). GMA-MS exposed cells followed a similar trend for this parameter, with significantly elevated proliferation ( $\sim 1.25$ fold) by 145 days ( $\sim 5$ months) of exposure, which was maintained through the rest of the exposure period, as compared to non-treated controls. However, $\mathrm{SiO}_{2}-\mathrm{nFe}_{2} \mathrm{O}_{3}$ exposed cells had no significant changes in cell 
proliferation throughout the entire exposure period. $\mathrm{TiO}_{2}$ exposed cells began to exhibit significantly decreased proliferation at 97 days of continuous exposure, which gradually increased until it became significantly elevated at 145 days. This elevation was maintained through the rest of the exposure period. $\mathrm{SiO}_{2}$ exposed cells had significantly elevated cell proliferation at 125 days continuous exposure, which then returned to be roughly similar to that of non-treated control cells by the end of the exposure period.

Attachment independent colony formation is an indicator of neoplastic-like cell transformation because abnormal or neoplastic cells can continue to proliferate without attachment to a solid surface ${ }^{164}$. This was assessed using soft agar colony formation assay throughout the sub-chronic exposure period (Figure 3-5). At 55 days ( $\sim 2$ months) of continuous exposure, there were no significant changes in colony formation across treatment groups. $\mathrm{nFe}_{2} \mathrm{O}_{3}$ and GMA-MS exposed cells had a significant increase $(1.2$ and 1.4 fold) in colony number at 83 days ( $\sim 2.75$ months) post-exposure, which was ablated by 111 days ( $\sim 3.7$ months). Colony number then became significantly elevated again (1.6 fold) at 138 days ( $\sim 4.5$ months) as compared to non-treated control cells, which was maintained through the remainder of the exposure period (202 days, $\sim 6.5$ months). $\mathrm{TiO}_{2}$ exposed cells had a significant 1.3 -fold increase in colony formation at 111 and 138 days, which then returned to be roughly similar to that of non-treated control cells by 174 days exposure and remained at baseline levels through the end of the exposure period. $\mathrm{SiO}_{2}$ $\mathrm{nFe}_{2} \mathrm{O}_{3}$ and $\mathrm{SiO}_{2}$ exposed cells had no significant changes in attachment independent colony formation throughout the exposure period. 


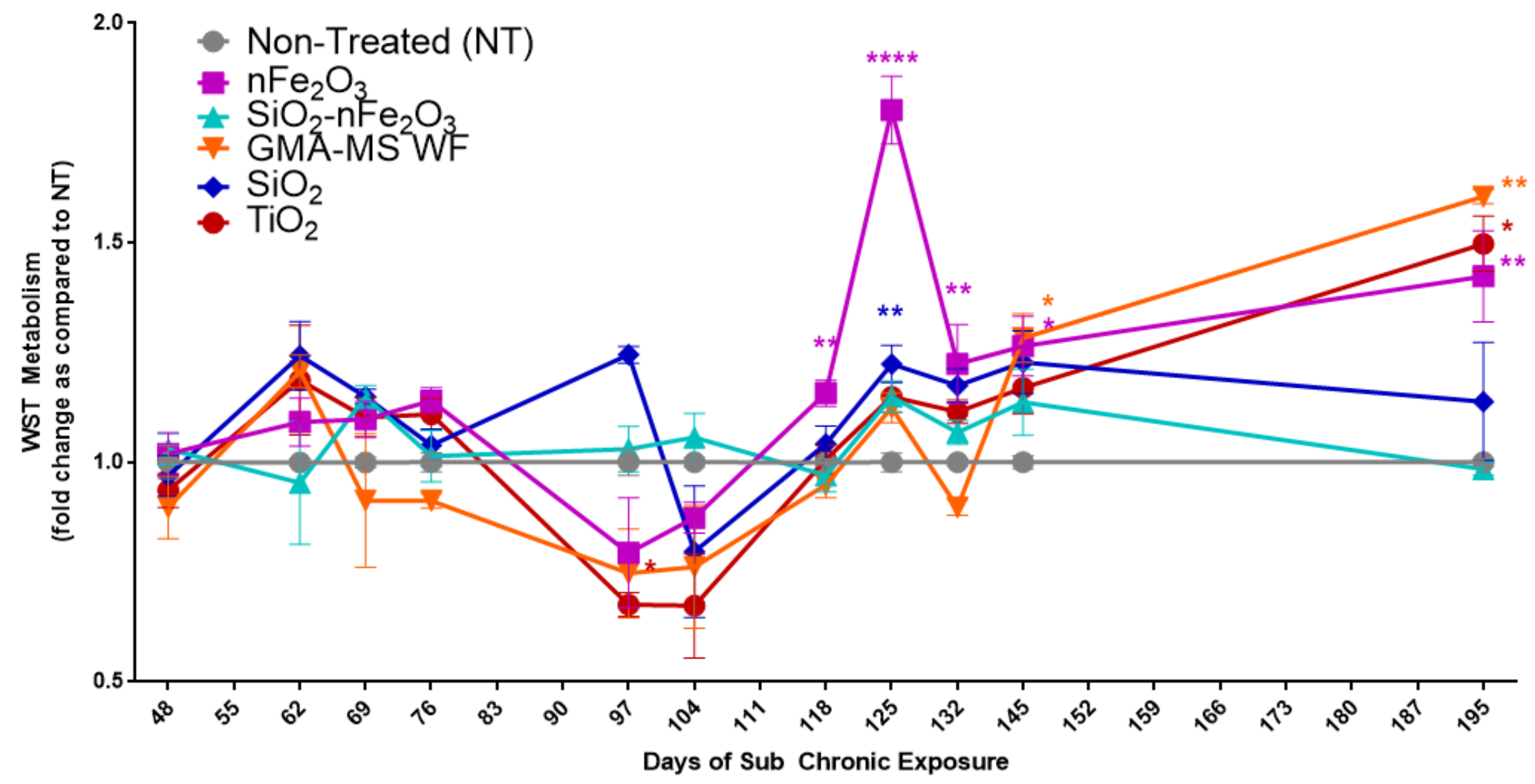

Figure 3-4. Cell proliferation throughout sub-chronic exposure to $0.6 \mu \mathrm{g} / \mathrm{cm}^{2}$ administered dose of specific particle treatment $\left(\sim 0.58 \mu \mathrm{g} / \mathrm{cm}^{2}\right.$ $\mathrm{nFe}_{2} \mathrm{O}_{3}, \sim 0.54 \mu \mathrm{g} / \mathrm{cm}^{2} \mathrm{SiO}_{2}-\mathrm{nFe}_{2} \mathrm{O}_{3}, \sim 0.57 \mu \mathrm{g} / \mathrm{cm}^{2}$ GMA-MS, $\sim 0.24 \mu \mathrm{g} / \mathrm{cm}^{2} \mathrm{SiO}_{2}$, or $\sim 0.57 \mu \mathrm{g} / \mathrm{cm}^{2} \mathrm{TiO}_{2}$ delivered dose). There were no significant changes in activity of non-treated control cells (Figure 3-S1), so fold change as compared to non-treated cells was calculated for each time point separately. ${ }^{*} \mathrm{p}<0.05,{ }^{*} \mathrm{p}<0.01,{ }^{* * *} \mathrm{p}<0.001,{ }^{* * * *} \mathrm{p}<0.0001$ as compared to non-treated control cells at the same time point. Error bars indicate mean $\pm \mathrm{SE}(\mathrm{n}=4)$. 
A.

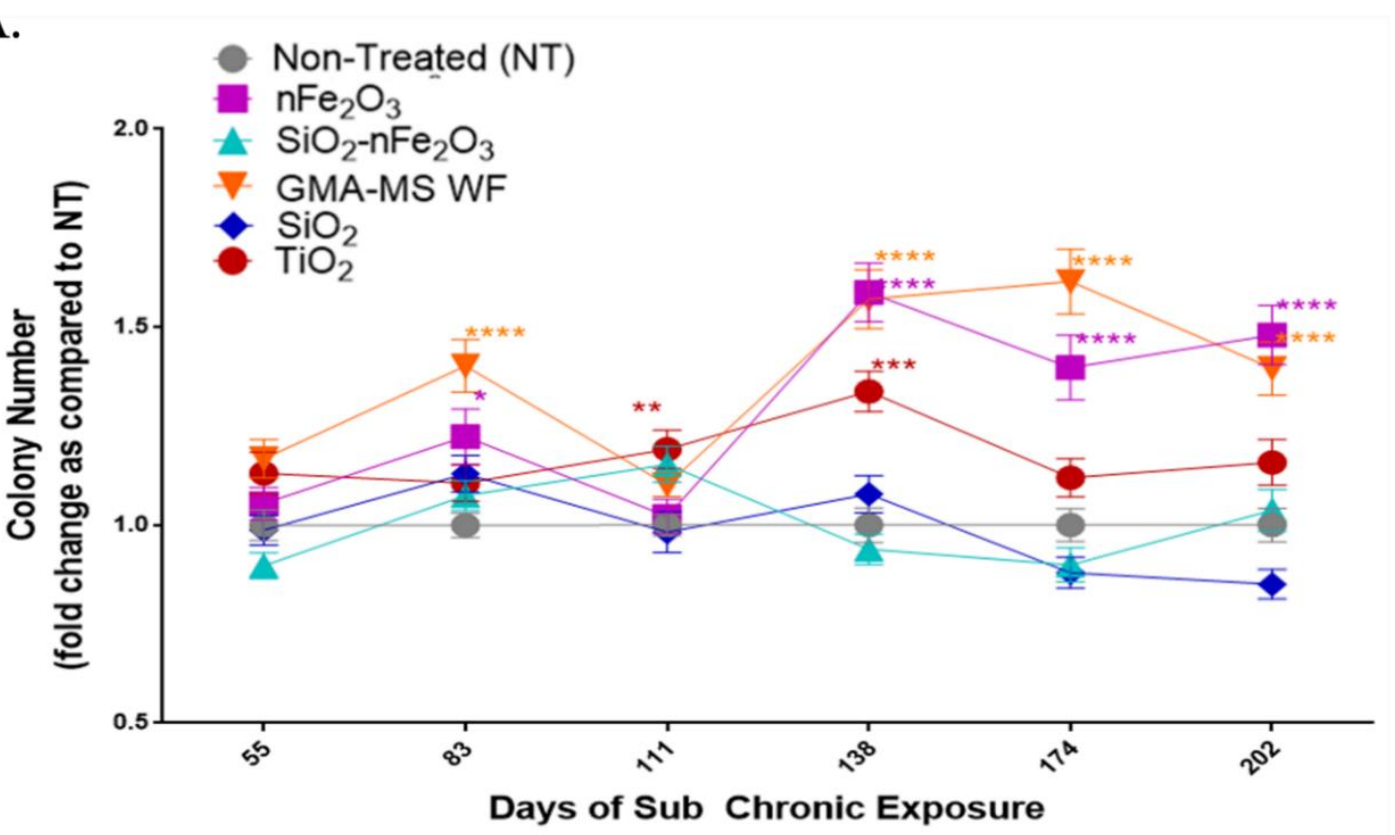

B. $\mathrm{D} 83$
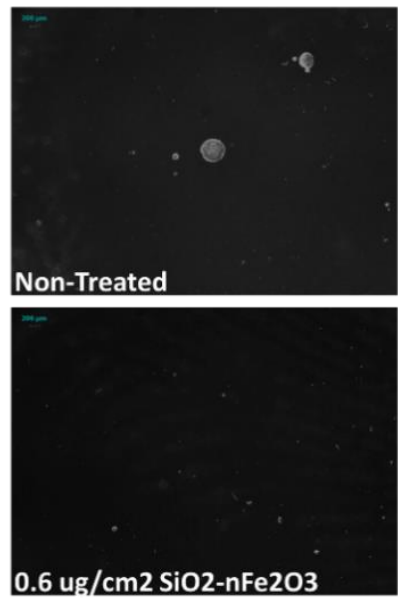
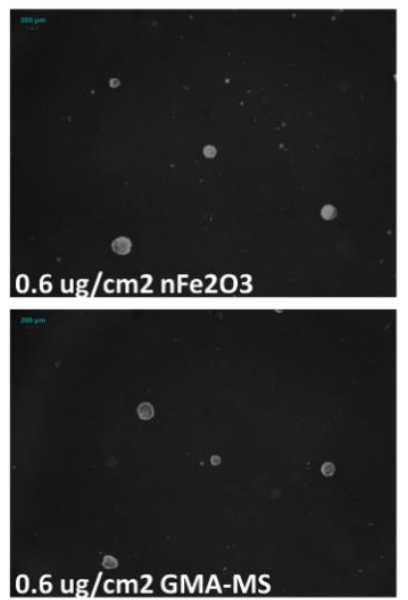

D. ${ }^{202}$
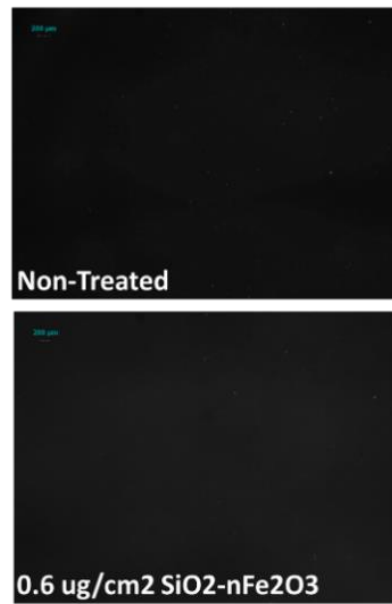

C. D138
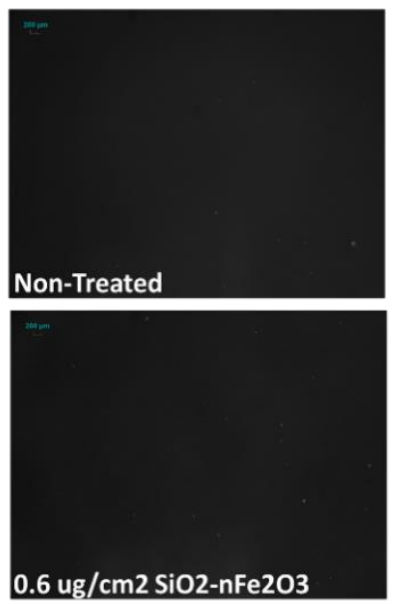

$0.6 \mathrm{ug} / \mathrm{cm} 2 \mathrm{nFe} 2 \mathrm{O} 3$
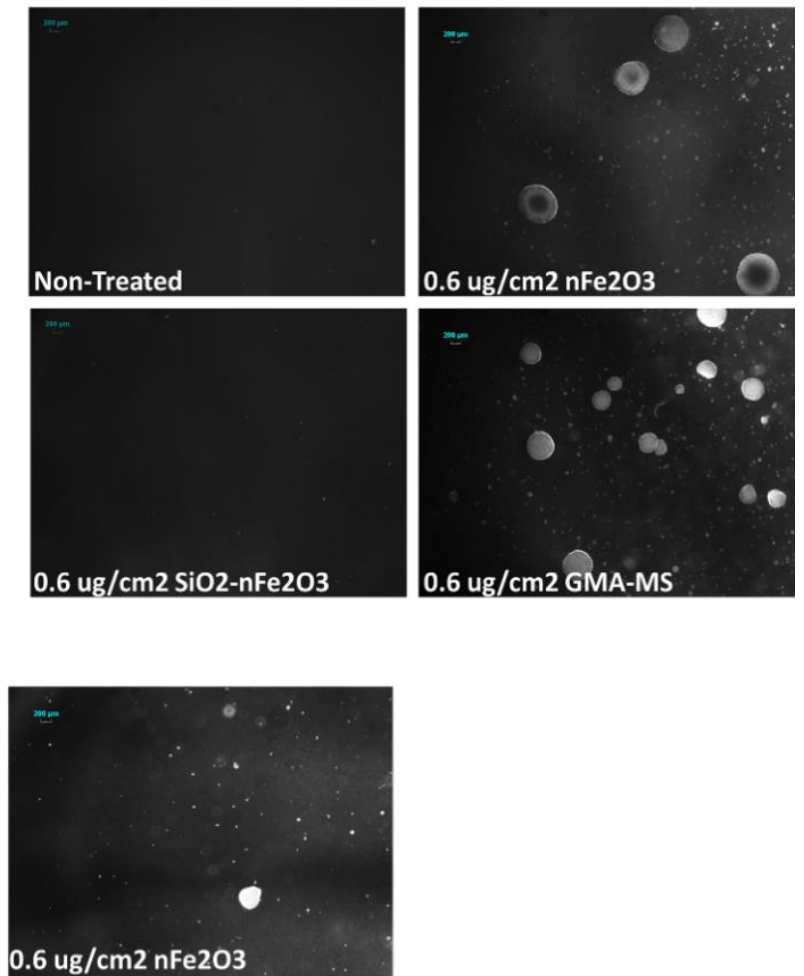

$0.6 \mathrm{ug} / \mathrm{cm} 2 \mathrm{nFe} 2 \mathrm{O}$

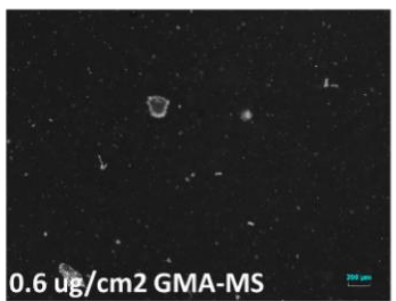


Figure 3-5. Attachment independent colony formation throughout sub-chronic exposure to $0.6 \mu \mathrm{g} / \mathrm{cm}^{2}$ administered dose of specific particle treatment $\left(\sim 0.58 \mu \mathrm{g} / \mathrm{cm}^{2} \mathrm{nFe}_{2} \mathrm{O}_{3}, \sim 0.54 \mu \mathrm{g} / \mathrm{cm}^{2} \mathrm{SiO}_{2}-\mathrm{nFe}_{2} \mathrm{O}_{3}\right.$, $\sim 0.57 \mu \mathrm{g} / \mathrm{cm}^{2}$ GMA-MS, $\sim 0.24 \mu \mathrm{g} / \mathrm{cm}^{2} \mathrm{SiO}_{2}$, or $\sim 0.57 \mu \mathrm{g} / \mathrm{cm}^{2} \mathrm{TiO}_{2}$ delivered dose). A) Quantification of attachment independent colonies followed by representative images of colonies from $B$ ) 83 days, $C$ ) 138 days, and $D$ ) 202 days of continuous exposure. There were no significant changes in the activity of non-treated control cells (Figure 3-S2), so fold change as compared to non-treated cells was calculated for each time point separately. ${ }^{*} \mathrm{p}<0.05,{ }^{* *} \mathrm{p}<0.01,{ }^{* * *} \mathrm{p}<0.001,{ }^{* * * *} \mathrm{p}<0.0001$ as compared to nontreated control cells at the same time point. Error bars indicate mean $\pm \operatorname{SE}(n=4)$. 


\section{3-3d. Sub-Chronic Exposure-Induced Changes in Cell Response}

Sub-chronically exposed cells were assessed for changes in intracellular iron, lysosome counts, ROS production, and DNA damage at key points during the sub-chronic exposure period. Intracellular iron and lysosome counts were evaluated using PhenGreen SK and LysoTracker fluorescent staining and high content image analysis (Figure 3-6). At all three measured time points (91, 132, and 202 days continuous exposure), $\mathrm{nFe}_{2} \mathrm{O}_{3}$-exposed cells had significantly decreased intracellular iron as compared to non-treated control cells $(\sim 70 \%, 55 \%$, and $90 \%$ of non-treated control cells at 91,132 , and 202 days continuous exposure, respectively). GMA-MS-exposed cells had significantly decreased intracellular iron at 91 days continuous exposure only ( $\sim 70 \%$ that of non-treated control cells), then returned to be similar to non-treated control cells at 132 days, which was maintained through the end of the exposure period. GMA-MS exposed cells also had significantly fewer average lysosomes per cell than non-treated controls at 202 days continuous exposure, but all other treatment groups showed no significant changes in this parameter at this or any other time points measured.

ROS production was also assessed throughout the sub-chronic exposure period (Figure 3-7). At the first measured time point for this parameter (48 days/1.5 months continuous exposure), all treatment groups had significantly decreased ROS as compared to non-treated controls. $\mathrm{nFe}_{2} \mathrm{O}_{3}$ exposed cells showed a trend of increased ROS production at 104, 125, and 145 days, which then decreased to become less than that of production by non-treated control cells by the end of the exposure period. Both GMAMS and $\mathrm{SiO}_{2}-\mathrm{nFe}_{2} \mathrm{O}_{3}$ exposed cells had slight and sometimes significantly decreased ROS production throughout the entire sub-chronic exposure period compared to non-treated controls. $\mathrm{SiO}_{2}$ and $\mathrm{TiO}_{2}$ exposed cells had no significant changes in ROS production throughout the exposure period, with the exception of the first time point measured (48 days). 
A.

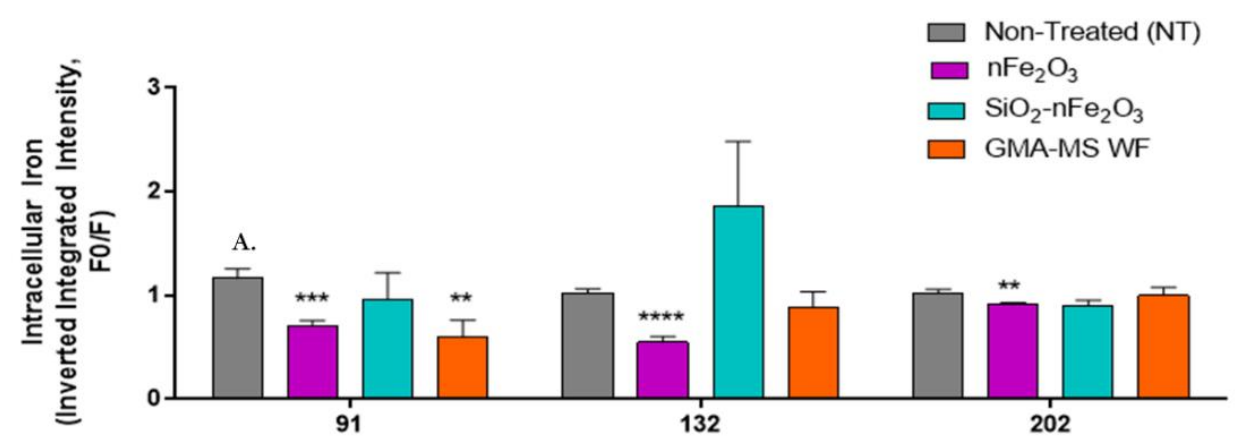

B.
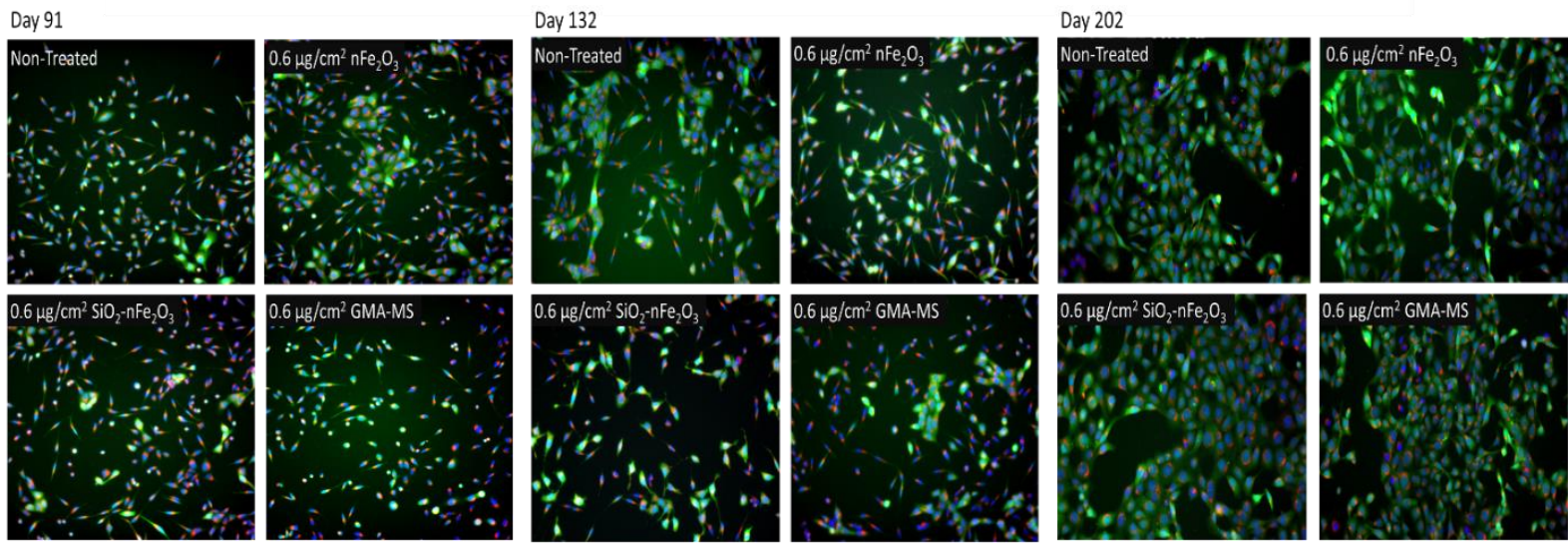

C.

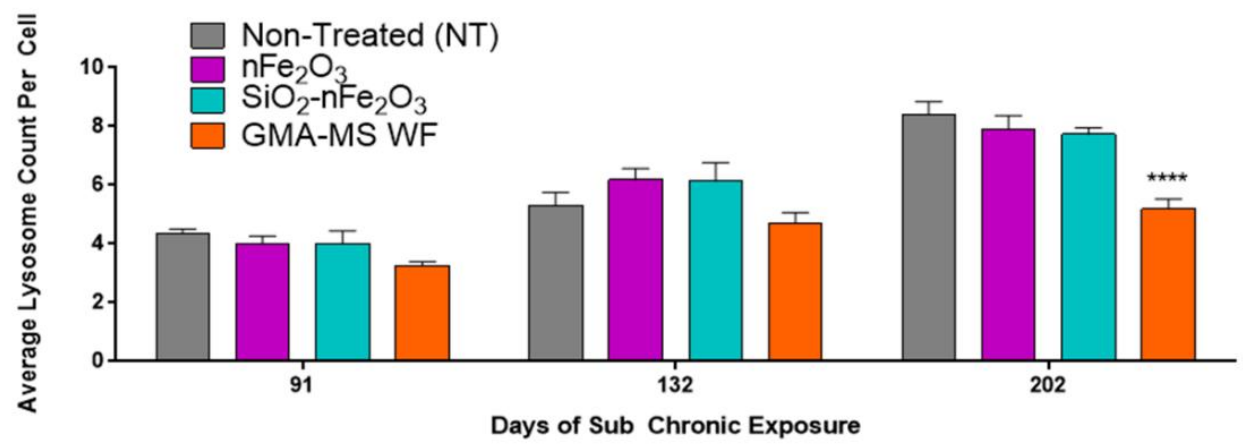

D.
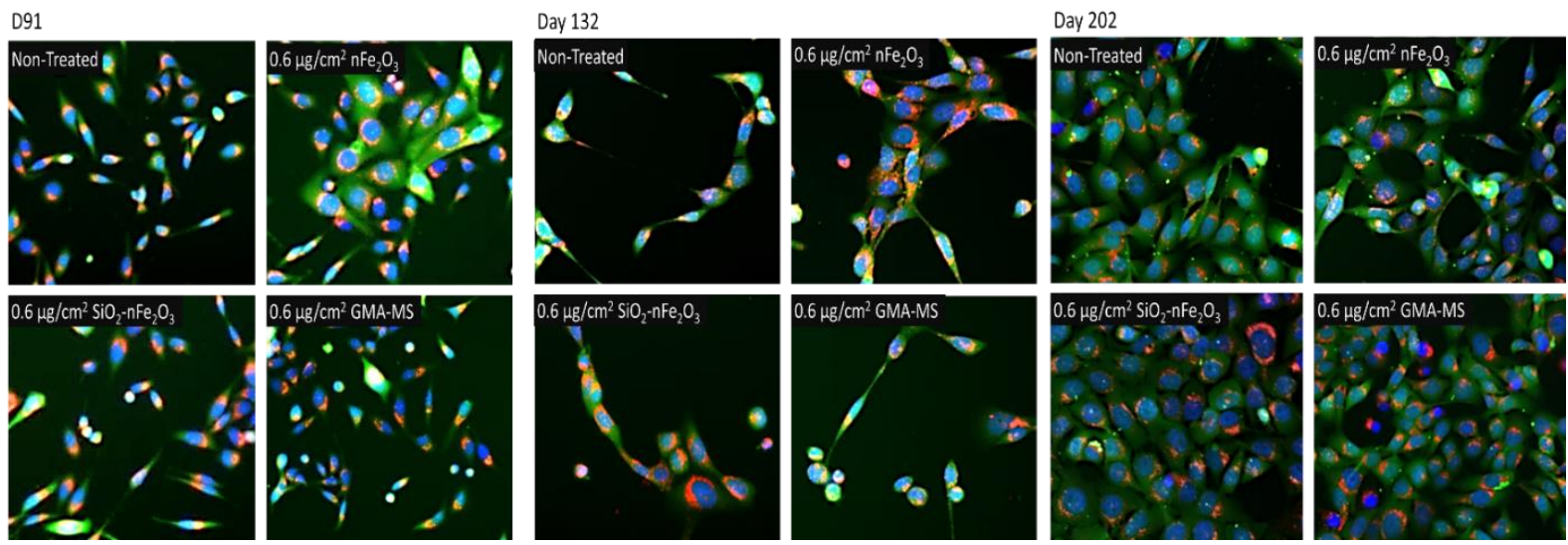

Figure 3-6. Intracellular iron and lysosome response during the sub-chronic exposure. A)

Quantification of intracellular iron fluorescent signal, $B$ ) representative images of 20X fluorescent 
staining, $C$ ) average lysosome count per cell, and $D$ ) representative images of $40 \mathrm{X}$ fluorescent staining. Images were taken at key time points during sub-chronic exposure to $0.6 \mu \mathrm{g} / \mathrm{cm}^{2}$ administered dose of specific particle treatments $\left(\sim 0.58 \mu \mathrm{g} / \mathrm{cm}^{2} \mathrm{nFe}_{2} \mathrm{O}_{3}, \sim 0.54 \mu \mathrm{g} / \mathrm{cm}^{2} \mathrm{SiO}_{2}-\mathrm{nFe}_{2} \mathrm{O}_{3}, \sim 0.57 \mu \mathrm{g} / \mathrm{cm}^{2}\right.$ GMA-MS, $\sim 0.24 \mu \mathrm{g} / \mathrm{cm}^{2} \mathrm{SiO}_{2}$, or $\sim 0.57 \mu \mathrm{g} / \mathrm{cm}^{2} \mathrm{TiO}_{2}$ delivered dose). For images, blue: nuclear staining; green: intracellular iron staining, red: lysosome staining. ${ }^{* *} \mathrm{p}<0.01,{ }^{* * *} \mathrm{p}<0.001,{ }^{* * * *} \mathrm{p}<0.0001$ as compared to non-treated control cells. Error bars: mean $\pm \mathrm{SE}(\mathrm{n}=3)$. F0/F: inverse integrated intensity of fluorescent signal. 


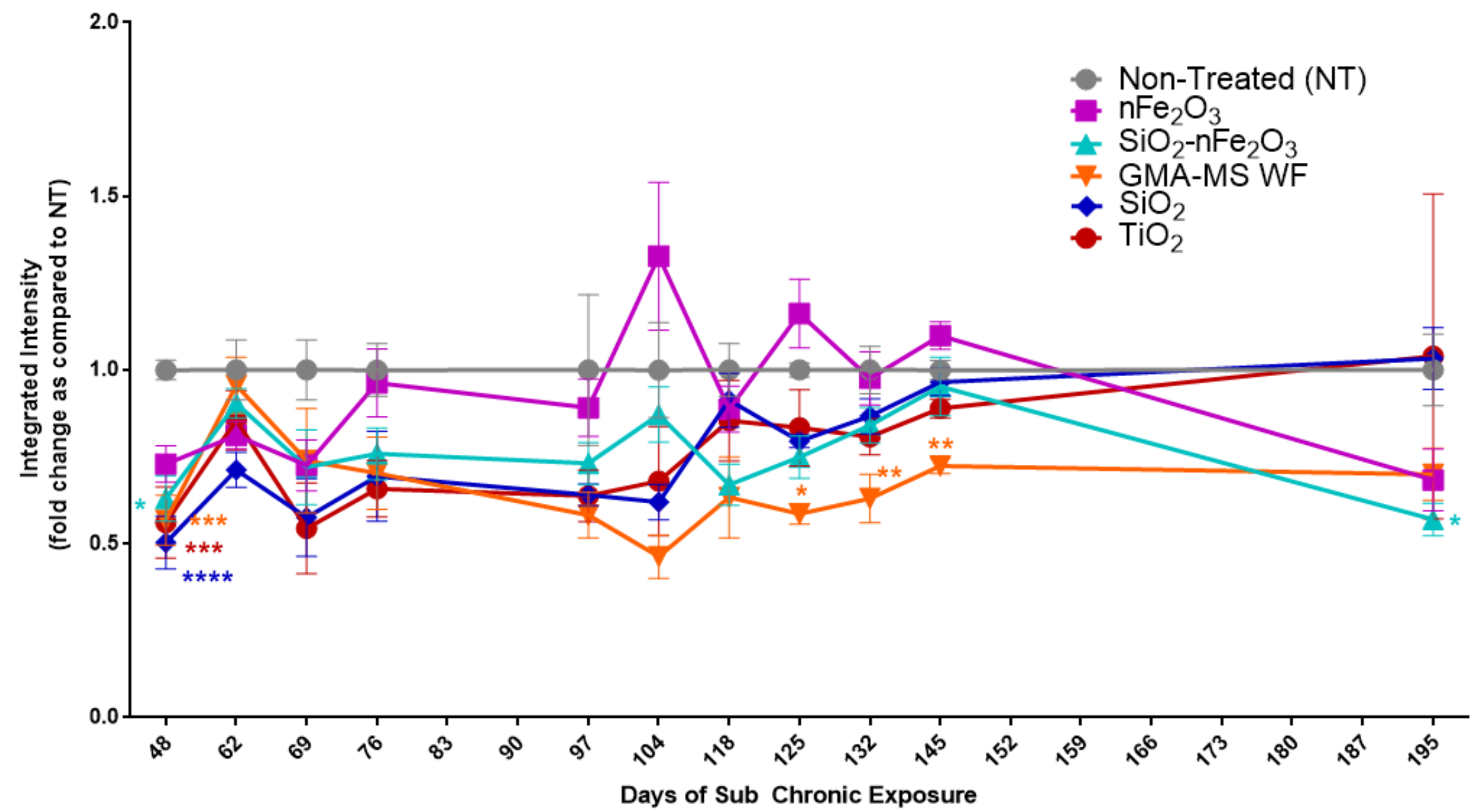

Figure 3-7. ROS production throughout sub-chronic exposure to $0.6 \mu \mathrm{g} / \mathrm{cm}^{2}$ administered dose of specific particle treatments $\left(\sim 0.58 \mu \mathrm{g} / \mathrm{cm}^{2}\right.$ $\mathrm{nFe}_{2} \mathrm{O}_{3}, \sim 0.54 \mu \mathrm{g} / \mathrm{cm}^{2} \mathrm{SiO}_{2}-\mathrm{nFe}_{2} \mathrm{O}_{3}, \sim 0.57 \mu \mathrm{g} / \mathrm{cm}^{2}$ GMA-MS, $\sim 0.24 \mu \mathrm{g} / \mathrm{cm}^{2} \mathrm{SiO}_{2}$, or $\sim 0.57 \mu \mathrm{g} / \mathrm{cm}^{2} \mathrm{TiO}_{2}$ delivered dose). There were no significant changes in ROS production of non-treated control cells (Figure 3-S3), so fold change as compared to non-treated cells was calculated for each time point separately. ${ }^{*} \mathrm{p}<0.05, * * \mathrm{p}<0.01, * * * \mathrm{p}<0.001, * * * * \mathrm{p}<0.0001$ as compared to non-treated control cells at the same time point. Error bars indicate mean $\pm \operatorname{SE}(n=4)$. 
Genomic instability and DNA damage are known to be key events associated with carcinogenesis

165. There are several types of DNA damage which have been implicated in carcinogenesis adverse outcome pathways, such as double stranded DNA damage, which is known to have a critical impact on cell phenotype ${ }^{166,167}$. To assess double stranded DNA damage of the transformed cells, $\gamma \mathrm{H} 2 \mathrm{AX}$ fluorescence was evaluated at key time points during the sub-chronic exposure period (Figure 3-8) as an indicator of double stranded DNA breaks ${ }^{168}$. At 132 days $(\sim 4.5$ months $)$ of continuous exposure, there were significantly more $\mathrm{nFe}_{2} \mathrm{O}_{3}$-exposed cells that were $\gamma \mathrm{H} 2 \mathrm{AX}$ positive as compared to $\mathrm{SiO}_{2}-\mathrm{nFe}_{2} \mathrm{O}_{3}$ treated cells. By 202 days continuous exposure, $\mathrm{nFe}_{2} \mathrm{O}_{3}$ exposed cells had significantly elevated $\gamma \mathrm{H} 2 \mathrm{AX}$ as compared to both non-treated and $\mathrm{SiO}_{2}-\mathrm{nFe}_{2} \mathrm{O}_{3}$ treated cells. GMA-MS cells also showed significant DNA damage at 202 days continuous exposure as compared to non-treated control cells.

\section{3-3e. Particle Dosimetry}

A critical issue with in vitro nanoparticle exposures is the difficulty in ascertaining accurate dosimetry. Particle agglomeration and settling rate will impact how the known administered dose may compare to actual delivered dose, while particle uptake may play a key role in the induction of adverse outcomes. First, previously calculated particle agglomeration (Table 3-1) and measured particle density were used to calculate particle settling rate. Raw particle density is known to related to effective density in cell culture medium, and effective density is a key factor in the calculation of in vitro particle deposition rate $^{158}$. 
A.

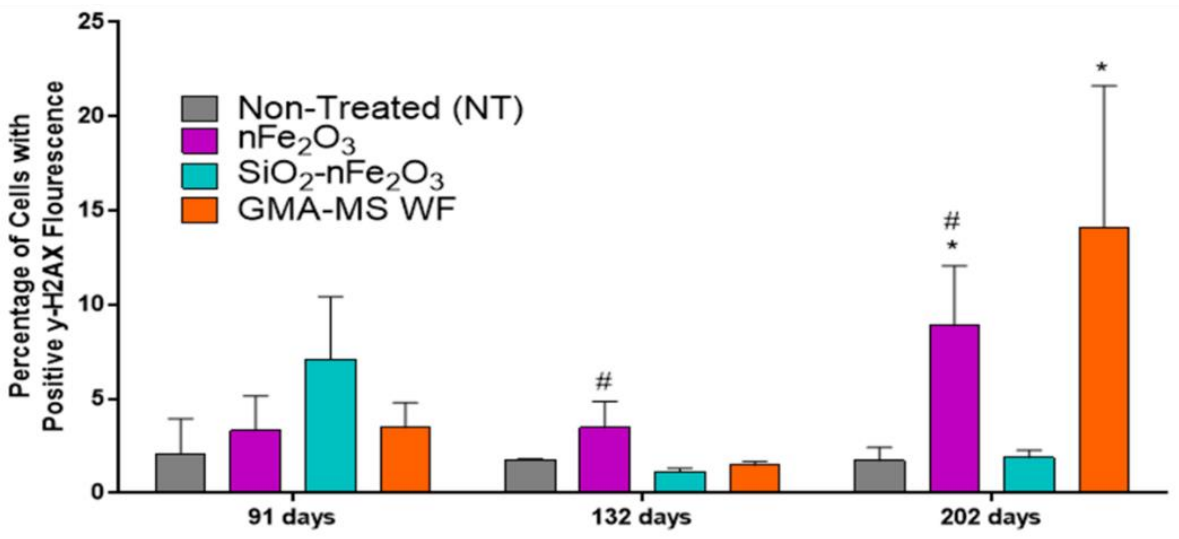

B. 91 Days

C. 132 Days
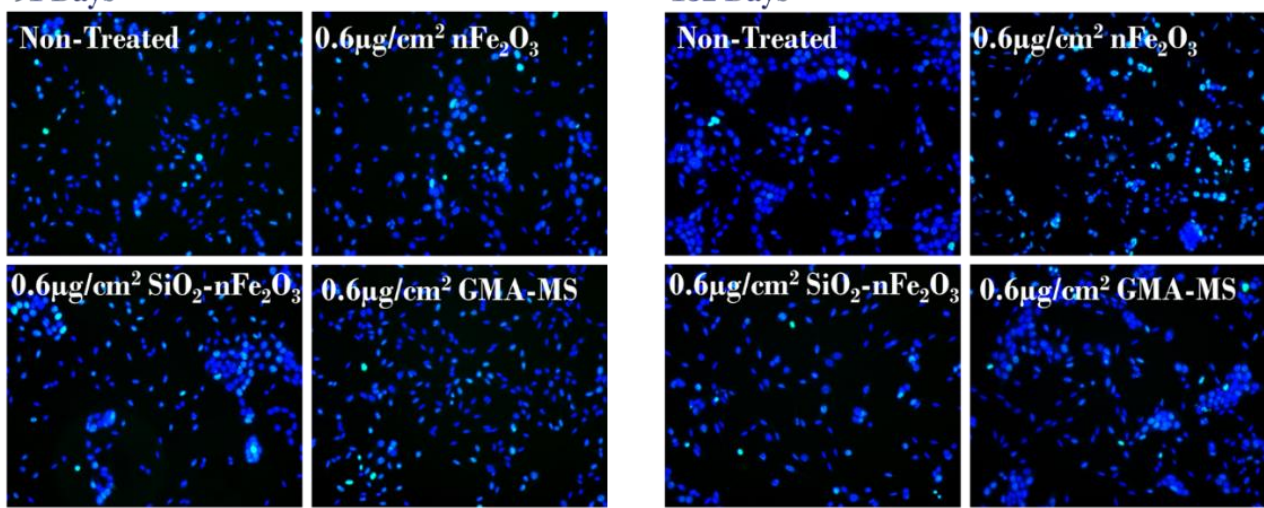

D. 202 Days
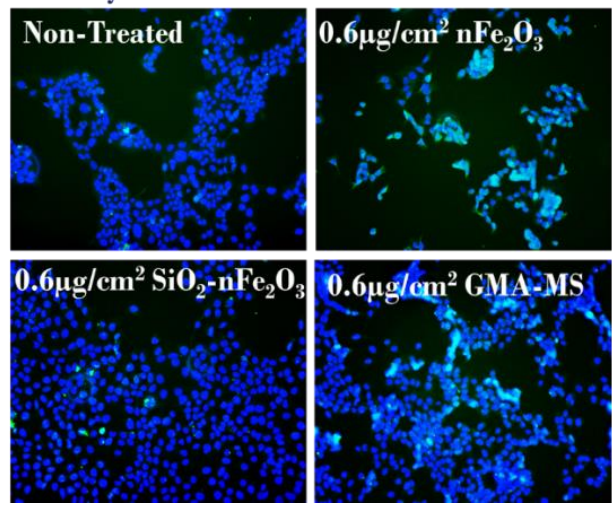

Figure 3-8. Double stranded DNA damage (p- $\gamma \mathrm{H} 2 \mathrm{AX})$ at key points during sub-chronic exposure to 0.6 $\mu \mathrm{g} / \mathrm{cm}^{2}$ of selected particle treatments $\left(\sim 0.58 \mu \mathrm{g} / \mathrm{cm}^{2} \mathrm{nFe}_{2} \mathrm{O}_{3}, \sim 0.54 \mu \mathrm{g} / \mathrm{cm}^{2} \mathrm{SiO}_{2}-\mathrm{nFe}_{2} \mathrm{O}_{3}, \sim 0.57 \mu \mathrm{g} / \mathrm{cm}^{2}\right.$ GMA-MS, $\sim 0.24 \mu \mathrm{g} / \mathrm{cm}^{2} \mathrm{SiO}_{2}$, or $\sim 0.57 \mu \mathrm{g} / \mathrm{cm}^{2} \mathrm{TiO}_{2}$ delivered dose). A) Quantification of integrated intensity of fluorescent signals, representative images of fluorescent staining at B) 91 days, $C$ ) 132 days, and $D) 202$ days continuous exposure. ${ }^{*} \mathrm{p}<0.05$ as compared to non-treated control cells at the same time point. $\# \mathrm{p}<0.05$ as compared to $\mathrm{SiO}_{2}-\mathrm{nFe}_{2} \mathrm{O}_{3}$ exposed cells at same time point. Error bars indicate mean \pm SE $(n=3)$. 
These values, along with hydrodynamic diameter, were used to model particle deposition (Table 3-S1). All particles except for $\mathrm{SiO}_{2}$ had greater than $90 \%$ particle deposition (average fraction deposited) within the first 24 hours following treatment, whereas $\mathrm{SiO}_{2}$ had roughly $70 \%$ deposition (average fraction deposited) by 24 hours following exposure $\left(0.6 \mu \mathrm{g} / \mathrm{cm}^{2}\right.$ administered dose or $\sim 0.42 \mu \mathrm{g} / \mathrm{cm}^{2}$ delivered dose). During the sub-chronic exposure period (6.5 months), particle suspensions in water were freshly prepared every four weeks, and were sonicated before each exposure (every 3-4 days), followed by dilution in BEGM to $0.6 \mu \mathrm{g} / \mathrm{cm}^{2}$ administrated dose. With repeated sonications ( $\leq 8$ times), all particles decreased in average agglomerate hydrodynamic diameter, but deposition remained $>86 \%\left(>0.52 \mu \mathrm{g} / \mathrm{cm}^{2}\right.$ delivered dose for sub-chronic exposures), with the exception of $\mathrm{SiO}_{2}$. For $\mathrm{SiO}_{2}$, agglomerate size and deposition decreased roughly 7-fold over the course of eight repeated sonications.

Qualitative particle uptake by Beas-2B cells was evaluated using TEM (Figure 3-9) following one week of continuous exposure, with two consecutive particle treatments. All particle treatments except $\mathrm{SiO}_{2}$ were clearly shown to be taken up by cells, and were shown encased in membrane bound organelles which were likely endosomes or phagolysosomes.

Particle dissolution of $\mathrm{nFe}_{2} \mathrm{O}_{3}$, GMA-MS, and $\mathrm{SiO}_{2}-\mathrm{nFe}_{2} \mathrm{O}_{3}$ was assessed in sterilized MilliQ water ( $\mathrm{pH}$ 6.40), BEGM ( $\mathrm{pH} 7.46$ ), or a phagolysosome-like buffer ( $\mathrm{pH} 4.55)$ over 72 hours by ICP-OES (Figure 3-10). In both water and $\mathrm{BEGM}, \mathrm{SiO}_{2}-\mathrm{nFe}_{2} \mathrm{O}_{3}$ had the greatest iron release as compared to other particle treatments. In phagolysosome-like buffer, GMA-MS had the greatest iron release, while $\mathrm{nFe}_{2} \mathrm{O}_{3}$ had the least. However, overall particle dissolution was relatively minimal, with the maximum dissolution at only $1.2 \%$ over 72 hours. 

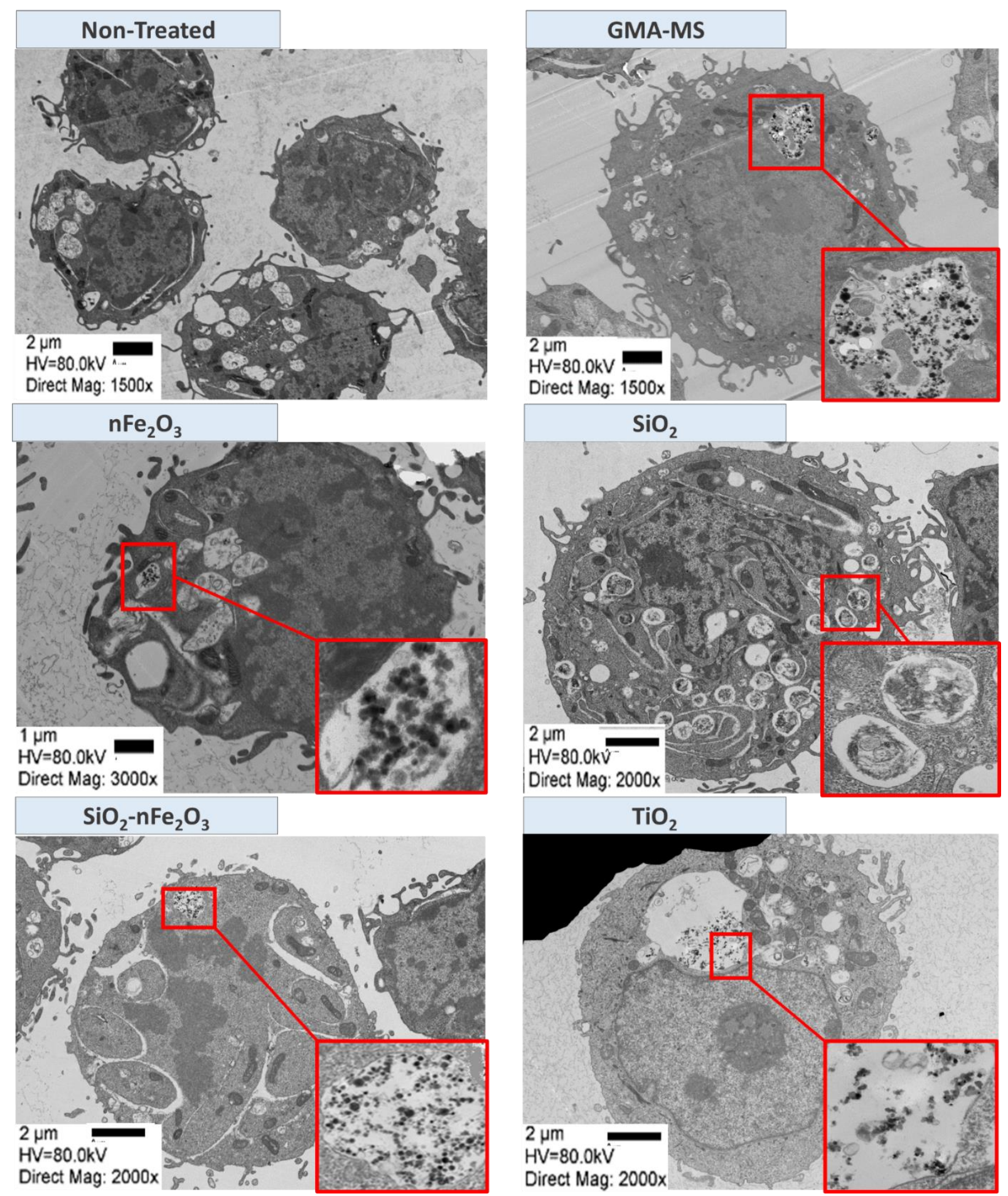

Figure 3-9. Representative transmission electron microscopy (TEM) images of Beas-2B uptake of particles following one week of continuous exposure (two consecutive particle treatments). Arrows refer to location of higher magnification images. 


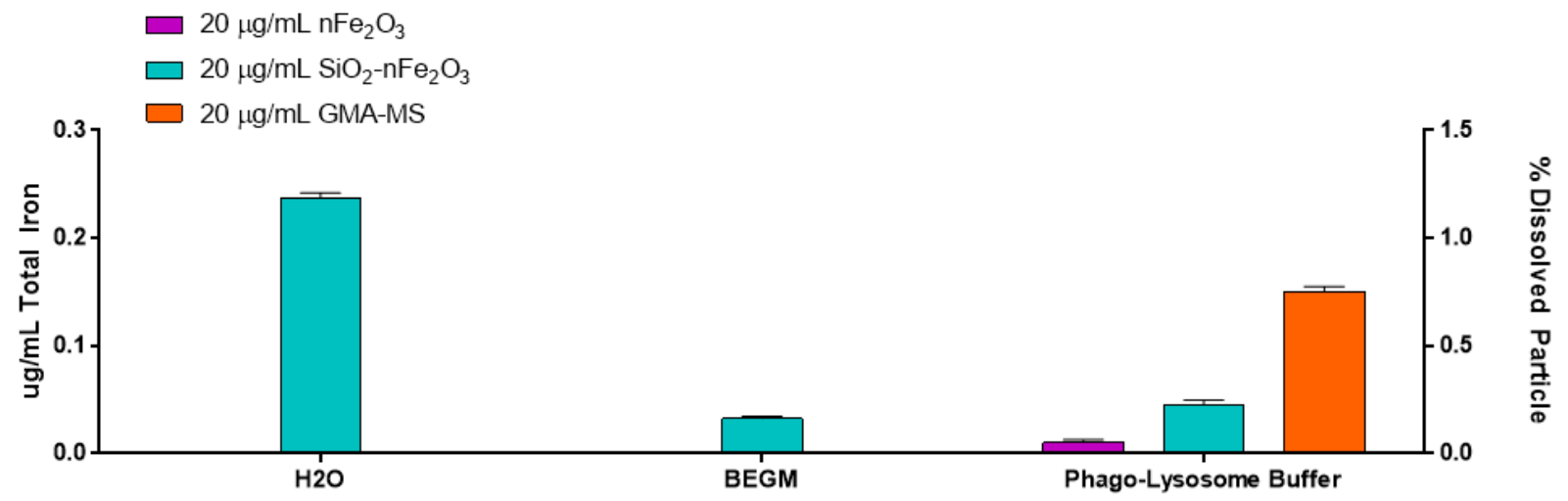

Figure 3-10. Particle dissolution following 72 hours suspension in sterilized water ( $\mathrm{pH} 6.40$ ), complete cell culture medium (BEGM, pH 7.46) or phagolysosome-like buffer ( $\mathrm{pH} 4.55)$ by ICP-OES. Error bars indicate mean $\pm \mathrm{SE}(\mathrm{n}=3)$. Limit of quantification: $0.0283 \mu \mathrm{g} / \mathrm{mL}$; Limit of detection: $0.0089 \mu \mathrm{g} / \mathrm{mL}$, with a maximum of $1.5 \%$ dissolved particle measured over 72 hours. 


\section{3-4. DISCUSSION}

Within the context of a sub-chronic in vitro exposure model, the present study showed a particle type and time dependent neoplastic-like cell transformation. Long-term exposure to $0.6 \mu \mathrm{g} / \mathrm{cm}^{2}$ administered dose $\left(\sim 0.58 \mu \mathrm{g} / \mathrm{cm}^{2}\right.$ delivered dose $)$ of $\mathrm{nFe}_{2} \mathrm{O}_{3}$ induced neoplastic-like transformation in Beas-2B cells beginning at 4-4.5 months, which was associated with decreases in intracellular iron, minimal changes in ROS production, and significantly elevated cell proliferation, colony formation, and double stranded DNA damage. The observed response was similar to that of GMA-MS exposed cells $(0.6$ $\mu \mathrm{g} / \mathrm{cm}^{2}$ administered dose, $\sim 0.57 \mu \mathrm{g} / \mathrm{cm}^{2}$ delivered dose). Conversely, Beas-2B cells exposed to amorphous silica coated $\mathrm{nFe}_{2} \mathrm{O}_{3}$ particles $\left(\mathrm{SiO}_{2}-\mathrm{nFe}_{2} \mathrm{O}_{3}, 0.6 \mu \mathrm{g} / \mathrm{cm}^{2}\right.$ administered dose, $\sim 0.54 \mu \mathrm{g} / \mathrm{cm}^{2}$ delivered dose) did not undergo a neoplastic-like transformation, nor exhibit significant changes in any of the above measured parameters.

Acute assessment of cytotoxicity and ROS production (Figure 3-2) showed that $\mathrm{nFe}_{2} \mathrm{O}_{3}$, GMAMS, and $\mathrm{TiO}_{2}$ exposure induced significantly elevated ROS production at 18 hours, which was maintained through 24 hours for GMA-MS and $\mathrm{TiO}_{2}$ treatments, at the highest dose used $\left(2.0 \mu \mathrm{g} / \mathrm{cm}^{2}\right)$. However, this influx did not have a significant impact on acute cytotoxicity or cell proliferation for $\mathrm{nFe}_{2} \mathrm{O}_{3}$ or GMAMS. There were also no significant changes in intracellular iron (Figure 3-2) across particle treatment groups, although GMA-MS induced a trend of increased intracellular iron at 24 hours post-exposure at both 0.6 and $2.0 \mu \mathrm{g} / \mathrm{cm}^{2}$ administered dose.

Based on the presented acute response, and previous cell transformation data ${ }^{169}$, a sub-toxic administered dose $\left(0.6 \mu \mathrm{g} / \mathrm{cm}^{2}\right)$ was selected for sub-chronic exposure. This dose was also lower than the calculated target tissue dose of IONP in the bronchial region of the lung $\left(1 \mu \mathrm{g} / \mathrm{cm}^{2}{ }^{100}\right)$ with exposure to the OSHA PEL (14 mg/m $\mathrm{m}^{3}$ over 8 hours). Such occupationally relevant low dose/long term exposure is more physiologically representative of occupational and environmental exposure conditions as compared 
to a high dose/acute exposure scenario, and may be more likely to contribute to human development of chronic conditions ${ }^{170}$.

Throughout the sub-chronic exposure period, cells were assessed for neoplastic-like transformation, using cell proliferation (Figure 3-4) and attachment independent colony formation (Figure 3-5) as primary indications. Uncontrolled or dysregulated cell proliferation can indicate some type of abnormal cell phenotype ${ }^{171}$, while soft agar colony formation assay is the recommended technique by OECD to assess continued proliferation when cells are plated in non-adherent conditions ${ }^{164}$, which is a hallmark of abnormal or cancer-like phenotype in cells ${ }^{171}$. Both $\mathrm{nFe}_{2} \mathrm{O}_{3}$ and GMA-MS exposed-cells followed a similar trend of decreased proliferation at roughly 3-3.5 months, which became significantly elevated by 4.5-5 months, and was maintained through the rest of the 6.5-month exposure period. The initial lower proliferation observed in the first few months of exposure may have indicated some type of chronic cell injury or stress, leading to cell adaptation, and ultimately resulting in significantly elevated proliferation and overall cell transformation by the end of the exposure period. The 4.5-5-month time point, when elevated cell proliferation was first observed, coincided with significant elevation of attachment independent colony formation, again indicating particle-induced cell transformation by $\mathrm{nFe}_{2} \mathrm{O}_{3}$ and GMA-MS. For $\mathrm{nFe}_{2} \mathrm{O}_{3}$ exposure, this trend has been previously reported ${ }^{144}$, and at the time was suggested to be attributable to chronic particle injury, which may have resulted in chronically stressed cells and resulting adaptations.

$\mathrm{TiO}_{2}$ exposure induced a similar trend in cell proliferation as GMA-MS and $n F e_{2} \mathrm{O}_{3}$, but without a sustained neoplastic-like transformation. $\mathrm{TiO}_{2}$ exposed cells also showed increased attachment independent colony formation at 4.5-5 months, but this effect was gone by the end of the exposure period, even though cell proliferation remained elevated. This suggested that $\mathrm{TiO}_{2}$ may have the potential to induce cell transformation, but a more transient kind. This is mirrored in the current literature, which has 
shown $\mathrm{TiO}_{2}$ exposure to be associated with in vitro cytotoxicity ${ }^{172,173}$ and in vivo tumorigenesis only at high doses ${ }^{174}$.

$\mathrm{nFe}_{2} \mathrm{O}_{3}$ and GMA-MS-induced cell transformation was hypothesized to be reliant on particleinduced changes in intracellular iron, ROS production, and double stranded DNA damage. It is generally believed that if a particle is engulfed by the cell via phagocytosis or endocytosis, the resulting phagosome will fuse with a lysosome for degradation. Once in this acidic environment, iron-containing particles may dissolve and release free iron ions into the cell's labile iron pool. This increase in catalytically available iron can participate in the Fenton reaction and generate $\operatorname{ROS}{ }^{107,109}$, which is known to induce DNA lesions ${ }^{108}$, and may ultimately result in the observed neoplastic-like phenotype predicted with sub-chronic $\mathrm{nFe}_{2} \mathrm{O}_{3}$ or GMA-MS exposure. Therefore, this proposed mechanism was evaluated using changes in intracellular iron, ROS production, and double stranded DNA damage at key points during the sub-chronic exposure for $\mathrm{nFe}_{2} \mathrm{O}_{3}, \mathrm{SiO}_{2}-\mathrm{nFe}_{2} \mathrm{O}_{3}$, or GMA-MS exposed cells, which, to our knowledge, has not been previously reported for any of these particles. However, our data showed that $\mathrm{nFe}_{2} \mathrm{O}_{3}$ and GMA-MS induced decreased intracellular iron and minimal changes in ROS production, but still induced significant double stranded DNA damage. Therefore, the observed sub-chronic effects were likely not due to an influx of intracellular iron, but rather some kind of alternative mechanism. The minimal changes in ROS production observed by $\mathrm{nFe}_{2} \mathrm{O}_{3}$ and GMA-MS exposed cells align with some previous literature, which has shown human lung adenocarcinoma cells to have minimal oxidative stress response with IONP exposure, even though the exposure still resulted in increased DNA damage ${ }^{175}$. Cadmium, a heavy metal which is a known carcinogen, induced decreased oxidative stress ${ }^{176}$ and minimal changes in related gene expression ${ }^{177}$ with low dose/long term exposure, as well. For cadmium, adaptation and tolerance to oxidative stress were believed to be critical mechanisms involved in its overall toxicity and carcinogenic capacity ${ }^{178}$. Arsenic, another heavy metal, was reported to have a similar effect. Arsenic-transformed Beas-2B cells 
exhibited a decrease in ROS generation, which was posited to be responsible for observed increases in cell growth and colony formation ${ }^{179}$.

However, the underlying mechanism of carcinogenic agent-induced cell transformation is not totally understood. The results presented here, as well as similarly conducted low dose/long term exposure studies suggest other mechanisms involved in the $\mathrm{nFe}_{2} \mathrm{O}_{3}$-induced cell transformation and DNA damage beyond the hypothesized intracellular iron-ROS-DNA damage pathway, such as direct nanoparticle surface interaction with exposed cells, cellular uptake efficiency, and intracellular distribution of the engulfed particles, which we are currently investigating in our lab.

Sub chronic GMA-MS exposure induced a similar response in cells compared to $\mathrm{nFe}_{2} \mathrm{O}_{3}$ treatment. Previous GMA-MS in vivo pulmonary exposure has shown minimal inflammatory or oxidative stress response, and no changes in iron homeostasis markers ${ }^{180}$, even though long term exposure did induce genotoxicity ${ }^{181}$ and tumor formation ${ }^{146}$. This aligns with the presented in vitro GMA-MS induced cell transformation, which occurred without direct increases in intracellular iron or ROS production. GMAMS exposed cells also had a decreasing average number of lysosomes per cell over time (Figure 3-6C), suggesting cellular changes in autophagy, which have been previously shown to act as a protective mechanism in some types of particle-induced cell transformation ${ }^{182}$. Autophagy dysfunction as a potential underlying mechanism is also under further investigation in our lab.

As was hypothesized, compared to $\mathrm{nFe}_{2} \mathrm{O}_{3}$ treatment, $\mathrm{SiO}_{2}-\mathrm{nFe}_{2} \mathrm{O}_{3}$ exposed cells did not show any significant changes in cell proliferation or attachment independent colony formation throughout the subchronic exposure period, and also did not exhibit any significant changes in intracellular iron, ROS production, or DNA damage. This suggested the protective capacity of the amorphous silica coating by reducing overall cell-interaction with $\mathrm{nFe}_{2} \mathrm{O}_{3}$. Many researchers have shown the utility of using a surface coating to alter particle function ${ }^{121-123}$. Previous studies have also shown the potential for an amorphous silica coating to reduce or postpone inflammatory outcomes in vivo with other types of nano-metal oxides 
${ }^{183}$, but this has not been previously shown for $\mathrm{SiO}_{2}-\mathrm{nFe}_{2} \mathrm{O}_{3}$ within the context of a low dose/long term in vitro exposure model, as is presented here. One caveat to this, however, is that the persistence of an amorphous silica coating is unknown. With the present repeated/continuous exposure model, fresh particle with intact amorphous silica coating was used for treatment. However, other in vivo studies which utilized an identical coating on a cerium oxide nanoparticles showed this coating may only last up to ten days in an animal lung ${ }^{50}$.

A complicating factor for in vitro nanotoxicology is the lack of information regarding dosimetry. In the present study, when able to do so, we evaluated how the known administered dose compared to the actual delivered dose of test particles. If known administered dose and calculated delivered dose to the cells vary significantly, this may be able to account for unexpected observed cell response. Particle characterization was done in the present study via DLS (Table 3-1), SEM-EDX, and TEM (Figures 3-1, 3-9) in conditions that replicated those of exposure. Delivered dose of each particle in complete cell culture medium (BEGM) was calculated using the Distorted Grid (DG) dosimetry model. Due to the extended exposure period (6.5 months), particle suspensions in MilliQ water were freshly prepared every four weeks, and sonicated before each particle treatment (every 3-4 days). This repeated sonication $(\leq 8$ times) affected average agglomerate hydrodynamic diameter for particle treatments. However, regardless of hydrodynamic diameter, all test particles except amorphous $\mathrm{SiO}_{2}$ had $>86 \%$ deposition within the first 24 hours after exposure (Table 3-S1). Previous research has shown that particle settling rates are dependent on a complex interplay of each particle's effective density, protein corona formation, and medium composition and viscosity ${ }^{184}$. The cell culture medium used in this study (BEGM) was serum-free and had low density/viscosity. This, combined with the relatively high effective density of the metal-oxide particles resulted in rapid particle deposition regardless of agglomerate size or number of sonications. Amorphous $\mathrm{SiO}_{2}$, however, had a much lower effective density, as well as steadily decreasing agglomerate size with repeated sonications, which resulted in the observed low deposition ( $\leq 70 \%$ after 24 hours). Cells 
treated with amorphous $\mathrm{SiO}_{2}$ did not receive a similar deposited dose as compared to other particle treatments; therefore, no definitive conclusions about the potential toxicity of amorphous $\mathrm{SiO}_{2}$ can made compared to other treatments used in the present study. Information about amorphous $\mathrm{SiO}_{2}$ toxicity can be inferred from previous research, which has shown the overall benign ${ }^{49,185}$ or protective ${ }^{183,185-188}$ qualities of amorphous $\mathrm{SiO}_{2}$, especially when used as a coating for other types of metallic nanoparticles. Furthermore, in the present study, $\mathrm{SiO}_{2}$ coated $\mathrm{nFe}_{2} \mathrm{O}_{3}$ had similar deposition to its uncoated counterpart $\left(\mathrm{nFe} \mathrm{O}_{3}\right)$, resulting in the direct contact of cells with amorphous $\mathrm{SiO}_{2}$, but did not induce neoplastic-like cell transformation, which may further support the potentially protective/benign qualities of amorphous $\mathrm{SiO}_{2}$. However, this example clearly emphasizes the importance of thorough particle characterization before exposure begins, to ensure consistent dosing each time.

\section{3-5. CONCLUSIONS}

Sub-chronic in vitro exposure to $\mathrm{nFe}_{2} \mathrm{O}_{3}\left(\sim 0.58 \mu \mathrm{g} / \mathrm{cm}^{2}\right.$ delivered dose, for 6.5 months $)$ induced a neoplastic-like cell transformation in human lung bronchial epithelial cells (Beas-2B), as characterized by elevated cell proliferation, increased attachment independent colony formation, and induction of DNA damage. An amorphous silica coated but otherwise identical $\mathrm{nFe}_{2} \mathrm{O}_{3}$ particle $\left(\mathrm{SiO}_{2}-\mathrm{nFe}_{2} \mathrm{O}_{3}, \sim 0.54 \mu \mathrm{g} / \mathrm{cm}^{2}\right.$ delivered dose) had markedly diminished neoplastic-like cell transformation, as indicated by no significant changes in any of the parameters described above.

GMA-MS sub-chronic exposure $\left(\sim 0.57 \mu \mathrm{g} / \mathrm{cm}^{2}\right.$ delivered dose $)$ induced a neoplastic-like cell transformation in Beas-2B cells similar to that induced by $\mathrm{nFe}_{2} \mathrm{O}_{3}$ exposure, which was also associated with the induction of double stranded DNA damage, but overall decreased ROS production and no significant changes in intracellular iron. Overall, this suggests that ROS may play a limited and not-critical role in particle-induced neoplastic-like transformation in vitro or carcinogenesis in vivo.

This study provides support for physicochemical property-dependent modes of toxicity for nanometal oxide induced carcinogenic potential, and helps establish "safe by design" hazard reduction 
strategy for emerging nanotechnology. Furthermore, this study gives evidence for the utility of a lowdose/long-term in vitro exposure model to assess risk of cancer-related outcomes for occupationally relevant nano-metal oxide exposures. 


\section{Supplemental Information:}

Table 3-S1: Particle dosimetry with repeated sonications. ${ }^{\text {b }}$

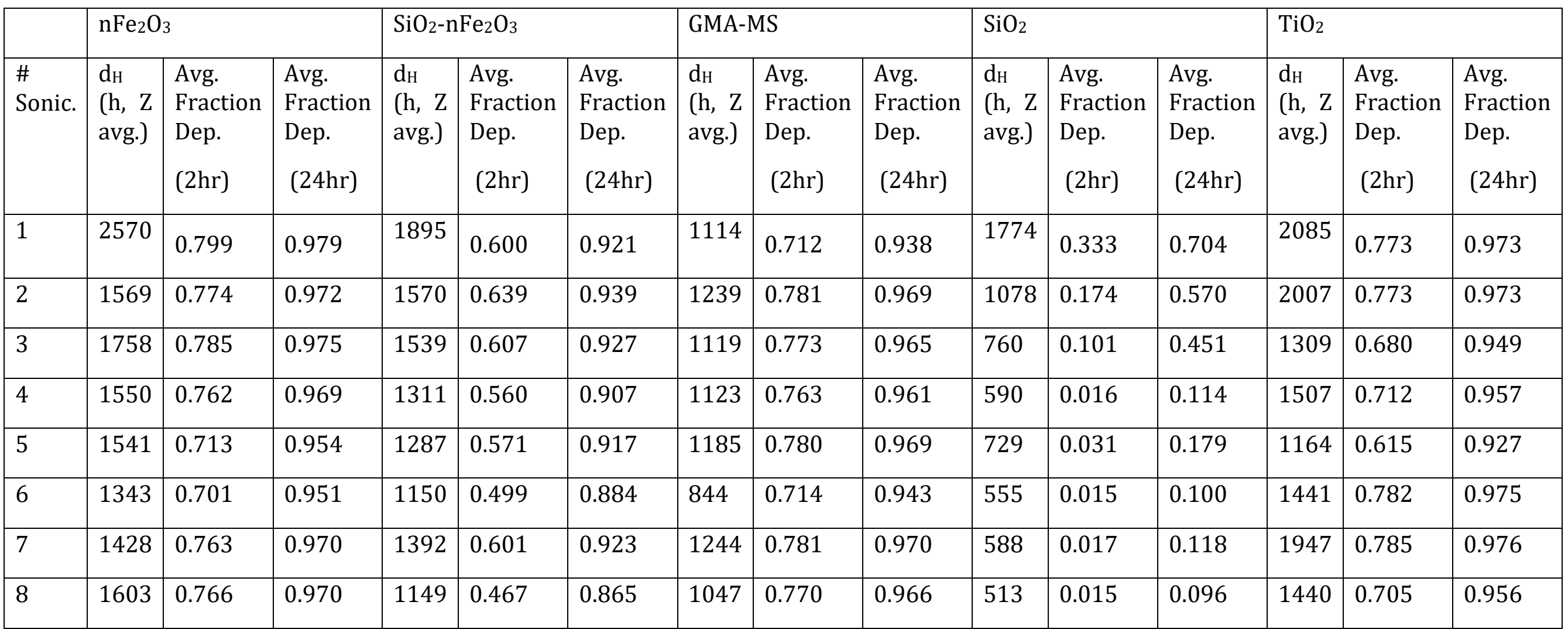

\footnotetext{
${ }^{\mathrm{b}}$ Particle size measured using dynamic light scattering (DLS), and incorporated into distorted grid (DG) fate and transport modeling algorithm. Each repeat sonication was conducted 3-4 days following previous one. Avg: Average. Dep: Deposition. Sonic: sonications.
} 


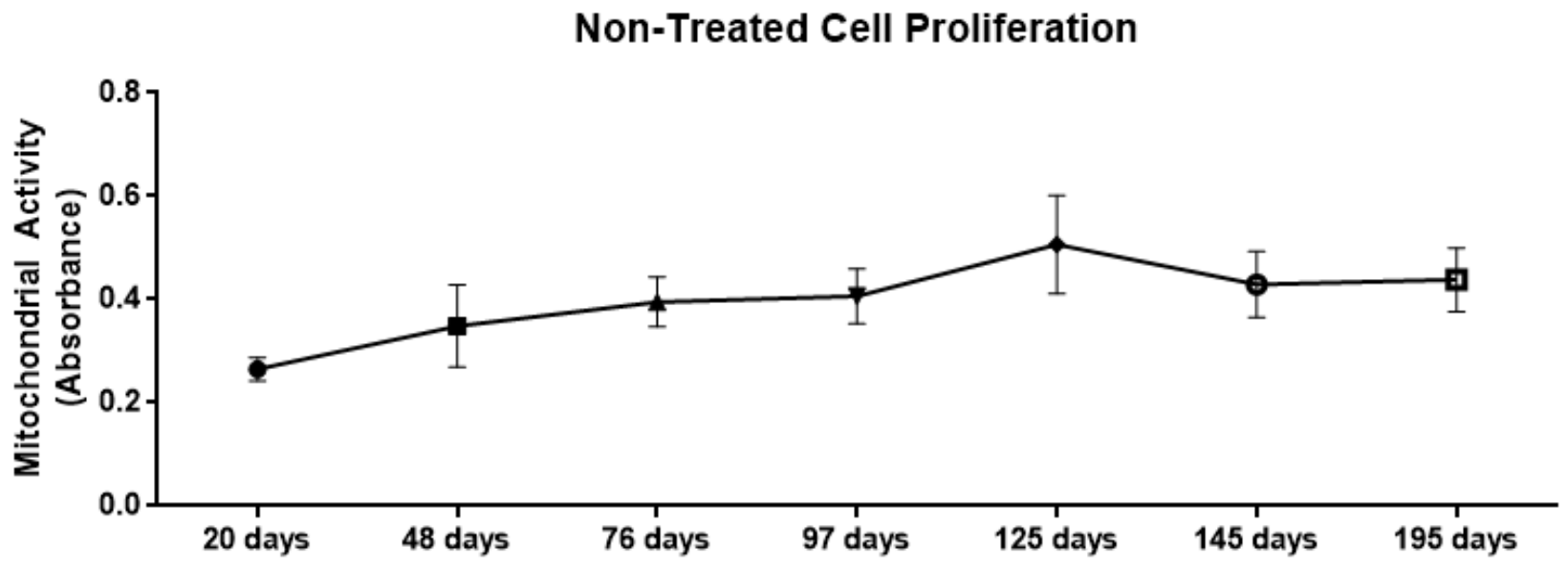

Figure 3-S1. Non-treated cell proliferation throughout sub-chronic exposure, using raw absorbance of WST1 assay as a measurement. There were no significant differences in activity across the exposure period. 


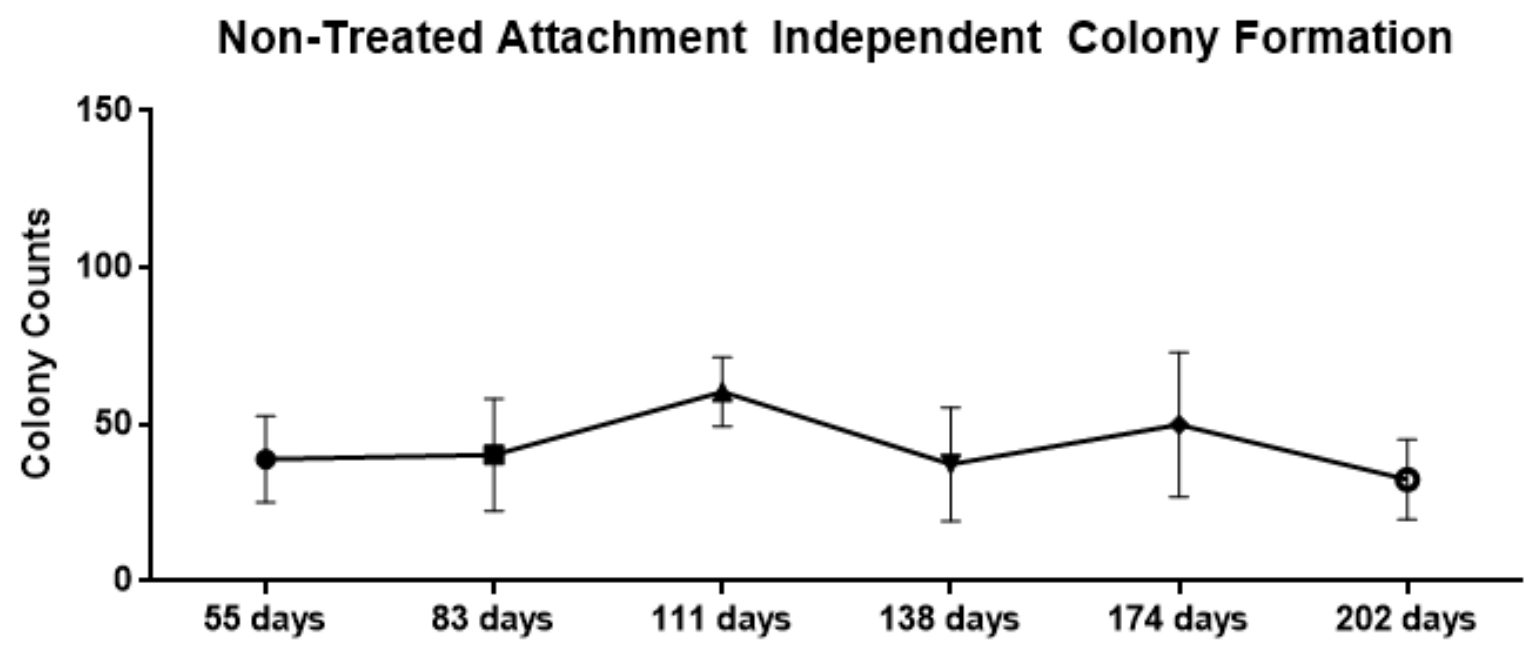

Figure 3-S2. Attachment independent colony formation of non-treated control cells throughout subchronic exposure, shown in raw colony counts. There were no significant differences in this parameter throughout the exposure period. 


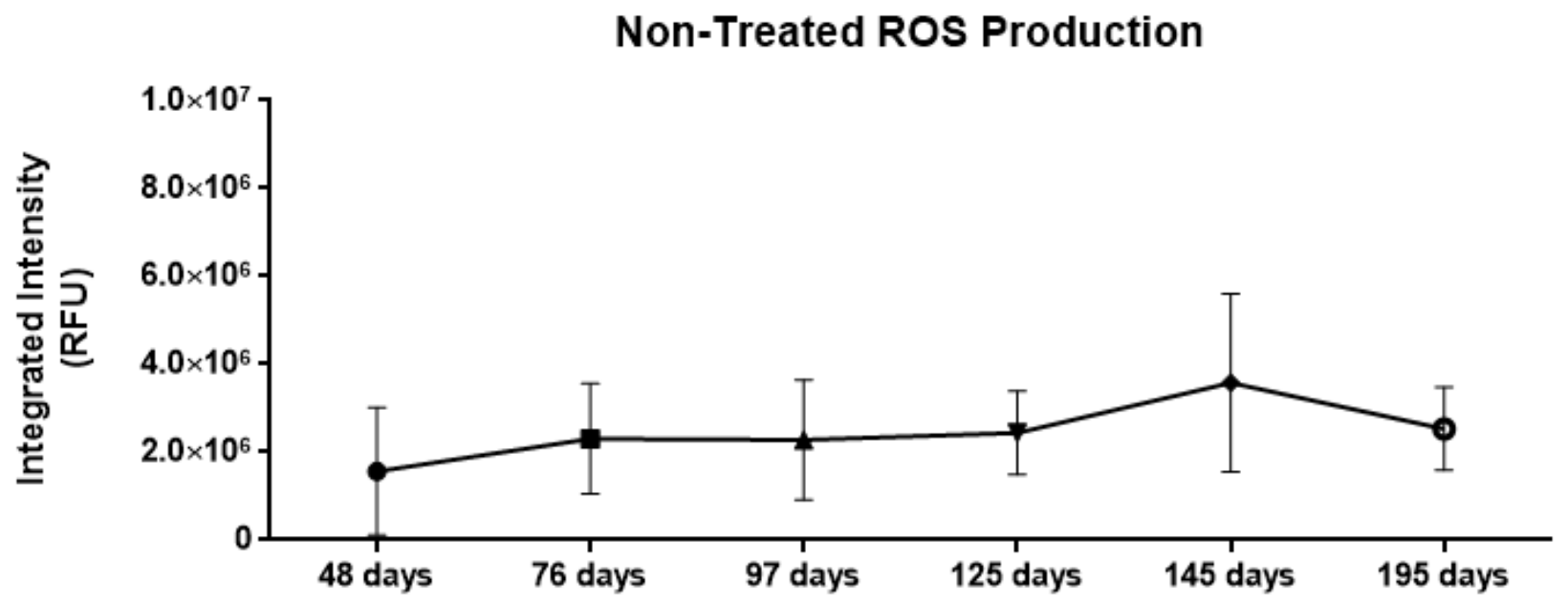

Figure 3-S3. ROS production of non-treated control cells throughout sub-chronic exposure, shown in raw fluorescent units. There were no significant changes in this parameter throughout the exposure period. 


\section{Chapter 4: $\mathrm{nCeO}_{2}$ Induces Size Dependent Changes in Inflammation, Fibrotic Potential, and Hematopoietic Outcomes with In Vivo Pulmonary Exposure.}

\section{Chapter Introduction:}

The overall goal of this research project was to show how the alteration of size as a

physicochemical property may play a role in $\mathrm{nCeO}_{2}$-induced pulmonary inflammation/fibrosis and hematopoietic changes. This study was done in the context of an occupationally relevant in vivo exposure model, with corresponding in vitro studies completed to show the translation and integration of these two types of techniques.

Adapted from: T. Kornberg, D. Davidson, et al., " $\mathrm{nCeO}_{2}$ Induces Size Dependent Changes in Inflammation, Fibrotic Potential, and Hematopoietic Outcomes with In Vivo Pulmonary Exposure," In Review. 


\title{
$\mathrm{nCeO}_{2}$ Induces Size Dependent Changes in Inflammation, Fibrotic Potential, and Hematopoietic Outcomes with In Vivo Pulmonary Exposure
}

\author{
Donna C. Davidson ${ }^{\S}$, Tiffany G. Kornberg ${ }^{\dagger, \S} *$,Todd A. Stueckle ${ }^{\S}$, Raymond Derk ${ }^{\S}$, Philip \\ Demokritoull, Liying W. Rojanasakul ${ }^{\dagger}, \$$
}

${ }^{\S}$ Allergy and Clinical Immunology Branch, Health Effects Laboratory Division, National Institute for Occupational Safety and Health, Morgantown, WV 26505.

`Department of Pharmaceutical and Pharmacological Sciences, School of Pharmacy, West Virginia University, Morgantown, WV 26506.

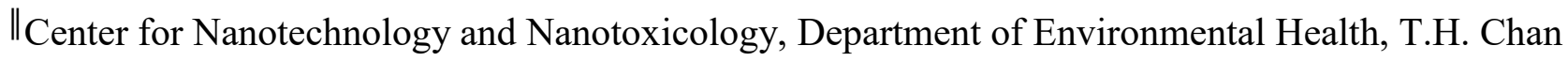
School of Public Health, Harvard University, Boston, MA 02115

* Co-First Authors 


\section{Abstract:}

Nano-sized $\mathrm{CeO}_{2}\left(\mathrm{nCeO}_{2}\right)$ particles have steadily increased in production and use as glass polishing agents, diesel additives, and in other applications. However, there is limited information as to their potential pulmonary toxicity, especially how specific physicochemical properties of $\mathrm{nCeO}_{2}$ may impact particle-induced adverse outcomes. It has been generally suggested that smaller particles may induce more toxicity on a per mass basis due to increased surface area, but this has not been clearly shown with $\mathrm{nCeO}_{2}$. Therefore, the overall goal of this paper was to evaluate potential size dependent toxicity of $\mathrm{nCeO}_{2}$ using chemically identical particles in an in vivo model system with an occupationally relevant dose, and further support this work using a comparable in vitro exposure model. Following oral-pharyngeal aspiration to small $(9.5 \mathrm{~nm})$, medium $(23.7 \mathrm{~nm})$, or large $(119 \mathrm{~nm}) \mathrm{nCeO}_{2}$, male $\mathrm{C} 57 \mathrm{BL} / 6 \mathrm{~J}$ mice were evaluated for markers of inflammation, pulmonary fibrosis, and systemic toxicity at days 1, 7, 28, and 84 post exposure. Results from this study showed that $\mathrm{nCeO}_{2}$ induced a modest size dependent systemic and inflammatory response in vivo, with small $\mathrm{nCeO}_{2}$ (which had 13 times greater surface area than large $\mathrm{nCeO}_{2}$ ) causing a more robust and prolonged response of inflammatory cells and platelet activation, whereas both medium and large $\mathrm{nCeO}_{2}$ induced a more moderate inflammatory response with increased fibrotic potential. A limitation of this study, however, is that a majority of mice were shown to have blocked airways following exposure, likely due to issues with particle dispersion, and may therefore have obscured further size dependent effects.

The present data suggested that the alteration of a particle physiochemical property, such as size, may alter $\mathrm{nCeO}_{2}$-induced bio- and toxic- effects. This could be used to inform future "safe by design" hazard reduction strategy for $\mathrm{nCeO}_{2}$ or other nano-metal oxides, and overall reduce risk for those who may be exposed. 


\section{4-1. Introduction}

Nano-scaled $\mathrm{CeO}_{2}\left(\mathrm{nCeO}_{2}\right)$ particulates have recently surged in use for a broad range of applications, including as glass polishing agents ${ }^{189}$, diesel additives ${ }^{42,43}$, and for development in biological and medical fields ${ }^{41}$. However, despite the influx in production and use of these particles, there is still very limited toxicity information available. Most evidence suggests that $\mathrm{nCeO}_{2}$ has the potential to induce functional changes in alveolar macrophages ${ }^{49}$, resulting in pulmonary inflammation $^{3}$, fibrosis ${ }^{183}$, and chronic lung injury ${ }^{51}$, as well as systemic oxidative stress ${ }^{190}$. For $\mathrm{nCeO}_{2}$, and other types of nanomaterials, it has been suggested that the alteration of specific physicochemical properties may be used to alleviate particle-induced toxicity. Some of these alterations, as part of a "safe by design" hazard reduction strategy, have already been shown to impact $\mathrm{nCeO}_{2}$-induced toxicity. For example, a nano-thin amorphous silica coating can reduce adverse outcomes following $\mathrm{nCeO}_{2}$ exposure both in vivo ${ }^{183}$ and in vitro ${ }^{185}$, and changes in surface charge alterations have been shown to affect overall in vitro cytotoxicity as well ${ }^{191 .}$

The physicochemical property of particle size may also play a critical role in particle-induced toxicity. However, this relationship is poorly understood. Previous studies have suggested that there may be a size dependent factor in toxicity for other types of nano-metal oxides ${ }^{7}$ largely due to differences in surface area with the alteration of size. Some studies have shown that nano- $\mathrm{CeO}_{2}$ has the potential to induce more severe adverse outcomes than "fine" sized $\mathrm{CeO}_{2}$ particulates $(>100$ $\mathrm{nm})^{192}$. However, to our knowledge, there have been no studies which directly study the size dependent effect of $\mathrm{nCeO}_{2}$ toxicity. Furthermore, while size-based conclusions on $\mathrm{nCeO}_{2}$ could be assumed by widely surveying $\mathrm{nCeO}_{2}$ literature, these separate studies may not involve chemically identical - or even similar - $\mathrm{nCeO}_{2}$ particles, thus obscuring any size dependent results.

Therefore, the overall goal of this study was to utilize chemically identical $\mathrm{nCeO}_{2}$ of various sizes to better demonstrate potential $\mathrm{nCeO}_{2}$ induced size dependent toxicity within the context of a 
physiologically relevant in vivo exposure model. We hypothesized that the small $\mathrm{nCeO}_{2}$ particle would induce a more robust inflammatory/pro-fibrotic response due to increased surface area as compared to the medium or large $\mathrm{nCeO}_{2}$ particle. In order to assess this, male $\mathrm{C} 57 \mathrm{BL} / 6 \mathrm{~J}$ mice were exposed to low or high dose (7 or $70 \mu \mathrm{g} /$ mouse) of small $(9.5 \mathrm{~nm})$, medium (23.7 nm), or large (119 nm) $\mathrm{nCeO}_{2}$ particles, with ultrafine $\mathrm{TiO}_{2}(23 \mathrm{~nm})$ as a reference particle control. Following pharyngeal aspiration, mice were sacrificed at $1,7,28$, and 84 days post exposure, and end points related to pulmonary inflammation, fibrosis, and blood platelet activation were assessed. Finally, corresponding in vitro doses were used to evaluate markers of pulmonary fibrosis in normal human lung fibroblasts, to better understand the potential mechanism underlying $\mathrm{nCeO}_{2}$ induced pulmonary toxicity, and show the utility of an in vitro/in vivo integrated approach.

Results from the present study may lend to a growing body of knowledge as to the significant role particle physiochemical properties may play in determining adverse outcomes. If these are better understood, they may be utilized to inform future particle design, and ultimately reduce severity of particle-induced adverse outcomes.

\section{4-2. Methods}

\section{4-2a. In vivo assessment of size dependent $\mathrm{CeO}_{2}$ induced lung inflammation and fibrosis}

\section{4-2a.i. Particle generation and characterization:}

$\mathrm{nCeO}_{2}$ (small, medium, and large) particles were generated at Harvard University Center for Nanotechnology and Nanotoxicology (Boston, MA) using the VEGNES-FSP system ${ }^{150}$ as previously

described. Briefly, the flame spray pyrolysis (FSP) synthesis platform involves the dispersion of organometallic precursors (cerium) and their combustion to form $\mathrm{nCeO}_{2}$. Particle size was controlled via changes in the oxygen dispersion flow rate during particle generation ${ }^{193}$. 
Aeroxide $\mathrm{TiO}_{2}$ (80:20 anatase/rutile structure, Evonik) was supplied from the Degussa Corporation (Parsippany, NJ) and provided by Dr. Tina Sager from CDC/NIOSH (Morgantown, WV). $\mathrm{TiO}_{2}$ particles were sieved three times, and only particulates which were able to pass through all filters $(1.18 \mathrm{~mm}, 250 \mathrm{~nm}$, and $45 \mathrm{~nm})$ were used for treatments.

Particle characterization in pristine powder phase for all three sizes of $\mathrm{nCeO}_{2}{ }^{194}$, and $\mathrm{TiO}_{2}{ }^{153}$ were previously determined as described. For exposures, particles were suspended in sterilized MilliQ water (pharmaceutical grade) at a concentration of $1 \mathrm{mg} / \mathrm{mL}$ in sterilized glass test tubes. Particle suspensions were sonicated with a cup horn sonicator (Sonics Vibra Cell, Newton, CT) based on sonicator efficiency and calculated critical energy needed to generate stable particle agglomerates $\left(\mathrm{CeO}_{2}: 242 \mathrm{~J} / \mathrm{mL}, \mathrm{TiO}_{2}: 161 \mathrm{~J} / \mathrm{mL}\right)$ as previously described 65 .

Particles were further diluted in MilliQ $\mathrm{H}_{2} \mathrm{O}$ for animal treatment, or complete Fibroblast Growth Medium (FGM) for in vitro exposures. Following suspension in MilliQ water, sonication, and serial dilution in complete cell culture media, hydrodynamic diameter $\left(\mathrm{d}_{\mathrm{H}}\right)$ was determined by dynamic light scattering (DLS, ZetaSizer Nano ZS, Model Zen3600, Malvern, Surrey, United

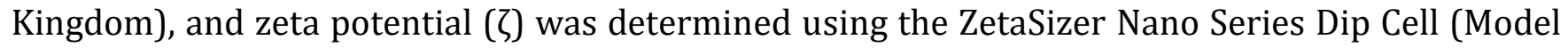
Zen1002, Malvern, Surrey, United Kingdom).

\section{4-2a.ii. Animal Exposures:}

Three-week-old male C57BL/6J mice (Jackson Laboratories, Bar Harbor, ME) were acclimated for three weeks in group housing before exposures began. Animals were provided Harlan 7913 irradiated NIH-31 modified 6\% feed and water ad libitum. Three mice were housed per cage in temperature and humidity-controlled environment, and closely monitored for evidence of fighting or lack of food access. All animal procedures used were reviewed and approved by the National Institute for Occupational Safety and Health's Animal Care and Use Committee. All methods 
were performed in accordance with the relevant guidelines and regulations by AAALAC, and the animal quarters used were AAALAC certified.

Six week old mice were anesthetized with isoflurane (Abbott Laboratories, Chicago, IL), then exposed to low ( $7 \mu \mathrm{g} / \mathrm{mouse})$ or high $(70 \mu \mathrm{g} / \mathrm{mouse})$ dose of small, medium, or large $\mathrm{nCeO}_{2}$, or $\mathrm{TiO}_{2}$ $(\mathrm{n}=12)$ via oral-pharyngeal aspirations, as previously described ${ }^{195}$. Sham control mice were dosed with an equivalent volume of sterilized MilliQ water.

\section{4-2a.iii. Blood platelet number and activity measurement}

At $1,7,28$, and 84 days post exposure, platelet activation was measured using a tail nick assay, which uses time to clot after tail nick as an indication of platelet activity ${ }^{195}$.

An aliquot of whole blood was used for blood cell differential analysis using the ProCyte Dx (IDEXX Laboratories, Westbrook, ME). Remainder of collected blood was centrifuged at $250 \mathrm{xg}$ for 15 min (no brake). "Buffy" coat was collected and centrifuged at $3.2 \mathrm{k}$ rpm for 5 min to separate platelets from platelet-poor plasma. Each fraction was collected, and platelets were lysed with RIPA lysis buffer (ThermoFisher Scientific, Grand Island, NY), then stored at $-80^{\circ} \mathrm{C}$.

\section{4-2a.iv. Collection of blood, bronchial alveolar lavage fluid, and lung tissue.}

The subset of mice used for the platelet activation studies $(n=6)$ were anesthetized and euthanized with isoflurane. Immediately following last breath, blood was collected via cardiac puncture ${ }^{195}$, with acid citrate-dextrose (ACD) used as an anticoagulant. This blood was processed and used for blood cell differential analysis as described above.

Following blood collection (exsanguination used as secondary method for euthanasia), transection of the abdominal aorta was performed, then whole lung was lavaged with cold, sterile, phosphate buffered saline (PBS, ThermoFisher, Grand Island, NY). First lavage (0.8 mL) was centrifuged at $1500 \mathrm{rpm}$ for $5 \mathrm{~min}$, and resulting supernatant was used for cytokine analysis. Three 
more lavages were performed, collected, and pooled with first lavage for cell differential analysis. These bronchial alveolar lavage (BAL) cell pellets were re-suspended in PBS, counted, and fixed via CytoSpin. Briefly, volume containing $1 \times 10^{4}$ cells from each animal was placed into centrifuge funnel with glass slides, and spun at $800 \mathrm{xg}$ for $5 \mathrm{~min}$. Slides were air dried, fixed, and then stained using HEMA 3 Giemsa staining kit (Fisher Scientific, Pittsburgh, PA).

Other subset of mice $(\mathrm{n}=6)$ were euthanized via intraperitoneal injection of $>100 \mathrm{mg} / \mathrm{kg}$ sodium pentobarbital followed by exsanguination. The left lung lobe was formalin-fixed, paraffin processed, and embedded. $5 \mu \mathrm{m}$ sections of lung tissue were prepared for hematoxylin and eosin (H \& E), picosirius red, and masson trichrome staining.

\section{4-2a.v. Evaluation of Lung Inflammation, Injury, and Fibrosis}

Collected BAL fluid was used to assess lung inflammation and injury via lactate dehydrogenase (LDH) activity and inflammatory/pro-fibrotic cytokine profile. LDH activity was measured using Cytotoxicity Detection Kit (Roche, MontClair, NJ) according to manufacturer's instructions.

Cell differentials and macrophage polarization were evaluated using flow cytometry, as previously described 196,197. Briefly, cell suspensions were prepared from BALF fluid, and Fc receptors were blocked to reduce non-specific binding (CD16/32 antibody in Dulbecco's phosphate buffered saline with 5\% fetal calf serum and 0.0005\% sodium azide). For staining, CD45 was used to identify leukocytes, which were further differentiated with CD170/Siglec F, CD11c, and Ly6G staining markers. Macrophage polarization was determined using CD80, CD86, and MHCII staining. Specific lymphocyte markers used were: CD19 for B cells, and CD3e for T cells. All antibodies (BioLegend, San Diego, CA) were used per manufacturer's instructions. After staining, suspensions were fixed (BD CytoFix) for differential analysis of cell populations. Cell populations were evaluated 
and differentiated using a BD LSRII flow cytometer system (BD Biosciences). Analysis of flow cytometry data was conducted using FlowJo v 7.6.5 software (Tree Star, Inc., Ashland, OR).

Cytokine profile was measured using custom Luminex cytokine panel (R\&D Systems, Minneapolis, MN) according to manufacturer's instructions with cytokines: GM-CSF, CXCL-1, TNF $\alpha$, IL-12p70, MCP-1, IL-1b, MIP-2, VEGF, IL-6, IL-10, IL-13, MIP-1a, MMP-9, FGF-basic, Eotaxin, Osteopontin, PDGF, as well as separate total TGF $\beta$ cytokine analysis with ELISA assay following manufacturer's protocol (R\&D Systems). TGF $\beta$ was activated using concentrated hydrochloric acid.

Stained H \& E slides were evaluated for inflammation and airway damage under polarized light. Particle penetration and overall acute inflammatory response were evaluated by a trained veterinary pathologist. Images were taken with an Olympus BX53 microscope and DP73 camera.

\section{4-2b. In Vitro Mechanistic Studies of Size Dependent CeO2 Induced Lung Fibrosis}

\section{4-2b.i. Cell culture}

Normal primary human lung fibroblasts (NHLF) were obtained from Lonza (Walkersville, MD) and cultured in complete Fibroblast Growth Medium (FGM), which is composed of Fibroblast Cell Basal Medium (FBM, Lonza) and all recommended growth supplements $(0.1 \%$ each of insulin, hFGF- $\beta$, and Gentamicin-1000; FGM-2 BulletKit, Lonza). Cells were cultured and maintained at subconfluent densities in a humidified incubator at $37^{\circ} \mathrm{C}$ with $5 \% \mathrm{CO}_{2}$. For each experiment, cells were seeded at density of $2.5 \times 10^{4}$ cells per well in a 24 well plate the day before treatments were performed. Only cells at passage 5-10 were used.

\section{4-2b.ii. Fibroblastic nodule formation and proliferation.}

Glass coverslips were treated with poly-L-lysine $(0.1 \mu \mathrm{g} / \mathrm{mL})$, rinsed, and dried. Then, NHLF were seeded onto the coverslips at a density of $2.5 \times 10^{4}$ cells per well in a 24 well plate, and allowed to adhere overnight. For treatment, nanoparticles were sonicated as previously described, then 
serial diluted in FGM to the desired concentration $\left(0.056\right.$ or $0.56 \mu \mathrm{g} / \mathrm{mL} \sim 0.014$ or $\left.0.14 \mu \mathrm{g} / \mathrm{cm}^{2}\right)$. Fibroblasts were incubated with nanoparticles for 48 hours and fixed in $4 \%$ paraformaldehyde and permeabilized using phosphate buffered saline containing $0.25 \%$ Triton-X 100 . Non-specific binding was blocked with $2 \%$ normal donkey serum and cells were incubated with primary raised against collagen I, followed by fluorescently conjugated secondary antibody. Cover slips were then slowly washed and mounted on glass slides using ProLong Glod Antifade mountant with DAPI. Fluorescent and brightfield images were captured using a Zeiss Axiovert 100 TV inverted microscope (Carl Zeiss Microscopy, LLC, Thornwood, NY). For nodule formation, two cover slides from each culture were analyzed and counted for nodule formation, and data was pooled from three independent replicates. For fibroblast proliferation, images were analyzed for total cell numbers via ImageJ software (Bethesda, MD) by counting the total number of DAPI stained nuclei per 10X field. Four fields were captured per coverslip in duplicate for each of the three independent replicates.

\section{4-2.c. Statistical Analysis.}

Data represents mean \pm standard error of the mean (SE) from three or more biological replicates and four or more technical replicates per biological replicate for in vitro studies, and six biological replicates for the in vivo studies. Samples were normalized to non-treated control for each biological replicate, then combined for all figures. Following normalization, samples were analyzed using a two-way ANOVA with Tukey's post-hoc test for multiple comparisons to determine significance. When treatment groups had different degrees of variance, a Wilcoxon Chi-squared test was used instead. Statistical significance is indicated in each figure as ${ }^{*} \mathrm{p}<0.05,{ }^{* *} \mathrm{p}<0.01,{ }^{* * *} \mathrm{p}<0.001$, and ${ }^{* * * *} \mathrm{p}<0.0001$. All statistical analyses were performed using GraphPad Prism Software (La Jolla, CA). Hierarchical clustering analysis was performed using JMP-SAS Version 13 (Cary, NC).

\section{4-3. Results}


Basic physiochemical properties of all particle treatments were evaluated via BET and XRD (Table 4-1). The three sizes of $\mathrm{nCeO}_{2}$ particles used, small (9.5 nm), medium (23.7 $\left.\mathrm{nm}\right)$, and large (119 $\mathrm{nm}$ ), had surface areas which were inversely proportional to their primary particle size. The small $\mathrm{nCeO}_{2}$ had the greatest surface area $\left(144 \mathrm{~m}^{2} / \mathrm{g}\right)$, which was roughly 13 times greater than that of large $\mathrm{nCeO}_{2}\left(11 \mathrm{~m}^{2} / \mathrm{g}\right)$. $\mathrm{TiO}_{2}$ primary particle size $(23 \mathrm{~nm})$ was comparable to that of medium $\mathrm{nCeO}_{2}$, and therefore likely had similar surface area, although this was not reported. Particle hydrodynamic diameter in the dosing media used (water) was also evaluated. In water, the small $\mathrm{nCeO}_{2}$ had the greatest agglomerate size $(371.6 \mathrm{~nm})$, whereas the large $\mathrm{nCeO}_{2}$ had the smallest agglomerate size $(218.2 \mathrm{~nm})$. Differences in polydispersity index (PDI) indicated that large $\mathrm{nCeO}_{2}$ had the most homogenous agglomerate population $(0.12)$, whereas the larger agglomerate size measured with small $\mathrm{nCeO}_{2}$ was relatively heterogenous in the dosing media used (0.5).

Following particle characterization, $\mathrm{C} 57 \mathrm{BL} / 6 \mathrm{~J}$ mice were exposed to $\mathrm{nCeO}_{2}$ (small, medium, or large) or $\mathrm{TiO}_{2}$ via oral-pharyngeal aspiration at a dose of 7 or $70 \mu \mathrm{g} /$ mouse $(0.35$ or $3.5 \mathrm{mg} / \mathrm{kg})$. A dose of $7 \mathrm{mg} / \mathrm{kg}$ is roughly equivalent to a 40-year occupational exposure to diesel exhaust ${ }^{49}$, and previous literature has shown doses as low as $0.15 \mathrm{mg} / \mathrm{kg}$ can induce pulmonary inflammation in rats $^{86}$. At 1, 7, 28, and 84 days post exposure, platelet activity was measured, then bronchial alveolar lavage (BAL) fluid was collected and evaluated for markers of lung injury and inflammation.

LDH enzymatic activity was used as an initial indicator of lung injury or damage. There were no significant changes in LDH activity across treatment groups throughout the exposure period (Figure 4-1). However, overall LDH activity increased roughly 5-fold from days one through twentyeight to day eighty-four for all treatment groups.

Inflammatory cell infiltration and differentials were used to indicate the specific nature of particle induced inflammatory response (Figure 4-2). The high dose of both small and medium nCeO 2 , as well as the high dose of $\mathrm{TiO}_{2}$, induced significant neutrophil infiltration and decreased 
alveolar macrophages at one day post exposure. For high dose of small $\mathrm{nCeO}_{2}$ and $\mathrm{TiO}_{2}$, the macrophage response was sustained through seven days, but resolved by 28 days post exposure.

BAL alveolar macrophages were further differentiated based on activity and polarization (Figure 4-3). CD80 and CD86 are co-stimulatory molecules which, when bound to CD28, are heavily involved in the regulation of $\mathrm{T}$ cell activation for subsequent immune response ${ }^{198}$. MHC II is also a marker of macrophage activation, and is essential for both M1 (classically activated) and M2 (alternatively activated) macrophage polarization ${ }^{199}$.

The high dose of small $\mathrm{nCeO}_{2}$ induced significantly elevated MHC II and CD80 expression at days 1,7 , and 28 post exposure. Mice exposed to the high dose of $\mathrm{nTiO}_{2}$ had significantly elevated MHC II and CD80 at one day post exposure, with increased MHC II sustained through seven days. The high dose of medium $\mathrm{nCeO}_{2}$ induced significantly elevated $\mathrm{MCH}$ II at seven days post exposure only. There were no corresponding changes in CD86 across treatment groups at any time point measured.

The specific nature of the inflammatory/pro-fibrotic response in the lung was analyzed using collected BAL fluid to test for a panel of 16 cytokine markers: GM-CSF, CXCL-1, TNF $\alpha$, IL-12p70, MCP-1, IL-1b, MIP-2, VEGF, IL-6, IL-10, IL-13, MIP-1a, MMP-9, FGF-basic, Eotaxin, Osteopontin, and TGF $\beta$ (Figure 4-4). The inflammatory cell response to particle exposure involves the release of specific cytokines and mediators in a highly complex process to initiate and sustain the inflammation. MIP- $1 \mathrm{a}^{200}$ and GM-CSF${ }^{201}$ are involved in initial monocyte recruitment and activation into macrophages. IL-6 is further involved in macrophage activation and phenotype polarization 202,203. Activated/polarized macrophages and other inflammatory cells will release TNF- $\alpha^{204}$, which is an established marker of inflammation. These macrophages may also secrete MIP-2, which mediates the neutrophil inflammatory response ${ }^{205}$. CXCL-1 production will stimulate the 
infiltration of neutrophils to the site of injury ${ }^{206}$, and these activated neutrophils can secrete MMP9207 , which is vital for extracellular matrix remodeling following lung injury ${ }^{208}$.

The high dose of small nCeO2 induced significantly upregulated MIP-1a, GM-CSF, CXCL-1, and VEGF, and IL-6 at one day post exposure, with increased MIP-1a, GM-CSF, and CXCL-1 sustained through seven days, and MIP-1a sustained through 28 days. At seven days post exposure, TNF $\alpha$, MIP-2, Osteopontin, TGF $\beta$, and MMP9 were also up-regulated, with the increase in MMP-9 sustained through 28 days post exposure. There were no significant elevations in any of these cytokines with the high dose of small $\mathrm{nCeO}_{2}$ by 84 days post exposure.

Low and high doses of medium and large $\mathrm{nCeO}_{2}$, as well as high dose of $\mathrm{nTiO}_{2}$, induced significantly elevated TGF $\beta$ at 28 days post exposure. The low dose of medium nCeO $\mathrm{O}_{2}$ also induced significantly up regulated IL-6 at this same time point. There were no other significant changes in these parameters at any of the time points measured.

Time to clot was used as a measure of platelet activation (Figure 4-5). All particle treatments induced significantly reduced bleed times at one- and seven-days post exposure. At day 28 , only mice exposed to the high dose of small $\mathrm{nCeO}_{2}$ or low dose of medium $\mathrm{nCeO}_{2}$ sustained the significantly reduced bleed times. By day 84 , there were no significant changes in bleed times across treatment groups.

The inflammatory response indicated in the BAL fluid was further evaluated via the physical characteristics of collected lung tissue (Figure 4-6). Particle penetration into the deep lung and overall acute inflammatory response were evaluated by a trained veterinary pathologist. The high dose of all treatment particles induced physical changes in the lung at one day post exposure. On average, roughly half of treated mice were observed to have particle present in the deep lung, and many had blocked airways. Other time points were not evaluated for histopathologic changes due to issues with particle penetration and observed blocked airways of some animals. Histopathology 
slides were also stained with Sirius Red to evaluate collagen as a potential pro-fibrotic marker, but showed no significant difference between treatment groups across time points (data not shown).

Despite the value of in vivo assessments for potential inflammation and fibrosis, there is a critical need for more rapid and cost-effective in vitro methods to evaluate these types of end points. In vitro model systems also allow for a better elucidation of the potential mechanism underlying particle-induced pulmonary effects, if they can be adequate and predictive of an in vivo response. Therefore, we translated our in vivo exposure model to a comparable in vitro system, for a better determination of potential size dependent $\mathrm{nCeO}_{2}$ induction of inflammatory/pro-fibrotic outcomes.

Inhalation of foreign particle may result in direct exposure and stimulation of alveolar fibroblasts $^{209}$. Excessive proliferation, nodule formation, and collagen production by these cells may ultimately induce fibrotic pathology. To assess this in vitro, normal human lung fibroblasts were exposed to equivalent particle dose as the previous in vivo exposure, and fibroblast nodule formation and proliferation were evaluated.

Low and high doses of medium and large $\mathrm{nCeO}_{2}$, as well as the low dose of $\mathrm{TiO}_{2}$, induced significantly elevated fibroblast proliferation, but with no significant changes in nodule formation (Figure 4-7).

\section{4-4. Discussion}

The overall goal of this study was to evaluate size dependent toxicity of $\mathrm{nCeO}_{2}$ on pulmonary inflammation and systemic platelet response. The physicochemical properties of nCeO2, such as surface coating or charge, have been previously shown to have an impact on subsequent adverse outcomes $^{48,183,185}$. Size, which is inverse of surface area, is generally known to play a role in severity of particle-induced response for other types of nano-metal oxides ${ }^{7}$, but this has not been well characterized for $\mathrm{nCeO}_{2}$. If specific properties, such as size/surface area, were identified which may 
have the greatest impact on $\mathrm{nCeO}_{2}$ toxicity, such information could be used to inform particle design, and overall reduce risk for those who may be exposed.

All three sizes of $\mathrm{nCeO}_{2}$ used here (small: $9.5 \mathrm{~nm}$, medium: $23.7 \mathrm{~nm}$, large: $119 \mathrm{~nm}$ ) induced an inflammatory response; the small sized $\mathrm{nCeO}_{2}$ induced a more robust and prolonged response, whereas medium and large sized $\mathrm{nCeO}_{2}$ induced a milder response with potential increased profibrotic capacity.

The overall cytotoxic response of three sizes of $\mathrm{nCeO}_{2}$ following in vivo exposure showed no significant changes in LDH activity (Figure 4-2). However, LDH release is increased roughly fivefold from days 1 through 28 to day 84 post exposure. Previous studies have shown $\mathrm{nCeO}_{2}$ does not induce a very robust LDH response, especially when particle dispersion is poor ${ }^{210}$.

Despite the low cytotoxic response, $\mathrm{nCeO}_{2}$ did induce a size dependent inflammatory response as indicated in collected $\mathrm{BAL}$ fluid (Figure 4-3). $\mathrm{Small}_{\mathrm{nCeO}}$ induced acute neutrophil infiltration, alveolar macrophage mediated inflammation, and platelet activation (Figures 4-3, 4-5). Exposure to this particle also induced significant elevation of inflammatory cytokines related to monocyte recruitment and activation (MIP-1a, GM-CSF), activated macrophages (TNF $\alpha$, MIP-2), and the infiltration and activation of neutrophils (CXCL-1, MMP-9) (Figure 4-5). This aligned with previous literature, which has shown that $\mathrm{nCeO}_{2}$ of varying sizes $(8-55 \mathrm{~nm})$ can induce a robust neutrophil response at early time points post exposure ${ }^{51,211,212}$. Previous research has also shown the capacity for $\mathrm{nCeO}_{2}$ to induce a chronic pro-inflammatory response ${ }^{51,211,212}$, as well as elevation of specific inflammatory markers (IL-12, IL-6, TGF $\beta$ ) at higher doses ${ }^{213}$, or other types of inflammatory markers $(\mathrm{TNF} \alpha, \mathrm{IL}-1 \beta)$ at lower $\operatorname{doses}^{45}$, all of which aligned with the research presented here. Clustering analysis of cytokines and treatment groups also revealed the high dose of small $\mathrm{nCeO}_{2}$ induced a specific and unique inflammatory response at 1 - and 7-days post exposure, as compared to other particle treatment groups or $\mathrm{H}_{2} \mathrm{O}$-treated control group. 
Small $\mathrm{nCeO}_{2}$ also induced significant changes in macrophage polarization, as indicated by changes in markers MHC II and CD80, although these did occur without corresponding changes in CD86 (Figure 4-4). Previous research has shown $\mathrm{CeO}_{2}$ exposure will activate $\mathrm{M} 1$ polarization in alveolar macrophages ${ }^{49}$, although typically CD80 and CD86 work in a co-stimulatory manner ${ }^{214,215}$, which was not shown here. This suggested M1 polarization was at least partially induced by small $\mathrm{nCeO}_{2}$ in a way other than this co-stimulatory mechanism, or that the negative population used to evaluate $\mathrm{CD} 86$ was not sufficient. Small $\mathrm{nCeO}_{2}$-induced inflammatory response was sustained through 28 days post exposure, and was resolved by 84 days post exposure.

Both the medium and large $\mathrm{nCeO}_{2}$ induced a milder inflammatory response, which was most apparent at later time points ( 7 and 28 days). Medium $\mathrm{nCeO}_{2}$ induced significantly elevated MHC II marker in alveolar macrophages at 7 days post exposure, and an overall influx of these macrophages, as well as increased IL- 6 and TGF $\beta$ expression, at 28 days post exposure, all of which was resolved by 84 days. Although these particles did not induce a very robust inflammatory response, both doses of medium and large $\mathrm{nCeO}_{2}$ induced significantly elevated fibroblast proliferation in vitro (Figure 4-7), which is often involved in the development of pulmonary fibrosis ${ }^{185}$. $\mathrm{CeO}_{2}$ has been generally considered to be a pro-fibrogenic agent, due to hypothesized inflammasome activation and production of pro-fibrogenic growth factors 216,217 . However, none of the particle treatments used in the present study induced significant nodule formation, or in vivo collagen production, both of which are also indications of fibrotic potential. Therefore, it was likely that the fibrotic potential of medium and large $\mathrm{nCeO}_{2}$, while existent, was very mild in this mouse model.

$\mathrm{TiO}_{2}$, which was used as a reference particle control, also induced a comparatively robust inflammatory response, the majority of which was sustained through 7 days post exposure. $\mathrm{TiO}_{2}$ exposure induced significant increases in expression of MHC II and CD80 macrophage markers one 
day post exposure, with MHC II remaining elevated through day 7 (Figure 4-4). However, because this response was not prolonged, and not coupled with an increase in CD86, this effect was likely transient and not necessarily indicative of the overall inflammatory response. $\mathrm{TiO}_{2}$ also induced a TGF $\beta$ mediated inflammatory response at 28 days post exposure (Figure 4-5), as well as significant increase in overall alveolar macrophage number at day 84 (Figure 4-3). TGF $\beta$ has been linked to pro-fibrotic outcomes 218 , which aligned with presented in vitro results (Figure 4-7), that showed increased fibrotic potential in $\mathrm{TiO}_{2}$-exposed cells, as indicated by the observed increase in fibroblast proliferation. Previous literature has associated in vivo $\mathrm{TiO}_{2}$ exposure with mild to moderate pulmonary fibrosis ${ }^{219}$, although there have been no clear links with $\mathrm{TiO}_{2}$ exposure and development of fibrosis in workers 220 .

Exposure to any treatment group caused significant platelet activation at one- and sevendays post exposure (Figure 4-5). A growing body of research has shown that platelets, which are typically involved in a clotting response to injury 221 , may play a critical role in response to pulmonary exposure to particles ${ }^{222}$. Macrophages can secrete a platelet activating factor ${ }^{223}$, which will activate platelets for inflammatory response. Ultra-fine particles have been shown to enhance peripheral thrombosis via platelet activation ${ }^{224}$, as can the rapid translocation of ultra-fine particles to the circulatory system following pulmonary exposure 224,225 , for direct interaction between particle and platelets ${ }^{225}$. Some recent studies have shown platelet activation may occur in a nanoparticle-specific way, with pulmonary exposure to carbon-based nanomaterials inducing a different type or severity of platelet response than nano-metal oxides ${ }^{226}$. In the present study, we showed that all particle treatments induced acute platelet activation, and the identification of specific biomarkers would allow for a less-invasive test to evaluate potential exposure in humans.

The present study showed a clear, albeit modest, size-dependent toxicity of $\mathrm{nCeO}_{2}$ using chemically identical particles, generated using the Harvard VEGNES-FSP system, which maintains 
chemical structure but alters particle size via changes in oxygen dispersion flow rate ${ }^{227}$. Size dependent differences in particle-induced adverse outcomes observed in the present study were likely related to corresponding changes in surface area and particle deposition. Small nCeO $\mathrm{Sad}_{2}$ surface area which was roughly 13 times larger than that of the large sized $\mathrm{nCeO}_{2}$ (Table 1). Particle size/surface area may also affect how and where a particle is deposited in the lung, which can in turn impact the subsequent response. In fact, surface area has been previously shown to play the most critical role in severity of particle-induced adverse outcomes ${ }^{228}$ as compared to other particle characteristics. Although histopathology showed that all particle exposures induced physical changes in the lung, only about half of treated mice were observed to have particle present in the deep lung (Figure 4-6), and a majority of mice were observed to have blocked airways/upper respiratory tracts. Generally, a critical concern has been particle-size dependent deposition into the deep lung. Previous studies have shown upper airway deposition of particle is more likely to induce acute health effects, whereas deep lung particle deposition is more likely to contribute to chronic adverse health effects, such as fibrosis ${ }^{229}$.

\section{4-5. Conclusion:}

The present results showed a modest size dependent factor to $\mathrm{nCeO}_{2}$ induced pulmonary inflammation. The small size $\mathrm{nCeO}_{2}(9.5 \mathrm{~nm})$, which had a surface area roughly 13 times greater than that of the largest sized $\mathrm{nCeO}_{2}$ used $(119 \mathrm{~nm})$, induced a more robust inflammatory response. Mice exposed to small $\mathrm{nCeO}_{2}$ had neutrophil infiltration, macrophage activation, and the upregulation of inflammatory and pro-fibrotic cytokines in the lung, which was sustained through 28 days post exposure, while both medium $(23.7 \mathrm{~nm})$ and large $(119 \mathrm{~nm}) \mathrm{nCeO}_{2}$ induced a milder inflammatory response. However, issues with blocked airways, which was observed for a majority of exposed animals, may have obscured actual size dependent toxicity of this particle. 
Overall, our results clearly indicate the significant role particle physicochemical properties, such as size, may play in particle-induced adverse outcomes. If these properties are better understood, they may be used to inform future particle design, and ultimately protect those who may be at risk of exposure. 
Table 4-1: Colloidal/physicochemical characterization of dispersed nanoparticles. Primary particle size as determined by X Ray diffraction $\left(\mathrm{dxRD}_{\mathrm{XR}}\right)$, surface area (SSA), hydrodynamic diameter $\left(\mathrm{d}_{\mathrm{H}}\right)$, zeta potentials $(\zeta)$, iron/iron oxide content, polydispersity index (PDI), raw material density ( $\left.\rho_{\mathrm{ENM}}\right)$, and agglomerate effective density $\left(\rho_{\mathrm{EV}}\right)$ of all particle treatments in complete cell culture media (BEGM). nd: no data. dBET for nTiO2 determined previously²30.

\begin{tabular}{|c|c|c|c|c|c|c|c|c|c|}
\hline & $\mathrm{dXRD}(\mathrm{nm})$ & dBET (nm) & $\operatorname{SSA}\left(\mathrm{m}^{2} / \mathrm{g}\right)$ & $\begin{array}{l}\mathrm{dH}(\mathrm{nm}, \\
\text { water) }\end{array}$ & $\begin{array}{l}\text { PDI } \\
\text { (water) }\end{array}$ & $\begin{array}{l}\zeta \text { potential } \\
\text { (mV, } \\
\text { water) } \\
{[\mathrm{pH}]}\end{array}$ & $\begin{array}{l}\mathrm{dH}(\mathrm{nm}, \\
\text { FGM) }\end{array}$ & $\begin{array}{l}\zeta \text { potential } \\
(\mathrm{mV}, \mathrm{FGM}) \\
{[\mathrm{pH}]}\end{array}$ & PDI (FGM) \\
\hline $\begin{array}{l}\text { Small } \\
\mathrm{nCeO}_{2}\end{array}$ & 9.5 & 13.8 & 144 & 371.6 & 0.5 & 17.4 [6.09] & 591.8 & $-9.5[7.42]$ & 0.64 \\
\hline $\begin{array}{l}\text { Medium } \\
\mathrm{nCeO}_{2}\end{array}$ & 23.7 & 33.6 & 59 & 274.3 & 0.57 & 32.8 [6.52] & 373.2 & $\begin{array}{l}-10.4 \\
{[7.42]}\end{array}$ & 0.50 \\
\hline $\begin{array}{l}\text { Large } \\
\mathrm{nCeO}_{2}\end{array}$ & 119 & 180 & 11 & 218.2 & 0.12 & 12.5 [6.53] & 311.6 & -10.7 [7.5] & 0.09 \\
\hline $\mathrm{TiO}_{2}$ & 23 & 29.3 & nd & 344.2 & 0.46 & 11.8 [7.12] & 448.4 & $-9.3[7.48]$ & 0.41 \\
\hline
\end{tabular}


Day 1 BALF LDH

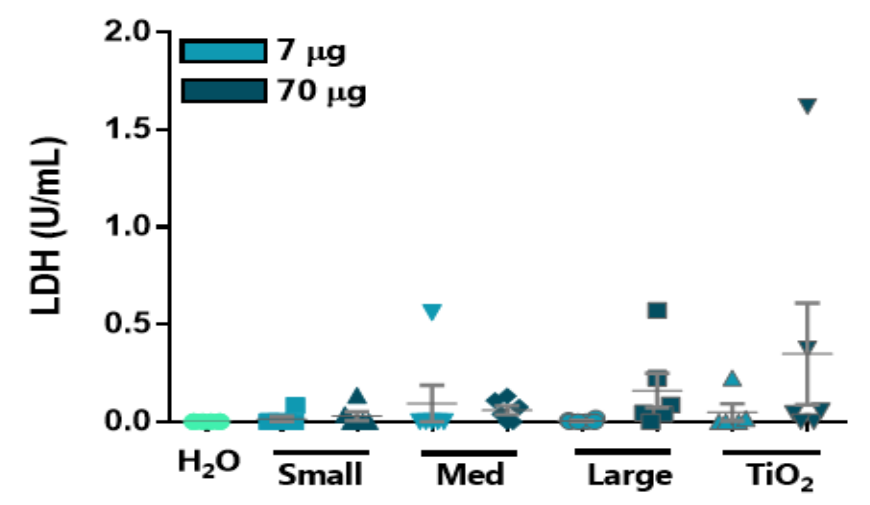

Day 28 BALF LDH

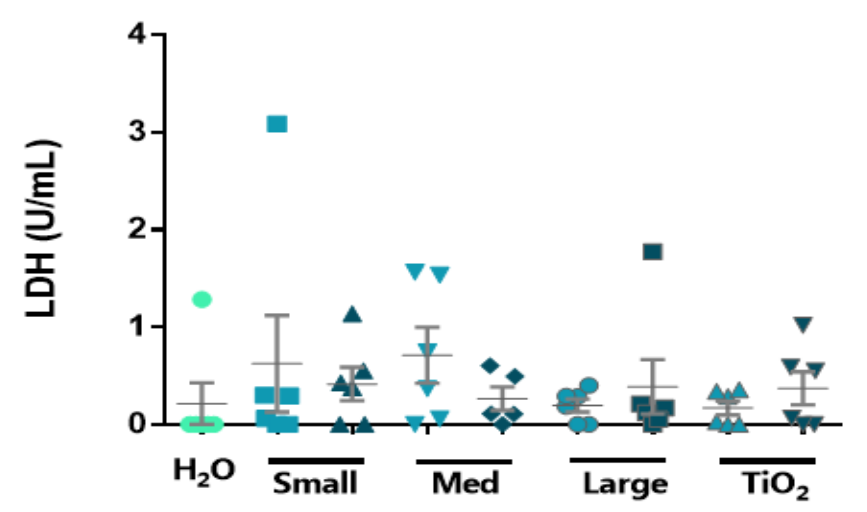

Day 7 BALF LDH

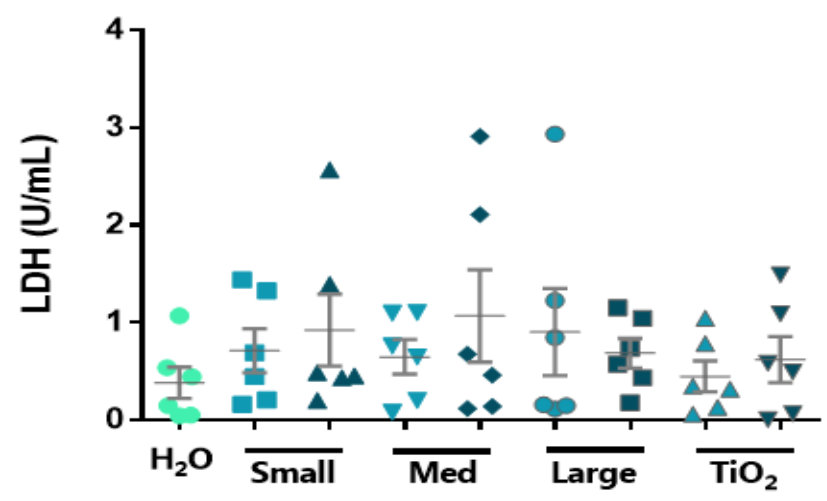

Day 84 BALF LDH

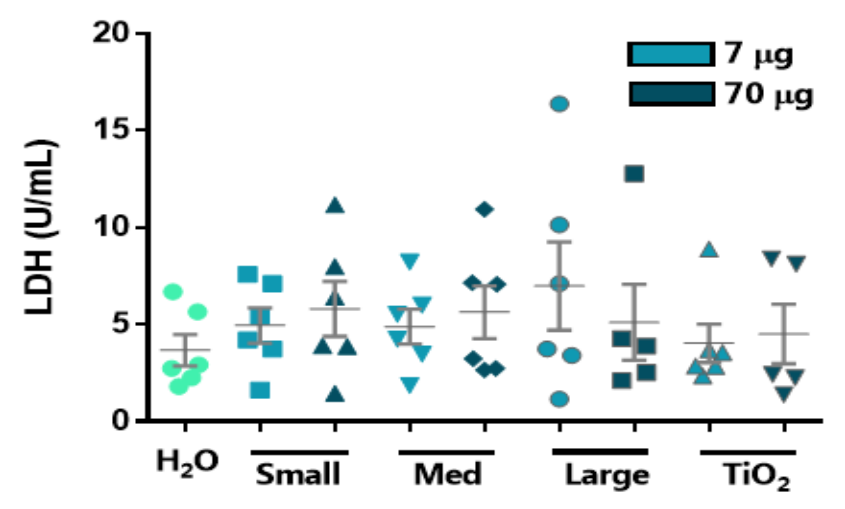

Figure 4-1: Lactic acid dehydrogenase (LDH) activity measured from bronchioalveolar lavage fluid collected at 1, 7, 28, and 84 days continuous exposure. Error bars indicate mean $\pm S E(n=6)$. 


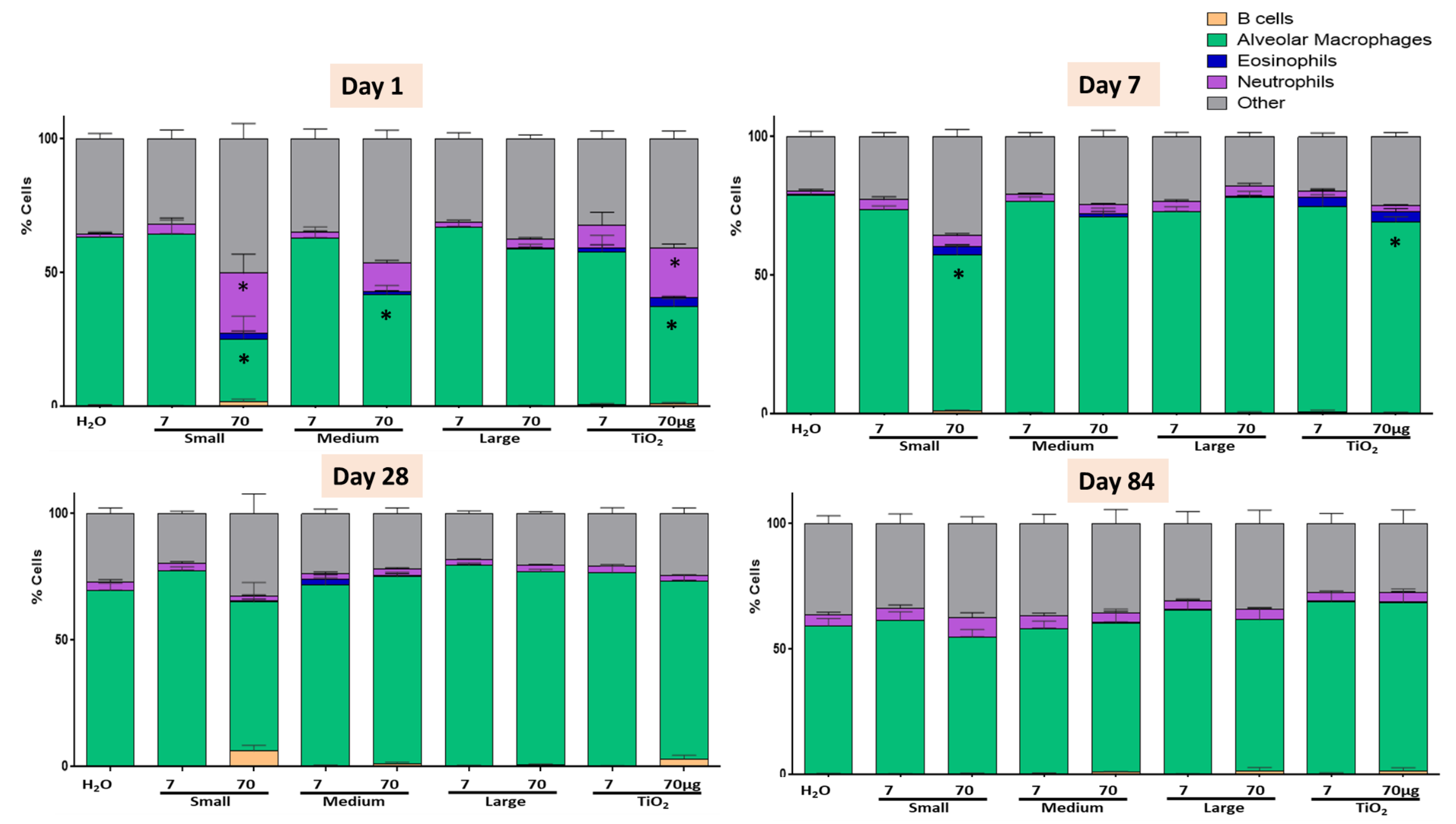

Figure 4-2: Cell composition/differentials of bronchioalveolar lavage fluid collected at 1, 7, 28, and 84 days post exposure. Error bars indicate mean $\pm \mathrm{SE}(\mathrm{n}=6) .{ }^{*} \mathrm{p}<0.05,{ }^{* *} \mathrm{p}<0.01,{ }^{* * *} \mathrm{p}<0.001,{ }^{* * * *} \mathrm{p}<0.0001$ from $\mathrm{H}_{2} \mathrm{O}$ Control group at same time point. 
A.

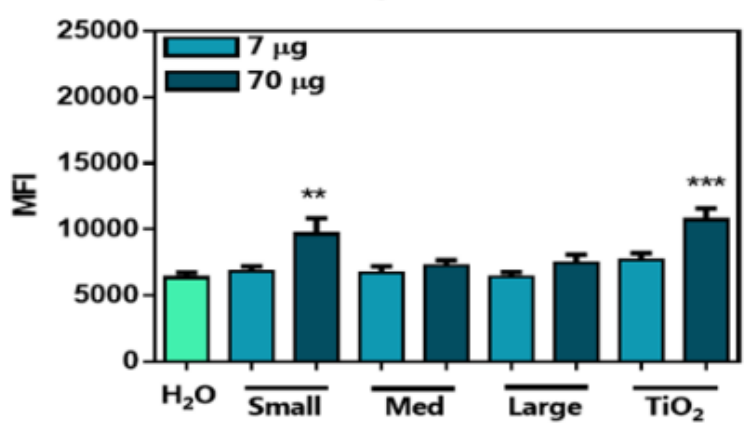

$\square 7 \mu \mathrm{g}$

ए70 $7 \mathrm{~g}$ Day 28 MHC II

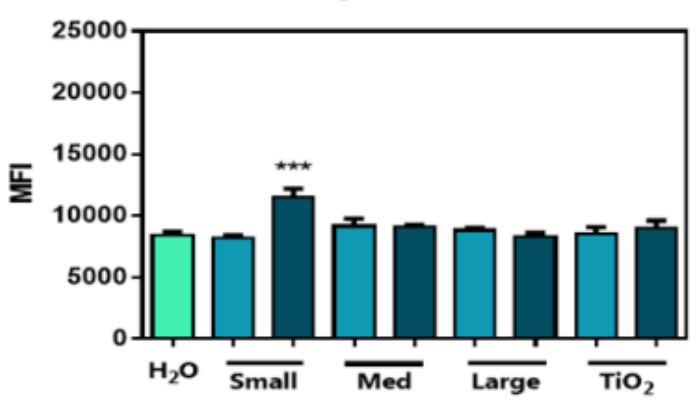

B.

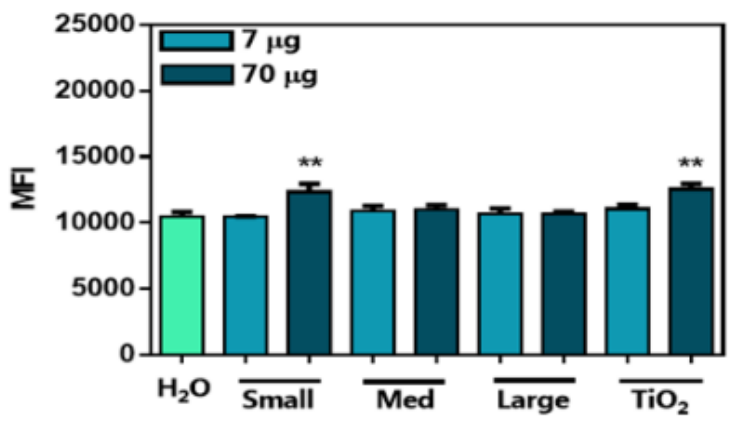

Day 28 CD80

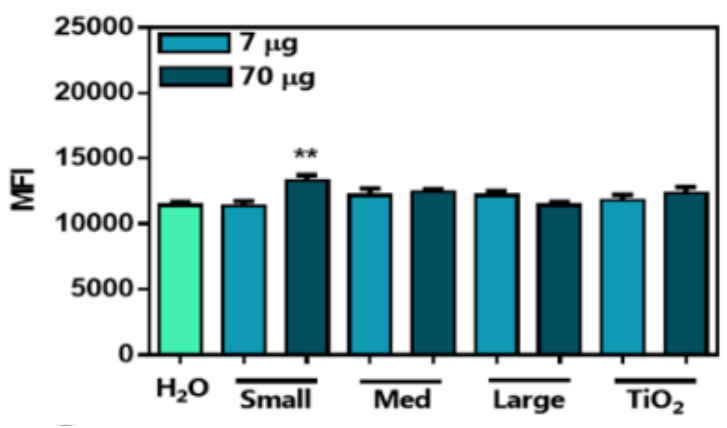

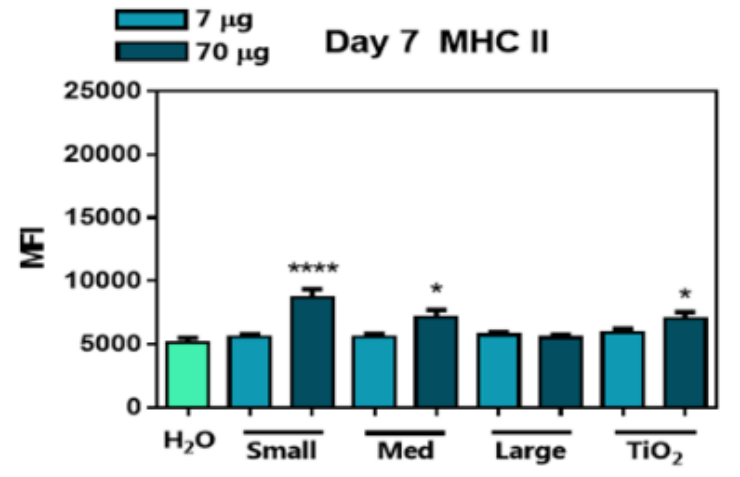

$\square 7 \mu$

$\square 70 \mu g \quad$ Day 84 MHC II

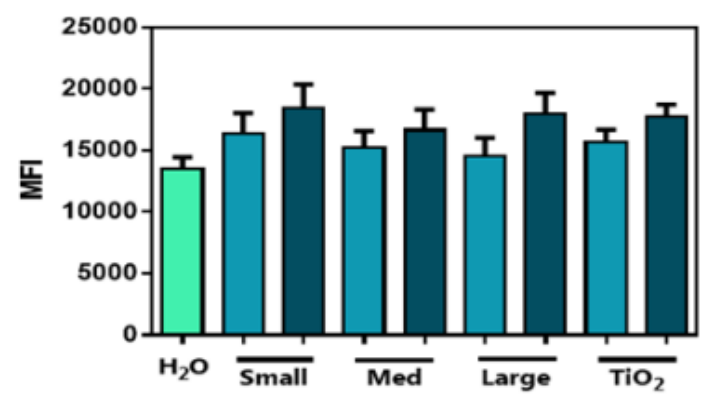

Day 7 CD80

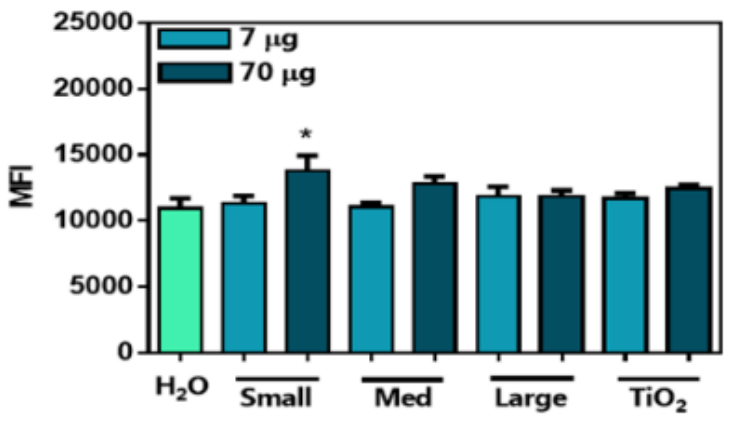

Day 84 CD80

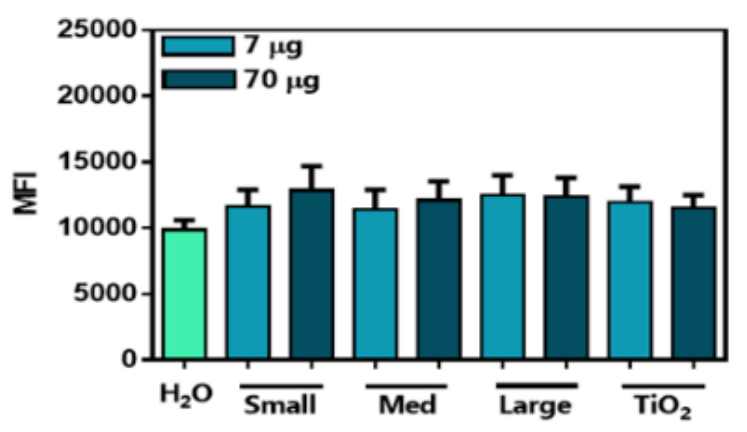



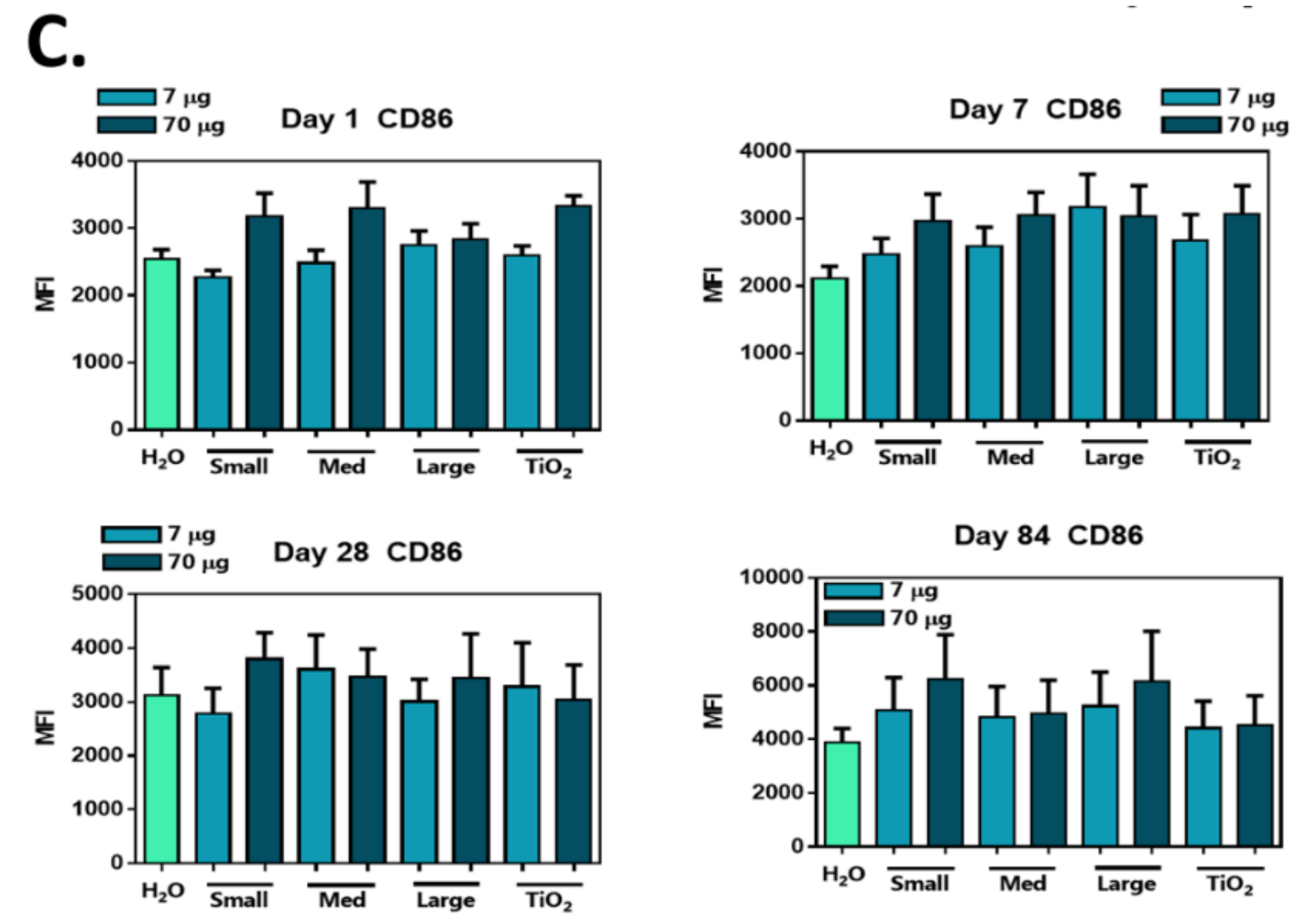

Figure 4-3: Alveolar Macrophage Polarization from bronchioalveolar lavage fluid collected at 1, 7, 28, and 84 days post exposure. Error bars indicate mean $\pm \operatorname{SE}(n=6) .{ }^{*} \mathrm{p}<0.05,{ }^{* *} \mathrm{p}<0.01$, ${ }^{* * *} \mathrm{p}<0.001,{ }^{* * * *} \mathrm{p}<0.0001$ from $\mathrm{H}_{2} \mathrm{O}$ Control group at same time point. Polarization markers used were: A) MHC II, B) CD80, and C) CD86. 
A.

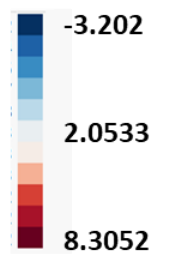

\section{Day 1}

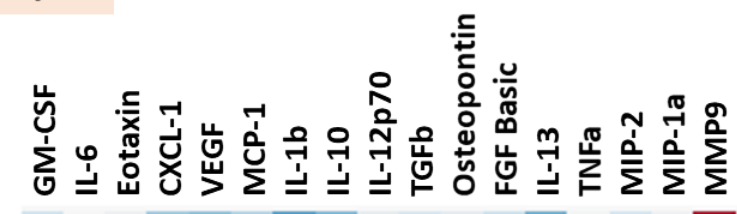

Small nCeO 2 Low $\mathrm{TiO}_{2} \mathrm{High}$

Med. $\mathrm{nCeO}_{2}$ High

$$
\mathrm{TiO}_{2} \text { Low }
$$

Small $\mathrm{nCeO}_{2} \mathrm{High}$

Med. $\mathrm{nCeO}_{2}$ Low

Large $\mathrm{nCeO}_{2}$ High

Large $\mathrm{nCeO}_{2}$ Low

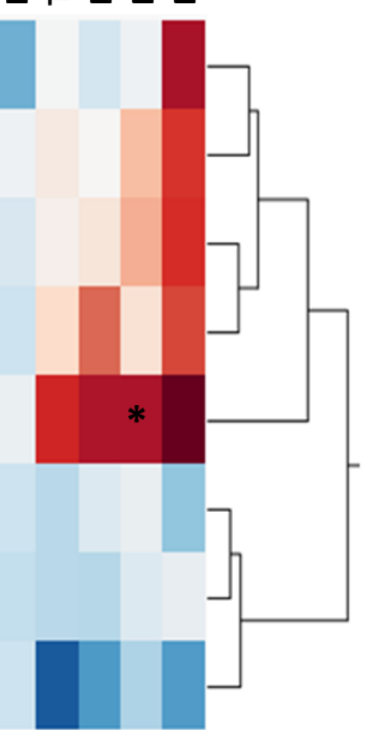

B.

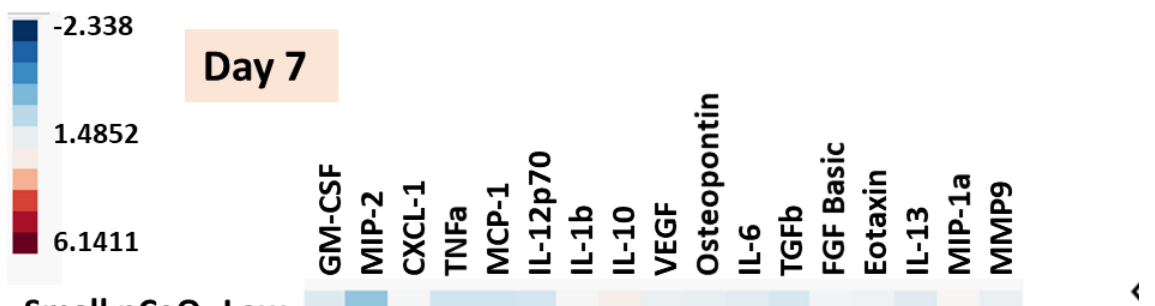

Small nCeO $\mathrm{n}_{2}$ Low

Large $\mathrm{nCeO}_{2}$ Low

Med. $\mathrm{nCeO}_{2}$ Low

$\mathrm{TiO}_{2}$ Low

Small $\mathrm{nCeO}_{2} \mathrm{High}$

Med. $\mathrm{nCeO}_{2}$ High

Large $\mathrm{nCeO}_{2}$ High

$\mathrm{TiO}_{2} \mathrm{High}$
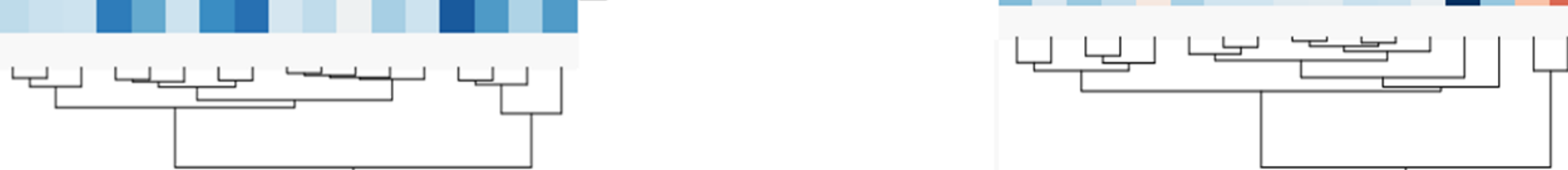
C.

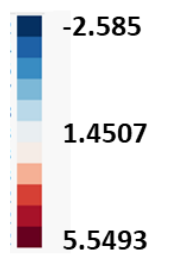

\section{Day 28}

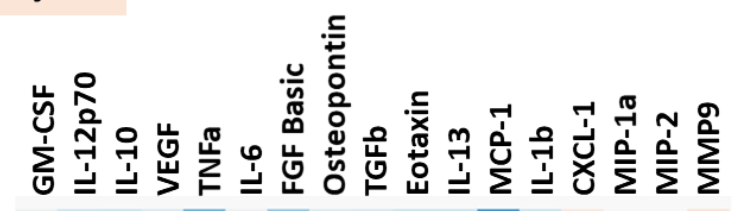

Small $\mathrm{nCeO}_{2}$ Low

Med. $\mathrm{nCeO}_{2} \mathrm{High}$

Large $\mathrm{nCeO}_{2} \mathrm{High}$

$\mathrm{TiO}_{2} \mathrm{High}$

Med. $\mathrm{nCeO}_{2}$ Low

Large $\mathrm{nCeO}_{2}$ Low

$\mathrm{TiO}_{2}$ Low

Small $\mathrm{nCeO}_{2} \mathrm{High}$

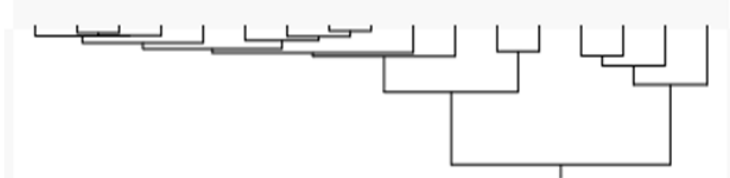

D.

$-2.585$

Day 84

0.2429

1.9787

$\diamond$

Small $\mathrm{nCeO}_{2}$ Low Large $\mathrm{nCeO}_{2} \mathrm{High}$

Large $\mathrm{nCeO}_{2}$ Low

$\mathrm{TiO}_{2} \mathrm{High}$

Small nCeO ${ }_{2}$ High

Med. nCeO 2 Low

Med. $\mathrm{nCeO}_{2} \mathrm{High}$

$\mathrm{TiO}_{2}$ Low

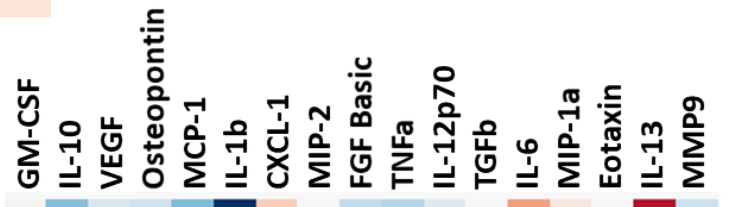

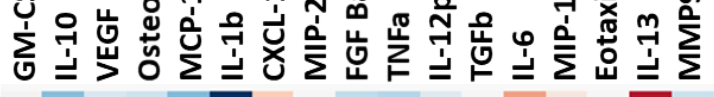

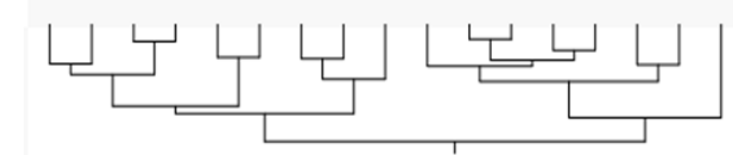

Figure 4-4: Cytokine analysis and hierarchical clustering of bronchioalveolar lavage fluid collected at A) 1, B) 7, C) 28, and D) 84 days post exposure. Blank well indicates values were too low to be detected. TGF $\beta$ on Day 1 was too low to be detected for all treatment groups. ${ }^{*} \mathrm{p}<0.05$ from $\mathrm{H} 2 \mathrm{O}$ Control group at same time point $(\mathrm{n}=6)$. 

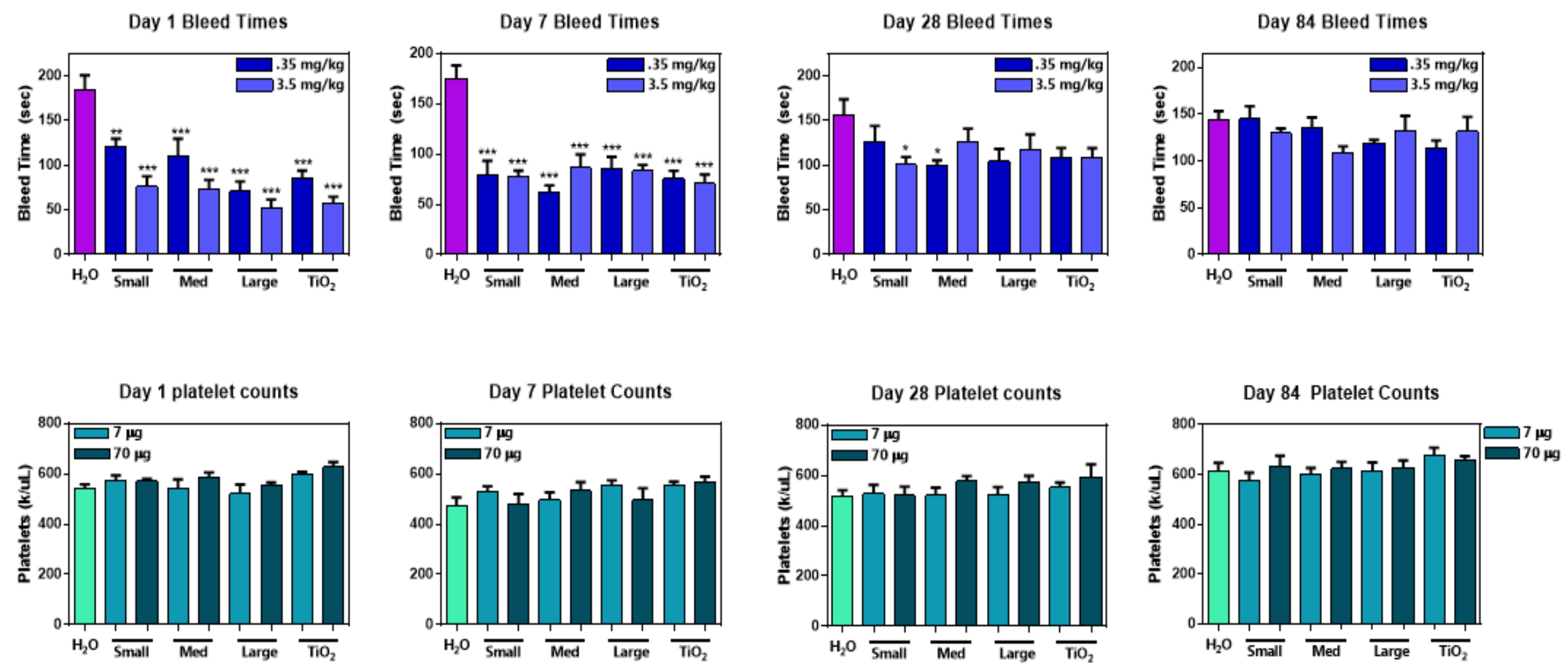

Figure 4-5: Platelet activation with nCeO2 treatment at 1, 7, 28, and 84 days post exposure. Platelet activity was measured using bleed times/time to clot (upper panel), and platelet counts from collected serum (bottom panel). Error bars indicate mean $\pm \operatorname{SE}(n=6)$. ${ }^{*} \mathrm{p}<0.05,{ }^{* *} \mathrm{p}<0.01,{ }^{* * *} \mathrm{p}<0.001$ from $\mathrm{H} 20$ Control group at same time point. 
A)

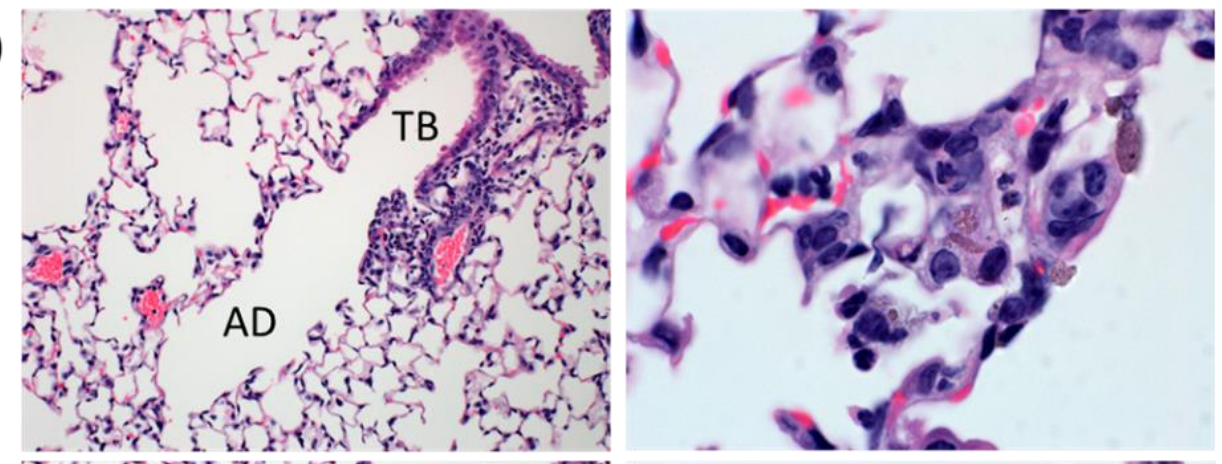

B)
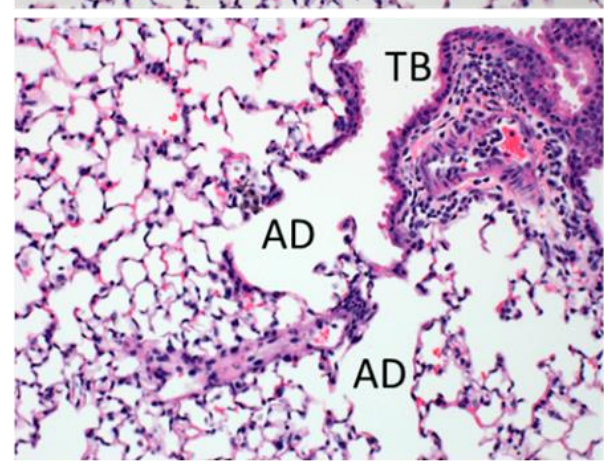

C)
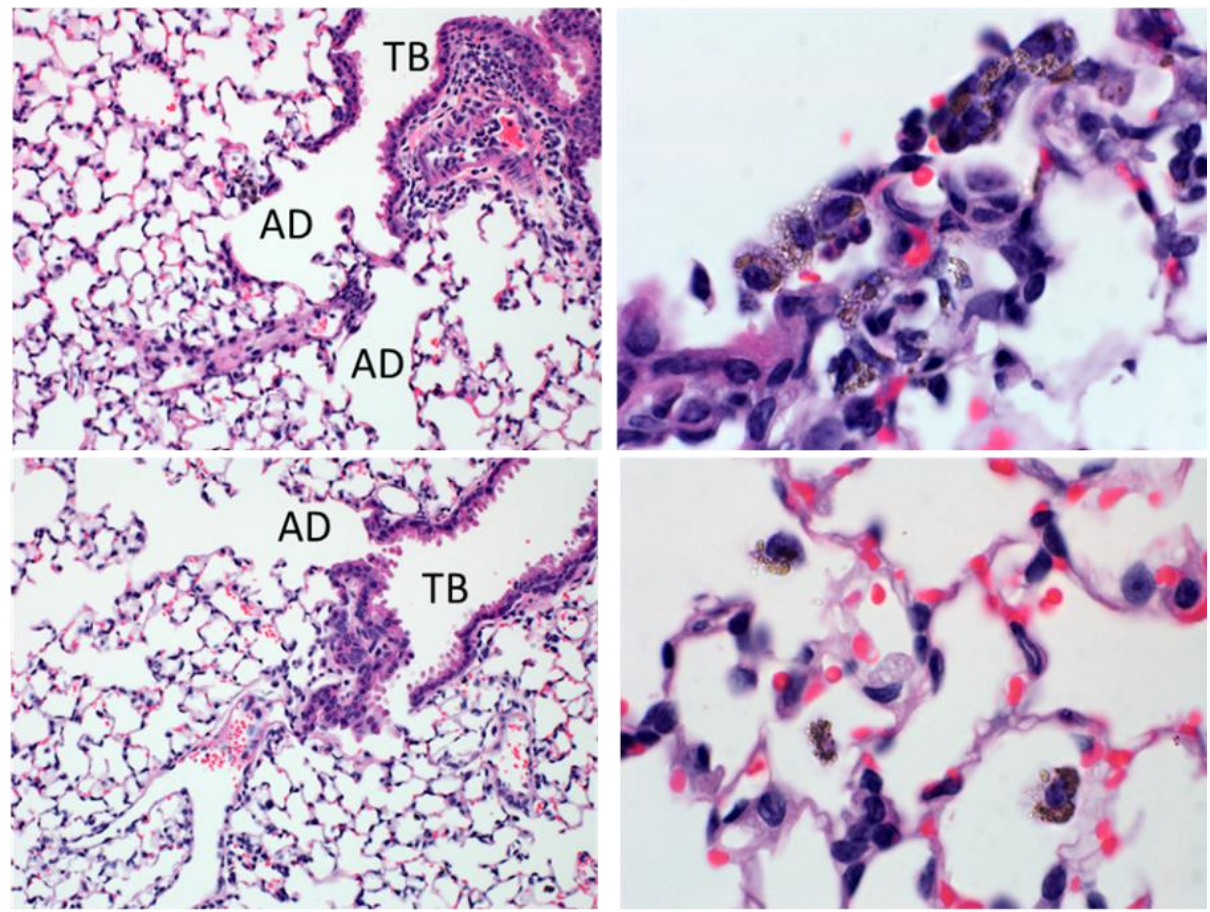

D)

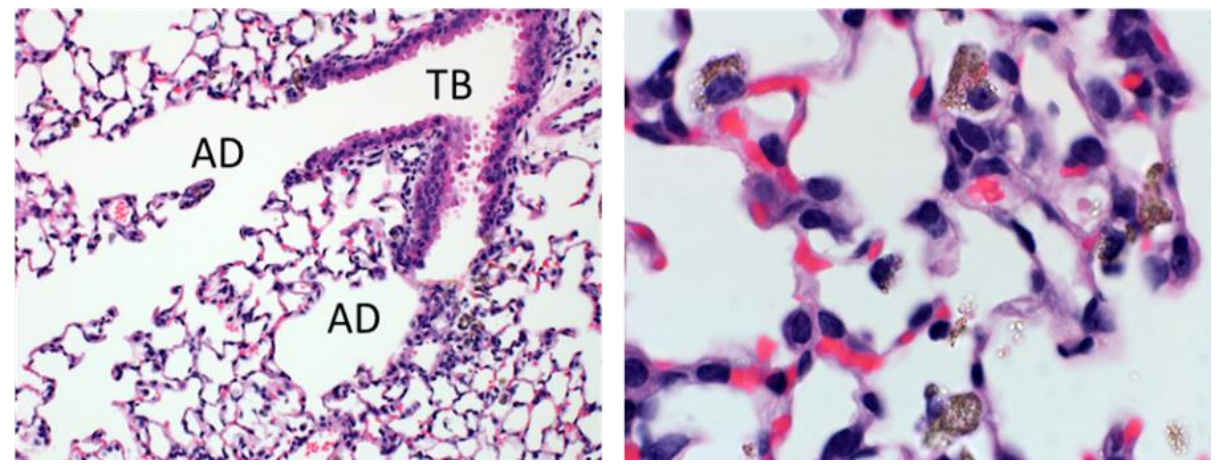

Figure 4-6: Representative histopathology images from 70 ug dose of $\mathrm{A}$ ) small $\mathrm{CeO}_{2} \mathrm{~B}$ ) medium

$\mathrm{CeO}_{2}, \mathrm{C}$ ) large $\mathrm{CeO}_{2}$, and $\left.\mathrm{D}\right) \mathrm{TiO}_{2}$ at 1 day post exposure. Particles were observed as golden brown, within alveolar macrophages. TB: terminal bronchioles, AD: alveolar ducts. 

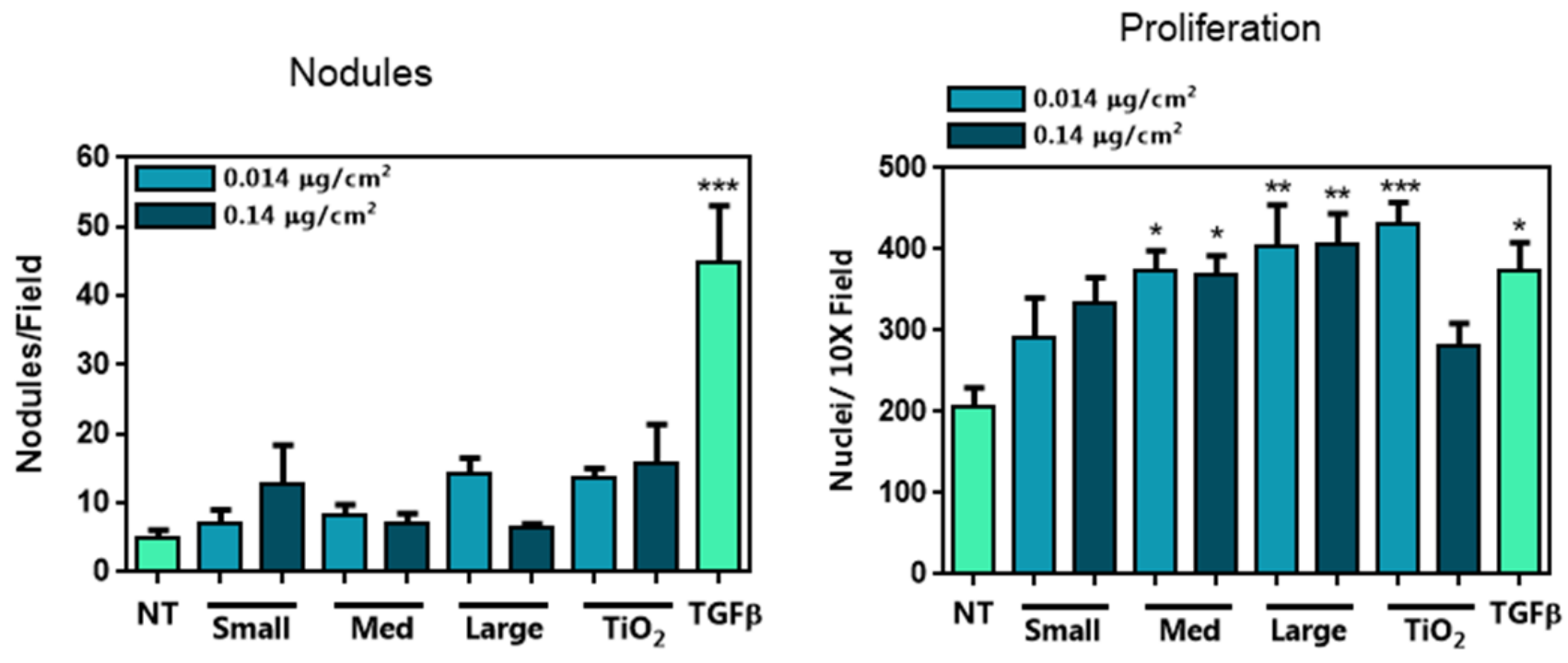

Figure 4-7: In vitro fibroblast nodule formation and fibroblast proliferation with 0.014 or 0.14 $\mathrm{ug} / \mathrm{cm}^{2}$ (comparable doses to in vivo exposure high and low dose). Error bars indicate mean $\pm \mathrm{SE}$ (n=6). ${ }^{*} \mathrm{p}<0.05,{ }^{* *} \mathrm{p}<0.01,{ }^{* * *} \mathrm{p}<0.001$ from $\mathrm{H}_{2} \mathrm{O}$ Control group at same time point. 


\section{Chapter 5: Mechanism Underlying IONP-Induced Cell Transformation - Future Directions and Preliminary Data}

\section{5-1. Introduction:}

Iron oxide nanoparticles (IONP), which measure $100 \mathrm{~nm}$ or less in diameter, have recently surged in development and use for a wide variety of applications. Their unique paramagnetic properties at these small sizes allow for utilization in MRI imaging techniques, targeted drug delivery systems, and as environmental catalysts for waste water cleanup ${ }^{4,16}$. However, despite the known risk of exposure for workers involved in their manufacture and production ${ }^{20,21}$, there is very little understood about the potential for IONP to induce toxicity. Recent evidence suggests that IONP have the potential to induce cancer-related adverse outcomes, including genotoxicity 69,98,99, neoplastic-like cell transformation 231 , and in vivo tumor formation ${ }^{232}$.

Our previous research showed that a specific IONP $\left(\mathrm{nFe}_{2} \mathrm{O}_{3}\right)$ could induce a neoplastic-like cell transformation with low dose/long term exposure, which was ablated with the addition of an amorphous silica coating. Previous literature suggested the underlying mechanism was likely related to particle dissolution, iron homeostasis disruption, oxidative stress, and resulting DNA damage. However, our study showed $\mathrm{nFe}_{2} \mathrm{O}_{3}$ exposure induced decreases in intracellular iron and minimal changes in ROS production, but still caused double stranded DNA damage and increased attachment independent colony formation. There were also no significant differences in particle dissolution between the uncoated and coated $\mathrm{nFe}_{2} \mathrm{O}_{3}$. However, we still observed a clear reduction in these adverse outcomes with the amorphous silica coated $\mathrm{nFe}_{2} \mathrm{O}_{3}$ particle. Therefore, alternative mechanisms were likely involved in the observed $\mathrm{nFe}_{2} \mathrm{O}_{3}$-induced cell transformation, which we have done some preliminary investigation into.

$\mathrm{nFe}_{2} \mathrm{O}_{3}$-induced cell transformation and response was roughly similar to that induced by GMA-MS exposure. Welding Fumes, in general, have been recently re-classified as a Group 1 
(known human) carcinogen, and GMA-MS are composed of roughly $80 \%$ insoluble iron. In our study, they served as a positive control for transformation, although there may have a different mechanism underlying the observed cell changes. The mechanism underlying GMA-MS-induced cell transformation is also currently unknown. Further exploration of this mechanism may support previously published GMA-MS studies, as well.

\section{5-2. Preliminary Results and Discussion:}

In our previous study, we observed cell transformation at 132 days continuous exposure. Non-treated, $\mathrm{nFe}_{2} \mathrm{O}_{3}$-treated, $\mathrm{SiO}_{2}$ - $\mathrm{nFe}_{2} \mathrm{O}_{3}$-treated, and GMA-MS-treated cells from this time point had their RNA isolated and sequenced. Next generation sequencing (NGS), done by ArrayStar, was used to assess this. NGS allows for a better understanding of the relationship between transcript changes and observed phenotype, without requiring prior knowledge of which pathways may be important. NGS is a more robust method than previous techniques, and has a lower false positive rate than microarrays.

As our previous study revealed discrepancies between the hypothesized mechanism underlying IONP-induced transformation, and what was actually observed, we wanted to utilize a technique which would not potential biases in place. Our results were used in conjunction with existing literature to identify potentially critical pathways which may be involved in this transformation, as supporting evidence for any likely critical pathways.

mRNA sequencing data, which showed changes in transcript levels, was used in conjunction with Core Analysis in Ingenuity Pathway Analysis (IPA). IPA compares changes in differentially expressed genes/transcripts to previously published literature, and matches them to common pathways and molecular functions. 
In the present study, IPA was used to identify key canonical pathways, critical genes, and related biomolecular functions, which were up- or down-regulated in $\mathrm{nFe}_{2} \mathrm{O}_{3}$ or GMA-MS exposed cells. First, principle component analysis of the cells sent for RNA sequencing revealed some differences in gene expression profile between biological replicates (Figure 5-1). This indicated that each biological replicate of the $\mathrm{nFe}_{2} \mathrm{O}_{3}$-transformed cells underwent transformation at different rates, and that these differences were especially apparent around the 132 day time point 233 .

The variability between replicates in some cell activity assays further indicated this potential, as is shown in our previous data. By the end of the exposure period (202 days continuous exposure), however, most biological replicates of the same treatment group were relatively similar in behavior, and therefore were also likely similar in mRNA sequence, although this has not yet been assessed. The variability observed in cells at 132 days continuous exposure did not automatically exclude any RNA sequencing results, but it was critical that any interpretation of potential mechanisms underlying cell transformation were done with this in mind.

IPA was used to identify canonical pathways which might be critical to IONP- or GMA-MSinduced cell transformation (Table 5-1).

For $\mathrm{nFe}_{2} \mathrm{O}_{3}$-exposed cells, some of the most common pathways identified were related to DNA damage repair (3 instances), as well as methionine degradation, cell junction signaling, and hypoxia. For GMA-MS exposed cells, DNA damage repair and methionine degradation were also highlighted as common pathways, as well as EIF2 signaling, PPAR signaling, and mitochondrial dysfunction. Some of the key genes identified in the top ranked networks (Table 5-2) for nFe203exposed cells included: fibronectin, NFkB, Hsp70, and several proteins known to be involved in cancer development (Akt ${ }^{234}$, P53235, and Jnk $\left.{ }^{236}\right)$. GMA-MS-exposed cells also showed changes in 
some of these same key genes (NFkB, Hsp70), as well as other genes also associated with cancer development (BRCA1 ${ }^{237}$ and ERK1/2238). Changes in these canonical pathways and critical genes were linked to several potentially critical biomolecular functions (Table 5-3). Both $\mathrm{nFe} 2 \mathrm{O3}$ - and GMA-MS-exposed cells showed changes in canonical pathways and critical genes related to: cancer, cell death, necrosis, apoptosis, and DNA or protein metabolism. In addition, nFe203exposed cells had changes linked to autophagy and nuclear morphology. For the present study, we used IPA results which matched previously published literature to identify key pathways which may be important to explore for our initial investigation.

Manipulations in DNA damage repair response and autophagy have both been linked to carcinogenic outcomes in previous literature ${ }^{165,239}$. Observed changes in intracellular iron in our previous study indicated that changes in iron homeostasis, which have also been linked to cancerrelated adverse outcomes ${ }^{240}$, may also be a critical pathway involved, but is not a fully recognized function in IPA, and therefore did not show up in the NGS analysis. None of these pathways have been well-studied with respect to IONP, or within the context of a low dose/long term model. We studied these potential changes at key points in the cell transformation - during the critical point of transformation (day 132-145) and the end of the transformation (day 202). Future studies will also include time points prior to transformation (day 91).

Therefore, we first investigated potential changes or dysfunctionality in DNA damage repair pathways with sub chronic $\mathrm{nFe}_{2} \mathrm{O}_{3}$ or GMA-MS treatment. Changes in this pathway have been previously implicated in heavy metal-induced cell transformation (chromium ${ }^{241}$ and arsenic $^{182}$ ), but has not been studied with long term IONP or GMA-MS exposure. Our previous study showed that both $\mathrm{nFe}_{2} \mathrm{O}_{3}$ and GMA-MS induced double stranded DNA breaks but without corresponding changes in ROS production. Typically, oxidative stress has been suggested as a key mechanism to induce DNA damage ${ }^{242}$, but our results indicated alternative pathways may be 
involved in the induction of this. A typical cell response to DNA damage, regardless of its source, involves the identification and repair of any non-intact DNA. There are three main types of DNA damage repair: non-homologous end joining, mismatch repair, and homologous recombination ${ }^{243}$. For these processes, key protein components of them are: Ku70 (which complexes with Ku80), $\mathrm{MSH} 2$, and $\mathrm{Rad} 51^{244} . \mathrm{nFe}_{2} \mathrm{O}_{3}$ transformed cells had a significant increase in transcripts of $\mathrm{MSH}$, and IPA identified increases in both MSH2 and Rad51 for these cells, as well (Table 5-4). Ku70 was not indicated in the mRNA sequencing results, but was still considered for this study. Although mRNA and transcript levels may give an idea as to which pathways may be critically important, protein expression is an even better indicator of these potential changes. Therefore, we assessed cells at both Day 145 and 202 of continuous exposure to identify potential changes in protein expression for MSH2, Ku70, or Rad51. Day 145 cells showed no significant changes in protein expression of MSH2 or Ku70 between treatment groups (Figure 5-2). At 202 days continuous exposure, there was a trend of decreased expression for both of these proteins in $\mathrm{nFe}_{2} \mathrm{O}_{3}$ - and GMA-MS exposed cells as compared to non-treated control cells, but this was also not significant. Rad51 was not able to be identified using immunoblotting techniques (data not shown). MSH2 and Ku70 protein expression did not match changes in mRNA transcript levels as indicated by either ArrayStar or IPA analysis. These discrepancies may have been due to the difference in exposure time between the RNA collected from cells (132 days) and the cells tested for protein expression (145 days). However, we also hypothesized that these discrepancies may actually have been an indication of these proteins (and connected pathways) being dysfunctional, and therefore would be unable to adequately repair DNA damage.

Cells with dysfunctional DNA damage repair proteins - particularly MSH2 - are known to be more resistant to cisplatin ${ }^{245}$. To assess this, cells collected at 145 days continuous exposure 
were treated with cisplatin at a range of doses to assess changes in viability (Figure 5-3). However, there were no significant differences between treatment groups for this parameter, either.

Even though mRNA sequencing identified DNA damage repair as being a critical mechanism underlying $\mathrm{nFe}_{2} \mathrm{O}_{3}$ - and GMA-MS induced transformation, our other preliminary data did not show a similar trend. Although it is likely that $\mathrm{nFe}_{2} \mathrm{O}_{3}$ - and GMA-MS exposed cells had changes in DNA damage repair pathways, either the proteins we tested were not affected by this treatment, or perturbations in these pathways were corrected by the cell before we could observe it in the presented experiments. In fact, in our previous study, doubled stranded DNA damage was not observed until the end of the exposure period. Late/delayed detection of double stranded DNA damage and perturbations in MSH2 and KU70 expression suggested this damage may be an effect rather than a cause of the observed $\mathrm{nFe}_{2} \mathrm{O}_{3}$-induced cell transformation. These discrepancies between protein expression and mRNA sequences revealed potential issues with our mRNA sequencing data, especially that the difficulty in clustering treatment groups prevented us from using this dataset to identify any kind of trend of important pathway from this data set. The freeze/thaw cycle undergone by these cells before RNA collection may have also contributed to this difficulty.

We are continuing to pursue alternative clustering methods which may allow for a more accurate analysis of mRNA sequences, and in the future could also utilize cells which had not gone through a freeze/thaw cycle, to correct for these issues.

Based on these issues, however, we opted to expand our preliminary investigation of potential mechanisms which may underlie $\mathrm{nFe}_{2} \mathrm{O}_{3}$-induced cell transformation to those suggested by previous literature using relevant dose, cell type, and exposure parameters. Although many researchers suggest that $\mathrm{nFe}_{2} \mathrm{O}_{3}$ exposure may induce oxidative stress, which has the potential to induce DNA damage and impact other pathways related to cancer development, there have also 
been several studies which looked at the potential for IONP or other heavy metal compounds to impact other pathways which have also been linked to carcinogenesis.

Autophagy was identified by IPA as being significantly decreased in $\mathrm{nFe}_{2} \mathrm{O}_{3}$-exposed cells (Table 5-3), and Beclin1 as a key autophagy protein had decreased transcripts in these cells as compared to non-treated control cells (Table 5-5). In general, autophagy can serve in either a protective capacity against tumor development, or can contribute to uncontrolled tumor cell proliferation ${ }^{246}$. In non-cancerous cells, autophagy allows for the recycling of dysfunctional/damage organelles and proteins ${ }^{247}$. In cancer cells, however, autophagy recycling of cell components can allow for continued growth by providing metabolites to aid with this ${ }^{248}$. In the literature, oxidative stress is known to be a trigger for autophagy ${ }^{249}$, to potentially reduce abnormal development of healthy cells. In our study, however, extended $\mathrm{nFe}_{2} \mathrm{O}_{3}$ or GMA-MS exposure actually led to reduced/suppressed ROS production, which may have prevented autophagic cell cycling in response to chronic cell injury, abnormal cell growth, ultimately leading to the observed cell transformation. It is also a possibility that increased autophagy may reduced/suppressed ROS production instead, although the sequence of these events is still unclear.

Beclin1 protein expression was therefore assessed at key time points during the cell transformation (Figure 5-4). At 145 days continuous exposure, $\mathrm{nFe}_{2} \mathrm{O}_{3}$-exposed cells had a trend of elevated Beclin1 expression, indicating increased autophagy ${ }^{250}$, whereas GMA-MS exposed cells had decreased Beclin1, indicating the inhibition of autophagy. By the end of the exposure period, however, Beclin1 protein expression had resolved to be similar to that of non-treated passage control cells for both $\mathrm{nFe}_{2} \mathrm{O}_{3}$ and GMA-MS exposed cells. Although the exact role of autophagy in cancer is somewhat unclear ${ }^{246}$, it has been shown that changes and/or dysfunction in autophagic networks can contribute to cancer-related adverse outcomes. The high variability and changes in 
Beclin1 observed here suggested autophagic pathways may be critically impacted with long term/low dose $\mathrm{nFe}_{2} \mathrm{O}_{3}$ or GMA-MS exposure. Further exploration into these potential pathways are still ongoing.

If there was dysfunction in autophagic recycling processes, it may also be likely that endocytosed particle may have been able to disrupt critical cell processes. Several studies have shown iron homeostasis disruption to be related to cancer development or other chronic disease states ${ }^{251}$. Even though both the $\mathrm{nFe}_{2} \mathrm{O}_{3}$ and GMA-MS particles used to induce cell transformation were relatively insoluble, it was still likely that direct surface interaction of the endocytosed particle with key cell receptors or proteins may have disrupted this pathway.

Iron homeostasis is a complex process which involves a highly complex network of ironrelated proteins. However, one of the most common methods to investigate potential changes in this pathway is to focus on Ferritin, a key iron storage protein. Furthermore, Ferritin was identified in IPA as being down-regulated in GMA-MS exposed cells (Table 5-6). Therefore, we evaluated protein expression of ferritin at key time points (Figure 5-5). Our results showed a trend of increased ferritin expression in IONP-exposed cells, and a trend of decreased ferritin expression in GMA-MS exposed cells at 145 days continuous exposure, both of which were resolved by the end of the exposure period. Again, this indicated that changes in iron homeostasis were likely occurring throughout the exposure period, but that by the end of the exposure period, chronic cell exposure/injury caused semi-permanent cell adaptation in these parameters. We are planning future investigations into this pathway, as well.

Overall, our process of investigating the potential mechanism underlying $\mathrm{nFe}_{2} \mathrm{O}_{3}$ and GMAMS induced cell transformation revealed both autophagy and iron homeostasis related pathways to play potentially critical roles in this. However, our preliminary research has been largely inconclusive, and therefore represents a key area of research which needs to be further explored. 
It is likely that time points prior to the point of transformation may show greater change in protein expression for these key pathways, as they may have been a cause of the cell transformation, rather than an effect. Therefore, another key aspect to future studies would be to incorporate earlier time points.

\section{5-3. Conclusions and Future Directions:}

Both $\mathrm{nFe}_{2} \mathrm{O}_{3}$ and GMA-MS sub chronic exposure induced a neoplastic-like cell transformation in Beas-2B cells. However, the mechanism(s) underlying this transformation remain unclear. RNA sequencing of exposed cells at the pivotal moment of transformation (132 days continuous exposure) indicated alterations in DNA damage repair, autophagy, and iron homeostasis may play a critical role. Previous literature also suggested these pathways may be impacted by continuous long-term exposure to iron containing particles. Our preliminary results showed some trends of changes in protein expression related to iron homeostasis and autophagy, but these were not conclusive. In the future, we plan to continue investigating these likely critical pathways, as well as identify additional pathways or networks which may also be critical to IONPor GMA-MS-induced cell transformation.

\section{5-4. Methods:}

\section{5-4a. Continuous Exposure:}

Naïve Beas-2B cells (ATCC) were cultured in serum-free BEGM (basal medium with 1\% penicillin/streptomycin, $0.4 \%$ bovine pituitary extract, $0.1 \%$ hydrocortisone, human epithelial growth factor, epinephrine, transferrin, insulin, retinoic acid, and triiodothyronine) from Lonza (Walkersville, MD) for a minimum of two passages before beginning exposures. Cells were passaged according to the ATCC guidelines, as previously described ${ }^{233}$. 
Beas-2B (passage 3) were seeded at 50,000 cells/well in six-well plates (Corning), with four biological replicates per treatment group. At 24 hours post-seeding, the medium was aspirated out and replaced with specific particle treatments, prepared as previously described. All particle treatments were administered at $0.6 \mu \mathrm{g} / \mathrm{cm}^{2}(2.88 \mu \mathrm{g} / \mathrm{mL})$. Particle-free vehicle exposed cells served as passage controls. Medium with particle treatments was replaced every three to four days. When cells were approximately $80-90 \%$ confluent (roughly once a week), cells were washed, trypsin/EDTA released from plate, and random selection of cells were re-plated at seeding density of 50,000 cells/well in 75\% of total volume. Particle treatments were added directly to these wells approximately 3 hours later in the remaining 25\% volume.

\section{5-4b. RNA collection:}

At 132 days continuous exposure, the critical time point for cell-transformation, cells that were not re-plated were frozen back for future use. Approximately 6 months after collection, these cells were thawed, passaged a maximum of three times, and had RNA isolated for sequencing. RNA was isolated using the RNeasy Mini Kit (Qiagen) according to manufacturer's instructions. RNA samples were frozen until sequencing, which was done by ArrayStar. mRNA data was sequenced using Illumina HiSeq 4000, and gene and transcript levels were calculated using R package Ballgown, done by ArrayStar (Rockville, MD).

\section{5-4c. RNA sequencing}

ArrayStar conducted all NGS mRNA sequencing. Total RNA from each sample sent to ArrayStar was quantified by them using a NanoDrop ND-1000 instrument. 1-2 $\mu$ g total RNA was used to prepare the sequencing library by enriching total RNA with oligo magnetic beads, and preparing the RNA-seq library using KAPA Stranded RNA-Seq Library Prep Kit (Illumina). The completed libraries were qualified with Agilent 2100 Bioanalyzer and quantified by absolute quantification qPCR method. To sequence the libraries on the Illumina HiSeq 4000 instrument, the 
barcoded libraries were mixed, denatured to single stranded DNA in $\mathrm{NaOH}$, captured on Illumina flow cell, amplified in situ, and subsequently sequenced for 150 cycles for both ends on Illumina HiSeq instrument.

Image analysis and base calling were performed using Solexa pipeline v1.8 (Off-Line Base Caller software, v1.8). Sequence quality was examined using the FastQC software. The trimmed reads were aligned to reference genome using Hisat2 software. The transcript abundances for each sample was estimated with StringTie, and the FPKM value for gene and transcript level were calculated with R package Ballgown. The differentially expressed genes and transcripts were filtered using R package Ballgown. The novel genes and transcripts were predicted from assembled results by comparing to the reference annotation using StringTie and Ballgown, then use CPAT to assess the coding potential of those sequences. Principle Component Analysis (PCA) and correlation analysis were based on gene expression level, Hierarchical Clustering, Gene Ontology, Pathway analysis, scatter plots and volcano plots were performed with the differentially expressed genes in R, Python or shell environment for statistical computing and graphics.

Differentially expressed transcripts (1.5 fold cutoff) were uploaded into the Ingenuity Pathway Analysis program, and key analysis was condensed and presented here. The number of differentially expressed genes was very low $(<10)$, so transcripts were used for all subsequent IPA analysis.

\section{5-4d. SimpleWes.}

At 145 and 202 days continuous exposure, time points at the mid-point and end of cell transformation, cells that were not re-plated were frozen back for future use (10\% DMSO in $80^{\circ} \mathrm{C}$ ). Approximately 6 months after collection, these cells were thawed, passaged a maximum of three times, and were lysed for western blots. Cells were lysed in RIPA buffer (Millipore-Sigma) with $1 \mathrm{X}$ protease inhibitors, $1 \mathrm{mM}$ PMSF, and $1 \mathrm{mM}$ sodium orthovonadate (Millipore-Sigma) on 
ice for 10 minutes. Cell scraper was used to agitate lysates, and collect in microcentrifuge tubes. Lysates were sonicated using a cup horn sonicator for 5 seconds, pelleted at 13,000 x g for 10 minutes $\left(4^{\circ} \mathrm{C}\right)$, and supernatant was collected and stored. Amount of protein was quantified using BCA assay (Pierce).

Immunoblotting was performed using the ProteinSimple (Wes), a gel filled capillary system, with total protein used as a loading control for normalization, according to manufacturer's instructions. All antibodies used were purchased from Cell Signaling (FTH, MSH2, Ku70, NQO1) or Novus Biologics (Bcl1, p53, phos-p53).

5-4e. Cisplatin Treatment:

At 145 days continuous exposure, cells that were not re-plated were frozen back for future use. Approximately 6 months after collection, these cells were thawed, passaged a maximum of three times, and evaluated for cisplatin resistance. Cells were plated at 10,000 cells/well in a 96 well plate and allowed to attach. 24 hours later, media was aspirated and replaced with appropriate cisplatin dilution (1.56-50uM, prepared in $0.9 \% \mathrm{NaCl})$, and incubated for 24 hours. Following which, WST reagent was added (1:10) for 2 hours, and absorbance was read on a spectrophotometer (Absorbance: 450/650 nm).

\section{5-4f. Statistical Analyses}

Data represents mean \pm SE from three or more biological replicates and four or more technical replicates per biological replicate. Samples were normalized to non-treated control for each biological replicate, then combined for all figures. Following normalization, samples were analyzed using a two-way ANOVA with Tukey's post-hoc test for multiple comparisons to determine significance. When treatment groups had different degrees of variance, a Wilcoxon Chi-squared test was used instead. Statistical significance is indicated in each figure as ${ }^{*} \mathrm{p}<0.05,{ }^{* *} \mathrm{p}<0.01,{ }^{* * *} \mathrm{p}<0.001$, 
and ${ }^{* * * *} \mathrm{p}<0.0001$. All statistical analyses were performed using GraphPad Prism Software (La Jolla, $\mathrm{CA})$. 


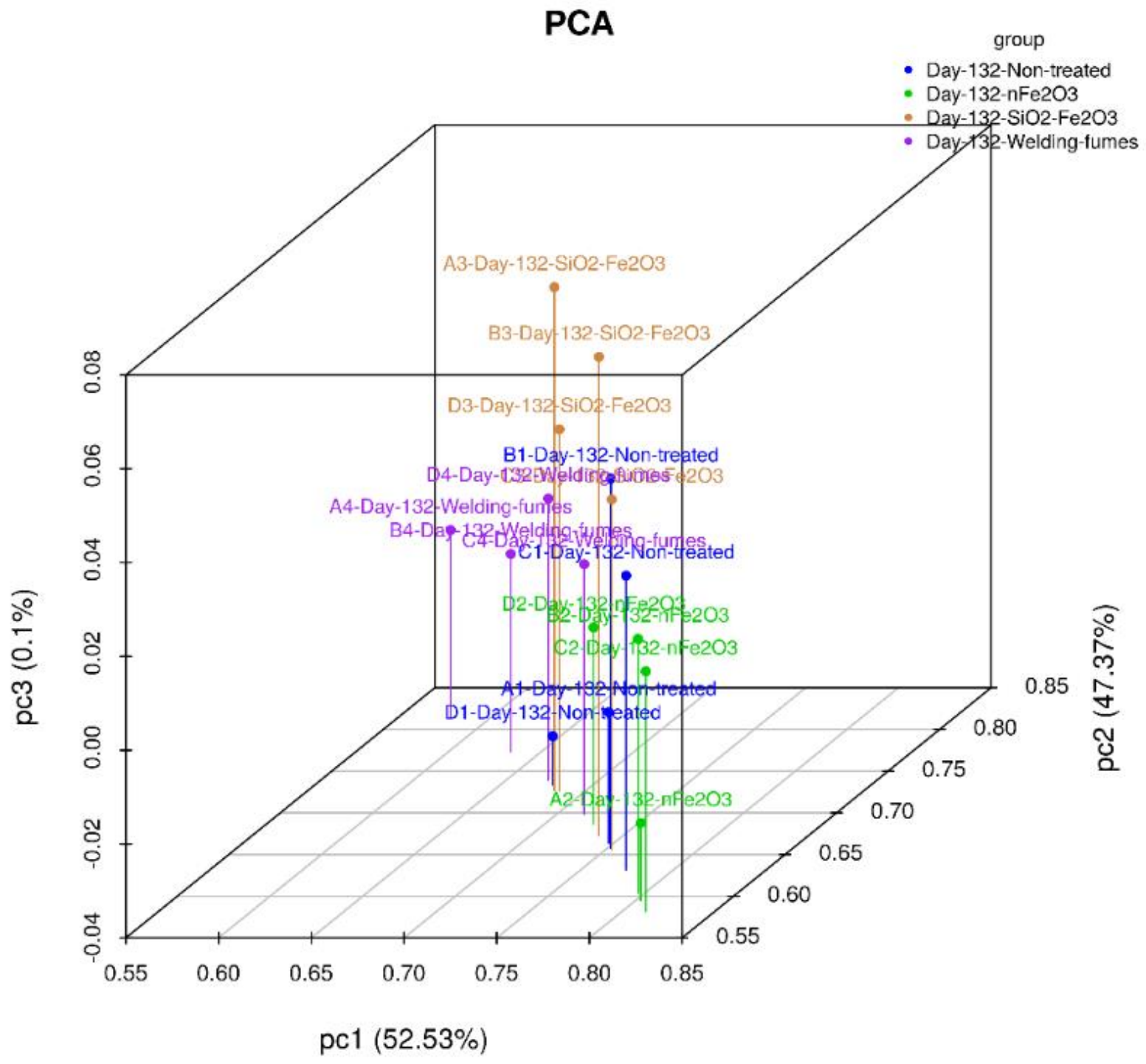

Figure 5-1: Principle Component Analysis (PCA) of day 132 Non-Treated, $\mathrm{nFe}_{2} \mathrm{O}_{3}, \mathrm{SiO}_{2}-\mathrm{nFe}_{2} \mathrm{O}_{3}$, and GMA-MS exposed cells. 
Table 5-1: Top Canonical Pathways as Identified by Ingenuity Pathway Analysis. Z-score: deviations from standard deviation using bell curve distribution. Only Z scores $>2$ or $<-2$ indicate activation or inhibition predictions. Ratio: number of genes from dataset in pathway to total number of genes in pathway.

\section{nFe2 $_{2} \mathrm{O}_{3}$-Exposed Cells}

\begin{tabular}{|l|l|l|l|}
\hline Ingenuity Canonical Pathways & -log(p-value) & Ratio & z-score \\
\hline Hypoxia Signaling in the Cardiovascular System & 5.26 & 0.133 & 1.342 \\
\hline Mismatch Repair in Eukaryotes & 4.75 & 0.312 & 0 \\
\hline $\begin{array}{l}\text { DNA Double-Strand Break Repair by Non-Homologous } \\
\text { End Joining }\end{array}$ & 3.72 & 0.286 & 0 \\
\hline Protein Ubiquitination Pathway & 3.57 & 0.0604 & 0 \\
\hline Colanic Acid Building Blocks Biosynthesis & 2.5 & 0.214 & 0 \\
\hline Germ Cell-Sertoli Cell Junction Signaling & 2.3 & 0.0578 & 0 \\
\hline Circadian Rhythm Signaling & 2.2 & 0.118 & 0 \\
\hline Role of BRCA1 in DNA Damage Response & 2.08 & 0.075 & 0.447 \\
\hline Methionine Degradation I (to Homocysteine) & 1.93 & 0.136 & 0 \\
\hline $\begin{array}{l}\text { Role of PKR in Interferon Induction and Antiviral } \\
\text { Response }\end{array}$ & 1.91 & 0.0976 & 0 \\
\hline
\end{tabular}

GMA-MS-Exposed Cells

\begin{tabular}{|l|l|l|l|}
\hline Ingenuity Canonical Pathways & $-\log (\mathrm{p}$-value $)$ & Ratio & z-score \\
\hline Mitochondrial Dysfunction & 3.72 & 0.0877 & 0 \\
\hline Aryl Hydrocarbon Receptor Signaling & 3.51 & 0.0922 & 0 \\
\hline EIF2 Signaling & 3.45 & 0.0769 & 0 \\
\hline PPAR Signaling & 3.27 & 0.105 & 0 \\
\hline Role of BRCA1 in DNA Damage Response & 3.21 & 0.113 & 0 \\
\hline Superpathway of Methionine Degradation & 3.14 & 0.162 & 0 \\
\hline Granzyme B Signaling & 2.97 & 0.25 & 0 \\
\hline Hereditary Breast Cancer Signaling & 2.89 & 0.0833 & 0 \\
\hline Cell Cycle: G2/M DNA Damage Checkpoint Regulation & 2.49 & 0.122 & 0 \\
\hline
\end{tabular}


Table 5-2: Top Ranked Networks and Hub Genes as identified by Ingenuity Pathway Analysis. Score of 2 indicates $p$ value of 0.001 . Focus Molecules indicates number of molecules in pathway which are up- or down- regulated as compared to non-treated control cells.

$\mathrm{nFe}_{2} \mathrm{O}_{3}$-Exposed Cells

\begin{tabular}{|l|l|l|l|}
\hline Hub Genes & Score & $\begin{array}{l}\text { Focus } \\
\text { Molecules }\end{array}$ & Top Diseases and Functions \\
\hline CSNK1E - Casein Kinase I & 56 & 33 & $\begin{array}{l}\text { Cell Cycle, Connective Tissue Disorders, } \\
\text { Developmental Disorder }\end{array}$ \\
\hline KIF22 - Kinesin-Like Protein & 56 & 33 & $\begin{array}{l}\text { Cellular Assembly and Organization, DNA Replication, } \\
\text { Recombination, and Repair, Cell Morphology }\end{array}$ \\
\hline FN1 - Fibronectin & 48 & 30 & $\begin{array}{l}\text { Post-Translational Modification, Amino Acid } \\
\text { Metabolism, Small Molecule Biochemistry }\end{array}$ \\
\hline Akt & 45 & 29 & $\begin{array}{l}\text { Tissue Morphology, Cellular Assembly and } \\
\text { Organization, Cellular Function and Maintenance }\end{array}$ \\
\hline NFkB & 43 & 28 & $\begin{array}{l}\text { Post-Translational Modification, Cellular Assembly } \\
\text { and Organization, Cellular Compromise }\end{array}$ \\
\hline $\begin{array}{l}\text { CCT3 - maintains cellular } \\
\text { proteostasis }\end{array}$ & 43 & 28 & $\begin{array}{l}\text { Cancer, Cardiac Congestive Cardiac Failure, } \\
\text { Cardiovascular Disease }\end{array}$ \\
\hline TP53 & 40 & 27 & \begin{tabular}{l} 
Cancer, Gastrointestinal Disease, Hereditary Disorder \\
\hline Histone H3
\end{tabular} \\
\hline Hsp70 & 32 & 23 & $\begin{array}{l}\text { Cellular Compromise, Tissue Development, Cellular } \\
\text { Development }\end{array}$ \\
\hline Jnk & 30 & 22 & $\begin{array}{l}\text { Developmental Disorder, Embryonic Development, } \\
\text { Organismal Development }\end{array}$ \\
\hline
\end{tabular}

GMA-MS-Exposed Cells

\begin{tabular}{|c|c|c|c|}
\hline Hub Genes & Score & $\begin{array}{l}\text { Focus } \\
\text { Molecules }\end{array}$ & Top Diseases and Functions \\
\hline NFkB & 49 & 32 & $\begin{array}{l}\text { RNA Post-Transcriptional Modification, Cellular } \\
\text { Compromise, Cardiovascular System Development } \\
\text { and Function }\end{array}$ \\
\hline $\begin{array}{l}\text { TADA2A - chromatin } \\
\text { organization }\end{array}$ & 49 & 32 & $\begin{array}{l}\text { RNA Post-Transcriptional Modification, Embryonic } \\
\text { Development, Organismal Development }\end{array}$ \\
\hline $\begin{array}{l}\text { PCM1 - centriolar satellite } \\
\text { components }\end{array}$ & 46 & 31 & Cell Cycle, Cell Morphology, Auditory Disease \\
\hline $\begin{array}{l}\text { LIMA1 - inhibits cancer cell } \\
\text { invasion }\end{array}$ & 46 & 31 & $\begin{array}{l}\text { Cellular Assembly and Organization, Cancer, } \\
\text { Gastrointestinal Disease }\end{array}$ \\
\hline NOP56 - ribonucleo protein & 41 & 29 & $\begin{array}{l}\text { Cancer, Cell Death and Survival, Organismal Injury } \\
\text { and Abnormalities }\end{array}$ \\
\hline BRCA1 & 41 & 29 & $\begin{array}{l}\text { Post-Translational Modification, Infectious Diseases, } \\
\text { Antimicrobial Response }\end{array}$ \\
\hline
\end{tabular}




\begin{tabular}{|l|l|l|l|}
\hline IKBKB - NFkB inhibitor & 37 & 27 & $\begin{array}{l}\text { Dermatological Diseases and Conditions, } \\
\text { Immunological Disease, Inflammatory Disease }\end{array}$ \\
\hline Ck2 - Casein Kinase II & 35 & 26 & $\begin{array}{l}\text { Cell Cycle, Cellular Assembly and Organization, } \\
\text { Connective Tissue Development and Function }\end{array}$ \\
\hline Hsp70 & 33 & 25 & $\begin{array}{l}\text { Hereditary Disorder, Neurological Disease, } \\
\text { Organismal Injury and Abnormalities }\end{array}$ \\
\hline ERK1/2 & 31 & 24 & $\begin{array}{l}\text { Developmental Disorder, Hereditary Disorder, } \\
\text { Ophthalmic Disease }\end{array}$ \\
\hline
\end{tabular}


Table 5-3: Top Biomolecular Functions as identified by Ingenuity Pathway Analysis. Z-score: deviations from standard deviation using bell curve distribution. Top functions/networks were ranked using $\mathrm{p}$ value.

$\mathrm{nFe}_{2} \mathrm{O}_{3}$-Exposed Cells

\begin{tabular}{|l|l|l|l|}
\hline Disease or Molecular Function & $\mathrm{p}$-Value & Activation z-score & \# Molecules \\
\hline Cancer & $9.43 \mathrm{E}-18$ & -0.437 & 455 \\
\hline Cell Death & $1.25 \mathrm{E}-06$ & 1.088 & 85 \\
\hline Cell Assembly/Organization & $3.39 \mathrm{E}-06$ & 1.195 & 39 \\
\hline Apoptosis & $3.65 \mathrm{E}-06$ & 0.113 & 127 \\
\hline Radiosensitivity of cells & $5.34 \mathrm{E}-06$ & -0.447 & 8 \\
\hline Autophagy & $9.3 \mathrm{E}-06$ & -1.436 & 31 \\
\hline Nuclear Morphology & $1.12 \mathrm{E}-05$ & 0 & 17 \\
\hline DNA Metabolism & $1.21 \mathrm{E}-05$ & -0.586 & 28 \\
\hline Necrosis & $1.96 \mathrm{E}-05$ & 1.002 & 124 \\
\hline
\end{tabular}

GMA-MS-Exposed Cells

\begin{tabular}{|l|l|l|l|}
\hline Diseases or Functions Annotation & p-value & Activation z-score & \# Molecules \\
\hline Cancer & $7.31 \mathrm{E}-17$ & 0.603 & 578 \\
\hline Cell Death & $1.15 \mathrm{E}-08$ & 0.795 & 216 \\
\hline RNA Expression & $2.79 \mathrm{E}-08$ & 0.116 & 154 \\
\hline Protein Metabolism & $3.64 \mathrm{E}-08$ & -0.114 & 80 \\
\hline Necrosis & $4.35 \mathrm{E}-08$ & 1.271 & 174 \\
\hline Cell Cycle Progression & $1.28 \mathrm{E}-07$ & -0.98 & 83 \\
\hline Apoptosis & $1.52 \mathrm{E}-07$ & 0.136 & 171 \\
\hline Spindle Apparatus Formation & $1.55 \mathrm{E}-07$ & 0.243 & 15 \\
\hline DNA Damage Response & $2.29 \mathrm{E}-07$ & 0 & 28 \\
\hline
\end{tabular}


Table 5-4: Changes in DNA damage repair proteins of $\mathrm{nFe}_{2} \mathrm{O}_{3}$-exposed cells (132 days) indicated by A) MSH2 mRNA transcript levels in $\mathrm{nFe}_{2} \mathrm{O}_{3}$ exposed cells (from ArrayStar analysis) and B) IPA analysis of transcript levels. FPKM: fragments per kilobase million; FC: fold change; Ratio: number of genes from dataset in pathway to total number of genes in pathway.

A)

\begin{tabular}{|l|l|l|l|l|}
\hline & Non-Treated FPKM & $\mathrm{nFe}_{2} \mathrm{O}_{3} \mathrm{FPKM}$ & $\log 2 \mathrm{FC}$ & $\mathrm{p}$ value \\
\hline MSH2 & 1.3061487 & 4.87338359 & 3.5676872 & 0.0364641 \\
\hline
\end{tabular}

B)

\begin{tabular}{|l|l|l|}
\hline & Expr Log Ratio & Expr $p$ value \\
\hline MSH2 & 3.568 & $3.65 \mathrm{E}-.02$ \\
\hline Rad51 & 1.207 & $4.10 \mathrm{E}-.02$ \\
\hline
\end{tabular}

Table 5-5: Change in autophagy-related protein (Beclin1) transcript levels in $\mathrm{nFe}_{2} \mathrm{O}_{3}$-exposed cells (132 days) as indicated by IPA analysis. Ratio: number of genes from dataset in pathway to total number of genes in pathway.

\begin{tabular}{|l|l|l|}
\hline & Expr Log Ratio & Expr $\mathrm{p}$ value \\
\hline Beclin & -1.055 & $1.36 \mathrm{E}-.02$ \\
\hline
\end{tabular}

Table 5-6: Change in iron homeostasis-related protein (Ferritin, FTH) transcript levels in GMA-MS exposed cells (132 days) as indicated by IPA analysis. Ratio: number of genes from dataset in pathway to total number of genes in pathway.

\begin{tabular}{|l|l|l|}
\hline & Expr Log Ratio & Expr p value \\
\hline FTH & -1.035 & $2.41 \mathrm{E}-.02$ \\
\hline
\end{tabular}



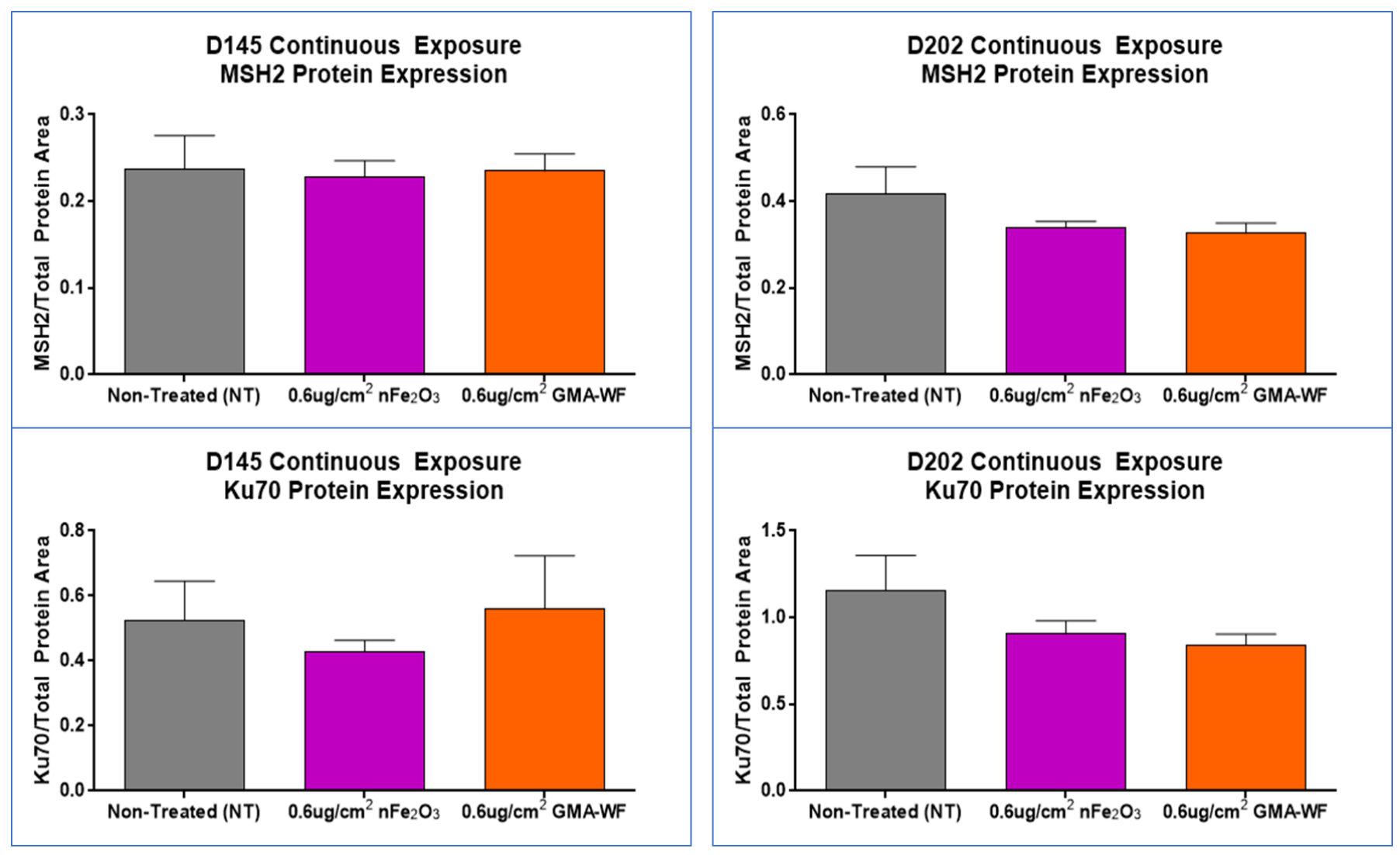

Figure 5-2: Expression of DNA damage repair proteins MSH2 and Ku70 at 145 and 202 days continuous exposure for non-treated, $\mathrm{nFe}_{2} \mathrm{O}_{3}$-treated, and GMA-MS-treated Beas-2B. Expression was normalized to total protein levels. Error bars indicate mean $\pm \operatorname{SE}(n=4)$. 


\section{D145 Continuous Exposure \\ 24hr Cisplatin Treatment}

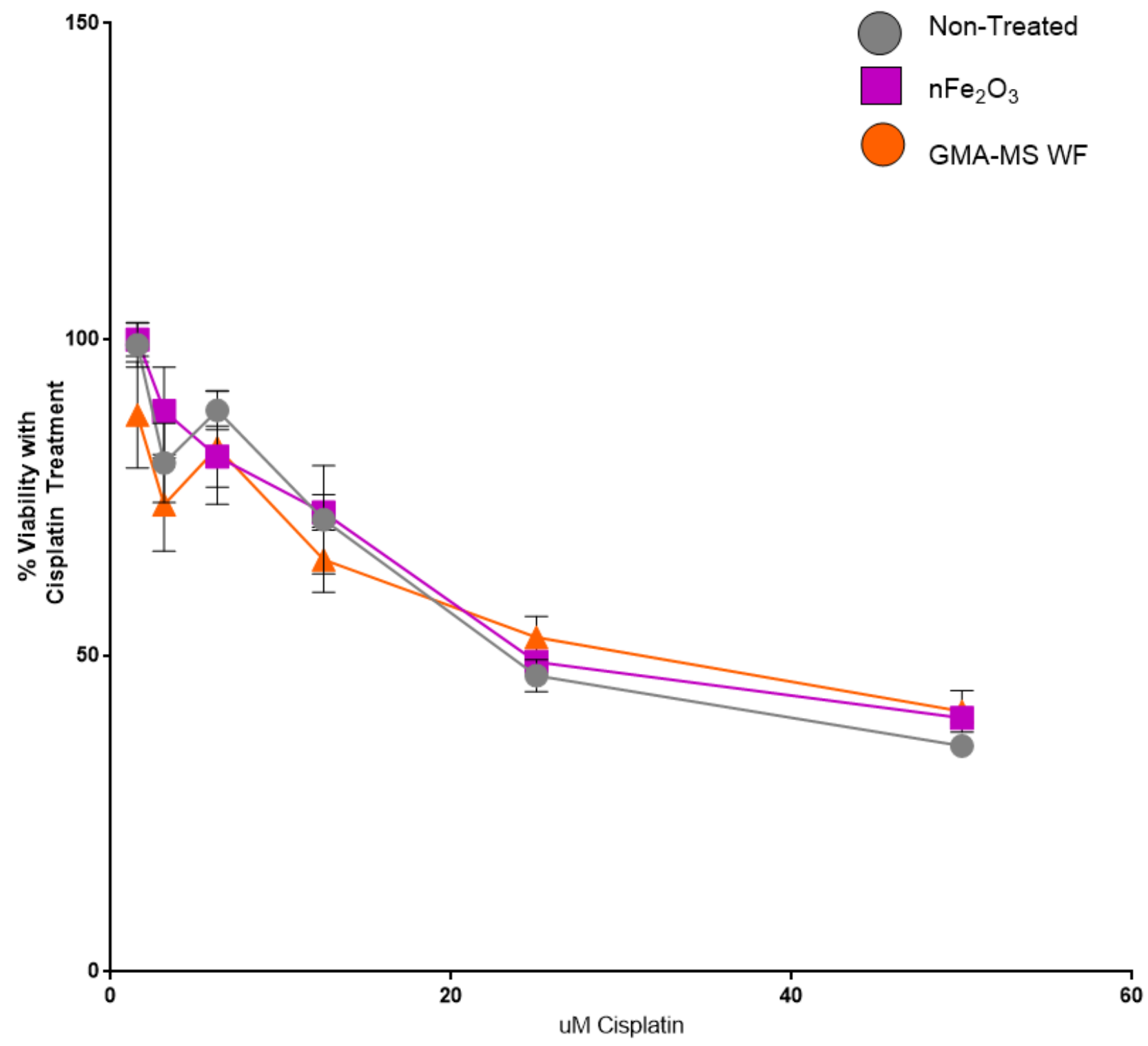

Figure 5-3: Percent Viability of sub chronic (145 days exposure) non-treated, $\mathrm{nFe}_{2} \mathrm{O}_{3}$-treated, and GMA-MS-treated Beas-2B cells with 24hr cisplatin exposure (0-50 $\mu \mathrm{M})$. Error bars indicate mean \pm SE $(n=4)$. 

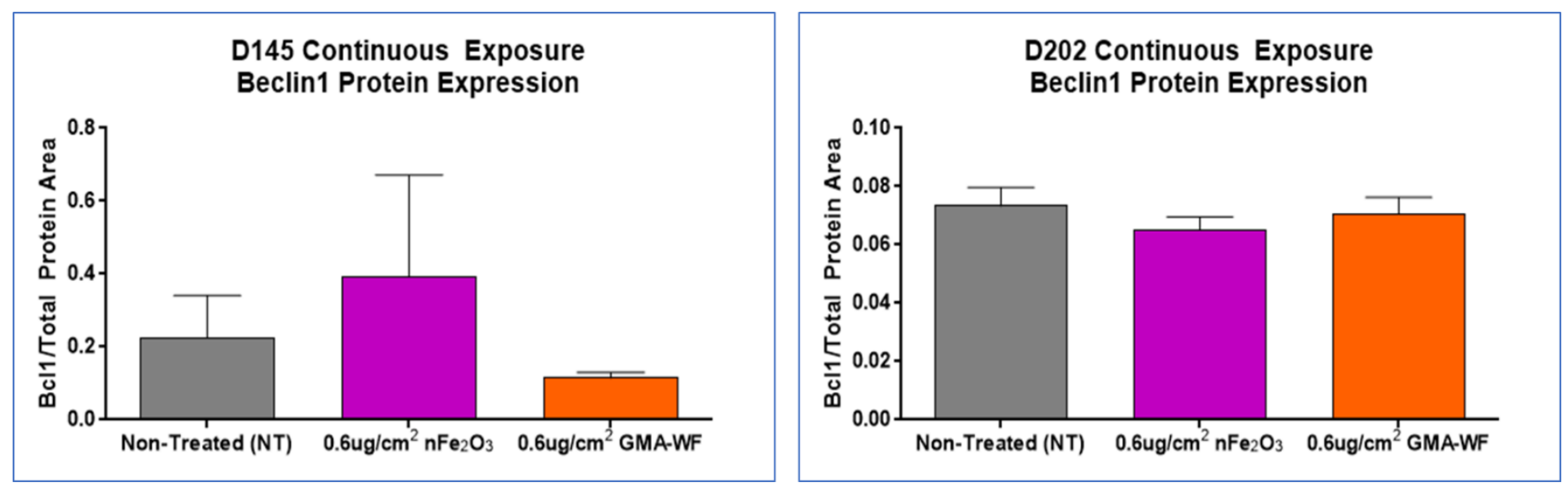

Figure 5-4: Expression of autophagy protein Beclin1 at 145 and 202 days continuous exposure for non-treated, $\mathrm{nFe}_{2} \mathrm{O}_{3}$-treated, and GMA-MS-treated Beas-2B. Expression was normalized to total protein levels. Error bars indicate mean $\pm S E(n=4)$. 

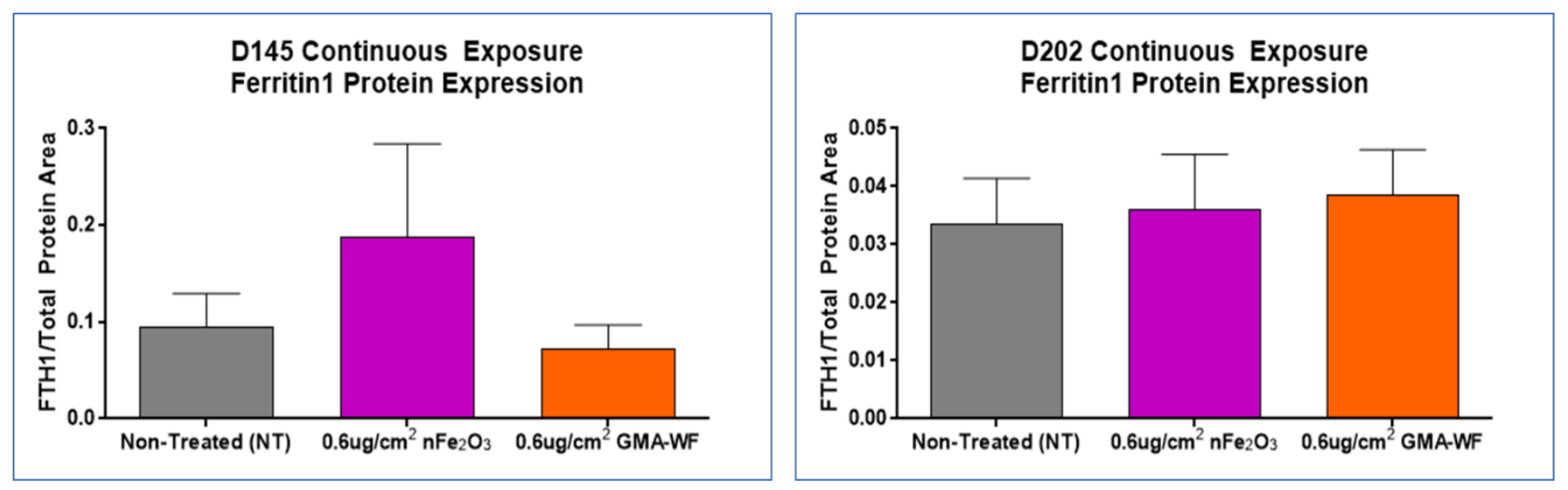

Figure 5-5: Expression of iron storage protein ferritin (FTH) at 145 and 202 days continuous exposure for non-treated, $\mathrm{nFe}_{2} \mathrm{O}_{3}$-treated, and GMA-MS-treated Beas-2B. Expression was normalized to total protein levels. Error bars indicate mean \pm SE $(n=4)$. 


\section{Chapter 6: Conclusions}

The overall goal of my dissertation project was to assess toxicity for two nano-metal oxides $\left(\mathrm{nFe}_{2} \mathrm{O}_{3}\right.$ and $\left.\mathrm{nCeO}_{2}\right)$, which had unclear toxicity profiles, within the context of physiologically relevant in vitro and in vivo model systems, as well as how the alteration of specific physicochemical properties which may impact their toxicity. The underlying concept of my work was to illustrate how the integration of in vivo and in vitro techniques may be used to gain a better understanding of potential adverse outcomes, while addressing the need for more rapid and costeffective methods to evaluate new and emerging materials with similarly unknown/unclear toxicity.

To address this, I first conducted a survey of what is known about IONP toxicity based on the current literature, and how critical issues with assay and model development may obscure actual IONP-induced adverse outcomes. I then utilized these concepts in a low dose/long term in vitro exposure model, to look at the impact of $\mathrm{nFe}_{2} \mathrm{O}_{3}$ on neoplastic-like cell transformation as a precursor to cancer-related adverse outcomes, as well as the use of an amorphous silica coating to alter particle surface chemistry, and how that may affect its toxicity. Through this, I was able to show $\mathrm{nFe}_{2} \mathrm{O}_{3}$ (as well as GMA-MS) could induce a neoplastic-like cell transformation, which matched recently published in vivo results with nearly identical particles. For this study, I used an alteration in particle chemistry/surface interaction (an amorphous silica coating) to demonstrate how changes in this physicochemical property may impact overall toxicity; and the addition of this coating was able to ablate nearly all $\mathrm{nFe}_{2} \mathrm{O}_{3}$ - or GMA-MS- induced cell changes. The direct impact of this study was to show the potential carcinogenic capacity of $\mathrm{nFe}_{2} \mathrm{O}_{3}$, the utility of a sub chronic in vitro study to assess this, and the value of using the known impact of specific physicochemical property changes to inform particle design and affect overall toxicity. 
Next, I showed size dependent toxicity of $\mathrm{nCeO}_{2}$ using chemically identical particles within an occupationally relevant in vivo exposure model. Through this study, I demonstrated correlation between size/surface area with $\mathrm{nCeO}_{2}$-induced pulmonary inflammation and pro-fibrosis. The initial goal was to match inflammation to fibrosis development in vivo with fibrotic markers in vitro. However, the minimal pro-fibrotic markers in vivo, likely due to issues with particle dispersion and blocked airways in exposed animals, may have obscured actual in vitro to in vivo translational results. Overall, this study shows how the alteration of a different physicochemical property - size - may have a critical impact on observed adverse outcomes, and that these may also be used to inform particle design to overall reduce risk for those who may be exposed. The confounding issues in this particular study - including particle dispersion and penetration inconsistencies - show the critical need for well informed particle characterization and study design before particle toxicity assessment.

Finally, I focused on the potential mechanism underlying $\mathrm{nFe}_{2} \mathrm{O}_{3}$-induced cell transformation using GNS sequencing and pathway analysis in conjunction with supporting literature, to show how properly designed in vitro studies may be used to glean information on underlying mechanisms of particle-induced toxicity. Our results showed that DNA damage, autophagy, and iron homeostasis may play critical roles in the observed neoplastic-like cell transformation, none of which have been well explored in the current literature for either $\mathrm{nFe}_{2} \mathrm{O}_{3}$ or GMA-MS. A better understanding of pathways which might impact $\mathrm{nFe}_{2} \mathrm{O}_{3}$ or GMA-MS transformation would allow for more informed study design, and could even lead to the use of some of these critical pathways as potential biomarkers for worker exposure or likely potential for cancer-related adverse outcomes.

The key objective of my dissertation work was to clearly show how the better integration of in vitro and in vivo techniques is critical both for a more clear understanding of particle-induced 
toxicity. A better integration of these techniques could help address the rapid surge in production and use for new and emerging particles with unknown toxicity profiles, having a critical impact on future particle toxicity methods. Without clear toxicity assessment methods in place to evaluate these particles, there is clear risk of exposure for workers and the general population. Better integration of cell culture and whole animal model-based techniques would allow for better assessment of particle toxicity at a pace in concordance with the recent surge in production and use of nanoparticles in general.

For my research, I focused on two chronic disease outcomes - pulmonary fibrosis and carcinogenesis. Both of these disease outcomes are understudied in the current literature, likely due to the extended length of time and high resource cost for these types of studies. By incorporating in vitro screening methods to assess these outcomes, there are clear applications to utilize this for other types of materials, and overall protect those at risk of development of these diseases due to recurring/chronic exposure.

As the production and use of new nanomaterials continues to increase, we need better ways to assess their potential toxicity and protect at risk workers. Current methods take too long, are too expensive, and may not accurately represent a human response. By better integrating in vitro and in vivo model systems, we can address these issues. However, this is reliant on the accuracy and predictiveness of the model systems used, and how those can translate to an animal or human toxicity response, especially for chronic disease states. Overall, my dissertation shows the critical nature of careful model design for nanoparticle toxicity studies. Without considering parameters such as particle agglomeration, deposition, exposure cell type, duration, particle interference, and others, it is impossible to make conclusions about particle toxicity which are useful to those who may be at risk of exposure. My dissertation project highlights unique ways in which these issues can be addressed, as well as additional factors which should be considered in the future. Overall, 
my dissertation project may have a critical impact on the future of nanotoxicology. The better integration of in vitro and in vivo techniques would allow for more rapid, accurate, and predictive toxicity testing for new and emerging particles. This would allow researchers to address critical knowledge gaps in nanoparticle toxicity, while protecting those who may be at risk of exposure to these materials. Through my dissertation work, I showed the potential for these types of strategies using two different nano-metal oxides $\left(\mathrm{nCeO}_{2}\right.$ and $\left.\mathrm{nFe}_{2} \mathrm{O}_{3}\right)$ within the context of physiologically relevant in vitro and in vivo models, and looked at their potential to induce chronic disease outcomes. The ultimate goal would be to utilize these ideas for materials with unclear/unknown toxicity profiles, to protect those who may be at risk of exposure, and positively impact nanoparticle design, development, and use in the workplace. 


\section{References:}

(1) Evangelista, A. C. J.; de Morais, J. F.; Tam, V.; Soomro, M.; Di Gregorio, L. T.; Haddad, A. N. Evaluation of Carbon Nanotube Incorporation in Cementitious Composite Materials. Materials (Basel). 2019, 12 (8).

(2) Lu, W.; Zu, M.; Byun, J. H.; Kim, B. S.; Chou, T. W. State of the Art of Carbon Nanotube Fibers: Opportunities and Challenges. Adv. Mater. 2012, 24 (14), 1805-1833.

(3) Cassee, F. R.; van Balen, E. C.; Singh, C.; Green, D.; Muijser, H.; Weinstein, J.; Dreher, K. Exposure, Health and Ecological Effects Review of Engineered Nanoscale Cerium and Cerium Oxide Associated with Its Use as a Fuel Additive. Crit. Rev. Toxicol. 2011, 41 (3), 213-229.

(4) Zhu, L.; Zhou, Z.; Mao, H.; Yang, L. Magnetic Nanoparticles for Precision Oncology: Theranostic Magnetic Iron Oxide Nanoparticles for Image-Guided and Targeted Cancer Therapy. Nanomedicine 2017, 12 (1), 73-87.

(5) Global Nanotechnology Market 2018-2024: Market is Expected to Exceed US\$ 125 Billion https://www.prnewswire.com/news-releases/global-nanotechnology-market-2018-2024market-is-expected-to-exceed-us-125-billion-300641054.html (accessed Jul 9, 2019).

(6) Baldauf, R. W.; Devlin, R. B.; Gehr, P.; Giannelli, R.; Hassett-Sipple, B.; Jung, H.; Martini, G.; McDonald, J.; Sacks, J. D.; Walker, K. Ultrafine Particle Metrics and Research Considerations: Review of the 2015 UFP Workshop. Int. J. Environ. Res. Public Health 2016, 13 (11).

(7) Kobayashi, N.; Naya, M.; Endoh, S.; Maru, J.; Yamamoto, K.; Nakanishi, J. Comparative Pulmonary Toxicity Study of Nano-TiO(2) Particles of Different Sizes and Agglomerations in Rats: Different Short- and Long-Term Post-Instillation Results. Toxicology 2009, 264 (1-2), $110-118$.

(8) Winkler, D. A.; Mombelli, E.; Pietroiusti, A.; Tran, L.; Worth, A.; Fadeel, B.; McCall, M. J. 
Applying Quantitative Structure-Activity Relationship Approaches to Nanotoxicology:

Current Status and Future Potential. Toxicology 2013, 313 (1), 15-23.

(9) Kumar, A.; Dhawan, A. Genotoxic and Carcinogenic Potential of Engineered Nanoparticles:

An Update. Arch. Toxicol. 2013, 87 (11), 1883-1900.

(10) Fröhlich, E. Cellular Elimination of Nanoparticles. Environ. Toxicol. Pharmacol. 2016, 46, 9094.

(11) Huang, Y. W.; Cambre, M.; Lee, H. J. The Toxicity of Nanoparticles Depends on Multiple Molecular and Physicochemical Mechanisms. Int. J. Mol. Sci. 2017, 18 (12).

(12) Ohta, K.; Cohen, R. E.; Hirose, K.; Haule, K.; Shimizu, K.; Ohishi, Y. Experimental and Theoretical Evidence for Pressure-Induced Metallization in FeO with Rocksalt-Type Structure. Phys. Rev. Lett. 2012, 108 (2), 026403.

(13) Helmenstine, A. M. Tattoo Ink Chemistry https://www.thoughtco.com/tattoo-inkchemistry-606170 (accessed Jul 28, 2017).

(14) RTI Contract Report; 2014.

(15) Hoff, D.; Sheikh, L.; Bhattacharya, S.; Nayar, S.; Webster, T. J. Comparison Study of Ferrofluid and Powder Iron Oxide Nanoparticle Permeability across the Blood-Brain Barrier. Int. J. Nanomedicine 2013, 8, 703-710.

(16) Peng, X.-H.; Qian, X.; Mao, H.; Wang, A. Y.; Chen, Z. G.; Nie, S.; Shin, D. M. Targeted Magnetic Iron Oxide Nanoparticles for Tumor Imaging and Therapy. Int. J. Nanomedicine 2008, 3 (3), $311-321$.

(17) Sotiriou, G. A.; Singh, D.; Zhang, F.; Chalbot, M.-C. G.; Spielman-Sun, E.; Hoering, L.; Kavouras, I. G.; Lowry, G. V; Wohlleben, W.; Demokritou, P. Thermal Decomposition of Nano-Enabled Thermoplastics: Possible Environmental Health and Safety Implications. J. Hazard. Mater. 2016, 305, 87-95. 
(18) Billings, C. G.; Howard, P. Occupational Siderosis and Welders' Lung: A Review. Monaldi Arch. chest Dis. $=$ Arch. Monaldi per le Mal. del torace / Fond. Clin. del Lav. IRCCS [and] Ist. di Clin. Tisiol. e Mal. Appar. Respir. Univ. di Napoli, Second. ateneo 1993, 48 (4), 304-314.

(19) Ghio, A. J.; Soukup, J. M.; Dailey, L. A. Air Pollution Particles and Iron Homeostasis. Biochim. Biophys. Acta - Gen. Subj. 2016, 1860 (12), 2816-2825.

(20) Xing, M.; Zhang, Y.; Zou, H.; Quan, C.; Chang, B.; Tang, S.; Zhang, M. Exposure Characteristics of Ferric Oxide Nanoparticles Released during Activities for Manufacturing Ferric Oxide Nanomaterials. Inhal Toxicol 2015, 27 (3), 138-148.

(21) Pelclova, D.; Zdimal, V.; Kacer, P.; Fenclova, Z.; Vlckova, S.; Syslova, K.; Navratil, T.; Schwarz, J.; Zikova, N.; Barosova, H.; et al. Oxidative Stress Markers Are Elevated in Exhaled Breath Condensate of Workers Exposed to Nanoparticles during Iron Oxide Pigment Production. J Breath Res 2016, 10 (1), 16004.

(22) Park, E. J.; Kim, H.; Kim, Y.; Yi, J.; Choi, K.; Park, K. Inflammatory Responses May Be Induced by a Single Intratracheal Instillation of Iron Nanoparticles in Mice. Toxicology 2010, 275 (13), 65-71.

(23) Park, E. J.; Oh, S. Y.; Lee, S. J.; Lee, K.; Kim, Y.; Lee, B. S.; Kim, J. S. Chronic Pulmonary Accumulation of Iron Oxide Nanoparticles Induced Th1-Type Immune Response Stimulating the Function of Antigen-Presenting Cells. Env. Res 2015, 143 (Pt A), 138-147.

(24) Sadeghi, L.; Yousefi Babadi, V.; Espanani, H. R. Toxic Effects of the Fe2O3 Nanoparticles on the Liver and Lung Tissue. Bratisl. lekárske List. 2015, 116 (6), 373-378.

(25) Srinivas, A.; Rao, P. J.; Selvam, G.; Goparaju, A.; Murthy, P. B.; Reddy, P. N. Oxidative Stress and Inflammatory Responses of Rat Following Acute Inhalation Exposure to Iron Oxide Nanoparticles. Hum. Exp. Toxicol. 2012, 31 (11), 1113-1131.

(26) Ban, M.; Langonne, I.; Huguet, N.; Guichard, Y.; Goutet, M. Iron Oxide Particles Modulate the 156 | Ko rn berg 
Ovalbumin-Induced Th2 Immune Response in Mice. Toxicol Lett 2013, 216 (1), 31-39.

(27) Gustafsson, A.; Bergstrom, U.; Agren, L.; Osterlund, L.; Sandstrom, T.; Bucht, A. Differential Cellular Responses in Healthy Mice and in Mice with Established Airway Inflammation When Exposed to Hematite Nanoparticles. Toxicol Appl Pharmacol 2015, 288 (1), 1-11.

(28) Zhu, M.-T.; Feng, W.-Y.; Wang, Y.; Wang, B.; Wang, M.; Ouyang, H.; Zhao, Y.-L.; Chai, Z.-F. Particokinetics and Extrapulmonary Translocation of Intratracheally Instilled Ferric Oxide Nanoparticles in Rats and the Potential Health Risk Assessment. Toxicol. Sci. 2009, 107 (2), $342-351$.

(29) Al Faraj, A.; Shaik, A. P.; Shaik, A. S. Effect of Surface Coating on the Biocompatibility and in Vivo MRI Detection of Iron Oxide Nanoparticles after Intrapulmonary Administration. Nanotoxicology 2015, 9 (7), 825-834.

(30) Totsuka, Y.; Ishino, K.; Kato, T.; Goto, S.; Tada, Y.; Nakae, D.; Watanabe, M.; Wakabayashi, K. Magnetite Nanoparticles Induce Genotoxicity in the Lungs of Mice via Inflammatory Response. Nanomaterials 2014, 4 (1), 175-188.

(31) Ishino, K.; Kato, T.; Kato, M.; Shibata, T.; Watanabe, M.; Wakabayashi, K.; Nakagama, H.; Totsuka, Y. Comprehensive DNA Adduct Analysis Reveals Pulmonary Inflammatory Response Contributes to Genotoxic Action of Magnetite Nanoparticles. Int J Mol Sci 2015, 16 (2), 3474-3492.

(32) Wang, L.; Wang, L.; Ding, W.; Zhang, F. Acute Toxicity of Ferric Oxide and Zinc Oxide Nanoparticles in Rats. J Nanosci Nanotechnol 2010, 10 (12), 8617-8624.

(33) Boyd, J. T.; Doll, R.; Faulds, J. S.; Leiper, J. Cancer of the Lung in Iron Ore (Haematite) Miners. Br J Ind Med 1970, 27 (2), 97-105.

(34) Faulds, J. S.; Stewart, M. J. Carcinoma of the Lung in Hæmatite Miners. J. Pathol. Bacteriol. 1956, 72 (2), 353-366. 
(35) Bjor, B.; Burstrom, L.; Jonsson, H.; Nathanaelsson, L.; Damber, L.; Nilsson, T. Fifty-Year Follow-up of Mortality among a Cohort of Iron-Ore Miners in Sweden, with Specific Reference to Myocardial Infarction Mortality. Occup Env. Med 2009, 66 (4), 264-268.

(36) Chen, S. Y.; Hayes, R. B.; Liang, S. R.; Li, Q. G.; Stewart, P. A.; Blair, A. Mortality Experience of Haematite Mine Workers in China. BrJ Ind Med 1990, 47 (3), 175-181.

(37) Ghio, A. J. Disruption of Iron Homeostasis and Lung Disease. Biochim. Biophys. Acta - Gen. Subj. 2009, 1790 (7), 731-739.

(38) Services, N. J. D. of H. and S. Hazardous Substance Fact Sheet - Iron Oxide; 2007.

(39) Kennaway, E. L.; Kennaway, N. M. A Further Study of the Incidence of Cancer of the Lung and Larynx. Br. J. Cancer 1947, 1 (3), 260-298.

(40) Turner, H. M.; Grace, H. G. An Investigation into Cancer Mortality among Males in Certain Sheffield Trades. J. Hyg. (Lond). 1938, 38 (1), 90-103.

(41) Charbgoo, F.; Ahmad, M.; Darroudi, M. Cerium Oxide Nanoparticles: Green Synthesis and Biological Applications. Int. J. Nanomedicine 2017, Volume 12, 1401-1413.

Dale, J. G.; Cox, S. S.; Vance, M. E.; Marr, L. C.; Hochella, M. F. Transformation of Cerium Oxide Nanoparticles from a Diesel Fuel Additive during Combustion in a Diesel Engine. Environ. Sci. Technol. 2017, 51 (4), 1973-1980.

(43) Snow, S. J.; McGee, J.; Miller, D. B.; Bass, V.; Schladweiler, M. C.; Thomas, R. F.; Krant, T.; King, C.; Ledbetter, A. D.; Richards, J.; et al. Inhaled Diesel Emissions Generated with Cerium Oxide Nanoparticle Fuel Additive Induce Adverse Pulmonary and Systemic Effects. Toxicol. Sci. 2014, 142 (2), 403-417.

(44) Gómez-Aracena, J.; Riemersma, R. A.; Gutiérrez-Bedmar, M.; Bode, P.; Kark, J. D.; GarciaRodríguez, A.; Gorgojo, L.; Veer, P. van t; Fernández-Crehuet, J.; Kok, F. J.; et al. Toenail Cerium Levels and Risk of a First Acute Myocardial Infarction: The EURAMIC and Heavy 
Metals Study. Chemosphere 2006, 64 (1), 112-120.

(45) Nemmar, A.; Yuvaraju, P.; Beegam, S.; Fahim, M. A.; Ali, B. H. Cerium Oxide Nanoparticles in Lung Acutely Induce Oxidative Stress, Inflammation, and DNA Damage in Various Organs of Mice. Oxid. Med. Cell. Longev. 2017, 2017 (96).

(46) Lyu, G. M.; Wang, Y. J.; Huang, X.; Zhang, H. Y.; Sun, L. D.; Liu, Y. J.; Yan, C. H. Hydrophilic CeO2 Nanocubes Protect Pancreatic $\beta$-Cell Line INS-1 from H2O2-Induced Oxidative Stress. Nanoscale 2016, 8 (15), 7923-7932.

(47) Ghaznavi, H.; Najafi, R.; Mehrzadi, S.; Hosseini, A.; Tekyemaroof, N.; Shakeri-Zadeh, A.; Rezayat, M.; Sharifi, A. M. Neuro-Protective Effects of Cerium and Yttrium Oxide Nanoparticles on High Glucose-Induced Oxidative Stress and Apoptosis in Undifferentiated PC12 Cells. Neurol. Res. 2015, 37 (7), 624-632.

(48) Dunnick, K. M.; Pillai, R.; Pisane, K. L.; Stefaniak, A. B.; Sabolsky, E. M.; Leonard, S. S. The Effect of Cerium Oxide Nanoparticle Valence State on Reactive Oxygen Species and Toxicity. Biol. Trace Elem. Res. 2015, 166 (1), 96-107.

(49) Ma, J. Y.; Zhao, H.; Mercer, R. R.; Barger, M.; Rao, M.; Meighan, T.; Schwegler-Berry, D.; Castranova, V.; Ma, J. K. Cerium Oxide Nanoparticle-Induced Pulmonary Inflammation and Alveolar Macrophage Functional Change in Rats. Nanotoxicology 2011, 5 (3), 312-325.

(50) Ma, J.; Mercer, R. R.; Barger, M.; Schwegler-Berry, D.; Cohen, J. M.; Demokritou, P.; Castranova, V. Effects of Amorphous Silica Coating on Cerium Oxide Nanoparticles Induced Pulmonary Responses. Toxicol. Appl. Pharmacol. 2015, 288 (1), 63-73.

(51) Srinivas, A.; Rao, P. J.; Selvam, G.; Murthy, P. B.; Reddy, P. N. Acute Inhalation Toxicity of Cerium Oxide Nanoparticles in Rats. Toxicol. Lett. 2011, 205 (2), 105-115.

(52) Metals, E. Cerium Safety Data Sheet; 2015.

(53) NewportGlass. Cerium Oxide Material Safety Data Sheet; 2015. 
(54) Fischer, H. C.; Chan, W. C. Nanotoxicity: The Growing Need for in Vivo Study. Curr. Opin. Biotechnol. 2007, 18 (6), 565-571.

(55) National Research Council. Values and Limitations of Animal Toxicity Data. In Intentional Human Dosing Studies for Epa Regulatory Purposes: Scientific and Ethical Issues; 2004.

(56) Roggen, E. L. In Vitro Toxicity Testing in the Twenty-First Century. Front. Pharmacol. 2011, 2 (3).

(57) McKim, J. M. Building a Tiered Approach to in Vitro Predictive Toxicity Screening: A Focus on Assays with in Vivo Relevance. Comb. Chem. High Throughput Screen. 2010, 13 (2), 188206.

(58) WHO. RISK FACTORS FOR CHRONIC RESPIRATORY 9 . Causes and Consequences of Chronic Respiratory Diseases Each Year : World Heal. Organ. 2000.

(59) Multhoff, G.; Molls, M.; Radons, J. Chronic Inflammation in Cancer Development. Front. Immunol. 2012, 2 (98).

(60) Development, O. for E. C. and. GUIDANCE DOCUMENT 116 ON THE CONDUCT AND DESIGN OF CHRONIC TOXICITY AND CARCINOGENICITY STUDIES, SUPPORTING TEST GUIDELINES.

(61) Organization for Economic Cooperation and Development (OECD). DETAILED REVIEW PAPER ON CELL TRANSFORMATION ASSAYS FOR DETECTION OF CHEMICAL CARCINOGENS.

(62) Bruinink, A.; Wang, J.; Wick, P. Effect of Particle Agglomeration in Nanotoxicology. Archives of Toxicology. 2015.

(63) Utembe, W.; Potgieter, K.; Stefaniak, A. B.; Gulumian, M. Dissolution and Biodurability: Important Parameters Needed for Risk Assessment of Nanomaterials. Part. Fibre Toxicol. 2015, 12 (11).

(64) DeLoid, G.; Cohen, J. M.; Darrah, T.; Derk, R.; Rojanasakul, L.; Pyrgiotakis, G.; Wohlleben, W.; 
Demokritou, P. Estimating the Effective Density of Engineered Nanomaterials for in Vitro Dosimetry. Nat. Commun. 2014, 5 (1), 3514.

(65) Cohen, J.; DeLoid, G.; Pyrgiotakis, G.; Demokritou, P. Interactions of Engineered Nanomaterials in Physiological Media and Implications for in Vitro Dosimetry. Nanotoxicology 2013, 7 (4), 417-431.

(66) DeLoid, G. M.; Cohen, J. M.; Pyrgiotakis, G.; Pirela, S. V; Pal, A.; Liu, J.; Srebric, J.; Demokritou, P. Advanced Computational Modeling for in Vitro Nanomaterial Dosimetry. Part. Fibre Toxicol. 2015, 12, 32.

(67) Roth, A. Advanced Cell Models, Organs on a Chip \& Microphysiological Systems in Drug Development: The Need, the Vision-and Challenges to Overcome.

(68) Hartung, T. Perspectives on in Vitro to in Vivo Extrapolations. Applied In Vitro Toxicology. 2018.

(69) Kain, J.; Karlsson, H. L.; Moller, L. DNA Damage Induced by Micro- and Nanoparticles-Interaction with FPG Influences the Detection of DNA Oxidation in the Comet Assay. Mutagenesis 2012, 27 (4), 491-500.

(70) Soenen, S. J.; De Cuyper, M. Assessing Cytotoxicity of (Iron Oxide-Based) Nanoparticles: An Overview of Different Methods Exemplified with Cationic Magnetoliposomes. Contrast Media Mol Imaging 2009, 4 (5), 207-219.

(71) Veranth, J. M.; Kaser, E. G.; Veranth, M. M.; Koch, M.; Yost, G. S. Cytokine Responses of Human Lung Cells (BEAS-2B) Treated with Micron-Sized and Nanoparticles of Metal Oxides Compared to Soil Dusts. Part Fibre Toxicol 2007, 4, 2.

(72) Armstead, A. L.; Li, B. Nanotoxicity: Emerging Concerns Regarding Nanomaterial Safety and Occupational Hard Metal (WC-Co) Nanoparticle Exposure. Int. J. Nanomedicine 2016, 11 (6421-6433). 
(73) Doll, R. Occupational Lung Cancer: A Review. Br J Ind Med 1959, 16, 181-190.

(74) Moulin, J. J.; Clavel, T.; Roy, D.; Dananche, B.; Marquis, N.; Fevotte, J.; Fontana, J. M. Risk of Lung Cancer in Workers Producing Stainless Steel and Metallic Alloys. Int Arch Occup Env. Heal. 2000, 73 (3), 171-180.

(75) Bourgkard, E.; Wild, P.; Courcot, B.; Diss, M.; Ettlinger, J.; Goutet, P.; Hemon, D.; Marquis, N.; Mur, J. M.; Rigal, C.; et al. Lung Cancer Mortality and Iron Oxide Exposure in a French SteelProducing Factory. Occup Env. Med 2009, 66 (3), 175-181.

(76) Teculescu, D.; Albu, A. Pulmonary Function in Workers Inhaling Iron Oxide Dust. Int Arch Arbeitsmed 1973, 31 (2), 163-170.

(77) Hematite: A primary ore of iron and a pigment mineral http://geology.com/minerals/hematite.shtml (accessed Jul 28, 2017).

(78) University of Minnesota. Magnetite: Ferric and Ferrous Oxides, Oxide Mineral Class https://www.esci.umn.edu/courses/1001/minerals/magnetite.shtml.

(79) Siew, S. S.; Kauppinen, T.; Kyyronen, P.; Heikkila, P.; Pukkala, E. Exposure to Iron and Welding Fumes and the Risk of Lung Cancer. Scand J Work Env. Heal. 2008, 34 (6), 444-450.

(80) Duffin, R.; Tran, L.; Brown, D.; Stone, V.; Donaldson, K. Proinflammogenic Effects of LowToxicity and Metal Nanoparticles In Vivo and In Vitro: Highlighting the Role of Particle Surface Area and Surface Reactivity. Inhal. Toxicol. 2008, 19 (10), 849-856.

(81) Andujar, P.; Simon-Deckers, A.; Galateau-Sallé, F.; Fayard, B.; Beaune, G.; Clin, B.; BillonGalland, M.-A.; Durupthy, O.; Pairon, J.-C.; Doucet, J.; et al. Role of Metal Oxide Nanoparticles in Histopathological Changes Observed in the Lung of Welders. Part. Fibre Toxicol. 2014, 11, 23.

(82) Zhu, M. T.; Feng, W. Y.; Wang, B.; Wang, T. C.; Gu, Y. Q.; Wang, M.; Wang, Y.; Ouyang, H.; Zhao, Y. L.; Chai, Z. F. Comparative Study of Pulmonary Responses to Nano- and Submicron-Sized 
Ferric Oxide in Rats. Toxicology 2008, 247 (2-3), 102-111.

(83) Szalay, B.; Tatrai, E.; Nyiro, G.; Vezer, T.; Dura, G. Potential Toxic Effects of Iron Oxide Nanoparticles in in Vivo and in Vitro Experiments. J Appl Toxicol 2012, 32 (6), 446-453.

(84) Beaver, L. M.; Stemmy, E. J.; Schwartz, A. M.; Damsker, J. M.; Constant, S. L.; Ceryak, S. M.; Patierno, S. R. Lung Inflammation, Injury, and Proliferative Response after Repetitive Particulate Hexavalent Chromium Exposure. Environ. Health Perspect. 2009, 117 (12), 1896-1902.

(85) Sayers, B. C.; Germolec, D. R.; Walker, N. J.; Shipkowski, K. A.; Stout, M. D.; Cesta, M. F.; Roycroft, J. H.; White, K. L.; Baker, G. L.; Dill, J. A.; et al. Respiratory Toxicity and Immunotoxicity Evaluations of Microparticle and Nanoparticle C60 Fullerene Aggregates in Mice and Rats Following Nose-Only Inhalation for 13 Weeks. Nanotoxicology 2016, 10 (10), 1458-1468.

(86) Ma, J. Y.; Mercer, R. R.; Barger, M.; Schwegler-Berry, D.; Scabilloni, J.; Ma, J. K.; Castranova, V. Induction of Pulmonary Fibrosis by Cerium Oxide Nanoparticles. Toxicol. Appl. Pharmacol. 2012, $262(3), 255-264$.

(87) Valdiglesias, V.; Fernandez-Bertolez, N.; Kilic, G.; Costa, C.; Costa, S.; Fraga, S.; Bessa, M. J.; Pasaro, E.; Teixeira, J. P.; Laffon, B. Are Iron Oxide Nanoparticles Safe? Current Knowledge and Future Perspectives. J Trace Elem Med Biol 2016, 38, 53-63.

(88) Singh, N.; Manshian, B.; Jenkins, G. J. S.; Griffiths, S. M.; Williams, P. M.; Maffeis, T. G. G.; Wright, C. J.; Doak, S. H. NanoGenotoxicology: The DNA Damaging Potential of Engineered Nanomaterials. Biomaterials 2009, 30 (23-24), 3891-3914.

(89) Pease, C.; Rucker, T.; Birk, T. Review of the Evidence from Epidemiology, Toxicology, and Lung Bioavailability on the Carcinogenicity of Inhaled Iron Oxide Particulates. Chem Res Toxicol 2016, 29 (3), 237-254. 
(90) Toyokuni, S. Role of Iron in Carcinogenesis: Cancer as a Ferrotoxic Disease. Cancer Sci 2009, 100 (1), 9-16.

(91) Campbell, J. A. Effects of Precipitated Silica and of Iron Oxide on the Incidence of Primary Lung Tumours in Mice. Br Med J 1940, 2 (4156), 275-280.

(92) Nemmar, A.; Beegam, S.; Yuvaraju, P.; Yasin, J.; Tariq, S.; Attoub, S.; Ali, B. H. Ultrasmall Superparamagnetic Iron Oxide Nanoparticles Acutely Promote Thrombosis and Cardiac Oxidative Stress and DNA Damage in Mice. Part. Fibre Toxicol. 2016, 13 (1), 22.

(93) Coricovac, D.-E.; Moacă, E.-A.; Pinzaru, I.; Cîtu, C.; Soica, C.; Mihali, C.-V.; Păcurariu, C.; Tutelyan, V. A.; Tsatsakis, A.; Dehelean, C.-A. Biocompatible Colloidal Suspensions Based on Magnetic Iron Oxide Nanoparticles: Synthesis, Characterization and Toxicological Profile. Front. Pharmacol. 2017, 8, 154.

(94) Karlsson, H. L.; Gustafsson, J.; Cronholm, P.; Moller, L. Size-Dependent Toxicity of Metal Oxide Particles--a Comparison between Nano- and Micrometer Size. Toxicol Lett 2009, 188 (2), 112-118.

(95) Freyria, F. S.; Bonelli, B.; Tomatis, M.; Ghiazza, M.; Gazzano, E.; Ghigo, D.; Garrone, E.; Fubini, B. Hematite Nanoparticles Larger than $90 \mathrm{Nm}$ Show No Sign of Toxicity in Terms of Lactate Dehydrogenase Release, Nitric Oxide Generation, Apoptosis, and Comet Assay in Murine Alveolar Macrophages and Human Lung Epithelial Cells. Chem Res Toxicol 2012, 25 (4), $850-861$.

(96) Kodali, V.; Littke, M. H.; Tilton, S. C.; Teeguarden, J. G.; Shi, L.; Frevert, C. W.; Wang, W.; Pounds, J. G.; Thrall, B. D. Dysregulation of Macrophage Activation Profiles by Engineered Nanoparticles. ACS Nano 2013, 7 (8), 6997-7010.

(97) Dwivedi, S.; Siddiqui, M. A.; Farshori, N. N.; Ahamed, M.; Musarrat, J.; Al-Khedhairy, A. A. Synthesis, Characterization and Toxicological Evaluation of Iron Oxide Nanoparticles in 
Human Lung Alveolar Epithelial Cells. Colloids Surf B Biointerfaces 2014, 122, 209-215.

(98) Bhattacharya, K.; Davoren, M.; Boertz, J.; Schins, R. P.; Hoffmann, E.; Dopp, E. Titanium Dioxide Nanoparticles Induce Oxidative Stress and DNA-Adduct Formation but Not DNABreakage in Human Lung Cells. Part Fibre Toxicol 2009, 6, 17.

(99) Sighinolfi, G. L.; Artoni, E.; Gatti, A. M.; Corsi, L. Carcinogenic Potential of Metal Nanoparticles in BALB/3T3 Cell Transformation Assay. Env. Toxicol 2016, 31 (5), 509-519.

(100) Teeguarden, J. G.; Mikheev, V. B.; Minard, K. R.; Forsythe, W. C.; Wang, W.; Sharma, G.; Karin, N.; Tilton, S. C.; Waters, K. M.; Asgharian, B.; et al. Comparative Iron Oxide Nanoparticle Cellular Dosimetry and Response in Mice by the Inhalation and Liquid Cell Culture Exposure Routes. Part Fibre Toxicol 2014, 11, 46.

(101) Watanabe, M.; Yoneda, M.; Morohashi, A.; Hori, Y.; Okamoto, D.; Sato, A.; Kurioka, D.; Nittami, T.; Hirokawa, Y.; Shiraishi, T.; et al. Effects of Fe304 Magnetic Nanoparticles on A549 Cells. Int J Mol Sci 2013, 14 (8), 15546-15560.

(102) Chen, Z.; Yin, J.-J.; Zhou, Y.-T.; Zhang, Y.; Song, L.; Song, M.; Hu, S.; Gu, N. Dual Enzyme-like Activities of Iron Oxide Nanoparticles and Their Implication for Diminishing Cytotoxicity. ACS Nano 2012, 6 (5), 4001-4012.

(103) Park, E. J.; Umh, H. N.; Choi, D. H.; Cho, M. H.; Choi, W.; Kim, S. W.; Kim, Y.; Kim, J. H. Magnetite- and Maghemite-Induced Different Toxicity in Murine Alveolar Macrophage Cells. Arch Toxicol 2014, 88 (8), 1607-1618.

(104) Park, E. J.; Umh, H. N.; Kim, S. W.; Cho, M. H.; Kim, J. H.; Kim, Y. ERK Pathway Is Activated in Bare-FeNPs-Induced Autophagy. Arch Toxicol 88 (2), 323-336.

(105) Watson, C.; Ge, J.; Cohen, J.; Pyrgiotakis, G.; Engelward, B. P.; Demokritou, P. HighThroughput Screening Platform for Engineered Nanoparticle-Mediated Genotoxicity Using CometChip Technology. ACS Nano 2014, 8 (3), 2118-2133. 
(106) Stueckle, T. A.; Davidson, D. C.; Derk, R.; Kornberg, T. G.; Schwegler-Berry, D.; Pirela, S. V.;

Deloid, G.; Demokritou, P.; Luanpitpong, S.; Rojanasakul, Y.; et al. Evaluation of Tumorigenic Potential of $\mathrm{CeO} 2$ and Fe2O3 Engineered Nanoparticles by a Human Cell in Vitro Screening Model. NanoImpact 2017, 6, 39-54.

(107) Donaldson, K.; Schinwald, A.; Murphy, F.; Cho, W. S.; Duffin, R.; Tran, L.; Poland, C. The Biologically Effective Dose in Inhalation Nanotoxicology. Acc Chem Res 2013, 46 (3), 723732.

(108) Tenopoulou, M.; Doulias, P. T.; Barbouti, A.; Brunk, U.; Galaris, D. Role of Compartmentalized Redox-Active Iron in Hydrogen Peroxide-Induced DNA Damage and Apoptosis. Biochem J 2005, 387 (Pt 3), 703-710.

(109) Galaris, D.; Pantopoulos, K. Oxidative Stress and Iron Homeostasis: Mechanistic and Health Aspects. Crit Rev Clin Lab Sci 2008, 45 (1), 1-23.

(110) Malvindi, M. A.; De Matteis, V.; Galeone, A.; Brunetti, V.; Anyfantis, G. C.; Athanassiou, A.; Cingolani, R.; Pompa, P. P. Toxicity Assessment of Silica Coated Iron Oxide Nanoparticles and Biocompatibility Improvement by Surface Engineering. PLoS One 2014, 9 (1), e85835.

(111) Ghio, A. J.; Soukup, J. M.; Dailey, L. A.; Richards, J. H.; Turi, J. L.; Pavlisko, E. N.; Roggli, V. L. Disruption of Iron Homeostasis in Mesothelial Cells after Talc Pleurodesis. Am. J. Respir. Cell Mol. Biol. 2012, 46 (1), 80-86.

(112) Ghio, A. J.; Turi, J. L.; Yang, F.; Garrick, L. M.; Garrick, M. D. Iron Homeostasis in the Lung. Biol. Res. 2006, 39 (1), 67-77.

(113) Giorgi, G.; D’Anna, M. C.; Roque, M. E. Iron Homeostasis and Its Disruption in Mouse Lung in Iron Deficiency and Overload. Exp Physiol 2015, 100 (10), 1199-1216.

(114) Wang, X.; Ghio, A. J.; Yang, F.; Dolan, K. G.; Garrick, M. D.; Piantadosi, C. A. Iron Uptake and Nramp2/DMT1/DCT1 in Human Bronchial Epithelial Cells. Am J Physiol Lung Cell Mol 
Physiol 2002, 282 (5), L987-95.

(115) Kartikasari, A. E.; Georgiou, N. A.; Visseren, F. L.; van Kats-Renaud, H.; van Asbeck, B. S.; Marx, J. J. Intracellular Labile Iron Modulates Adhesion of Human Monocytes to Human Endothelial Cells. Arter. Thromb Vasc Biol 2004, 24 (12), 2257-2262.

(116) Ghio, A. J. Disruption of Iron Homeostasis and Lung Disease. Biochim Biophys Acta 2009, 1790 (7), 731-739.

(117) Zhang, X.; Zhang, H.; Liang, X.; Zhang, J.; Tao, W.; Zhu, X.; Chang, D.; Zeng, X.; Liu, G.; Mei, L. Iron Oxide Nanoparticles Induce Autophagosome Accumulation through Multiple Mechanisms: Lysosome Impairment, Mitochondrial Damage, and ER Stress. Mol. Pharm. 2016, 13 (7), 2578-2587.

(118) Zhang, L.; Wang, X.; Miao, Y.; Chen, Z.; Qiang, P.; Cui, L.; Jing, H.; Guo, Y. Magnetic Ferroferric Oxide Nanoparticles Induce Vascular Endothelial Cell Dysfunction and Inflammation by Disturbing Autophagy. J. Hazard. Mater. 2016, 304, 186-195.

(119) Li, R.; Kou, X.; Geng, H.; Xie, J.; Yang, Z.; Zhang, Y.; Cai, Z.; Dong, C. Effect of Ambient PM(2.5) on Lung Mitochondrial Damage and Fusion/Fission Gene Expression in Rats. Chem. Res. Toxicol. 2015, 28 (3), 408-418.

(120) Schumacker, P. T.; Gillespie, M. N.; Nakahira, K.; Choi, A. M. K.; Crouser, E. D.; Piantadosi, C. A.; Bhattacharya, J. Mitochondria in Lung Biology and Pathology: More than Just a Powerhouse. Am. J. Physiol. Lung Cell. Mol. Physiol. 2014, 306 (11), L962-74.

(121) Gupta, A. K.; Naregalkar, R. R.; Vaidya, V. D.; Gupta, M. Recent Advances on Surface Engineering of Magnetic Iron Oxide Nanoparticles and Their Biomedical Applications. Nanomedicine (Lond) 2007, 2 (1), 23-39.

(122) Bekaroğlu, M. G.; İşçi, Y.; İşçi, S. Colloidal Properties and in Vitro Evaluation of Hydroxy Ethyl Cellulose Coated Iron Oxide Particles for Targeted Drug Delivery. Mater. Sci. Eng. C 2017, 78, 
847-853.

(123) Truzzi, E.; Bongio, C.; Sacchetti, F.; Maretti, E.; Montanari, M.; Iannuccelli, V.; Vismara, E.; Leo, E. Self-Assembled Lipid Nanoparticles for Oral Delivery of Heparin-Coated Iron Oxide Nanoparticles for Theranostic Purposes. Molecules 2017, 22 (6), 963.

(124) Elmaci, G.; Frey, C. E.; Kurz, P.; Zümreoğlu-Karan, B. Water Oxidation Catalysis by Birnessite@Iron Oxide Core-Shell Nanocomposites. Inorg. Chem. 2015, 54 (6), 2734-2741.

(125) Orlandi, M.; Dalle Carbonare, N.; Caramori, S.; Bignozzi, C. A.; Berardi, S.; Mazzi, A.; El Koura, Z.; Bazzanella, N.; Patel, N.; Miotello, A. Porous versus Compact Nanosized Fe(III)-Based Water Oxidation Catalyst for Photoanodes Functionalization. ACS Appl. Mater. Interfaces 2016, 8 (31), 20003-20011.

(126) Hajesmaeelzadeh, F.; Shanehsazzadeh, S.; Gruttner, C.; Daha, F. J.; Oghabian, M. A. Effect of Coating Thickness of Iron Oxide Nanoparticles on Their Relaxivity in the MRI. Iran J Basic Med Sci 2016, 19 (2), 166-171.

(127) Levy, M.; Lagarde, F.; Maraloiu, V. A.; Blanchin, M. G.; Gendron, F.; Wilhelm, C.; Gazeau, F. Degradability of Superparamagnetic Nanoparticles in a Model of Intracellular Environment: Follow-up of Magnetic, Structural and Chemical Properties. Nanotechnology 2010, 21 (39), 395103.

(128) Tian, F.; Chen, G.; Yi, P.; Zhang, J.; Li, A.; Zhang, J.; Zheng, L.; Deng, Z.; Shi, Q.; Peng, R.; et al. Fates of Fe304 and Fe304@SiO2 Nanoparticles in Human Mesenchymal Stem Cells Assessed by Synchrotron Radiation-Based Techniques. Biomaterials 2014, 35 (24), 64126421.

(129) Chusuei, C. C.; Wu, C. H.; Mallavarapu, S.; Hou, F. Y.; Hsu, C. M.; Winiarz, J. G.; Aronstam, R. S.; Huang, Y. W. Cytotoxicity in the Age of Nano: The Role of Fourth Period Transition Metal Oxide Nanoparticle Physicochemical Properties. Chem Biol Interact 2013, 206 (2), 319-326. 
(130) Guldris, N.; Argibay, B.; Kolen'ko, Y. V; Carbo-Argibay, E.; Sobrino, T.; Campos, F.; Salonen, L. M.; Banobre-Lopez, M.; Castillo, J.; Rivas, J. Influence of the Separation Procedure on the Properties of Magnetic Nanoparticles: Gaining in Vitro Stability and T1-T2 Magnetic Resonance Imaging Performance. J Colloid Interface Sci 2016, 472, 229-236.

(131) Shukla, S.; Jadaun, A.; Arora, V.; Sinha, R. K.; Biyani, N.; Jain, V. K. In Vitro Toxicity Assessment of Chitosan Oligosaccharide Coated Iron Oxide Nanoparticles. Toxicol. Reports 2015, 2, 27-39.

(132) Cochran, D. B.; Wattamwar, P. P.; Wydra, R.; Hilt, J. Z.; Anderson, K. W.; Eitel, R. E.; Dziubla, T. D. Suppressing Iron Oxide Nanoparticle Toxicity by Vascular Targeted Antioxidant Polymer Nanoparticles. Biomaterials 2013, 34 (37), 9615-9622.

(133) Starmans, L. W. E.; Burdinski, D.; Haex, N. P. M.; Moonen, R. P. M.; Strijkers, G. J.; Nicolay, K.; Grüll, H. Iron Oxide Nanoparticle-Micelles (ION-Micelles) for Sensitive (Molecular) Magnetic Particle Imaging and Magnetic Resonance Imaging. PLoS One 2013, 8 (2), e57335.

(134) Unterweger, H.; Tietze, R.; Janko, C.; Zaloga, J.; Lyer, S.; Taccardi, N.; Goudouri, M.; Hoppe, A.; Eberbeck, D.; Schubert, D.; et al. Development and Characterization of Magnetic Iron Oxide Nanoparticles with a Cisplatin-Bearing Polymer Coating for Targeted Drug Delivery. Int. J. Nanomedicine 2014, 9, 3659.

(135) Gonçalves, M.; Guerreiro, M. C.; de Oliveira, L. C. A.; de Castro, C. S. A Friendly Environmental Material: Iron Oxide Dispersed over Activated Carbon from Coffee Husk for Organic Pollutants Removal. J. Environ. Manage. 2013, 127, 206-211.

(136) Singh, D.; Schifman, L. A.; Watson-Wright, C.; Sotiriou, G. A.; Oyanedel-Craver, V.; Wohlleben, W.; Demokritou, P. Nanofiller Presence Enhances Polycyclic Aromatic Hydrocarbon (PAH) Profile on Nanoparticles Released during Thermal Decomposition of Nano-Enabled Thermoplastics: Potential Environmental Health Implications. Environ. Sci. Technol. 2017, 
$51(9), 5222-5232$.

(137) DeLoid, G. M.; Wang, Y.; Kapronezai, K.; Lorente, L. R.; Zhang, R.; Pyrgiotakis, G.; Konduru, N. V.; Ericsson, M.; White, J. C.; De La Torre-Roche, R.; et al. An Integrated Methodology for Assessing the Impact of Food Matrix and Gastrointestinal Effects on the Biokinetics and Cellular Toxicity of Ingested Engineered Nanomaterials. Part. Fibre Toxicol. 2017, 14 (1).

(138) Pirela, S. V; Sotiriou, G. A.; Bello, D.; Shafer, M.; Bunker, K. L.; Castranova, V.; Thomas, T.;

Demokritou, P. Consumer Exposures to Laser Printer-Emitted Engineered Nanoparticles: A Case Study of Life-Cycle Implications from Nano-Enabled Products. Nanotoxicology 2015, 9 (6), 760-768.

(139) Servin, A. D.; White, J. C. Nanotechnology in Agriculture: Next Steps for Understanding Engineered Nanoparticle Exposure and Risk. NanoImpact 2016, 1, 9-12.

(140) De La Torre Roche, R.; Pagano, L.; Majumdar, S.; Eitzer, B. D.; Zuverza-Mena, N.; Ma, C.; Servin, A. D.; Marmiroli, N.; Dhankher, O. P.; White, J. C. Co-Exposure of Imidacloprid and Nanoparticle Ag or CeO2to Cucurbita Pepo (Zucchini): Contaminant Bioaccumulation and Translocation. NanoImpact 2018, 11, 136-145.

(141) Cai, F.; Wu, X.; Zhang, H.; Shen, X.; Zhang, M.; Chen, W.; Gao, Q.; White, J. C.; Tao, S.; Wang, X. Impact of TiO2nanoparticles on Lead Uptake and Bioaccumulation in Rice (Oryza Sativa L.). NanoImpact 2017, 5, 101-108.

(142) Wild, P.; Bourgkard, E.; Paris, C. Lung Cancer and Exposure to Metals: The Epidemiological Evidence. Methods Mol. Biol. 2009, 472, 139-167.

(143) Watson, C.; Ge, J.; Cohen, J.; Pyrgiotakis, G.; Engelward, B. P.; Demokritou, P. HighThroughput Screening Platform for Engineered Nanoparticle-Mediated Genotoxicity Using CometChip Technology. ACS Nano 2014, 8 (3), 2118-2133.

(144) Stueckle, T. A.; Davidson, D. C.; Derk, R.; Kornberg, T. G.; Schwegler-Berry, D.; Demokritou, P.; 
Luanpitpong, S.; Rojanasakul, Y.; Wang, L. Evaluation on Carcinogenesis Potential of Fe2O3 and CeO2 Nanoparticles by a Rapid in Vitro Screening Model. NanoImpact 2016, 11 (1).

(145) Zeidler-Erdely, P. C.; Salmen, R.; Erdely, A.; Keane, M.; Kodali, V.; Antonini, F.; Falcone, L. Pulmonary Toxicity of Gas Metal Arc-Stainless Steel Welding Fume and Component Metals. Toxicol. 2017, 150 (1), 2125.

(146) Falcone, L. M.; Erdely, A.; Kodali, V.; Salmen, R.; Battelli, L. A.; Dodd, T.; McKinney, W.; Stone, S.; Donlin, M.; Leonard, H. D.; et al. Inhalation of Iron-Abundant Gas Metal Arc Welding-Mild Steel Fume Promotes Lung Tumors in Mice. Toxicology 2018, 409, 24-32.

(147) Liu, Y.; Li, J.; Xu, K.; Gu, J.; Huang, L.; Zhang, L.; Liu, N.; Kong, J.; Xing, M.; Zhang, L.; et al. Characterization of Superparamagnetic Iron Oxide Nanoparticle-Induced Apoptosis in PC12 Cells and Mouse Hippocampus and Striatum. Toxicol. Lett. 2018, 292, 151-161.

(148) Guha, N.; Loomis, D.; Guyton, K. Z.; Grosse, Y.; El Ghissassi, F.; Bouvard, V.; Benbrahim-Tallaa, L.; Vilahur, N.; Muller, K.; Straif, K.; et al. Carcinogenicity of Welding, Molybdenum Trioxide, and Indium Tin Oxide. Lancet. Oncol. 2017, 18 (5), 581-582.

(149) Xiong, W.; Wang, L.; Yu, F. Regulation of Cellular Iron Metabolism and Its Implications in Lung Cancer Progression. Med. Oncol. 2014, 31 (7), 28.

(150) Gass, S.; Cohen, J. M.; Pyrgiotakis, G.; Sotiriou, G. A.; Pratsinis, S. E.; Demokritou, P. A Safer Formulation Concept for Flame-Generated Engineered Nanomaterials. ACS Sustain. Chem. Eng. 2013, 1 (7), 843-857.

(151) Sotiriou, G. A.; Watson, C.; Murdaugh, K. M.; Darrah, T. H.; Pyrgiotakis, G.; Elder, A.; Brain, J. D.; Demokritou, P. Engineering Safer-by-Design Silica-Coated ZnO Nanorods with Reduced DNA Damage Potential. Environ. Sci. Nano 2014, 1 (2), 144-153.

(152) Antonini, J. M.; Lawryk, N. J.; Murthy, G. G.; Brain, J. D. Effect of Welding Fume Solubility on Lung Macrophage Viability and Function in Vitro. J. Toxicol. Environ. Health. A 1999, 58 (6), 
343-363.

(153) Sager, T. M.; Porter, D. W.; Robinson, V. A.; Lindsley, W. G.; Schwegler-Berry, D. E.;

Castranova, V. Improved Method to Disperse Nanoparticles for in Vitro and in Vivo Investigation of Toxicity. Nanotoxicology 2007, 1 (2), 118-129.

(154) Hackley, V. A.; Stefaniak, A. B. "Real-World” Precision, Bias, and between-Laboratory Variation for Surface Area Measurement of a Titanium Dioxide Nanomaterial in Powder Form. J. Nanoparticle Res. 2013, 15 (6).

(155) Cohen, J. M.; Beltran-Huarac, J.; Pyrgiotakis, G.; Demokritou, P. Effective Delivery of Sonication Energy to Fast Settling and Agglomerating Nanomaterial Suspensions for Cellular Studies: Implications for Stability, Particle Kinetics, Dosimetry and Toxicity. NanoImpact 2018, 10, 81-86.

(156) Deloid, G. M.; Cohen, J. M.; Pyrgiotakis, G.; Demokritou, P. Preparation, Characterization, and in Vitro Dosimetry of Dispersed, Engineered Nanomaterials. Nat. Protoc. 2017, 12 (2), 355371.

(157) Stefaniak, A. B.; Guilmette, R. A.; Day, G. A.; Hoover, M. D.; Breysse, P. N.; Scripsick, R. C. Characterization of Phagolysosomal Simulant Fluid for Study of Beryllium Aerosol Particle Dissolution. Toxicol. Vitr. 2005, 19 (1), 123-134.

(158) DeLoid, G.; Cohen, J. M.; Darrah, T.; Derk, R.; Rojanasakul, L.; Pyrgiotakis, G.; Wohlleben, W.; Demokritou, P. Estimating the Effective Density of Engineered Nanomaterials for in Vitro Dosimetry. Nat Commun 2014, 5, 3514.

(159) Cohen, J. M.; Teeguarden, J. G.; Demokritou, P. An Integrated Approach for the in Vitro Dosimetry of Engineered Nanomaterials. Part. Fibre Toxicol. 2014, 11 (1), 20.

(160) Chen, B. T.; Schwegler-Berry, D.; Cumpston, A.; Cumpston, J.; Friend, S.; Stone, S.; Keane, M. Performance of a Scanning Mobility Particle Sizer in Measuring Diverse Types of Airborne 
Nanoparticles: Multi-Walled Carbon Nanotubes, Welding Fumes, and Titanium Dioxide Spray. J. Occup. Environ. Hyg. 2016, 13 (7), 501-518.

(161) Espósito, B. P.; Epsztejn, S.; Breuer, W.; Cabantchik, Z. I. A Review of Fluorescence Methods for Assessing Labile Iron in Cells and Biological Fluids. Anal. Biochem. 2002, 304 (1), 1-18.

(162) Buss, J. L.; Arduini, E.; Ponka, P. Mobilization of Intracellular Iron by Analogs of Pyridoxal Isonicotinoyl Hydrazone (PIH) Is Determined by the Membrane Permeability of the IronChelator Complexes. Biochem Pharmacol 2002, 64 (12), 1689-1701.

(163) Hanahan, D.; Weinberg, R. A. Hallmarks of Cancer: The Next Generation. Cell 2011, 144 (5), 646-674.

(164) Horibata, S.; Vo, T. V.; Subramanian, V.; Thompson, P. R.; Coonrod, S. A. Utilization of the Soft Agar Colony Formation Assay to Identify Inhibitors of Tumorigenicity in Breast Cancer Cells. J. Vis. Exp. 2015, No. 99, e52727.

(165) O'Connor, M. J. Targeting the DNA Damage Response in Cancer. Mol. Cell 2015, 60 (4), 547560.

(166) Lorat, Y.; Timm, S.; Jakob, B.; Taucher-Scholz, G.; Rübe, C. E. Clustered Double-Strand Breaks in Heterochromatin Perturb DNA Repair after High Linear Energy Transfer Irradiation. Radiother. Oncol. 2016, 121 (1), 154-161.

(167) Nikitaki, Z.; Nikolov, V.; Mavragani, I. V.; Mladenov, E.; Mangelis, A.; Laskaratou, D. A.; Fragkoulis, G. I.; Hellweg, C. E.; Martin, O. A.; Emfietzoglou, D.; et al. Measurement of Complex DNA Damage Induction and Repair in Human Cellular Systems after Exposure to Ionizing Radiations of Varying Linear Energy Transfer (LET). Free Radic. Res. 2016, 50, S64S78.

(168) Evans, M. D.; Dizdaroglu, M.; Cooke, M. S. Oxidative DNA Damage and Disease: Induction, Repair and Significance. Mutat. Res. Mutat. Res. 2004, 567 (1), 1-61. 
(169) Stueckle, T. A.; Davidson, D. C.; Derk, R.; Demokritou, P.; Kornberg, T.; Schwegler-Berry, D.; Wang, L. Nano-Ferric Oxide Induced Neoplastic-Like Transformation in a Human Primary Cell Model: Iron Homeostasis Disruption? Toxicol. 2016, 2783, 419.

(170) Villeneuve, P. J.; Jerrett, M.; Brenner, D.; Su, J.; Chen, H.; McLaughlin, J. R. A Case-Control Study of Long-Term Exposure to Ambient Volatile Organic Compounds and Lung Cancer in Toronto, Ontario, Canada. Am. J. Epidemiol. 2014, 179 (4), 443-451.

(171) Hanahan, D.; Weinberg, R. A. The Hallmarks of Cancer. Cell 2000, 100 (1), 57-70.

(172) Wang, Y.; Cui, H.; Zhou, J.; Li, F.; Wang, J.; Chen, M.; Liu, Q. Cytotoxicity, DNA Damage, and Apoptosis Induced by Titanium Dioxide Nanoparticles in Human Non-Small Cell Lung Cancer A549 Cells. Environ. Sci. Pollut. Res. Int. 2015, 22 (7), 5519-5530.

(173) Setyawati, M. I.; Sevencan, C.; Bay, B. H.; Xie, J.; Zhang, Y.; Demokritou, P.; Leong, D. T. NanoTiO2Drives Epithelial-Mesenchymal Transition in Intestinal Epithelial Cancer Cells. Small 2018, $14(30)$.

(174) Hong, F.; Ji, L.; Zhou, Y.; Wang, L. Chronic Nasal Exposure to Nanoparticulate TiO 2 Causes Pulmonary Tumorigenesis in Male Mice. Environ. Toxicol. 2017, 32 (5), 1651-1657.

(175) Mesárošová, M.; Kozics, K.; Bábelová, A.; Regendová, E.; Pastorek, M.; Vnuková, D.; Buliaková, B.; Rázga, F.; Gábelová, A. The Role of Reactive Oxygen Species in the Genotoxicity of Surface-Modified Magnetite Nanoparticles. Toxicol. Lett. 2014, 226 (3), 303-313.

(176) Kamiyama, T.; Miyakawa, H.; Jing Ping Li; Akiba, T.; Liu, J.; Liu, J. H.; Marumo, F.; Sato, C. Effects of One-Year Cadmium Exposure on Livers and Kidneys and Their Relation to Glutathione Levels. Res. Commun. Mol. Pathol. Pharmacol. 1995, 88 (2), 177-186.

(177) Prozialeck, W. C.; Vaidya, V. S.; Liu, J.; Waalkes, M. P.; Edwards, J. R.; Lamar, P. C.; Bernard, A. M.; Dumont, X.; Bonventre, J. V. Kidney Injury Molecule-1 Is an Early Biomarker of Cadmium Nephrotoxicity. Kidney Int. 2007, 28 (5), 478-485. 
(178) Liu, J.; Qu, W.; Kadiiska, M. B. Role of Oxidative Stress in Cadmium Toxicity and Carcinogenesis. Toxicol. Appl. Pharmacol. 2009, 238 (3), 209-214.

(179) Chang, Q.; Pan, J.; Wang, X.; Zhang, Z.; Chen, F.; Shi, X. Reduced Reactive Oxygen SpeciesGenerating Capacity Contributes to the Enhanced Cell Growth of Arsenic-Transformed Epithelial Cells. Cancer Res. 2010, 70 (12), 5127-5135.

(180) Shoeb, M.; Kodali, V.; Farris, B.; Bishop, L. M.; Meighan, T.; Salmen, R.; Eye, T.; Roberts, J. R.; Zeidler-Erdely, P.; Erdely, A.; et al. Evaluation of the Molecular Mechanisms Associated with Cytotoxicity and Inflammation after Pulmonary Exposure to Different Metal-Rich Welding Particles. Nanotoxicology 2017, 11 (6), 1-12.

(181) Lu, X.; Miousse, I. R.; Pirela, S. V.; Melnyk, S.; Koturbash, I.; Demokritou, P. Short-Term Exposure to Engineered Nanomaterials Affects Cellular Epigenome. Nanotoxicology 2015, $10(2), 1-11$.

(182) Zhang, T.; Qi, Y.; Liao, M.; Xu, M.; Bower, K. A.; Frank, J. A.; Shen, H. M.; Luo, J.; Shi, X.; Chen, G. Autophagy Is a Cell Self-Protective Mechanism against Arsenic-Induced Cell Transformation. Toxicol Sci 2012, 130 (2), 298-308.

(183) Ma, J.; Mercer, R. R.; Barger, M.; Schwegler-Berry, D.; Cohen, J. M.; Demokritou, P.; Castranova, V. Effects of Amorphous Silica Coating on Cerium Oxide Nanoparticles Induced Pulmonary Responses. Toxicol. Appl. Pharmacol. 2015, 288 (1), 63-73.

(184) McKeon, K. D.; Love, B. J. The Presence of Adsorbed Proteins on Particles Increases Aggregated Particle Sedimentation, as Measured by a Light Scattering Technique. J. Adhes. 2008, 84 (7), 664-674.

(185) Davidson, D. C.; Derk, R.; He, X.; Stueckle, T. A.; Cohen, J.; Pirela, S. V; Demokritou, P.; Rojanasakul, Y.; Wang, L. Direct Stimulation of Human Fibroblasts by NCeO2 in Vitro Is Attenuated with an Amorphous Silica Coating. Part Fibre Toxicol 2016, 13 (1), 23. 
(186) Konduru, N. V; Jimenez, R. J.; Swami, A.; Friend, S.; Castranova, V.; Demokritou, P.; Brain, J. D.;

Molina, R. M. Silica Coating Influences the Corona and Biokinetics of Cerium Oxide Nanoparticles. Part Fibre.Toxicol. 2015, 12 (1).

(187) Konduru, N. V.; Murdaugh, K. M.; Sotiriou, G. A.; Donaghey, T. C.; Demokritou, P.; Brain, J. D.; Molina, R. M. Bioavailability, Distribution and Clearance of Tracheally-Instilled and Gavaged Uncoated or Silica-Coated Zinc Oxide Nanoparticles. Part. Fibre Toxicol. 2014, 11 (1).

(188) Demokritou, P.; Gass, S.; Pyrgiotakis, G.; Cohen, J. M.; Goldsmith, W.; McKinney, W.; Frazer, D.; Ma, J.; Schwegler-Berry, D.; Brain, J.; et al. An in Vivo and in Vitro Toxicological Characterisation of Realistic Nanoscale CeO2 Inhalation Exposures. Nanotoxicology 2013, 7 (8), 1338-1350.

(189) Toxicological Review of Nano Cerium Oxide IN SUPPORT OF PROSPECT: Ecotoxicology Test Protocols for Representative Nanomaterials in Support of the OECD Sponsorship Programme. 2010.

(190) Nemmar, A.; Al-Salam, S.; Beegam, S.; Yuvaraju, P.; Ali, B. H. The Acute Pulmonary and Thrombotic Effects of Cerium Oxide Nanoparticles after Intratracheal Instillation in Mice. Int. J. Nanomedicine 2017, Volume 12, 2913-2922.

(191) Sendra, M.; Yeste, P. M.; Moreno-Garrido, I.; Gatica, J. M.; Blasco, J. CeO 2 NPs, Toxic or Protective to Phytoplankton? Charge of Nanoparticles and Cell Wall as Factors Which Cause Changes in Cell Complexity. Sci. Total Environ. 2017, 590-591, 304-315.

(192) Arnold, M. C.; Badireddy, A. R.; Wiesner, M. R.; Di Giulio, R. T.; Meyer, J. N. Cerium Oxide Nanoparticles Are More Toxic than Equimolar Bulk Cerium Oxide in Caenorhabditis Elegans. Arch. Environ. Contam. Toxicol. 2013, 65 (2), 224-233.

(193) Demokritou, P.; Büchel, R.; Molina, R. M.; Deloid, G. M.; Brain, J. D.; Pratsinis, S. E. Development and Characterization of a Versatile Engineered Nanomaterial Generation 
System (VENGES) Suitable for Toxicological Studies. Inhal. Toxicol. 2010, 22 Suppl 2 (April 2016), 107-116.

(194) Pyrgiotakis, G.; Blattmann, C. O.; Pratsinis, S.; Demokritou, P. Nanoparticle-Nanoparticle Interactions in Biological Media by Atomic Force Microscopy. Langmuir 2013, 29 (36), 11385-11395.

(195) Stueckle, T. A.; Davidson, D. C.; Derk, R.; Kornberg, T. G.; Battelli, L.; Friend, S.; Orandle, M.; Wagner, A.; Dinu, C. Z.; Sierros, K. A.; et al. Short-Term Pulmonary Toxicity Assessment of Pre- and Post-Incinerated Organomodified Nanoclay in Mice. ACS Nano 2018, 12 (3), 22922310.

(196) Roach, K. A.; Anderson, S. E.; Stefaniak, A. B.; Shane, H. L.; Kodali, V.; Kashon, M.; Roberts, J. R. Surface Area- and Mass-Based Comparison of Fine and Ultrafine Nickel Oxide Lung Toxicity and Augmentation of Allergic Response in an Ovalbumin Asthma Model. Inhal. Toxicol. 2019, 1-26.

(197) Nayak, A. P.; Croston, T. L.; Lemons, A. R.; Goldsmith, W. T.; Marshall, N. B.; Kashon, M. L.; Germolec, D. R.; Beezhold, D. H.; Green, B. J. Aspergillus Fumigatus Viability Drives Allergic Responses to Inhaled Conidia. Ann. Allergy, Asthma Immunol. 2018, 121 (2), 200-210.e2.

(198) Nolan, A.; Kobayashi, H.; Naveed, B.; Kelly, A.; Hoshino, Y.; Hoshino, S.; Karulf, M. R.; Rom, W. N.; Weiden, M. D.; Gold, J. A. Differential Role for CD80 and CD86 in the Regulation of the Innate Immune Response in Murine Polymicrobial Sepsis. PLoS One 2009, 4 (8), e6600. (199) Orabona, C.; Grohmann, U.; Belladonna, M. L.; Fallarino, F.; Vacca, C.; Bianchi, R.; Bozza, S.; Volpi, C.; Salomon, B. L.; Fioretti, M. C.; et al. CD28 Induces Immunostimulatory Signals in Dendritic Cells via CD80 and CD86. Nat. Immunol. 2004, 5 (11), 1134-1142.

(200) Wolpe, S. D.; Davatelis, G.; Sherry, B.; Beutler, B.; Hesse, D. G.; Nguyen, H. T.; Moldawer, L. L.; Nathan, C. F.; Lowry, S. F.; Cerami, A. Macrophages Secrete a Novel Heparin-Binding Protein 
with Inflammatory and Neutrophil Chemokinetic Properties. J. Exp. Med. 1988, 167 (2), $570-581$.

(201) Francisco-Cruz, A.; Aguilar-Santelises, M.; Ramos-Espinosa, O.; Mata-Espinosa, D.; MarquinaCastillo, B.; Barrios-Payan, J.; Hernandez-Pando, R. Granulocyte?Macrophage ColonyStimulating Factor: Not Just Another Haematopoietic Growth Factor. Med. Oncol. 2014, 31 (1), 774 .

(202) Fernando, M. R.; Reyes, J. L.; Iannuzzi, J.; Leung, G.; McKay, D. M. The Pro-Inflammatory Cytokine, Interleukin-6, Enhances the Polarization of Alternatively Activated Macrophages. PLoS One 2014, 9 (4), e94188.

(203) Mauer, J.; Chaurasia, B.; Goldau, J.; Vogt, M. C.; Ruud, J.; Nguyen, K. D.; Theurich, S.; Hausen, A. C.; Schmitz, J.; Brönneke, H. S.; et al. Signaling by IL-6 Promotes Alternative Activation of Macrophages to Limit Endotoxemia and Obesity-Associated Resistance to Insulin. Nat. Immunol. 2014, 15 (5), 423-430.

(204) Olszewski, M. B.; Groot, A. J.; Dastych, J.; Knol, E. F. TNF Trafficking to Human Mast Cell Granules: Mature Chain-Dependent Endocytosis. J. Immunol. 2007, 178 (9).

(205) Driscoll, K. E. TNF? And MIP-2: Role in Particle-Induced Inflammation and Regulation by Oxidative Stress. Toxicol. Lett. 2000, 112-113, 177-183.

(206) Moser, B.; Clark-Lewis, I.; Zwahlen, S. R.; Baggiolini, M. Materials and Methods Brief Definitive Report NEUTROPHIL-ACTIVATING PROPERTIES OF THE MELANOMA GROWTHSTIMULATORY ACTIVITY. 1990, 171, 1797-1802.

(207) Parks, W. C.; Wilson, C. L.; L?pez-Boado, Y. S. Matrix Metalloproteinases as Modulators of Inflammation and Innate Immunity. Nat. Rev. Immunol. 2004, 4 (8), 617-629.

(208) Opdenakker, G.; Van den Steen, P. E.; Van Damme, J. Gelatinase B: A Tuner and Amplifier of Immune Functions. Trends Immunol. 2001, 22 (10), 571-579. 
(209) Wynn, T. A.; Ramalingam, T. R. Mechanisms of Fibrosis: Therapeutic Translation for Fibrotic Disease. Nat. Med. 2012, 18 (7), 1028-1040.

(210) Sager, T. M.; Wolfarth, M.; Leonard, S. S.; Morris, A. M.; Porter, D. W.; Castranova, V.; Holian, A. Role of Engineered Metal Oxide Nanoparticle Agglomeration in Reactive Oxygen Species Generation and Cathepsin B Release in NLRP3 Inflammasome Activation and Pulmonary Toxicity. Inhal. Toxicol. 2016, 28 (14), 686-697.

(211) Morimoto, Y.; Izumi, H.; Yoshiura, Y.; Tomonaga, T.; Oyabu, T.; Myojo, T.; Kawai, K.; Yatera, K.; Shimada, M.; Kubo, M.; et al. Pulmonary Toxicity of Well-Dispersed Cerium Oxide Nanoparticles Following Intratracheal Instillation and Inhalation. J. Nanopart. Res. 17 (11), 442.

(212) Aalapati, S.; Ganapathy, S.; Manapuram, S.; Anumolu, G.; Prakya, B. M. Toxicity and BioAccumulation of Inhaled Cerium Oxide Nanoparticles in CD1 Mice. Nanotoxicology 2014, 8 (7), 786-798.

(213) Ma, J. Y. C.; Young, S. H.; Mercer, R. R.; Barger, M.; Schwegler-Berry, D.; Ma, J. K.; Castranova, V. Interactive Effects of Cerium Oxide and Diesel Exhaust Nanoparticles on Inducing Pulmonary Fibrosis. Toxicol. Appl. Pharmacol. 2014, 278 (2), 135-147.

(214) de Haar, C.; Kool, M.; Hassing, I.; Bol, M.; Lambrecht, B. N.; Pieters, R. Lung Dendritic Cells Are Stimulated by Ultrafine Particles and Play a Key Role in Particle Adjuvant Activity. J. Allergy Clin. Immunol. 2008, 121 (5), 1246-1254.

(215) Koike, E.; Takano, H.; Inoue, K. I.; Yanagisawa, R.; Sakurai, M.; Aoyagi, H.; Shinohara, R.; Kobayashi, T. Pulmonary Exposure to Carbon Black Nanoparticles Increases the Number of Antigen-Presenting Cells in Murine Lung. Int. J. Immunopathol. Pharmacol. 2008, 21 (1), 3542.

(216) Ma, J.; Bishoff, B.; Mercer, R. R.; Barger, M.; Schwegler-Berry, D.; Castranova, V. Role of 
Epithelial-Mesenchymal Transition (EMT) and Fibroblast Function in Cerium Oxide

Nanoparticles-Induced Lung Fibrosis. Toxicol. Appl. Pharmacol. 2017, 323, 16-25.

(217) Wang, X.; Sun, B.; Liu, S.; Xia, T. Structure Activity Relationships of Engineered

Nanomaterials in Inducing NLRP3 Inflammasome Activation and Chronic Lung Fibrosis.

NanoImpact 2017, 6, 99-108.

(218) Thomas, B. J.; Kan-O, K.; Loveland, K. L.; Elias, J. A.; Bardin, P. G. In the Shadow of Fibrosis:

Innate Immune Suppression Mediated by Transforming Growth Factor- $\beta$. Am. J. Respir. Cell

Mol. Biol. 2016, 55 (6), 759-766.

(219) Baggs, R. B.; Ferin, J.; Oberdörster, G. Regression of Pulmonary Lesions Produced by Inhaled Titanium Dioxide in Rats. Vet. Pathol. 1997, 34 (6), 592-597.

(220) Chen, J. L.; Fayerweather, W. E. Epidemiologic Study of Workers Exposed to Titanium Dioxide. J. Occup. Environ. Med. 2006, 30 (12), 937-942.

(221) Fröhlich, E. Action of Nanoparticles on Platelet Activation and Plasmatic Coagulation. Curr. Med. Chem. 2016.

(222) Weyrich, A. S.; Zimmerman, G. A. Platelets in Lung Biology. Annu. Rev. Physiol. 2013.

(223) Stafforini, D. M.; Elstad, M. R.; McIntyre, T. M.; Zimmerman, G. A.; Prescott, S. M. Human Macrophages Secret Platelet-Activating Factor Acetylhydrolase. J. Biol. Chem. 1990, 265 (17), 9682-9687.

(224) Nemmar, A.; Hoet, P. H. M.; Dinsdale, D.; Vermylen, J.; Hoylaerts, M. F.; Nemery, B. Diesel Exhaust Particles in Lung Acutely Enhance Experimental Peripheral Thrombosis. Circulation 2003, 107 (8), 1202-1208.

(225) Solomon, A.; Smyth, E.; Mitha, N.; Pitchford, S.; Vydyanath, A.; Luther, P. K.; Thorley, A. J.; Tetley, T. D.; Emerson, M. Induction of Platelet Aggregation after a Direct Physical Interaction with Diesel Exhaust Particles. J. Thromb. Haemost. 2013, 11 (2), 325-334. 
(226) Radomski, A.; Jurasz, P.; Alonso-Escolano, D.; Drews, M.; Morandi, M.; Malinski, T.; Radomski, M. W. Nanoparticle-Induced Platelet Aggregation and Vascular Thrombosis. Br. J. Pharmacol. 2005, $146(6), 882-893$.

(227) Demokritou, P.; Bchel, R.; Molina, R. M.; Deloid, G. M.; Brain, J. D.; Pratsinis, S. E. Development and Characterization of a Versatile Engineered Nanomaterial Generation System (VENGES) Suitable for Toxicological Studies. Inhal. Toxicol. 2016, Suppl 2, 107-116.

(228) Schmid, 0.; Stoeger, T. Surface Area Is the Biologically Most Effective Dose Metric for Acute Nanoparticle Toxicity in the Lung. J. Aerosol Sci. 2016.

(229) Deng, Q.; Deng, L.; Miao, Y.; Guo, X.; Li, Y. Particle Deposition in the Human Lung: Health Implications of Particulate Matter from Different Sources. Environ. Res. 2019, 169, 237-245.

(230) Sager, T. M.; Kommineni, C.; Castranova, V. Pulmonary Response to Intratracheal Instillation of Ultrafine versus Fine Titanium Dioxide: Role of Particle Surface Area. Part. Fibre Toxicol. 2008, 5, 17.

(231) Wang, L.; Davidson, D. C.; Stueckle, T. A.; Derk, R.; Chen, M.; Sotiriou, G. A.; Demokritou, P.; Luanpitpong, S.; Ma, J.; Mercer, R.; et al. In Vitro Assessment of Nano-Cerium Oxide (NCeO2) and Nano-Ferric Oxide (NFe203) on Fibrogenic and Carcinogenic Potential. In Technical Proceedings of the 2014 NSTI Nanotechnology Conference and Expo, NSTI-Nanotech 2014; 2014.

(232) Falcone, L. M.; Erdely, A.; Salmen, R.; Keane, M.; Battelli, L.; Kodali, V.; Bowers, L.; Stefaniak, A. B.; Kashon, M. L.; Antonini, J. M.; et al. Pulmonary Toxicity and Lung Tumorigenic Potential of Surrogate Metal Oxides in Gas Metal Arc Welding-Stainless Steel Fume: Iron as a Primary Mediator versus Chromium and Nickel. PLoS One 2018, 13 (12).

(233) Kornberg, T. G.; Stueckle, T. A.; Coyle, J.; Derk, R.; Demokritou, P.; Rojanasakul, Y.; Rojanasakul, L. W. Iron Oxide Nanoparticle-Induced Neoplastic-like Cell Transformation in 
Vitro Is Reduced with Protective Amorphous Silica Coating. Chem. Res. Toxicol. 2019.

(234) Pérez-Ramírez, C.; Canãdas-Garre, M.; Molina, M. Á.; Faus-Dáder, M. J.; Calleja-Hernández, M.

Á. PTEN and PI3K/AKT in Non-Small-Cell Lung Cancer. Pharmacogenomics. 2015.

(235) Li, W.; Lai, B.; Yang, X.; Zhang, C.; Wang, H. A Truncated P53 in Human Lung Cancer Cells as a Critical Determinant of Proliferation and Invasiveness. Tumor Biol. 2017, 39 (6).

(236) Feng, X.; Liu, H.; Zhang, Z.; Gu, Y.; Qiu, H.; He, Z. Annexin A2 Contributes to Cisplatin Resistance by Activation of JNK-P53 Pathway in Non-Small Cell Lung Cancer Cells. J. Exp. Clin. Cancer Res. 2017, 36 (1), 123.

(237) Moschetta, M.; George, A.; Kaye, S. B.; Banerjee, S. BRCA Somatic Mutations and Epigenetic BRCA Modifications in Serous Ovarian Cancer. Ann. Oncol. 2016, 27 (8), 1449-1455.

(238) Wan, J.; Wu, W. Hyperthermia Induced HIF-1a Expression of Lung Cancer through AKT and ERK Signaling Pathways. J. Exp. Clin. Cancer Res. 2016, 35 (1), 119.

(239) Su, Z.; Yang, Z.; Xu, Y.; Chen, Y.; Yu, Q. Apoptosis, Autophagy, Necroptosis, and Cancer Metastasis. Mol. Cancer 2015, 14, 48.

(240) Ghio, A. J.; Pavlisko, E. N.; Roggli, V. L. Iron and Iron-Related Proteins in Asbestosis. J. Environ. Pathol. Toxicol. Oncol. 2015, 34 (4), 277-285.

(241) Wise, J. T. F.; Wang, L.; Alstott, M. C.; Ngalame, N. N. O.; Wang, Y.; Zhang, Z.; Shi, X. Investigating the Role of Mitochondrial Respiratory Dysfunction during Hexavalent Chromium-Induced Lung Carcinogenesis. J. Environ. Pathol. Toxicol. Oncol. 2018, 37 (4), 317-329.

(242) Han, Y.; Chen, J. Z. Oxidative Stress Induces Mitochondrial DNA Damage and Cytotoxicity through Independent Mechanisms in Human Cancer Cells. Biomed Res. Int. 2013, 2013, 1-8.

(243) Chatterjee, N.; Walker, G. C. Mechanisms of DNA Damage, Repair, and Mutagenesis. Environ. Mol. Mutagen. 2017, 58 (5), 235-263. 
(244) Jackson, S. P.; Bartek, J. The DNA-Damage Response in Human Biology and Disease. Nature. 2009.

(245) Aebi, S.; Kurdi-Haidar, B.; Gordon, R.; Cenni, B.; Zheng, H.; Fink, D.; Christen, R. D.; Boland, C. R.; Koi, M.; Fishel, R.; et al. Loss of DNA Mismatch Repair in Acquired Resistance to Cisplatin. Cancer Res. 1996, 56 (13), 3087-3090.

(246) Amaravadi, R.; Kimmelman, A. C.; White, E. Recent Insights into the Function of Autophagy in Cancer. Genes Dev. 2016, 30 (17), 1913-1930.

(247) Choi, K. S. Autophagy and Cancer. Exp Mol Med 2012, 44 (2), 109-120.

(248) Goldsmith, J.; Levine, B.; Debnath, J. Autophagy and Cancer Metabolism. In Methods in Enzymology; 2014.

(249) Malaviya, R.; Laskin, J. D.; Laskin, D. L. Oxidative Stress-Induced Autophagy: Role in Pulmonary Toxicity. Toxicol. Appl. Pharmacol. 2014, 275 (2), 145-151.

(250) Biologicals, N. Beclin 1 - a Key Regulator of Autophagosome Formation; 2015.

(251) Ghio, A. J.; Pavlisko, E. N.; Roggli, V. L. Iron and Iron-Related Proteins in Asbestosis. J. Environ. Pathol. Toxicol. Oncol. 2015, 34 (4), 277-285. 